\title{
Mix and Match
}

New Monomers for Interfacial Polymerization

Evelien Maaskant 


\title{
Mix and Match \\ New Monomers for Interfacial Polymerization
}

\author{
Evelien Maaskant
}


Promotiecommissie:

Voorzitter:

prof. dr. ir. J.W.M. Hilgenkamp Universiteit Twente

Promotor:

prof. dr. ir. N.E. Benes

Leden:

prof. dr. T.J. Dingemans

Universiteit Twente

prof. dr. A.P.H.J. Schenning

prof. dr. D. Stamatialis

dr. M.A. Hempenius

dr. T. Kudernac

The University of North Carolina

at Chapel Hill

Technische Universiteit Eindhoven

Universiteit Twente

Universiteit Twente

Universiteit Twente

This research has been conducted within the framework of the Institute for Sustainable Process Technology (ISPT, project BL-20-02)

ISBN: $978-90-365-4516-7$

DOI: $10.3990 / 1.9789036545167$

Printed by Ipskamp Printing, The Netherlands.

Copyright 2018, Evelien Maaskant, Enschede, The Netherlands. 


\title{
MIX AND MATCH \\ NEW MONOMERS FOR INTERFACIAL POLYMERIZATION
}

\section{PROEFSCHRIFT}

\author{
ter verkrijging van \\ de graad van doctor aan de Universiteit Twente, \\ op gezag van de rector magnificus, \\ prof. dr. T.T.M. Palstra, \\ volgens besluit van het College voor Promoties \\ in het openbaar te verdedigen \\ op vrijdag 6 juli 2018 om 16:45 uur
}

door

Evelien Maaskant

geboren op 5 april 1991

te Arnhem 
Dit proefschrift is goedgekeurd door:

prof. dr. ir. N.E. Benes, promotor 


\section{Contents}

Summary vii

Samenvatting $\quad$ xi

1 Introduction 1

1.1 An introduction to membrane separation ............ 3

1.2 Interfacial Polymerization . . . . . . . . . . . . 6

1.3 Beyond classical chemistry in interfacial polymerization . . . . . 21

1.4 Thesis outline . . . . . . . . . . . . . . . 32

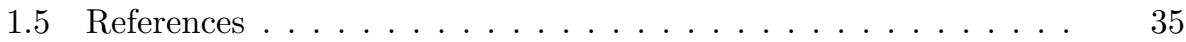

2 The use of a star-shaped trifunctional acyl chloride for the preparation of polyamide thin film composite membranes $\quad 45$

2.1 Introduction . . . . . . . . . . . . . . . 47

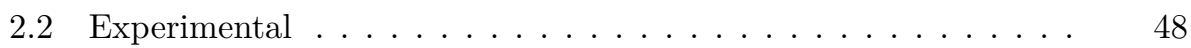

2.3 Results and discussion . . . . . . . . . . . . . 54

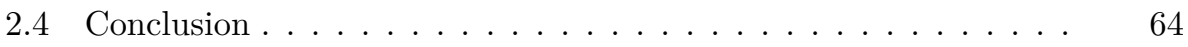

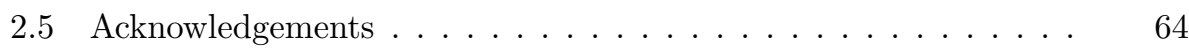

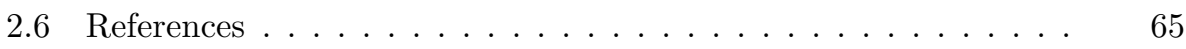

2.7 Supplementary information . . . . . . . . . . . 67

3 Hyper-cross-linked thin polydimethylsiloxane films $\quad 77$

3.1 Introduction . . . . . . . . . . . . . 79

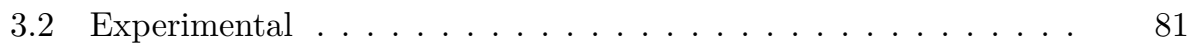

3.3 Results and discussion . . . . . . . . . . . . 85

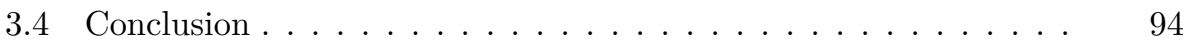

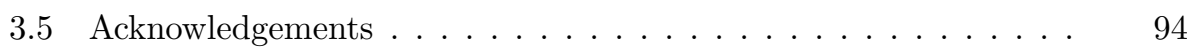

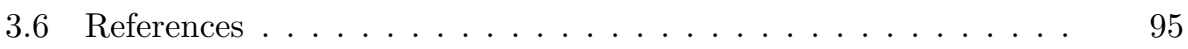

3.7 Supplementary information . . . . . . . . . . . 97 
4 Thin cyclomatrix polyphosphazene films: Interfacial polymerization of hexachlorocyclotriphosphazene with aromatic biphenols

4.1 Introduction . . . . . . . . . . . . . . . . . . . . . 105

4.2 Experimental . . . . . . . . . . . . . . 106

4.3 Results and discussion . . . . . . . . . . . . . . 110

4.4 Conclusion . . . . . . . . . . . . . . . . . . . . . 124

4.5 Acknowledgements . . . . . . . . . . . . . . 125

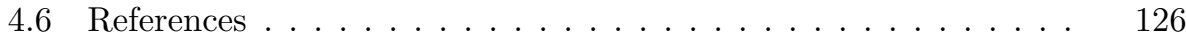

5 Synthesis and pH-stability of poly(aryl ether) films prepared by interfacial polymerization of cyanuric chloride with trialchols $\mathbf{1 2 9}$

5.1 Introduction . . . . . . . . . . . . . . . . . 131

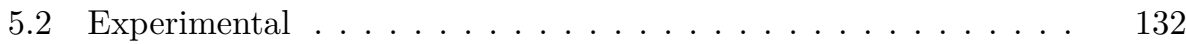

5.3 Results and discussion . . . . . . . . . . . . . . 136

5.4 Conclusion . . . . . . . . . . . . . . . . . . . . . . . . 144

5.5 Acknowledgements . . . . . . . . . . . . . . . . . 144

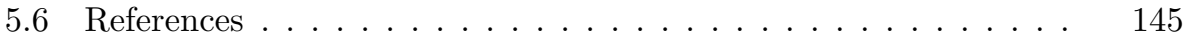

5.7 Supporting information . . . . . . . . . . . . . . . 147

6 All-aromatic cross-linked hyperbranched poly(aryl ether ketone)s for gas separation at elevated temperatures 153

6.1 Introduction . . . . . . . . . . . . . . . . 155

6.2 Experimental . . . . . . . . . . . . . . 156

6.3 Results and discussion . . . . . . . . . . . . . . 162

6.4 Conclusion . . . . . . . . . . . . . . . . . . . 177

6.5 Acknowledgements . . . . . . . . . . . . . . . . 177

6.6 References . . . . . . . . . . . . . . . . . . 178

6.7 Supporting information . . . . . . . . . . . . . . . . . . . 181

7 Direct interfacial polymerization onto thin ceramic hollow fibers

7.1 Introduction . . . . . . . . . . . . . . . . . 195

7.2 Experimental . . . . . . . . . . . . . . 196

7.3 Results and discussion . . . . . . . . . . . . . . . 199

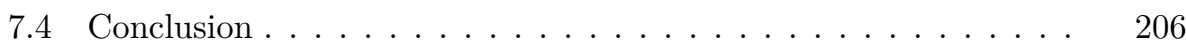

7.5 Acknowledgements . . . . . . . . . . . . . . . . 206

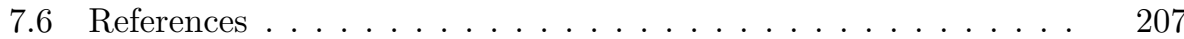


8 Reflections and perspectives $\quad 209$

8.1 Traditional polyamide thin film composite membranes . . . . . 211

8.2 Hybrid materials bearing POSS as network former . . . . . . . . . 213

8.3 Cyclomatrix polyphosphazenes . . . . . . . . . . . . . . . . 224

$8.4 \mathrm{pH}$-stable poly(aryl ether) films . . . . . . . . . . . . 230

8.5 Hyperbranched poly(aryl ether ketone)s . . . . . . . . . . 232

8.6 Interfacial polymerization on ceramic hollow fibers . . . . . . . 232

8.7 Some other monomers that could be of interest for interfacial polymerization . . . . . . . . . . . . . . 233

8.8 Requirements for the application of new monomers in interfacial

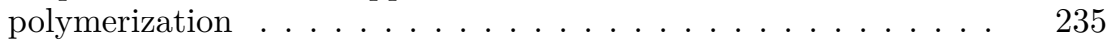

8.9 General conclusions . . . . . . . . . . . . . . . . 238

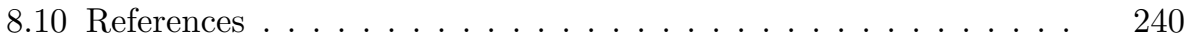

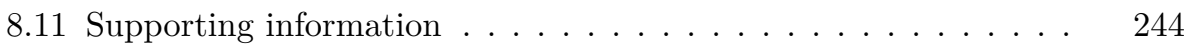

$\begin{array}{ll}\text { About the author } & \mathbf{2 4 5}\end{array}$ 



\section{Summary}

Interfacial polymerization (IP) is a very versatile technique that allows for the production of thin, defect-free films in a localized manner. These films can be used as membranes for, e.g., gas separation, reverse osmosis, or nanofiltration. Interfacial polymerization allows for the use of a large variety of monomers, and therefore a virtually unlimited amount of possible networks could be designed. This thesis focuses on the synthesis of new materials prepared by interfacial polymerization by incorporating new monomers.

An overview of interfacial polymerization and the influence of its reaction parameters based on the well-studied classical polyamide chemistry is given in the first part of Chapter 1. The second part of this chapter focuses on the possibilities of new monomers that could be used within interfacial polymerization. First, an overview of chemical bonds, in this thesis referred to as anchors, that could be formed during interfacial polymerization is given. This is followed by an overview of multifunctional monomers, in this thesis referred to as network former, that have been applied or could be of interest in interfacial polymerization.

Chapter 2 focuses in more detail on a structure variation of the acyl chloride monomer used in the preparation of polyamide thin film composite membranes. A new star-shaped trifunctional acyl chloride monomer bearing flexible ether linkages has been synthesized. Due to the electron donating character of the ether linkages, the reactivity of the acyl chloride groups is lower than those of the commonly used trimesoyl chloride. Because of this lower reactivity, the influence of the structural isomerism of the aromatic diamine is more pronounced. Defect-free TFC membranes $\left(R_{\text {rose bengal }}>97 \%\right.$ ) are obtained when using $0.3 \mathrm{w} / \mathrm{v} \%$ acyl chloride in toluene and an aqueous $2 \mathrm{w} / \mathrm{v} \%$ p-phenylenediamine solution.

The subsequent chapters will focus on the preparation of non-polyamide networks. In Chapter 3, the preparation of a hybrid poly(PDMS-POSSimide) film is described. This hybrid film consists of perfectly alternating polyhedral oligomeric silsesquioxane (POSS) and polydimethylsiloxane (PDMS) units. The films are prepared in a two-step reaction. The first step is the polymerization of the two monomers, yielding a poly(PDMS-POSSamic acid). The second step involves a thermal treatment of the poly(PDMS-POSSamic acid) resulting in the final poly(PDMS-POSSimide). The poly(PDMS-POSSimide) films show, in comparison to conventional PDMS, a significant reduction in swelling in $n$-hexane and ethyl acetate vapor. However, a slightly enhanced swelling is observed in ethanol. We attribute this to the presence of unreacted positively charged ammonium groups, which enhance the affinity for polar solvents.

Chapter 4 describes for the first time the preparation of thin $(2-5 \mu \mathrm{m})$ cyclomatrix polyphosphazene films. These films have been prepared by the interfacial 
polymerization of hexachlorocyclotriphosphazene (HCCP) with an aromatic biphenol. Depending on the $\mathrm{pKa}_{1}$ and $\mathrm{pKa}_{2}$ of the biphenol, the cross-link density of the films can be altered. This difference in cross-link density is reflected in, e.g., surface morphology and mechanical properties of the resulting films. Lower pKa values of the biphenol result in films with broadly distributed Young's moduli $(255 \pm 140 \mathrm{MPa}$ and $306 \pm 98 \mathrm{MPa})$, whereas higher pKa values result in films with sharp distributed moduli (44 $\pm 5 \mathrm{MPa}$ and $69 \pm 12 \mathrm{MPa})$.

In Chapter 5, a series of pH-stable poly(aryl ether)s is presented. By eliminating the carbonyl bond that is present in the commonly used polyamide and polyester membranes, the stability of the membrane against extreme $\mathrm{pH}$ conditions could be enhanced. The poly(aryl ether)s are prepared by the interfacial polymerization of cyanuric chloride (CC) with (fully) aromatic trialcohols. The pH-stability of these poly(aryl ether)s has been tested by immersing polyethersulfone (PES) supported films into $0.1 \mathrm{M} \mathrm{NaOH}$ or $0.1 \mathrm{M} \mathrm{HNO}_{3}$ for up to 6 weeks. Top-view scanning electron micrographs do not show any severe degradation of the poly(aryl ether) top layer. Additionally, it has been found that the size of the trialcohol has a strong influence on the thickness of the top layer. A relatively small monomer $\left(306 \mathrm{~g} \mathrm{~mol}^{-1}\right)$ allows for the formation of films ranging from a few micrometer down to the nanometer scale, depending on the reaction time. Larger sized trialcohols $\left(>438 \mathrm{~g} \mathrm{~mol}^{-1}\right)$ reach a constant film thickness $(40-50 \mathrm{~nm})$ within one minute.

Chapter 6 describes the synthesis of hyperbranched poly(aryl ether ketone)s (HBPAEKs) using a multifunctional monomer $\left(\mathrm{AB}_{2}\right)$ approach. This approach results in a HBPAEK with fluorine end-groups that can be modified to alter the properties of the polymer. In this thesis, the fluorine end-groups are partially replaced by 4-(phenylethynyl)phenol (PEP) end-groups, of which the alkyne moieties cross-link upon heating. The curing behavior of HBPAEKs with and without PEP has been studied using spectroscopic ellipsometry. Post-condensation of the fluorine and hydroxyl end-groups increases the glass transition temperature $\left(\mathrm{T}_{\mathrm{g}}\right)$ and excess free fractional volume (EFFV) slightly. A more pronounced effect on $\mathrm{T}_{\mathrm{g}}$ and EFFV due to alkyne cross-linking is found when introducing up to $20 \% \mathrm{PEP}$ end-groups. With this method, HBPAEKs with a $\mathrm{T}_{\mathrm{g}}$ up to $250{ }^{\circ} \mathrm{C}$ and an EFFV $>9 \%$ are obtained. Gas separation membranes have been prepared by spin-coating HBPAEKs containing $10 \%$ or $20 \%$ PEP onto a ceramic porous support. The first HBPAEKs membranes show moderate overall selectivity, and relatively low permeability. However, these membranes show excellent thermal stability, retaining selectivity at $200{ }^{\circ} \mathrm{C}$ for up to two weeks.

Chapter 7 focuses on the porous support material that provides mechanical strength to a thin top layer prepared by interfacial polymerization. Membranes that have to operate under harsh conditions, such as a high pressure, a high temperature, or in the presence of aggressive chemicals, require a stable support. In academia, ceramics disks are commonly used for this purpose. However, they lack a high surface-area-to-volume ratio that is needed for practical applications. In this chapter, a porous $\alpha$-alumina hollow fiber is presented that can be used as support for a thin top layer prepared by interfacial polymerization. It has been 
found that the fiber has to be coated with a thin layer of $\gamma$-alumina prior to interfacial polymerization to i) allow for a sufficiently high concentration of surface hydroxyl groups that can covalently bind to the IP layer, and ii) to ensure the presence of sufficient monomer in a large volume of small pores. With this method, a defect-free piperazine-trimesoyl chloride top layer has been coated atop of such a fiber. The resulting membrane has clean water permeances in the order of $2-5 \mathrm{~L} \mathrm{~m}^{-2} \mathrm{~h}^{-1} \mathrm{bar}^{-1}$ with a rose bengal retention of $>99 \%$.

The last chapter of this thesis, Chapter 8, reflects on the results presented in this thesis and gives possible directions for further research on these topics. Additionally, this chapter reports on other monomers that could be of interest for interfacial polymerization, but have not been used in this thesis. This is followed by some general requirements for the application of new monomers in interfacial polymerization. This chapter ends with some general conclusions regarding the monomer functionality, the monomer reactivity and reaction conditions. 



\section{Samenvatting}

Gensvlakpolymerisatie is een veelzijdige techniek die het mogelijk maakt om lokaal dunne, defect vrije lagen te produceren. De resulterende lagen kunnen bijvoorbeeld gebruikt worden als membranen voor gasscheiding, omgekeerde-osmose, of voor nanofiltratie. Bij grensvlakpolymerisatie kan een grote verscheidenheid aan monomeren gebruikt worden, waardoor een virtueel oneindig aantal mogelijke netwerken kan worden ontworpen. Dit proefschrift focust op de synthese van nieuwe materialen middels grensvlakpolymerisatie waarin nieuwe monomeren worden gebruikt.

Het eerste deel van hoofdstuk 1 geeft een overzicht van grensvlakpolymerisatie en de invloed van de reactieparameters hierop, gebaseerd op de veel gebruikte klassieke polyamide-chemie. Het tweede deel van dit hoofdstuk focust op de mogelijkheden om nieuwe monomeren toe te passen in grensvlakpolymerisatie. Eerst wordt er een overzicht gegeven van mogelijke chemische bindingen tussen twee monomeren. Daarna wordt een overzicht gegeven van multifunctionele monomeren die al zijn gebruikt in grensvlakpolymerisatie, of mogelijk hiervoor interessant zijn.

In hoofdstuk 2 wordt een variatie gemaakt op het carbonzuurchloride monomeer dat wordt gebruikt in de synthese van polyamide dunnefilmcomposietmembranen. Een nieuw stervormig drievoudig carbonzuurchloride monomeer met etherbindingen is gesynthetiseerd. De reactiviteit van deze carbonzuurchloridegroepen is lager dan die van het meer gebruikte trimesoylchloride, vanwege het elektrondonerende karakter van de etherbindingen. Als gevolg van deze lagere reactiviteit, is de structuurisomerie van het aromatische diamine sterker van invloed op de membraaneigenschappen. Er zijn defect-vrije dunnefilmcomposietmembranen ( $R_{\text {bengaals rood }}>97 \%$ ) gemaakt van $0.3 \mathrm{~m} / \mathrm{v} \%$ carbonzuurchloride in tolueen en een $2 \mathrm{~m} / \mathrm{v} \%$ waterige $p$-fenyleendiamine oplossing.

De resterende hoofdstukken van dit proefschrift focussen op andere materialen dan polyamides. In hoofdstuk $\mathbf{3}$ wordt de synthese van een dunne hybride poly(PDMS-POSSimide)laag beschreven. Deze laag bestaat uit de perfect alternerende moleculen polyhedrale oligomere silsesquioxaan (POSS) en polydimethylsiloxaan (PDMS). De synthese van deze lagen bestaat uit twee stappen. De eerste stap is de polymerisatie van de monomeren, wat een poly(PDMS-POSSamidocarbonzuur) oplevert. De tweede stap is de thermische behandeling van dit poly(PDMS-POSSamidocarbonzuur) naar de cyclische poly(PDMS-POSSimide). Wanneer de zwelling van deze lagen vergeleken wordt met dat van conventioneel PDMS valt op dat de zwelling in $n$-hexaan en ethylacetaat sterk is afgenomen. Daarentegen is er een lichte toename in de zwelling in ethanol. Dit kan ver- 
klaard worden door de positief geladen ammoniumgroepen in dit materiaal, die de affiniteit voor polaire oplosmiddelen verhogen.

In hoofdstuk 4 wordt voor het eerst de synthese van dunne $(2-5 \mu \mathrm{m})$ vernette polyfosfazeenlagen beschreven. Deze lagen zijn gemaakt middels grensvlakpolymerisatie van hexachloorcyclotrifosfazeen (HCCP) en een aromatisch bifenol. De vernettingsgraad kan worden gevarieerd middels verandering van de $\mathrm{pKa}_{1}$ en $\mathrm{pKa}_{2}$ van het bifenol. Het verschil in vernettingsgraad is onder andere van belang voor de oppervlaktemorfologie en de mechanische eigenschappen van de lagen. Een lagere pKa van het bifenol resulteert in lagen met een sterk verdeelde elasticiteitsmodulus $(255 \pm 140 \mathrm{MPa}$ en $306 \pm 98 \mathrm{MPa})$, terwijl een hogere pKa resulteert in lagen met een nauw verdeelde elasticiteitsmodulus ( $44 \pm 5 \mathrm{MPa}$ en $69 \pm 12 \mathrm{MPa}$ ).

In hoofdstuk $\mathbf{5}$ wordt een serie van poly(arylether)s gepresenteerd. Door het weglaten van de carbonylgroep, die wel aanwezig is in veel gebruikte polyamideen polyestermembranen, wordt de stabiliteit ten aanzien van extreme $\mathrm{pH}$-condities verhoogd. De poly(arylether)s zijn gemaakt middels grensvlakpolymerisatie van cyanuurchloride (CC) en (volledig) aromatische trifenolen. De pH-stabiliteit van deze lagen is getest door lagen, die zijn ondersteund door polyethersulfon (PES), in $0.1 \mathrm{M} \mathrm{NaOH}$ en $0.1 \mathrm{M} \mathrm{HNO}_{3}$ te bewaren tot maximaal zes weken. Rasterelektronenmicroscoopfoto's van het bovenaanzicht laten geen significante verandering van de oppervlaktemorfologie van deze lagen zien. Daarnaast laat dit hoofdstuk zien dat de grootte van het trifenol een sterke invloed heeft op de laagdikte. Wanneer een relatief klein trifenol $\left(306 \mathrm{~g} \mathrm{~mol}^{-1}\right)$ wordt gebruikt, kan een laag worden gevormd van een aantal micrometer tot en met een aantal nanometer, afhankelijk van de reactietijd. Wanneer daarentegen grotere trifenolen $\left(>438 \mathrm{~g} \mathrm{~mol}^{-1}\right)$ worden gebruikt, is de laagdikte beperkt tot $40-50 \mathrm{~nm}$.

Hoodstuk 6 beschrijft de synthese van hypervertakte poly(aryletherketon) polymeren (HBPAEKs) via een $\mathrm{AB}_{2}$ methode. Deze methode resulteert in HBPAEKs met fluoreindgroepen, die op hun beurt weer kunnen worden gemodificeerd om de eigenschappen van het polymeer te veranderen. In dit proefschrift zijn de fluoreindgroepen deels vervangen door 4-(fenylethynyl)fenoleindgroepen (PEP-eindgroepen), waarvan de alkyngroepen kunnen worden vernet door middel van verwarming. De eigenschappen van de HBPAEKs met en zonder PEP-eindgroepen na verwarming zijn bestudeerd met spectroscopische ellipsometrie. Na-condensatie van fluor- en hydoxyleindgroepen verhoogt de glasovergangstemperatuur $\left(T_{g}\right)$ en het vrije volume (EFFV) licht. Het vernetten van de alkyneindgroepen resulteert in een sterkere toename van de $\mathrm{T}_{\mathrm{g}}$ en het EFFV. Door het introduceren van $20 \%$ PEP-eindgroepen kan een $\mathrm{T}_{\mathrm{g}}$ van $250{ }^{\circ} \mathrm{C}$ en een EFFV van $>9 \%$ worden behaald. Gasscheidings membranen zijn gemaakt door het spincoaten van HBPAEKs met $10 \%$ of $20 \%$ PEP-eindgroepen op een poreus keramisch substraat. Deze eerste HBPAEK membranen hebben een middelmatige selectiviteit en relatief lage permeabiliteit. Daarentegen hebben deze membranen een uitstekende thermische stabiliteit en tonen ze geen verlies in selectiviteit na twee weken op $200{ }^{\circ} \mathrm{C}$. 
Hoofdstuk 7 beschrijft een poreus substraat dat mechanische sterkte biedt aan de dunne toplaag die wordt gemaakt door middel van grensvlakpolymerisatie. Membranen die moeten opereren onder moeilijke omstandigheden, zoals een hoge druk, hoge temperatuur of in de aanwezigheid van agressieve chemicaliën, hebben een stabiel poreus substraat nodig. In wetenschappelijk onderzoek worden vaak keramische schijven gebruikt, maar deze hebben een te lage oppervlaktetot-volume verhouding voor de meeste toepassingen. Dit proefschrift presenteert een poreuze $\alpha$-alumina holle vezel als drager voor lagen gemaakt middels grensvlakpolymerisatie. Een dunne laag $\gamma$-alumina is vereist om een goed membraan te maken. Deze $\gamma$-alumina laag zorgt i) voor een voldoende hoge concentratie hydroxylgroepen die covalent kunnen binden aan de grensvlakpolymerisatielaag, en ii) voor voldoende monomeer aanwezig in een groot volume van kleine poriën. Een defect-vrije piperazine-trimesoylchloride laag is gevormd op een dergelijke keramische holle vezel middels grensvlakpolymerisatie. Dit membraan heeft een schoonwaterpermeatie van $2-5 \mathrm{~L} \mathrm{~m}^{-2} \mathrm{~h}^{-1}$ bar $^{-1}$ en een retentie van bengaals rood van $>99 \%$.

Het laatste hoofdstuk van dit proefschrift, hoofdstuk $\mathbf{8}$, reflecteert op de resultaten die zijn gepresenteerd in dit proefschrift en geeft mogelijke richtingen voor verder onderzoek op dit gebied. Daarnaast presenteert dit hoofdstuk een aantal monomeren die interessant kunnen zijn voor grensvlakpolymerisatie, maar nog niet in dit proefschrift beschreven zijn. Dit wordt gevolgd door een aantal generieke vereisten voor het toepassen van nieuwe monomeren in grensvlakpolymerisatie. Dit hoofdstuk eindigt met een aantal generieke conclusies met betrekking tot de functionaliteit van de monomeren, de reactiviteit van de monomeren en de reactiecondities van de grensvlakpolymerisatie. 

Chapter 1

Introduction 



\subsection{An introduction to membrane separation}

Membranes are thin discrete interfaces that allow for the selective separation of a mixture of molecules. The selective separation is due to the different permeation rates of the different molecules through the membrane ${ }^{[1]}$. Membranes can be classified in various ways. For liquid feed mixtures the classification is generally related to the size of the molecules that are retained by the membrane ${ }^{[2]}$. The following classes are distinguished: microfiltration (MF), ultrafiltration (UF), nanofiltration (NF), and reverse osmosis (RO) (Figure 1.1).

Microfiltration and ultrafiltration membranes are porous membranes with rigid and highly voided structures. The pores of these membranes are randomly distributed and interconnected and have a size in the range of $0.01-10 \mu \mathrm{m}$. The transport of the liquid through the pores of micro- and ultrafiltration membranes occurs via viscous flow that is driven by a pressure gradient. The rejection of solutes by the porous membranes is mainly by size exclusion and hence is a function of the molecular size of the solute and the pore size distribution of the membrane ${ }^{[1]}$.

In addition to porous membranes, dense membranes exist. These membranes do not have pores. The transport of a solute through a dense membrane occurs via the solution-diffusion process ${ }^{[1]}$ and the membrane selectivity is based on the differences in solubility and diffusivity of the solutes. In contrast to porous membranes, dense membranes can separate solutes of similar size if these posses a different solubility and diffusivity in the membrane material. Dense membranes are mainly used in reverse osmosis, pervaporation (selective evaporation of a liquid feed through the membrane), and gas separation ${ }^{[1]}$. Transport of a species $i$ through dense membranes by the solution-diffusion mechanism is driven by a gradient in the molar Gibbs free energy expressed in $\mathrm{J} \mathrm{mol}^{-1}$ (Equation 1.1).

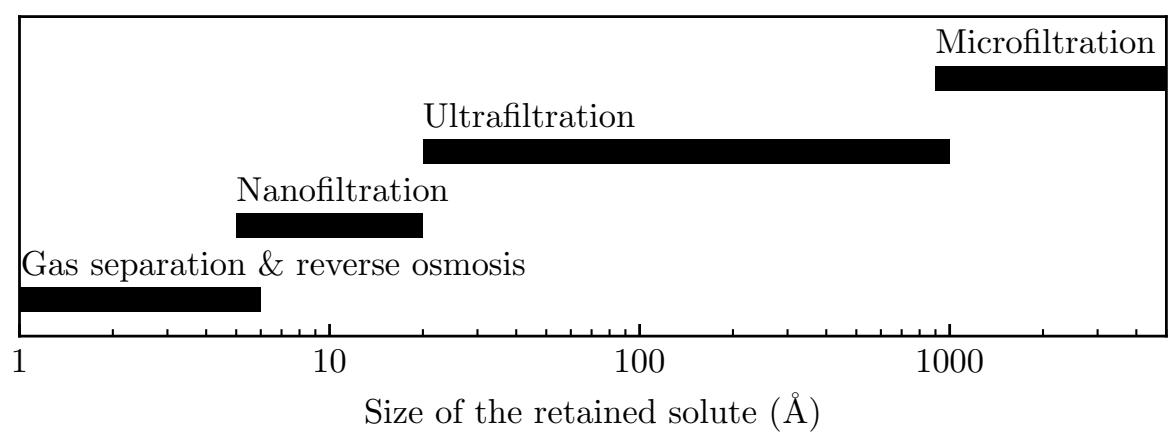

Figure 1.1: Classification of membrane processes based on the size of the retained solute. 


$$
g_{i}=\frac{\mathrm{d} G}{\mathrm{~d} n_{i}}=-S_{i} \mathrm{~d} T+V_{i} \mathrm{~d} p+\mu_{i}+\ldots
$$

Where $T$ is the temperature, $p$ the pressure, $S_{i}$ the molar entropy, $V_{i}$ the molar volume, and $\mu_{i}$ the chemical gradient of compound $i$. The ellipsis (...) indicates that more potentials, such as an electrical potential, can contribute to the free energy. A gradient in the molar Gibbs free energy can be induced by a difference in the chemical potential (via the composition), the pressure, the temperature, or the electrical potential between the two sides of the membrane ${ }^{[1]}$.

Nanofiltration membranes retain solutes with sizes between those retained by reverse osmosis and ultrafiltration (Figure 1.1). The mechanism for transport through nanofiltration membranes is a combination of those underlying porous and dense membranes.

Membranes can be characterized by their flux (amount transported per unit surface area per unit time) or permeance (flux per unit of pressure) and their rejection or selectivity. A good membrane material generally combines a high permeance with a high selectivity, which allows a reduced the surface area and enhanced process economics ${ }^{[1]}$. In the separation of liquids, the flux is often expressed in $\mathrm{L} \cdot \mathrm{m}^{-2} \cdot \mathrm{h}^{-1}$, and the permeance is expressed in $\mathrm{L} \cdot \mathrm{m}^{-2} \cdot \mathrm{h}^{-1} \cdot \mathrm{bar}^{-1}$. In gas separation the flux is often expressed in the non-SI unit "gas permeance units" (GPU, with $\left.1 \mathrm{GPU}=10^{-6} \mathrm{~cm}^{3}(\mathrm{STP}) \cdot \mathrm{cm}^{-2} \cdot \mathrm{s}^{-1} \cdot \mathrm{cmHg}^{-1}\right)$. The permeance corrected for the membrane thickness is referred to as permeability. The permeability to gases is often expressed in the non-SI unit Barrer $\left(10^{-10} \mathrm{~cm}^{3}(\mathrm{STP}) \cdot \mathrm{cm}^{-1} \cdot \mathrm{s}^{-1} \cdot \mathrm{cmHg}^{-1}\right)$. Fortunately, SI-units for permeance $\left(\mathrm{mol} \cdot \mathrm{m}^{-2} \cdot \mathrm{s}^{-1} \cdot \mathrm{Pa}^{-1}\right)$ and permeability $\left(\mathrm{mol} \cdot \mathrm{m}^{-1} \cdot \mathrm{s}^{-1} \cdot \mathrm{Pa}^{-1}\right)$ are also still used.

The rejection $(R)$ in liquid filtration can be expressed as the difference in solute concentration in the feed and permeate $\left(c_{f}-c_{p}\right)$ divided over the solute concentration in the feed $\left(c_{f}\right)$ as given in Equation 1.2.

$$
R=\frac{c_{f}-c_{p}}{c_{f}} \cdot 100 \%
$$

The ideal selectivity $\alpha_{i j}(-)$ of the gases $i$ and $j$ can be expressed as ${ }^{[3]}$ :

$$
\alpha_{i j}=\frac{P_{i}}{P_{j}}
$$

where $P_{i}$ and $P_{j}$ are the permeances of the gases $i$ and $j$, respectively. The ideal selectivity is measured with pure gases. However, real membrane processes involve gas mixtures and the overall selectivity of these processes will in general not be equal to the ideal selectivity for gases. For example, for gases such as $\mathrm{CO}_{2}$ competitive sorption in the membrane material will affect the permeance of the 
other gas components in the mixture. This results typically in a lower mixed gas selectivity ${ }^{[1]}$.

Since the permeance of a species is inversely proportional to the thickness of a membrane, membranes are preferred to be as thin as possible. Therefore, anisotropic membranes gained much interest due to the ability to prepare a thin separating layer on a porous support. A major breakthrough for membrane processes in industrial applications was the development of the Loeb-Sourirajan process in the early 1960 s to prepare anisotropic reverse osmosis membranes ${ }^{[4]}$. Later the membranes made by the Loeb-Sourirajan process provided the basis for more selective thin film composite membranes (TFC) that are the current standard for industrial separation processes ${ }^{[1]}$.

TFC membranes are asymmetric membranes that consist of multiple layers. In general three layers can be distinguished: (i) a non-woven backing material (commonly polyethylene or polypropylene) that provides mechanical strength and allows for handling of the membrane, (ii) a porous support layer, that is often an asymmetric polymeric UF membrane made by the Loeb-Sourirajan process, and (iii) an ultra thin top layer, that is the actual separating layer (Figure 1.2). Because the properties of the thin separating layer and the porous support can be individually tuned, TFC membranes provide a flexible platform for the optimization of a membrane for a specific application ${ }^{[6]}$.

TFC membranes can be prepared by a variety of methods of which some examples are (i) casting an ultra thin film and laminating it to a support, (ii) interfacial polymerization directly atop a porous support, (iii) dip-coating or solvent casting of a polymer solution atop a support, (iv) dip-coating of a reactive monomer or prepolymer atop a support followed by a post-curing step, or (v) depositing a film directly from a gaseous phase monomer plasma. Among these methods, dipcoating and interfacial polymerization are the most commonly used methods ${ }^{[7]}$. Of these, the interfacial polymerization process provides the possibility of local formation of a highly cross-linked network layer. In particular from the point of view of chemical stability, such cross-linked networks are beneficial. Within this context interfacial polymerization will be the main method for film synthesis explored in the remainder of this thesis.

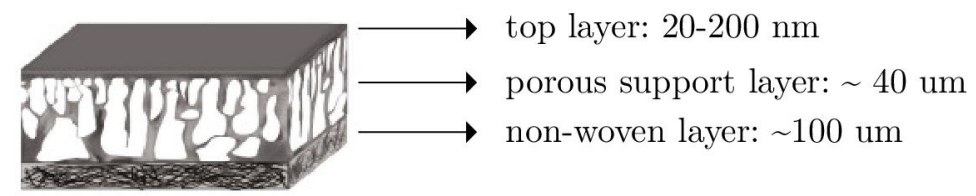

Figure 1.2: Schematic representation of an thin film composite membrane. A porous support layer is supported by a non-woven backing material. Atop of this porous support sits the thin separating layer. Reprinted from ${ }^{[5]}$. Copyright (2013), with permission from Elsevier 


\subsection{Interfacial Polymerization}

Interfacial polymerization (IP), or alternatively called interfacial polycondensation, is the rapid reaction of two or more monomers at the interface between two immiscible phases, most commonly two liquids of one which one is water (Figure 1.3). A typical interfacial polymerization reaction is based on the SchottenBaumann reaction of an acyl chloride with compounds containing active hydrogen atoms such as $-\mathrm{OH},-\mathrm{NH}$, and $-\mathrm{SH}^{[8]}$. Due to the localized nature of the reaction, higher molecular weight polymers could be obtained at milder reaction conditions compared to single-solvent polymerizations ${ }^{[9]}$. Because the monomers are dissolved in two immiscible phases, the monomer in the aqueous phase is more likely to meet a polymer with a reactive chain-end, than a free monomer in the organic phase.

\subsubsection{Basic principles of interfacial polymerization}

Interfacial polymerization is the localized reaction of two or more monomers at the interface between two immiscible phases resulting in polymer formation. The most common type of interfacial polymerization is when two liquid phases are used, although interfacial polymerization is not limited to two immiscible liquid phases. One could think of the use of a combination of a solid ${ }^{[10]}$ or gaseous phase in combination with a liquid phase.

Often, the monomers are dissolved into either of the two immiscible phases, although one of the phases can contain a reaction initiator or catalyst ${ }^{[11-13]}$. Song et al. ${ }^{[14]}$ defined 5 sub-classes of IP reactions using two immiscible liquid phases as depicted in Figure 1.4. The authors distinguished a phase with a monomer

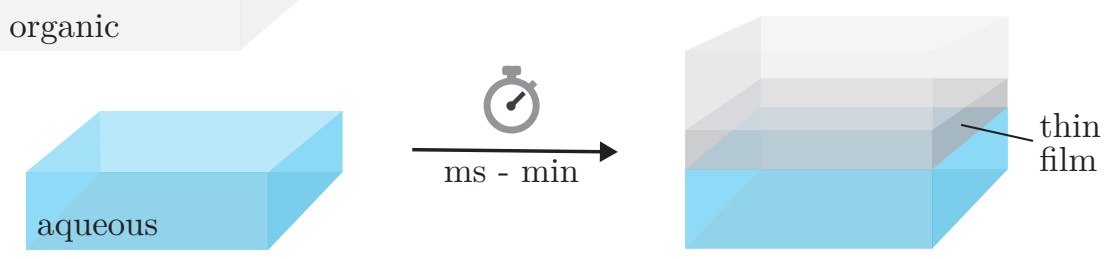

Figure 1.3: A schematic representation of interfacial polymerization. Two or more monomers plus possible additives are dissolved into two immiscible phases. At the interface, these monomers can react, thereby forming a thin film. 


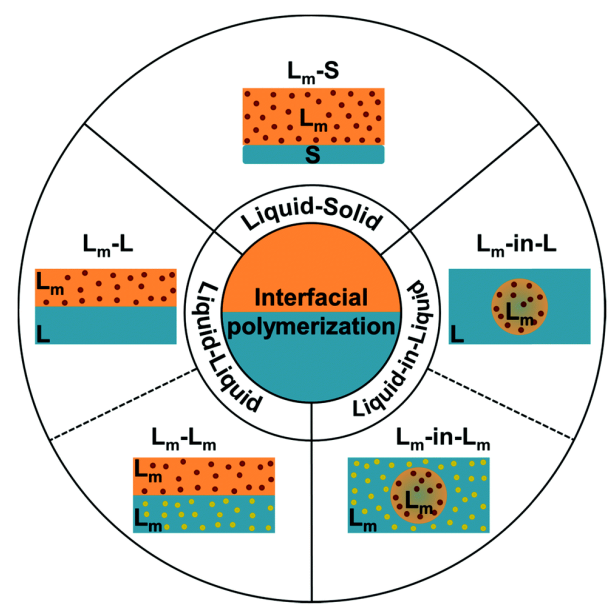

Figure 1.4: The sub-classes of liquid-liquid interfacial polymerization. $L$ represents a liquid phase without monomer, $L_{m}$ with monomer, and $S$ represents a solid. Reproduced from ${ }^{[14]}$ with permission of The Royal Society of Chemistry.

dissolved $\left(\mathrm{L}_{\mathrm{m}}\right)$, and a liquid phase were none or non-monomeric compounds were dissolved (L).

Liquid-in-liquid (L-in-L) interfacial polymerization is based on the emulsion of one phase into the other phase. When the monomer is dissolved in the inner liquid phase, and a initiator or catalyst is dissolved in the outer liquid phase, one is referring to a $\mathrm{L}_{\mathrm{m}}$-in-L reaction. When the outer phase contains both monomer and initiator or catalyst, the reaction can be classified as $\mathrm{L}_{\mathrm{m}}$-in- $\mathrm{L}_{\mathrm{m}}$. Free-standing polymeric films can be prepared by classical liquid-liquid $\left(\mathrm{L}_{\mathrm{m}}-\mathrm{L}_{\mathrm{m}}\right)$ polymerization. When one of the phases is contained in a porous support, the interfacial polymerization can be classified as $\mathrm{L}_{\mathrm{m}}-\mathrm{S}$, and a polymeric film will be formed atop of the porous support ${ }^{[14]}$.

The $\mathrm{L}_{\mathrm{m}}-\mathrm{S}$ method is commonly applied for the preparation of TFC membranes. In this method the porous support is wet with one of the liquid phases. This is often the aqueous phase because of the higher density compared to the organic phase. The excess aqueous phase is removed from the surface, and the organic phase is poured atop of the porous support, resulting in the L-L interface and thus polymer formation will occur at the top of the support. When the polymer formation is finished, the formed TFC membrane is washed with excess solvent to remove unreacted monomers from the surface and from the porous support.

Some factors that can influence the properties of the polymeric film which is formed are the miscibility of solvents, the solubility of reactants, and the reactivity of the reactants. The miscibility affects the diffusion of the reactants as well as the diffusion of water molecules to the organic phase. The solubility of one of the reactants in the other phase will alter the morphology of the top layer. When the 
monomers of one phase has a high solubility in the other phase, a more corrugated film is formed ${ }^{[15]}$. A high reactivity between the monomers results in rapid film formation, and the diffusion of new monomers limits the film growth, hence submicrometer film thicknesses are obtained ${ }^{[16]}$. In general, well-defined dense films are prepared from monomers with a high reactivity and a low solubility in the opposite phase.

Many attempts have been made to model the kinetics and the properties of films derived by interfacial polymerization ${ }^{[17-24]}$. All these models differ in their approach, and hence there is no consensus on the exact mechanism of interfacial polymerization reactions. Freger and Srebnik ${ }^{[21]}$ published a model that fits relatively well with experimental data obtained from interfacial polymerized films. According to their model, the reaction could be split into three different regimes: incipient film formation, slowdown and diffusion-limited growth. The interfacial polymerization starts with incipient film formation in a thin reaction zone. As the reaction proceeds this reaction zone shrinks due to, e.g., decreasing diffusivity or increasing film resistance. A dense film is formed inside this incipient loose polymer film. The resulting polymer film possesses a dense core within a looser polymer structure. The concentration of monomer and type of end-groups differ on both sides of this dense core, resulting in an excess of either ${ }^{[21,23]}$.

Interfacial polymerization benefits from a high reaction rate at mild reaction conditions, preferably at room temperature, with polymer formation within seconds to minutes. Typical TFC membranes are prepared from the reaction of a multifunctional amine in the aqueous phase and a multifunctional acyl chloride in the organic phase resulting in a relatively stable polyamide. Cadotte was the first to describe these membranes prepared from $m$-phenylenediamine (MPD) and trimesoyl chloride $(\mathrm{TMC})^{[25]}$. Scheme 1.1 shows the chemical structure of this polyamide, bearing linear and cross-linked repeating units.

Interfacial polymerization has three main advantages for the preparation of TFC membranes. First of all membranes prepared by interfacial polymerization are inherently defect-free. In case of a defect, the two monomers are still able to meet resulting in continuing polymer growth at this spot. Furthermore, interfacial polymerization allows for the synthesis of ultra-thin polymer films, enhancing the permeance through the membrane. Finally, the dimensions of the interface at which the monomers react, is potentially unlimited allowing for the production of membranes on a large scale.

The properties of the classical TFC membranes, mainly prepared from TMC and MPD, have been studied in great detail in the last decades. Many factors can influence the outcome of the interfacial polymerization reaction. The following sections will discuss some aspects of the interfacial polymerization reaction such as the influence of the porous support, reaction parameters during the reaction, possible treatments after the reaction, and the effect of the monomers forming the polyamide. Although this section is mainly written for the classical polyamides, most of it can also be transferred to the use of other monomers. 

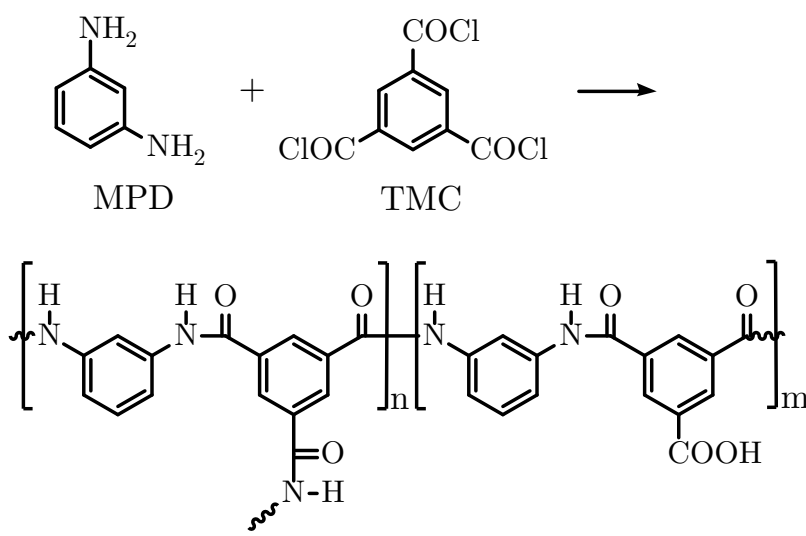

polyamide

Scheme 1.1: The structure of a typical polyamide membrane synthesized by the interfacial polymerization of $m$-phenylenediamine (MPD) and trimesoyl chloride (TMC).

\subsubsection{The porous support}

The porous support layer (support) is an important parameter in the applicability of TFC membranes in industrial processes. It has an important role in the interfacial polymerization process, since it acts as a reactant reservoir for the aqueous phase and co-defines the interface of the interfacial polymerization ${ }^{[26]}$. In addition. the support provides mechanical support for the actual separating layer. It is important that the support is stable under the operating conditions of the final TFC membrane, and that it can withstand for example high pressure, high temperature, and/or chemically aggressive environments. The support can be both organic (polymeric) and inorganic, and can have several geometries such as flat sheets or hollow fibers. Although flat-sheets can be eventually used in spiral wound modules, a hollow fiber geometry provides a very high surface-to-volume ratio and thus facilitates higher permeances.

Inorganic supports provide excellent thermal stability and can withstand high pressures. In contrast to polymeric supports, inorganics do not suffer from aging or compaction effects. A commonly used ceramic material for supports is alumina $\left(\mathrm{Al}_{2} \mathrm{O}_{3}\right)$. Alumina is stable in most solvents, but especially $\gamma$-alumina lacks stability at extreme $\mathrm{pH}$ conditions. Alumina supports are often made of at least two porous sublayers. The $\alpha$-alumina layer provides mechanical strength and determines the shape of the membrane. Atop of this $\alpha$-alumina layer are one or more layers of $\gamma$-alumina coated. $\gamma$-Alumina has, depending on the sintering procedure, a pore size of $3-8 \mathrm{~nm}$ which provides a sufficient reactant reservoir.

At milder conditions, polymeric supports provide excellent cost-efficient alternatives to inorganic supports. These polymeric supports are mainly used to support the commercial polyamide membranes. The class of organic supports is made 
of polymers such as polysulfone (PSf), poly(ether sulfone) (PES), polyacrilonitrile (PAN), poly(vinylidene fluoride) (PVDF), polyimides (PI), or polypropylene $(\mathrm{PP})^{[7,27,28]}$. In general, polymeric supports are prepared via non-solvent induced phase separation (NIPS) resulting in asymmetric structures with a dense top layer and macrovoids more towards the bottom. A solution containing the polymer is casted on the non-woven, and immersed in a non-solvent. The polymer precipitates from the surface down into two phases: a polymer-rich and a polymer-lean phase. The polymer-rich phase forms the membrane matrix, and the polymer-lean phase forms the membrane pores ${ }^{[1,29]}$. The stability of some polymeric supports could be enhanced by cross-linking the support ${ }^{[30-33]}$.

Many papers have been published on the influence of the interaction of the polyamide film with the support ${ }^{[34-38]}$. The porosity and hydrophilicity of the support are key parameters for the successful preparation of polyamide films. The pore size determines the stability of the liquid-liquid interface. Very small pores provide a stable interface, but are difficult to wet, whereas the aqueous phase can evaporate too quickly from very large pores. Besides pore size, hydrophilicity plays an important role in the wetting of the support by the aqueous phase. Hydrophilic supports improve the wettability and adhesion between the support and top layer ${ }^{[26]}$.

Polyamide films that are prepared by support-free interfacial polymerization, and then transferred to a support result in improved membrane performance compared to conventionally prepared membranes ${ }^{[39]}$. One method to obtain support-free thin films is by sacrificial cadmium hydroxide nanostrands. Polyamide films could be formed atop of a nanostrand layer, and when film formation was complete the nanostrands could be removed by dissolution in acids ${ }^{[40,41]}$. Park et al. ${ }^{[39]}$ prepared support-free films by bulk interfacial polymerization, followed by controlled drainage of the solutions.

\subsubsection{Reaction parameters influencing the interfacial poly- merization reaction}

The interfacial polymerization reaction on itself provides many parameters that could be altered to optimize the performance of the resulting polyamide thin film. This section discusses the influence of the concentration of monomers, the solvents, the reaction time and temperature, and additives and surfactants on the resulting membrane performance, mainly described in permeance and rejection.

\section{The concentration of monomers}

In contrast to classical single solvent polycondensation reactions, the reaction stoichiometry of the monomers is not necessarily equal to that of the formed polymer. The local monomer stoichiometry at the interface is described as a function of monomer reactivity, concentration, diffusivity and solubility in either phase ${ }^{[16]}$. 
The interfacial polymerization reaction mainly takes place in the organic phase due to the low solubility of most acid chlorides in water. To enhance the diffusion of the diamine to the organic phase, a large excess of amine is commonly used ${ }^{[42]}$. Typical amine concentrations vary between $1-2 \mathrm{w} / \mathrm{v} \%$, and TMC concentrations between $0.1-0.15 \mathrm{w} / \mathrm{v} \%$.

\section{The solvents}

Most polyamide membranes are prepared using water and an organic solvent. The organic solvent must be immiscible with water. Commonly used organic solvents are $n$-hexane, cyclohexane, $n$-heptane, toluene, and Isopar G (C9-C12 isoalkanes). Chlorinated solvents, such as chloroform or dichloromethane, could be used as well. In contrast to non-chlorinated solvents, chlorinated solvents have a higher density compared to water, resulting in an inverted system where the organic solvent is the bottom phase.

The choice of organic solvent is one of the most important factors that influences the molecular weight of the polymer formed at the interface ${ }^{[43,44]}$. The polymer is formed in the organic phase, meaning that a higher polymer solubility in the organic phase results in a higher molecular weight polymer, i.e. the polymer precipitates at a higher molecular weight. Jegal et al. ${ }^{[4]}$ showed that by only changing the organic solvent, the membrane performance could be altered from NF to RO. Ghosh et al. ${ }^{[42]}$ studied the effect of the organic solvent as well. The organic solvent influences the diffusivity and solubility of the MPD into the organic phase. The authors showed that a high MPD solubility results in a more permeable film for both salt and water, whereas high diffusivity results in a higher water permeance but does not enhance salt permeability.

\section{Reaction time and temperature}

The removal of the excess aqueous phase solution and the drying of the top of the porous support are a critical parameters in the successful formation of TFC membranes. A thin water film present on the surface results in interfacial polymerization away from the support's surface, and therefore in a loose film that is not attached to the support. This can result in major defects, which is undesirable, therefore the proper drying of the support is a critical step. Some commonly used methods to dry the support are: i) removal of the excess aqueous phase using an air knife, ii) draining of the excess aqueous phase, and let air dry in either horizontal or vertical position iii) removal of the excess aqueous phase by a rubber roller ${ }^{[45]}$. Dalwani et al. ${ }^{[46]}$ showed a difference in membrane performance depending on the drying technique used. When a rubber roller was used, the flux

\footnotetext{
${ }^{\mathrm{i}}$ The symbol $\mathrm{w} / \mathrm{v} \%$ denotes a mass per volume percentage, thus a $1 \mathrm{w} / \mathrm{v} \%$ solution is equal to $1 \mathrm{~g}$ dissolved in a final volume of $100 \mathrm{~mL}$.
} 
showed a non-linear dependence on the transmembrane pressure and lower salt rejection, whereas air drying resulted in a linear relation between flux and pressure and higher rejections.

Another important parameter influencing the performance of a membrane prepared by IP is the reaction time. A longer reaction time improves the membrane's selectivity, as thicker and denser top layers are obtained ${ }^{[26]}$. At some point the increase in reaction time does not result in enhanced membrane performance. When the top layer is dense enough to stop the diffusion of the amine into the organic phase, the growth will stop and the separation performance stays constant (Figure 1.5 $)^{[47-51]}$.

Often, interfacial polymerization is performed with both the aqueous phase and the organic phase at room temperature. There are however some examples where the temperature of the organic phase was varied both above and below room temperature. Ghosh et al. ${ }^{[42]}$ showed the effect of temperature $\left(8-38{ }^{\circ} \mathrm{C}\right)$ when using Isopar G (C9-12 isoalkanes) as solvent. With increasing temperature, the permeance increased but rejection slightly decreased. The morphology showed a transition from a tightly packed small nodular structure at low temperatures, to a rough ridge-and-valley morphology at higher temperatures. Khorshidi et al. ${ }^{[52]}$ varied the temperature of the organic phase (heptane) between $-20{ }^{\circ} \mathrm{C}$ and $50{ }^{\circ} \mathrm{C}$. Although they found similar temperature dependent morphological features as Ghosh, in contrast to Ghosh they found an increase in rejection and decrease in permeance up to $25{ }^{\circ} \mathrm{C}$. An increase in organic phase temperature results in a higher amine solubility and diffusivity. Due to the higher amine concentration, the reaction speed increases, resulting in thicker layers ${ }^{[42,52]}$. At higher temperatures,

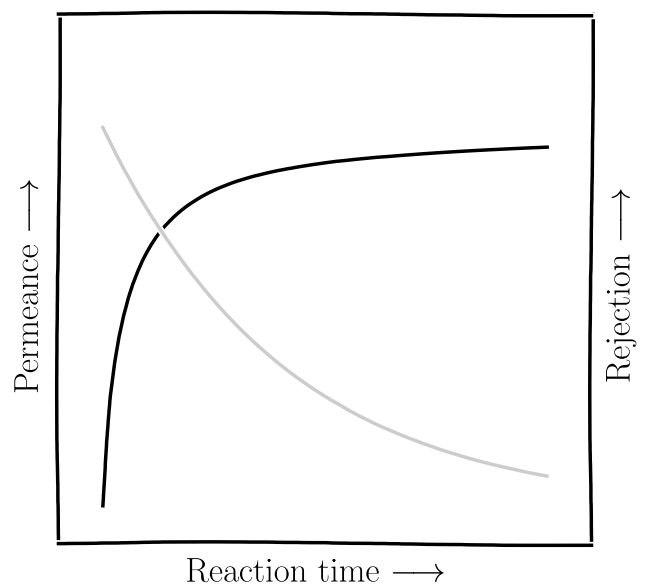

Figure 1.5: The permeance and rejection as a function of reaction time. 
the miscibility of water with solvents increases ${ }^{[53,54]}$, resulting in a higher rate of hydrolysis of the acyl chloride ${ }^{[55]}$, resulting in a lower cross-link density.

\section{Additives and surfactants}

Additives and surfactants can be added in either the aqueous or organic phase to improve the performance of the membrane. Acid acceptors are commonly used additives. The $\mathrm{pH}$ of the aqueous solution initially decreases during the interfacial polymerization reaction. However, at some point the $\mathrm{pH}$ increases substantially due to the formation of hydrochloric acid $(\mathrm{HCl})$ that is released in the condensation reaction of an amine with an acyl chloride ${ }^{[27,55]}$. Acid acceptors could be mixed with the aqueous phase to remove the hydrochloric acid. Some examples of commonly used acid acceptors are sodium hydroxide, sodium carbonate, sodium phosphate, and triethylamine ${ }^{[27]}$. It is believed that the strength of the acid acceptor influences the degree of hydrolysis, and hence influences the membrane structure and performance ${ }^{[42]}$.

Besides acid receptors, other additives could be added to enhance water permeance. The addition of hydrophilic water-soluble compounds to the aqueous phase such as alcohols or ethers enhances the water permeance and salt rejection ${ }^{[56]}$. Furthermore, nanoparticles can be added to the polyamide matrix to improve the membrane's properties ${ }^{[57]}$. Examples reported in literature are silica particles $^{[58,59]}$, zeolites ${ }^{[60-62]}$, or inorganic salts ${ }^{[63]}$.

Another method to enhance water permeance is to add aprotic solvents such as $N$ methyl-2-pyrrolidone (NMP), or dimethylformamide (DMF) to the aqueous phase as described in patents by Chau ${ }^{[64,65]}$. The solvent reacts with the acyl chloride to form an amidinium chloride. This amidinium chloride is relatively unreactive towards aromatic diamines, resulting in a lower cross-linking degree. The addition of dimethyl sulfoxide (DMSO) to the aqueous phase also results in an enhanced water permeance, but by a different mechanism ${ }^{[66,67]}$. The presence of DMSO enhances the miscibility of water and the organic solvent ( $n$-hexane) resulting in a thinner polyamide film. The enhanced miscibility of water and the organic phase results in an enhanced acyl chloride hydrolysis and a lower cross-linking degree. Therefore, the amount of additive should be carefully controlled.

Kong et al. ${ }^{[68]}$ reported on the use of a solvent in the organic phase as an additive and named this process "co-solvent assisted interfacial polymerization" (CAIP). A controlled amount of co-solvent (acetone) is added to the non-polar organic phase ( $n$-hexane). A narrow misscibility zone is formed at the water $/ n$-hexane interface that is eliminating the great immiscibility gap between water and $n$-hexane while retaining the liquid-liquid interface. CAIP results in a thinner, more open, and smoother dense layer with a more than 3-fold higher water permeance and similar rejection compared to conventional membranes ${ }^{[68-70]}$.

Other additives are phase transfer catalysts (PTC). Phase transfer catalysis was for the first time reported by Starks ${ }^{[71]}$. PTCs facilitate the transport of reactants 
from one to the other phase, thereby increasing the polymerization rate. Phase transfer catalysts are often quaternary ammonium salts, because they are cheap and readily available. However, tertiary aliphatic amines, phosphonium salts or crown ethers can be used as well ${ }^{[72]}$.

Figure 1.6 shows the reaction mechanism of PTC as reported on by Starks. The ammonium salt $\left(\mathrm{Q}^{+} \mathrm{X}^{-}\right)$is in equilibrium with the charged monomer $\left(\mathrm{M}^{+} \mathrm{Y}^{-}\right)$, where $\mathrm{M}^{+}$is a metal cation, often sodium or potassium. The monomer $\mathrm{Y}^{-}$is transported to the organic phase, where the nucleophilic substitution to $\mathrm{R}-\mathrm{Y}$ takes place ${ }^{[73]}$.

PTC can be used to enhance membrane performance of polyamides ${ }^{[43,74,75]}$ but can also be used to enable the interfacial reaction of less reactive monomers.

Besides additives, surfactants or organic acids (e.g., camphor sulfonic acid) can be added to improve the wettability of the porous support. Surfactants can also help to increase the solubility of reactants, or alter the surface tension ${ }^{[28]}$. The surfactants are often added to the aqueous phase ${ }^{[76,77]}$. Alternatively, the support can be pre-wet by the surfactant before wetting with the aqueous phase ${ }^{[46,78-80]}$.

\subsubsection{Post-condensation and chemical functionalization}

Some reactive groups can still be present after the interfacial polymerization reaction. These groups provide the possibility of post-condensation or chemical functionalization after the interfacial polymerization step.

TFC membranes can be cured at elevated temperatures to accelerate the evaporation of the solvents (both organic solvents and water) and to further cross-link the film by the reaction of unreacted amines and carboxyl groups. The curing of TFC membranes at elevated temperatures is also referred to as post-condensation. This post-condensation tends to increase the permeance and rejection ${ }^{[42]}$. However, increasing the curing temperature (or time) results in a densification of the

Organic phase

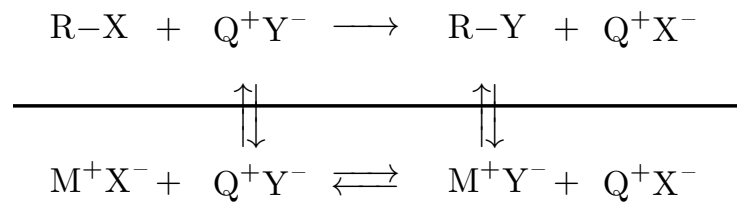

Aqueous phase

Figure 1.6: Starks' $\mathrm{PTC}$ mechanism for the nucleophilic substitution reaction $\mathrm{R}-\mathrm{X}+$ $\mathrm{M}^{+} \mathrm{Y}^{-} \longrightarrow \mathrm{R}-\mathrm{Y}+\mathrm{M}^{+} \mathrm{X}^{-} . \mathrm{Q}^{+} \mathrm{X}^{-}$represents the phase transfer catalyst. 
surface. Due to this densification, the water permeance is reduced significantly, but the rejection increases. Increasing the curing temperature too close to the boiling point of the solvent results in film shrinkage and increased surface roughness. This results in damage to the top layer of the membrane, due to the fast evaporation of the solvent, and reduces the permeance and rejection ${ }^{[42,77]}$. Besides this top layer damage, the porous support can suffer from pore shrinkage when curing temperatures are too high.

Traditional polyamide membranes prepared from, e.g., MPD and TMC have a negatively charged surface originating from unreacted acyl chloride groups that eventually turn into carboxylic acid groups ${ }^{[81]}$. Because the interfacial polymerization reaction takes place in the organic phase, the amines have to diffuse through the water-organic solvent interface and diffuse trough the forming film into the organic phase. Due to this diffusion, there is a gradient of amine groups with fewer and fewer amine groups closer to the organic phase side of the film. This automatically results in more acyl acid groups at the membrane's surface ${ }^{[82,83]}$. Kang et al. ${ }^{[83]}$ showed that the hydrolysis into carboxylic acid groups is slow enough to allow for post modification by amino functionalized poly(ethylene glycol) $\left(\mathrm{PEG}-\mathrm{NH}_{2}\right)$ chains. Mahdavi et al. ${ }^{[84]}$ used a two-step process, where they first reacted the acyl chloride groups with ethylenediamine, followed by the Michael addition of a hyperbranched poly(amine ester) to alter the membrane's surface properties. To reduce fouling, Yin et al. ${ }^{[85]}$ functionalized the surface with silver nanoparticles covalently bound to the membrane surface using a thiol. In addition, Solomon et al. ${ }^{[86]}$ functionalized polyamide membranes with fluoroalkylamines or siliconealkylamines to result hydrophobic surfaces that showed excellent performance in organic solvent nanofiltration (OSN).

The permeance of TFC membranes can be enhanced by solvent activation. Solvents that showed to enhance the permeance of TFC membranes are alcohols such as ethanol and 2-propanol ${ }^{[87]}, \mathrm{DMF}^{[33,41,86,88-90]}$, or DMSO ${ }^{[33,88,90]}$. In most examples, the rejection is unchanged, although examples can be found where the rejection is enhanced ${ }^{[33]}$ or reduced ${ }^{[90]}$. The exact mechanism behind this solvent activation is unknown. The common hypothesis is that it is due to the removal of low molecular weight oligomers due to the swelling of the top layer. The enhanced retention is hypothesized to originate from annealing effects during the solvent activation; small defects are removed during the annealing ${ }^{[33,88]}$.

\subsubsection{The effect of aqueous and/or organic phase monomers}

So far, the influence of interfacial polymerization reaction parameters on mainly TMC-MPD based polyamides have been discussed. However, the structure of both the amine and acyl chloride could be altered to further improve the membrane performance. The effect of both the amine and the acyl chloride structure on the membrane performance has been studied in literature by many authors. For example, the use of aromatic or aliphatic monomers results in different membrane performance. In general, the use of aromatic diamines results in better 
rejection but lower permeances compared to using aliphatic diamines ${ }^{[91]}$. Another important parameter is the substitution pattern of the reactive groups in aromatic monomers, i.e., ortho-, meta-, or para- ${ }^{[92,93]}$.

The IP reaction is mostly limited by the diffusion of aqueous phase monomer. Therefore $\mathrm{Li}$ et al. ${ }^{[94]}$ proposed that most can be gained when optimizing the organic phase monomer, although many examples of amine modification can be found in literature as well. Table 1.1 gives examples of amine modifications and Table 1.2 gives examples of acyl chloride modifications reported on in literature.

Table 1.1: Structures of some diamines used in the preparation of polyamide membranes. References of literature reporting on less common diamines are given.

\begin{tabular}{|c|c|c|}
\hline Amine & Reference & Structure \\
\hline $\begin{array}{l}m \text {-phenylenediamine } \\
\text { (MPD) }\end{array}$ & & \\
\hline $\begin{array}{l}p \text {-phenylenediamine } \\
\text { (PPD) }\end{array}$ & & \\
\hline $\begin{array}{l}\text { piperazine } \\
\text { (Pip) }\end{array}$ & & \\
\hline $\begin{array}{l}N, N^{\prime} \text {-diaminopiperazine } \\
\text { (DAP) }\end{array}$ & [95] & \\
\hline $\begin{array}{l}\text { 1,3-cyclohexanebis- } \\
\text { (methylamine) (CHMA) }\end{array}$ & {$[96]$} & \\
\hline $\begin{array}{l}\text { 2,4-diaminotoluene } \\
(\mathrm{MMPD})\end{array}$ & {$[97]$} & \\
\hline 3,5-diaminobenzoic acid & {$[98-101]$} & \\
\hline $\begin{array}{l}\text { 2,5-diaminobenzene- } \\
\text { sulfonic acid }\end{array}$ & {$[102]$} & \\
\hline
\end{tabular}


Table 1.1 - continued from previous page

\begin{tabular}{lll}
\hline Amine & Reference & Structure \\
\hline $\begin{array}{l}\text { 4,4'-diaminodiphenyl- } \\
\text { sulfone }\end{array}$ & {$[103,104]$} &
\end{tabular}

Table 1.2: Structures of some acyl chlorides used in the preparation of polyamide membranes. References of literature reporting on less common acyl chlorides are given.

Acyl chloride
Reference
trimesoyl chloride
(TMC)
cyclohexane-1,3,5-tri-
carbonyl chloride (HTC)
isophthaloyl chloride
(IPC)
(TPC)
biphenyl diacyl chloride
(BDC)
1,2,4,5-benzene tetra-
carbonyl chloride ${ }^{\mathrm{T}}$ (BTC)
chloride (BTRC)


Table 1.2 - continued from previous page

\begin{tabular}{llll}
\hline Acyl chloride & Reference & \\
biphenyl tetraacyl chloride ${ }^{\mathrm{b}}$ & {$[94,105,108]$} \\
(BTEC) & {$[76,109]$}
\end{tabular}

${ }^{\text {a }}$ The reaction with a diamine results in a polyimide.

b The structure of $m m$-BTEC is drawn here, however om-BTEC and op-BTEC have been used in the preparation of polyamides as well.

Polyamides lack stability to chlorine disinfectants that are commonly applied to clean membranes from fouling ${ }^{[111,112]}$. When polyamides are exposed to free chlorine, several undesired reactions occur such as the chlorination of the amide $\mathrm{N}-\mathrm{H}$ bond to $\mathrm{N}-\mathrm{Cl}$, possibly followed by Orton rearrangement leading to chlorination of the aromatic ring (Scheme 1.2). The chloro-substituted aromatic ring causes a negative inductive effect, and weakens the amide bond, and therefore makes it more susceptible to hydrolysis in the presence of an acid or base ${ }^{[111,113,114]}$. A lot of research has been done on the improved chlorine stability of polyamides. In general, aromatic polyamides have the highest chlorine stability, followed by cycloaliphatic and aliphatic polyamides. In addition, chlorine stability could be enhanced further by: i) aliphatic or cycloaliphatic diamines with a secondary amine group, ii) aliphatic or cycloaliphatic diamines with a short methylene chain length between end amino groups, and iii) aromatic diamines with a $-\mathrm{Cl}$ or $-\mathrm{CH}_{3}$ substituent at the ortho position of the amino groups. In general it can be concluded that a lower pKa of the amine results in a higher chlorine resistance ${ }^{[103]}$.

A chemically similar structure that, in contrast to polyamides, is stable in strong acidic, basic or oxidative environments is polysulfonamide. It can be prepared from 4,4'-diaminodiphenylsulfone and TPC as depicted in Scheme 1.3. Although this polysulfonamide still contains amide groups in its main chain, it shows excellent stability due to the strongly electronegative sulfone groups ${ }^{[115]}$. 
i)<smiles>Cc1cccc(C(=O)Nc2cccc(C(C)(C)C(=O)N(Cl)c3cccc(C)c3)c2)c1</smiles>

ii)

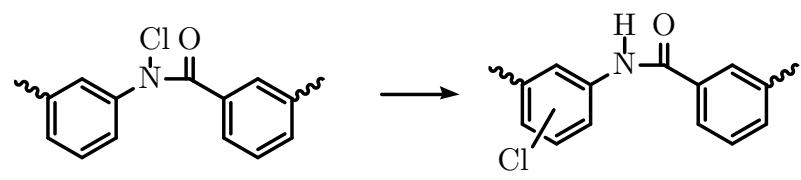

Scheme 1.2: (i) The $\mathrm{N}$-chlorination, and (ii) the Orton rearrangement of an amide bond in a polyamide when exposed to free chlorine.
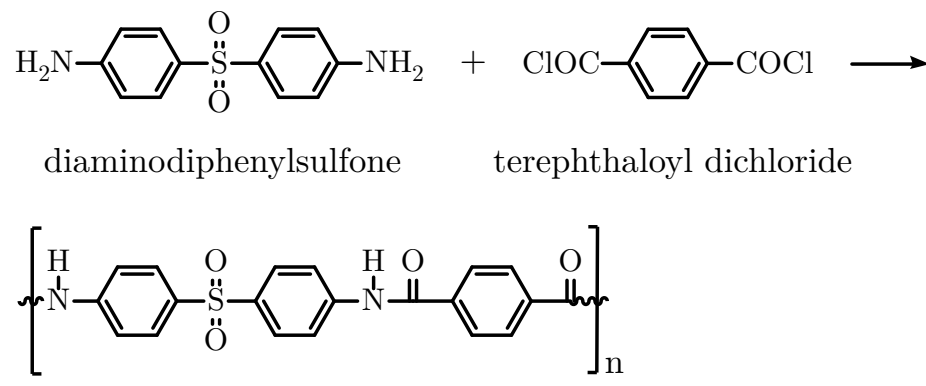

polysulfonamide

Scheme 1.3: The formation of a polysulfonamide from diaminodiphenylsulfone and terephthaloyl dichloride (TDC). 


\subsection{Beyond classical chemistry in interfacial poly- merization}

So far, the common polyamide thin films have been discussed, however many more classes of compounds could be synthesized with interfacial polymerization. In this thesis, four structural elements of networks prepared by IP are distinguished: the network former, the bridge in between network formers, functional side groups of the bridge molecule, and the anchor connecting the network former and the bridge molecules. A schematic representation of these elements is given in Figure 1.7.

The network former is a multifunctional compound, that facilitates the crosslinking of the network. Possible structures are small organic or inorganic molecules, dendrimers, enzymes, or, (in)organic polymers. The bridge molecule plays an important role in the separation performance of the resulting film. The selectivity of the film could be tuned towards a specific compound by tuning, for example, the length or rigidity or the bridge, or by adding functional side groups with affinity for a specific compound. The last structural element is the anchor. Despite having a small influence on separation performance, it is an important parameter in stability. Amine bonds, for example, show excellent stability at extreme $\mathrm{pH}$ conditions, whereas imide bonds provide stability at elevated temperatures. This improved stability, however, comes at the cost of for example a lower reactivity of the network former, or the necessity of an additional thermal treatment step at elevated temperatures.

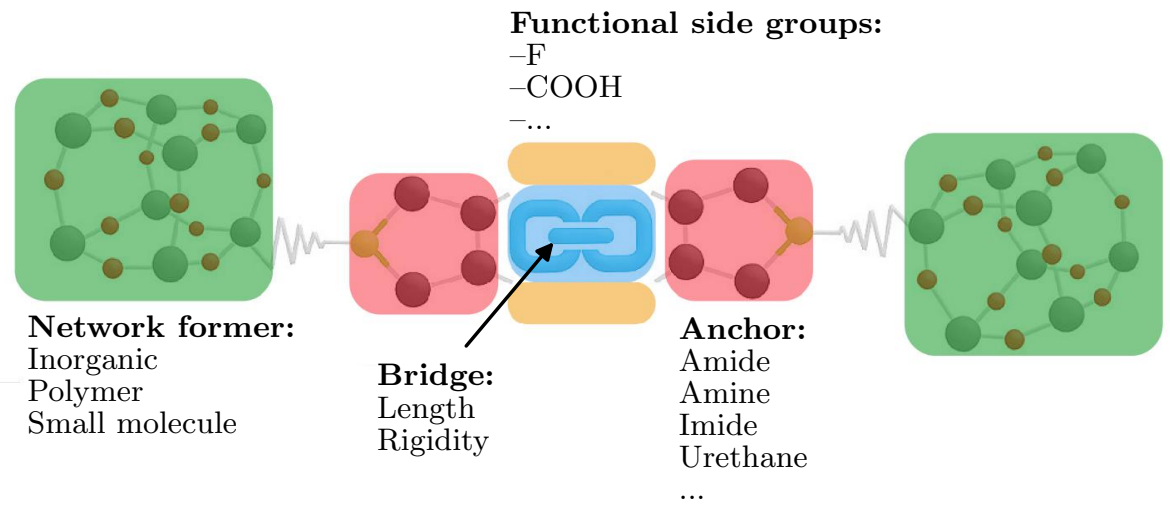

Figure 1.7: A schematic representation of the chemical structure of a cross-linked film made by interfacial polymerization. Several structural elements could be defined that influence the final properties of the film. These elements are defined as: the network former, the bridge with functional side groups, and the anchor between the network former and bridge. 
In classical polyamides, the acyl chloride monomer can be considered as the network former, and the aromatic diamine as the bridge. The anchor is obviously an amide. These structural elements, that can be distinguished in films prepared by IP, provide a very flexible platform for the design of new networks with properties that could be altered specifically to the application. All elements could be altered individually or in combination with other elements. The following paragraphs will focus on the chemistry of the anchor and the network former. Both existing examples from literature and potential new structures will be discussed.

\subsubsection{The anchor}

The functional groups on the network former in combination with the functional group on the bridge molecule result in the chemistry of the anchor. This chemistry plays an important role in the stability of the network that is formed. A high reactivity between the two functional groups forming the anchor under ambient conditions is an important requirement to be able to form cross-linked networks via interfacial polymerization.

Polyamides have been discussed in the previous sections, but analog to polyamides, polyesters can be prepared from the condensation reaction of acyl halides and alcohols:

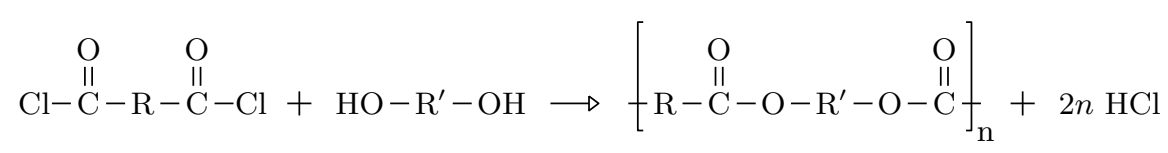

Polyester based TFC top layers prepared by interfacial polymerization have been reported in literature ${ }^{[116,117]}$, however polyesters are more susceptible to hydrolysis under acidic and basic conditions compared to polyamides ${ }^{[16]}$.

Similar to polyamides, polysulfonamides could be formed from the reaction of a diamine with a sulfonyl chloride ${ }^{[118,119]}$ :

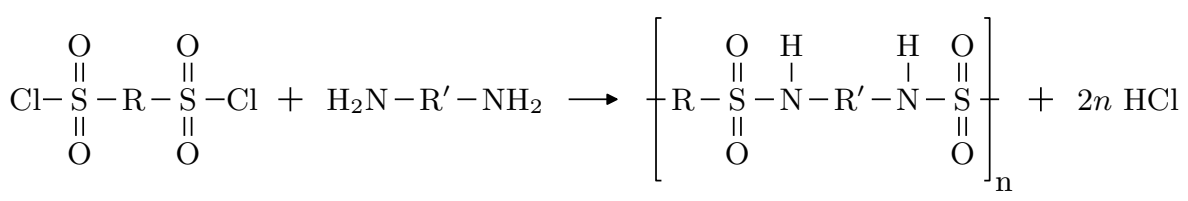

Note that this structure is different to the polysulfonamide described before. Polysulfonamides have a superior chemical and thermal stability compared to polyamides due to the electron withdrawing sulfone group ${ }^{[120]}$. However, the synthesis of polysulfonamides by interfacial polymerization is not straight forward.

Disulfonyl chlorides hydrolyze more easily upon contact with water ${ }^{[119]}$, and have 
a lower reactivity ${ }^{[120]}$ compared to acyl chlorides. Despite this, some polysulfonamides membranes have been published in literature ${ }^{[120-123]}$.

Another possible anchor is the epoxide linkage. Epoxides can react with a nucleophile (e.g., amines, alcohols, thiols, carboxylic acids) to form a polyepoxide (also referred to as epoxy):

$$
\begin{aligned}
& \underset{\mathrm{H}_{2} \mathrm{C}}{\mathrm{O}}-\mathrm{CH}-\mathrm{R}-\mathrm{CH}_{-}=\underset{\mathrm{CH}_{2}}{\mathrm{O}}+\mathrm{HO}-\mathrm{R}^{\prime}-\mathrm{OH} \rightarrow \\
& {\left[\begin{array}{cr}
\stackrel{\mathrm{OH}}{\mathrm{I}} \\
\mathrm{R}-\stackrel{\mathrm{CH}}{\mathrm{C}}-\mathrm{CH}_{2}-\mathrm{O}-\mathrm{R}^{\prime}-\mathrm{OH} \\
\stackrel{\mathrm{I}}{\mathrm{C}} \mathrm{H}
\end{array}\right]_{\mathrm{n}}}
\end{aligned}
$$

Weaker nucleophiles such as $\mathrm{H}_{2} \mathrm{O}, \mathrm{R}-\mathrm{OH}$, and $\mathrm{R}-\mathrm{NH}_{2}$ need an acidic catalyst to make the epoxide more electrophilic ${ }^{[124]}$. The reaction of an epoxide is generally considered to be fast due to the ring strain present in the epoxide monomer.

A method to improve the stability against hydrolysis of the amide bond is to design an anchor without a carbonyl group. An example is the polyamine linkage. Aliphatic polyamines can be formed from the alkylation of amines with alkyl halides. The reaction product is always a higher substituted amine, i.e., the reaction of a primary amine with an alkyl halide results in a secondary amine:

$$
\mathrm{H}_{2} \mathrm{~N}-\mathrm{R}-\mathrm{NH}_{2}+\mathrm{X}-\mathrm{R}^{\prime}-\mathrm{X} \longrightarrow\left[\begin{array}{cr}
\mathrm{H} & \mathrm{H} \\
\mathrm{I} & \mathrm{L} \\
\mathrm{R}-\mathrm{N}-\mathrm{R}^{\prime}-\mathrm{N} &
\end{array}\right]_{\mathrm{n}}+2 n \mathrm{HX}
$$

When tertiary amines are alkylated, the reaction is called the Menschutkin reaction $^{[125,126]}$. Aryl halides need to be activated by strong electron-withdrawing groups to be able to undergo this arylation reaction.

Another linkage that provides thermal stability is a polyurethane ${ }^{[127]}$. Polyurethanes can be formed from the reaction of a diisocyanate $(-\mathrm{N}=\mathrm{C}=\mathrm{O})$ with a dialcohol:

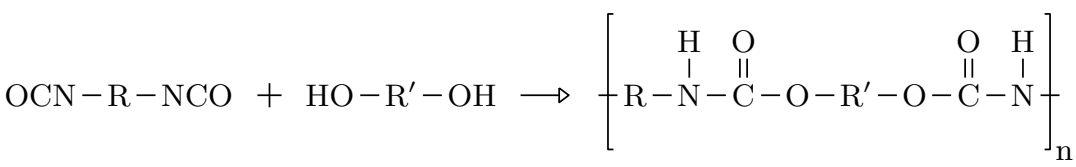

This reaction is not a condensation reaction, since there is no release of a small molecule, instead the atoms rearrange into the urethane structure. The main drawback for synthesizing polyurethanes via interfacial polymerization is the reaction of isocyanates with water. When an isocyanate reacts with water an primary amine and $\mathrm{CO}_{2}$ are formed: 


$$
\mathrm{R}-\mathrm{NCO}+\mathrm{H}-\mathrm{O}-\mathrm{H} \longrightarrow \mathrm{R}-\mathrm{NH}_{2}+\mathrm{CO}_{2} \uparrow
$$

The formed amine can subsequently react with another isocyanate group to form a urea bond ${ }^{[128,129]}$. The properties of the formed polymer vary with the urethane/urea ratio, and are therefore dependent on the hydrolysis rate of the isocyanate used ${ }^{[16]}$. Polyureas are formed in a similar fashion as polyurethanes. In polyurea formation the diisocyanate reacts with a diamine:

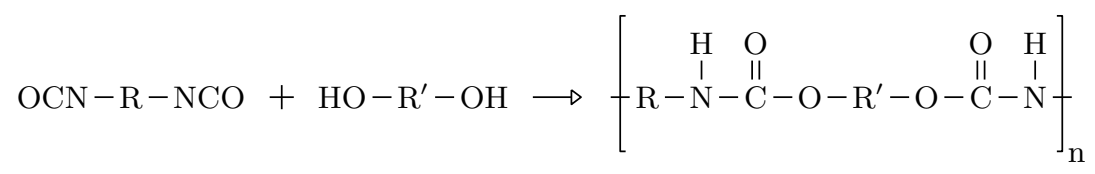

Polyurethanes and polyureas have been synthesized by interfacial polymerization, mainly for the synthesis of (hollow) nano- and microcapsules via emulsion-based interfacial polymerization ${ }^{[16]}$. Ichiura et al. ${ }^{[130]}$ successfully prepared a polyurea film atop a filter paper to prepare functional paper that slowly released $N, N$ diethyl-3-methylbenzamide (DEET). The authors emulsified DEET in an aqueous solution of ethylenediamine and polysorbate 20 (surfactant), and let it react with hexamethylene diisocyanate in cyclohexane.

A thermally and chemically stable anchor is the imide ring. Polyimides are often synthesized from the condensation polymerization of an anhydride with a primary amine, resulting in a poly(amic acid). This is followed by ring-closure due to dehydration (imidization) to form the poly(imide):

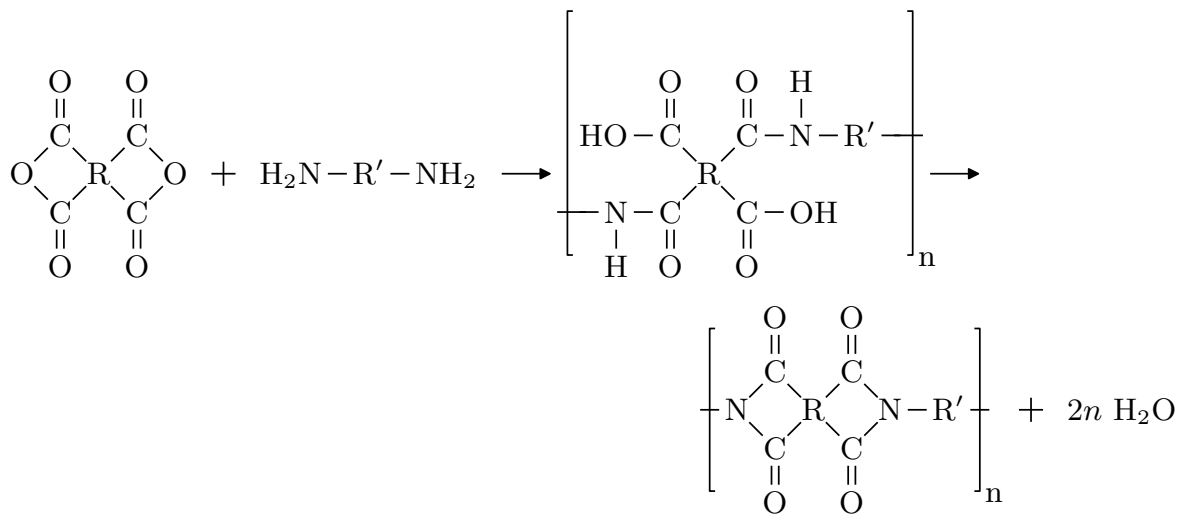

The imidization is an important step, since the amic acid group is susceptible to hydrolytic cleavage. Imidization can be achieved either thermally by heating 
the polymer ${ }^{[131,132]}$ or chemically by treating the polymer with a dehydrating agent in combination with a base catalyst under mild conditions ${ }^{[133]}$. In general, anhydride monomers are not well soluble in most apolar solvents used as organic phase in interfacial polymerization. Yet, there are some examples of the successful interfacial preparation of polyimides where the anhydride monomer was dissolved in toluene ${ }^{[134,135]}$.

\subsubsection{The network former}

The anchor provides the covalent bond between the network former and the bridge molecule. The network former is an, at least, trifunctional molecule to provide cross-linking of the network. Cross-linking results favorable properties for membrane applications compared to linear analogues. For example, cross-linking suppresses plasticization in gas separation, and increases solvent stability and reduces swelling in organic solvents.

Examples using (hyperbranched) polymers and dendrimers as alternatives to small multifunctional molecules can be found in literature, and will be described in the following section. In this thesis other network formers, including the organic triazine and the inorganic monomers polyhedral oligomeric silsesquioxane (POSS) and hexachlorocyclotriphosphazene (HCCP) are used. These network formers will be explained in the subsequent sections.

\section{(Hyperbranched) polymers and dendrimers}

Besides monomeric amines, one of the two reagents in interfacial polymerization could also be a (hyperbranched) polymer. Many polymeric amines have been studied, e.g., polyvinylamine ${ }^{[136,137]}$ and polyvinylimidazoline ${ }^{[138,139]}$. The most commonly studied polymeric amine is polyethyleneimine (PEI). PEI is a cationic polymer and exists in linear and branched geometries. PEI contains primary and secondary amines that can react with acyl chlorides to form a cross-linked network (Scheme 1.4). In contrast to monomeric amine based membranes, PEI membranes have a positive surface charge. Membranes with PEI have been prepared by IP with toluene-di-isocyanate ${ }^{[140]}, \operatorname{IPC}^{[141,142]}, \mathrm{TPC}^{[143]}, \mathrm{TMC}^{[143-146]}$, and cyanuric chloride ${ }^{[79]}$.

Polymeric reactants are mostly not as highly reactive as monomeric reactants, resulting in different membrane properties. For example, films derived from PEI have a loose structure with large pores and a thick dense layer ${ }^{[28]}$. Adding some monomeric amine could enhance the cross-link density ${ }^{[147]}$. Interestingly, Chiang et al. ${ }^{[143]}$ showed that PEI-TMC membranes have a much larger pore size than ethylenediamine-TMC membranes, and possess a higher salt rejection. The authors attribute this to pendant charged amine groups drifting into the pore, and therefore hindering ion transport but not water transport. 
<smiles>NCCNCCN(CCNCCN(CCN)CCN)CCN(CCN)CCN(CCN)CCN</smiles>

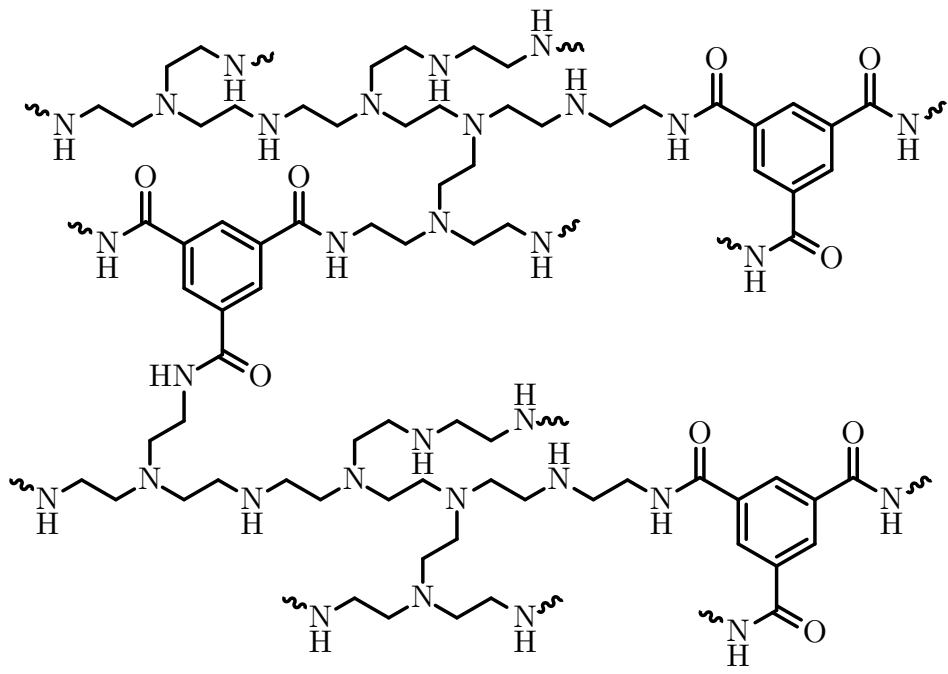

Scheme 1.4: The structure of a PEI-TMC polyamide.

The structure of multifunctional reactive polymers does not allow for the controlled cross-linking with a monomeric reagent. While two monomeric reagents result in a perfect alternating structure, a polymeric reagent results in a more random structure. More structural control can be obtained using dendrimers. Dendrimers are spherical or globular macromolecules, built from a core with branches that increase in number exponentially outwards. Most dendrimers are synthesized via a divergent process, starting with a multifunctional core from which the branches are grown in a step-by-step iterative fashion ${ }^{[148]}$. The divergent approach is synthetically demanding, and due to the large number of steps the overall yield can be very low. An alternative is the convergent method, in which dendrons are coupled together via a multifunctional core molecule. More information on the synthesis of dendrimers can be found in references ${ }^{[149-151]}$. Dendrimers have a low polydispersity (theoretically 1), and their molecular weight depends on the generation of the dendrimer ${ }^{[149-151]}$. 
Polyamidoamine (PAMAM) dendrimers are readily available ${ }^{[150]}$, and can be synthesized from the repetitive Michael addition and aminolysis of an ethylenediamine core ${ }^{[152]}$ as depicted in Scheme 1.5. There are only a few examples available in literature describing the interfacial polymerization of PAMAM G0-G2 with $\mathrm{TMC}^{[153,154]}$.

Whereas dendrimers contain only terminal and dendritic units, hyperbranched polymers also contain linear units ${ }^{[148]}$. Hyperbranched polymers can be synthesized in a single-step polymerization, but possess a higher polydispersity compared to dendrimers ${ }^{[155]}$. Despite this higher polydispersity, hyperbranched polymers are an attractive alternative because their synthesis is less demanding. Examples of the interfacial polymerization with hyperbranched polymers are hyperbranched polyesters ${ }^{[156,157]}$.
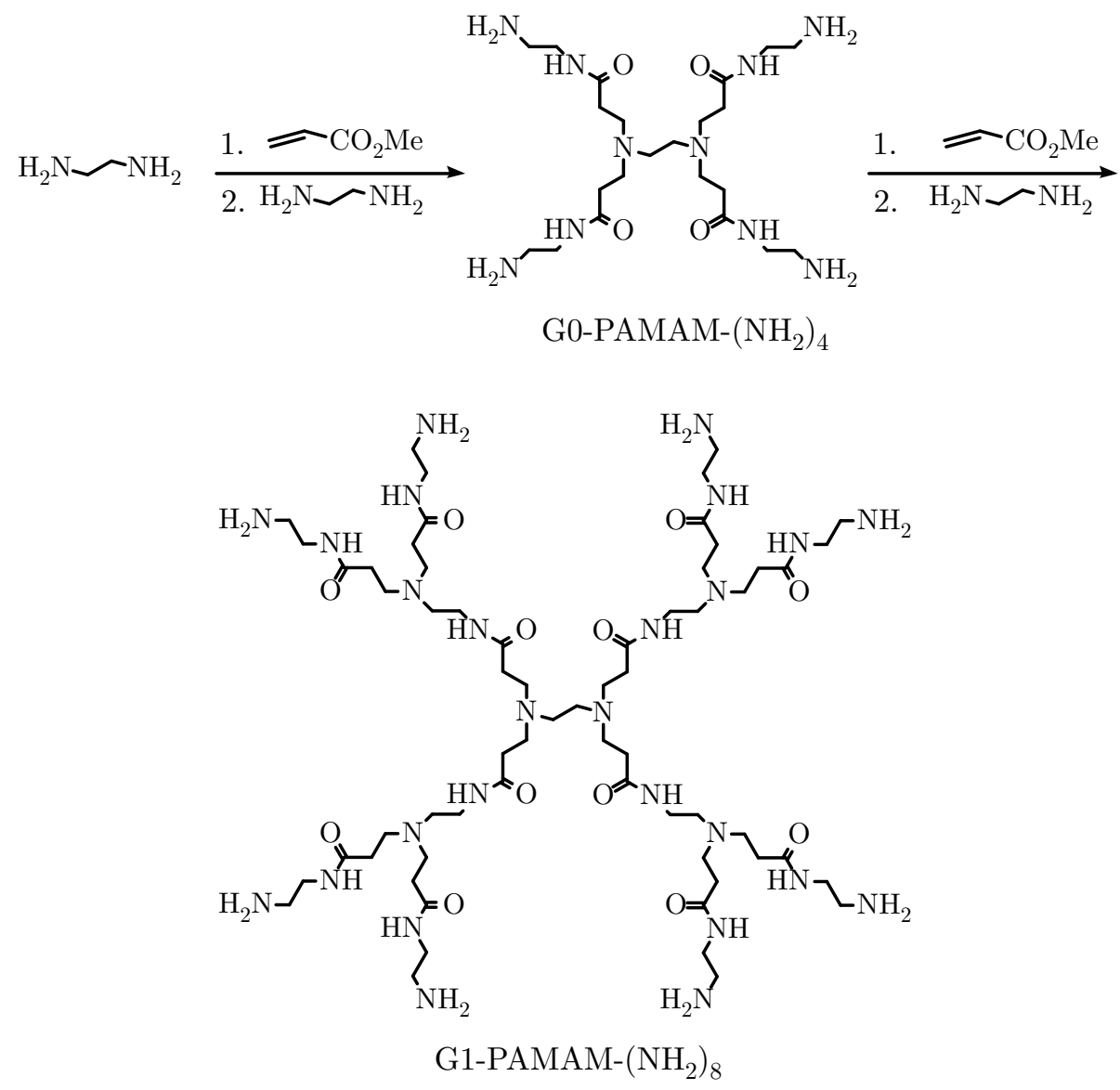

Scheme 1.5: The synthesis of PAMAM from the repetitive Michael addition and hydrolysis of an ethylenediamine core. The number of amine end-groups increases exponentially with the generation. G0 has 4 amine end-groups, G1 has 8, G2 has 16 and so on. 


\section{Triazines}

Triazines are a class of nitrogen containing heterocyclic compounds. Three isomers of triazine exist: 1,2,3-triazine, 1,2,4-triazine, and 1,3,5-triazine or s-triazine. Of particular interest in the formation of cross-linked films is the class of 2,4,6-trisubstituted-triazines due to its ability as network former.

An example of a trisubstituted triazine is 1,3,5-triazine-2,4,6-triamine or melamine. Han ${ }^{[158]}$ showed the preparation of a melamine-TMC membrane with similar permeances but lower salt rejection compared to poly(piperazine-TMC) membranes. However, melamine suffers from a low solubility in water ${ }^{[159]}$ and low reactivity towards other functional groups at room temperature, making it an unattractive network former when other anchors than polyamides are required ${ }^{[80]}$.

A readily available, cheap, and versatile triazine building block is 2,4,6-trichloro1,3,5-triazine or cyanuric chloride (CC). Each chloride atom of cyanuric chloride can be substituted by any nucleophile such as amines, alcohols, thiols, or Grignard reagents. Cyanuric chloride allows for controlled sequential addition due to the difference in reactivity of the chloride atoms. The substitution of the first chloride is exothermic, and therefore the temperature must be maintained at $0{ }^{\circ} \mathrm{C}$. The second substitution can be performed at room temperature, while the third substitution must be performed under reflux conditions ${ }^{[160-162]}$ (Scheme 1.6).

Cyanuric chloride can be used as a building block for the synthesis of many network formers, as well as directly in an interfacial polymerization reaction ${ }^{[79]}$. This makes it a compound of great interest in membrane formation.

\section{Polyhedral oligomeric silsesquioxanes}

An interesting class of network formers is that of the inorganic polyhedral oligomeric silsesquioxanes (POSS). Covalent bonding between POSS and an organic monomer results in a hybrid material, with properties that differ from the individual constituents ${ }^{[16]}$. POSS is considered to be an inorganic monomer due to the inorganic $\mathrm{Si}-\mathrm{O}-\mathrm{Si}$ core, with organic side groups $\mathrm{R}$, and can be described by the general formula $\left(\mathrm{RSiO}_{3 / 2}\right)_{\mathrm{n}}$, where $\mathrm{n}$ is commonly $6,8,10$, or $12 .^{[163,164]}$. The nomenclature of siloxane polymers can be applied to POSS; a silicon atom bearing three oxygen atoms connected to another silicon is denoted by "T". The cubic<smiles>Clc1nc(Cl)nc(Cl)n1</smiles><smiles>[AlH2]c1nc(Cl)nc(Cl)n1</smiles><smiles>[AlH2]c1nc([AlH2])nc(Cl)n1</smiles>

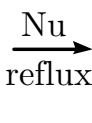<smiles>[AlH2]c1nc([AlH2])nc([AlH2])n1</smiles>

Scheme 1.6: The substitution pattern of chloride atoms from cyanuric chloride by a nucleophile depending on the temperature. The nucleophile does not necessarily have to be the same in each substitution step, resulting in symmetric or asymmetric trisubstituted-triazines. 
POSS $\mathrm{T}_{8}$ is more prevalent than, e.g., $\mathrm{T}_{10}, \mathrm{~T}_{12}$, probably because of the stability of the $\mathrm{Si}_{4} \mathrm{O}_{4}$ ring structure present in $\mathrm{T}_{8}$ POSS. The eight silicon atoms of the $\mathrm{T}_{8}$ POSS molecule could all be bearing the same substituent or two or more different substituents, resulting in $\mathrm{T}_{8} \mathrm{R}_{8}, \mathrm{~T}_{8} \mathrm{R}_{\mathrm{x}} \mathrm{R}_{\mathrm{y}}^{\prime}$, or $\mathrm{T}_{8} \mathrm{R}_{\mathrm{x}}^{\prime} \mathrm{R}_{\mathrm{y}}^{\prime \prime} \mathrm{R}_{\mathrm{z}}^{\prime \prime \prime}$ structures. Unfortunately, there is no control over the isomers formed when two or more substituents are present ${ }^{[163]}$.

$\mathrm{T}_{8}$ POSS compounds can be synthesized from two main synthesis strategies: the hydrolysis and condensation reaction of functionalized simple chloro- or alkoxysilanes or the modification of the side groups of an existing cage (Scheme 1.7). The hydrolysis and condensation route often results in low yields due to the formation of different side products such as nonpolyhedral or $\mathrm{T}_{10}$ and $\mathrm{T}_{12}$ substances. Besides the low yield, the formation of $\mathrm{T}_{8}$ POSS is via this route is complicated due to the formation of a complex mixture of isomers that are difficult to separate $^{[163,165,166]}$.

There are many reactions possible to modify a $\mathrm{T}_{8} \mathrm{R}_{8}$ POSS cage. One of the most commonly used reactions is hydrosilylation, a platinum-catalyzed addition of a $\mathrm{Si}-\mathrm{H}$ to an unsaturated compound ${ }^{[167]}$. Well-known examples of $\mathrm{T}_{8}$ POSS that can undergo hydrosilylation are $\mathrm{T}_{8} \mathrm{H}_{8}$ and $\mathrm{T}_{8}\left(\mathrm{OSiMe}_{2} \mathrm{H}\right)_{8}$. The reaction equation of the hydrosilylation of $\mathrm{T}_{8} \mathrm{H}_{8}$ with an alkene is as follows:

$$
\mathrm{T}_{8} \mathrm{H}_{8}+\mathrm{CH}_{2}=\mathrm{CH}-\mathrm{R} \longrightarrow \mathrm{T}_{8}-\mathrm{CH}_{2}-\mathrm{CH}_{2}-\mathrm{R}
$$

Besides hydrosilylation, conventional organic synthesis strategies could be used to modify the end groups of the POSS cage. However, the stability of the POSS cage under certain reaction conditions could be a problem. Strong bases can easily cleave the $\mathrm{Si}-\mathrm{O}$ bonds, destroying the cage structure ${ }^{[163,168,169]}$. When reaction parameters are chosen with care, many substitution or addition reactions are possible, resulting in a great platform for inorganic network formers.

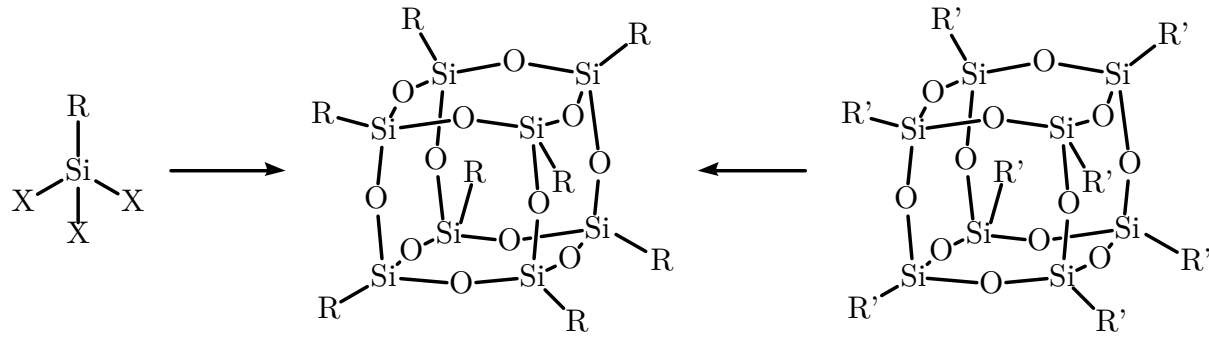

$\mathrm{X}=\mathrm{Cl}$, OMe, or OEt

Scheme 1.7: The synthesis of $\mathrm{T}_{8}$ POSS from the hydrolysis and condensation reaction of simple chloro- or alkoxysilanes or the modification of side groups of an existing POSS cage. 
A POSS that can easily be prepared on a large scale from an inexpensive organosilicon precursor is octa-ammoniumPOSS $\left(\mathrm{R}=\left(\mathrm{CH}_{2}\right)_{3} \mathrm{NH}_{3}{ }^{+} \mathrm{Cl}^{-}\right)^{[169]}$. To allow for reactions, the ammonium groups must be converted to the free amine group. This can be done by treatment with a base. The base attacks the Si/O framework as well resulting in the loss of a perfect cage structure. Another method is by eluting a methanolic solution of the octa-ammoniumPOSS over a Amberlite IRA-400 resin. However the free amine decomposes rapidly after preparation ${ }^{[169,170]}$.

Dalwani et al. ${ }^{[78]}$ reported on the first cross-linked films made by interfacial polymerization using octa-ammoniumPOSS and TMC resulting in a poly(POSSamide). Due to the ammonium salt side groups, the POSS is readily soluble in water. To activate the side groups into reactive free amine groups, the authors added triethylamine or $\mathrm{NaOH}$ to the octa-ammoniumPOSS solution. Titration measurements showed that below $\mathrm{pH} 7$ there is no significant conversion into free amine groups, while at $\mathrm{pH}$ 9-10 around 4 free amine groups have been formed per POSS molecule. At these high $\mathrm{pH}$ values, there is simultaneous hydrolysis of the Si/O framework, resulting in a mixture of cage and ladder POSS structures. Furthermore, the authors showed that a better membrane performance was obtained using $\mathrm{NaOH}$ instead of triethylamine, due to the lower solubility of $\mathrm{NaOH}$ in the organic phase.

In addition to poly(POSSamides), poly(POSSimides) have been reported in literature $^{[134,135]}$. These imides are made from the interfacial polymerization of octa-ammoniumPOSS with several organic dianhydrides. The resulting thin films showed excellent thermal stability, and were able to separate gases up to $300{ }^{\circ} \mathrm{C}$. Depending on the length and flexibility of the imide bridge, the membrane permeability and selectivity could be tuned.

\section{Polyposphazenes prepared from hexachlorocyclotriphosphazene}

Polyphosphazenes are hybrid polymers with an inorganic backbone of alternating phosphorous and nitrogen atoms, and two organic side groups connected to each phosphorous atom. Polyphosphazenes are well known for their excellent thermal stability and flame retardant properties ${ }^{[171,172]}$. The linear polymer is mostly synthesized from the ring-opening polymerization of the cyclic trimer hexachlorocyclotriphosphazene (HCCP) at $250{ }^{\circ} \mathrm{C}$ under vacuum. The formed polyphosphazene bears two chlorine atoms per repeating unit that undergo halogen replacement by organic nucleophiles such as alkoxides, aryloxides, amines, or organometallic reagents ${ }^{[173-175]}$. One of the phosphorous atoms in the polymer backbone could be replaced by a heteroatom, such as carbon or sulfur, resulting in poly(heterophosphazene)s (Scheme 1.8) ${ }^{[176-178]}$.

Polycarbophosphazenes are intermediates between cyanuric chloride and HCCP, and contain a carbon atom in their backbone. Both the cyclic monomer and polymer undergo nucleophilic substitution reactions analogue to that of $\mathrm{HCCP}^{[179-182]}$. Polythiophosphazenes contain $\mathrm{S}(\mathrm{IV})$ in their backbone ${ }^{[183,184]}$. The $\mathrm{S}-\mathrm{Cl}$ bond 


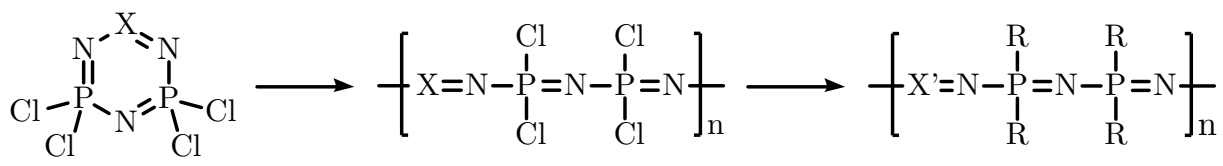<smiles>[X]P(Cl)(Cl)(Cl)Cl</smiles>

Scheme 1.8: The ring-opening polymerization of cyclic phosphazene rings to yield poly(hetero)phosphazenes. The temperature of this polymerization is dependent on the cyclic ring structure and can vary between 90 and $250{ }^{\circ} \mathrm{C}$.

shows a higher reactivity compared to the $\mathrm{P}-\mathrm{Cl}$ bond, allowing for the preparation of mixed substituent polymers ${ }^{[178]}$. However, even completely substituted polythiophosphazenes show a lower hydrolytic stability compared to polyphosphazenes due to the presence of the reactive sulfur(IV) atoms. Replacement of these sulfur(IV) atoms by the SOCl group, that contains sulfur(VI) atoms, results in an increased hydrolytic stability. The resulting polythionylphosphazene can undergo complete nucleophilic substitution with a number of primary and secondary amines ${ }^{[185,186]}$. However, the $\mathrm{S}-\mathrm{Cl}$ bond does not undergo nucleophilic substitution with aryloxides ${ }^{[187]}$.

Besides linear polyphosphazenes, many other skeletal architectures could be designed. Examples are blockcopolymers, dendrimers, and cyclolinear or cyclomatrix polymers ${ }^{[173-175]}$. Whereas most skeletal architectures are based on the alternating $\mathrm{P}-\mathrm{N}$ backbone with organic side groups, cyclolinear and cyclomatrix architectures are prepared from HCCP rings linked via exocyclic groups forming linear and crosslinked polymers, respectively. Scheme 1.9 shows the chemical structure of such a cyclomatrix material prepared from HCCP with an organic dialkoxide, diaryloxide, or diamine. The synthesis of cyclolinear materials is complex and therefore cyclomatrix materials are more of interest ${ }^{[171]}$. In addition, the high cross-link density makes cyclomatrix polyphosphazenes a very interesting candidate for applications in membranes. To our knowledge, the monomer HCCP has never been applied in the preparation of thin cyclomatrix polyphosphazenes by interfacial polymerization. In this thesis, we report on a method to prepare these thin and highly cross-linked cyclomatrix materials from HCCP and aromatic biphenols. 


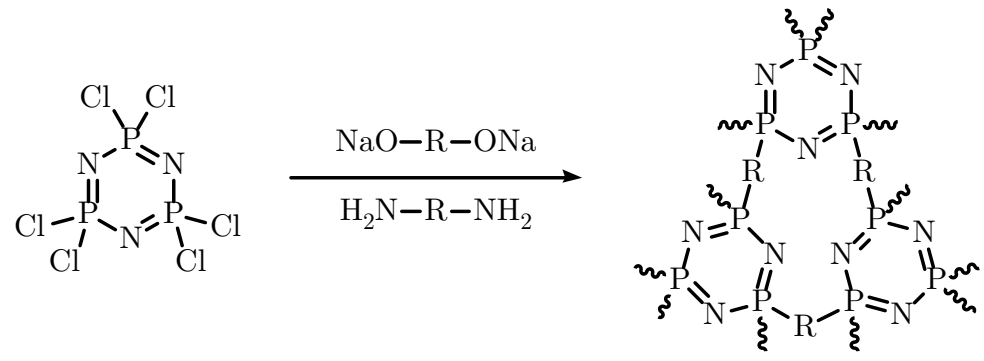

Scheme 1.9: The formation of a cyclomatrix polyphosphazene from hexachlorocyclotriphosphazene with an organic dialkoxide, diaryloxide, or diamine.

\subsection{Thesis outline}

The previous sections discussed the preparation and the chemistry of the crosslinked top layer of TFC membranes. The cross-linked network can be divided into four structural elements: the network former, the bridge in between network formers, functional side groups of the bridge molecule, and the anchor connecting the network former and the bridge molecules. These structural elements can be individually altered to allow for chemistry beyond classical polyamide chemistry as shown in Section 1.3 for the anchor and the network former.

Chapters 2 until 5 of this thesis examine several variations in network former, bridge, and anchor to implement new chemistry in interfacial polymerization reactions that eventually could be applied into membranes. An overview of the chemical structure of the network former, bridge, and anchor used in these chapters is given in Table 1.3.

In Chapter 2 an adjustment to the classical TMC-MPD system is made. A new triacyl chloride bearing ether linkages that provide flexibility is synthesized. Thin films are formed by reacting this triacyl chloride with either MPD or PPD. The effect of this newly synthesized acyl chloride, in combination with the arene substitution pattern of the diamine bridge, on the membrane performance is studied. The results are compared to the classical TMC-MPD and TMC-PPD polyamides.

The subsequent chapters report on alternatives to the classical polyamide chemistry. Chapter 3 reports on the synthesis of a hyper-cross-linked polydimethylsiloxane (PDMS) network by the interfacial polymerization with POSS. An poly(PDMS-POSSimide) is formed by the reaction of an amine-functionalized POSS with a succinic anhydride-functionalized PDMS. The swelling behavior of these networks in organic solvents is compared to that of conventional PDMS.

A completely new network former, the cyclic trimer HCCP, is discussed in Chapter 4. The chemical structure of the biphenol bridge is altered, thereby influencing the pKa and thus the reactivity of the phenolic groups. The influence of the biphe- 
Table 1.3: The chemical structure of the network former, bridge, and anchor used in Chapters 2-5 of this thesis.

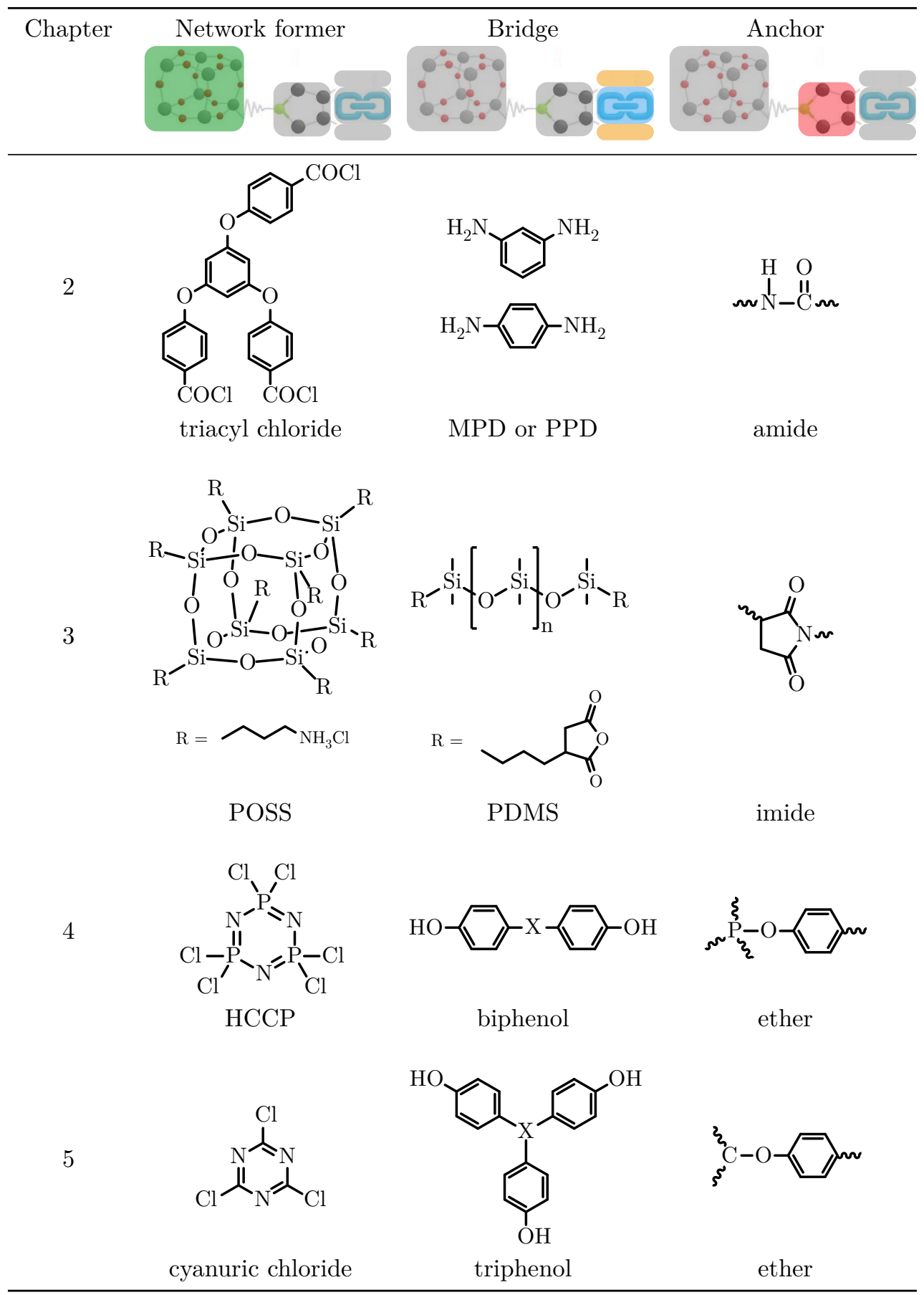


nol structure on film formation, mechanical properties, and thermal properties are studied.

Chapter 5 reports on the synthesis of $\mathrm{pH}$-stable networks by the reaction of $\mathrm{CC}$ with a triphenol. It was already shown in literature that $\mathrm{CC}$ can react with, at least, trifunctional amines. In this chapter the possibility of the reaction with various trifunctional (fully) aromatic alcohols is explored. The pH-stability of the resulting networks and the kinetics of the interfacial polymerization reaction are studied.

The potential of a hyperbranched poly(aryl ether ketone) (HBPAEK) for gas separation is studied in Chapter 6. Because of the chemistry, these HBPAEKs provide excellent possibilities for side-group modification and cross-linking. A thermal cross-linkable end-group is introduced and the effect of cross-linking on glass transition temperature and excess free volume is studied. In addition, HBPAEK films are analyzed for their $\mathrm{CO}_{2}$ sorption behavior and gas separation performance at elevated temperatures.

Chapter $\mathbf{7}$ discusses a method to prepare interfacial polymerized thin films onto inorganic hollow fibers. The polyamide prepared from piperazine and TMC is used as a model system. Inorganic hollow fibers provide a stable, cost-efficient geometry when membranes are used in demanding conditions such as high temperatures or pressures. This chapter mainly focuses on the surface modifications that are required to allow proper adhesion of the polyamide film to the inorganic fiber.

Chapter 8 reflects on all results in the previous chapters of this thesis and provides direction for further research. 


\subsection{References}

[1] Baker, R. W. Membrane Technology and Applications, 3rd ed.; John Wiley \& Sons, Ltd, 2012.

[2] Koros, W.; Ma, Y.; Shimidzu, T. Terminology for membranes and membrane processes. Pure and Applied Chemistry 1996, 68, 1479-1489.

[3] Park, H. B.; Kamcev, J.; Robeson, L. M.; Elimelech, M.; Freeman, B. D. Maximizing the right stuff: The trade-off between membrane permeability and selectivity. Science $\mathbf{2 0 1 7}$ 356 .

[4] Loeb, S.; Sourirajan, S. Saline Water Conversion-II; Advances in Chemistry; American Chemical Society, 1963; Vol. 38; Chapter 9: Sea Water Demineralization by Means of an Osmotic Membrane, pp 117-132.

[5] Dolar, D.; Košutić, K. In Analysis, Removal, Effects and Risk of Pharmaceuticals in the Water Cycle; Petrovic, M., Barcelo, D., Pérez, S., Eds.; Comprehensive Analytical Chemistry; Elsevier, 2013; Vol. 62; pp 319 - 344.

[6] Lau, W.; Ismail, A.; Misdan, N.; Kassim, M. A recent progress in thin film composite membrane: A review. Desalination 2012, 287, 190 - 199, Special Issue in honour of Professor Takeshi Matsuura on his 75th Birthday.

[7] Marchetti, P.; Jimenez Solomon, M. F.; Szekely, G.; Livingston, A. G. Molecular Separation with Organic Solvent Nanofiltration: A Critical Review. Chemical Reviews 2014, 114, 10735-10806.

[8] Wittbecker, E. L.; Morgan, P. W. Interfacial polycondensation. I. Journal of Polymer Science 1959, 40, 289-297.

[9] Odian, G. Principles of Polymerization, 4th ed.; John Wiley \& Sons, Inc., 2004.

[10] Compton, R. G.; Harding, M. S.; Atherton, J. H.; Brennan, C. M. Mechanism of a solid/liquid interfacial reaction: the reaction of an aqueous solution of an aromatic amine with cyanuric chloride. The Journal of Physical Chemistry 1993, 97, 4677-4682.

[11] Huang, J.; Kaner, R. B. A General Chemical Route to Polyaniline Nanofibers. Journal of the American Chemical Society 2004, 126, 851-855.

[12] Bean, K.; Black, C. F.; Govan, N.; Reynolds, P.; Sambrook, M. R. Preparation of aqueous core/silica shell microcapsules. Journal of Colloid and Interface Science 2012, 366, 16 22.

[13] Xiong, S.; Wang, Y.; Lu, Y.; Li, H.; Liu, J.; Li, S.; Qiu, Z.; Gong, M.; Wu, B.; Chu, J.; Wang, X.; Zhang, R. Enhancing the electrochromic performances of polyaniline film through incorporating polyaniline nanofibers synthesized by interfacial polymerization approach. Polymer Bulletin 2017,

[14] Song, Y.; Fan, J.-B.; Wang, S. Recent progress in interfacial polymerization. Mater. Chem. Front. 2017, 1, 1028-1040.

[15] Zhang, Y.; Benes, N. E.; Lammertink, R. G. H. Visualization and characterization of interfacial polymerization layer formation. Lab Chip 2015, 15, 575-580.

[16] Raaijmakers, M. J.; Benes, N. E. Current trends in interfacial polymerization chemistry. Progress in Polymer Science 2016, 63, 86 - 142.

[17] Mikos, A. G.; Kiparissides, C. Skin formation in heterogeneous polymerization reactions. Journal of Membrane Science 1991, 59, 205 - 217.

[18] Janssen, L.; te Nijenhuis, K. Encapsulation by interfacial polycondensation. I. The capsule production and a model for wall growth. Journal of Membrane Science 1992, 65, $59-$ 68.

[19] Karode, S.; Kulkarni, S.; Suresh, A.; Mashelkar, R. New insights into kinetics and thermodynamics of interfacial polymerization. Chemical Engineering Science 1998, 53, 2649 -2663 .

[20] Ji, J.; Dickson, J. M.; Childs, R. F.; McCarry, B. E. Mathematical Model for the Formation 
of Thin-Film Composite Membranes by Interfacial Polymerization: Porous and Dense Films. Macromolecules 2000, 33, 624-633.

[21] Freger, V.; Srebnik, S. Mathematical model of charge and density distributions in interfacial polymerization of thin films. Journal of Applied Polymer Science 2003, 88, 1162-1169.

[22] Yashin, V. V.; Balazs, A. C. Theoretical model of interfacial polymerization. The Journal of Chemical Physics 2004, 121, 11440-11454.

[23] Freger, V. Kinetics of Film Formation by Interfacial Polycondensation. Langmuir 2005, 21, 1884-1894.

[24] Dhumal, S. S.; Wagh, S. J.; Suresh, A. Interfacial polycondensation-Modeling of kinetics and film properties. Journal of Membrane Science 2008, 325, 758 - 771.

[25] Cadotte, J. E. Interfacially Synthesized Reverse Osmosis Membrane. 1981; U.S. Patent 4 227344.

[26] Vandezande, P.; Gevers, L. E. M.; Vankelecom, I. F. J. Solvent resistant nanofiltration: separating on a molecular level. Chem. Soc. Rev. 2008, 37, 365-405.

[27] Li, D.; Wang, H. Recent developments in reverse osmosis desalination membranes. $J$. Mater. Chem. 2010, 20, 4551-4566.

[28] Paul, M.; Jons, S. D. Chemistry and fabrication of polymeric nanofiltration membranes: A review. Polymer 2016, 103, 417 - 456, New Polymeric Materials and Characterization Methods for Water Purification.

[29] Guillen, G. R.; Pan, Y.; Li, M.; Hoek, E. M. V. Preparation and Characterization of Membranes Formed by Nonsolvent Induced Phase Separation: A Review. Industrial 86 Engineering Chemistry Research 2011, 50, 3798-3817.

[30] Liu, Y.; Pan, C.; Ding, M.; Xu, J. Effect of crosslinking distribution on gas permeability and permselectivity of crosslinked polyimides. European Polymer Journal 1999, 35, 1739 -1741 .

[31] Han, S. S.; Im, S. S.; Won, J. C.; Lee, J. H.; Choi, K.-Y.; Kim, Y. S. Synthesis and characterization of new polyimides containing ethynylene linkages. European Polymer Journal 2007, 43, $1541-1548$.

[32] Vanherck, K.; Cano-Odena, A.; Koeckelberghs, G.; Dedroog, T.; Vankelecom, I. A simplified diamine crosslinking method for PI nanofiltration membranes. Journal of Membrane Science 2010, 353, 135 - 143.

[33] Hermans, S.; Dom, E.; Mariën, H.; Koeckelberghs, G.; Vankelecom, I. F. Efficient synthesis of interfacially polymerized membranes for solvent resistant nanofiltration. Journal of Membrane Science 2015, 476, 356 - 363.

[34] Singh, P. S.; Joshi, S.; Trivedi, J.; Devmurari, C.; Rao, A. P.; Ghosh, P. Probing the structural variations of thin film composite $\mathrm{RO}$ membranes obtained by coating polyamide over polysulfone membranes of different pore dimensions. Journal of Membrane Science 2006, 278, $19-25$.

[35] Ghosh, A. K.; Hoek, E. M. Impacts of support membrane structure and chemistry on polyamide-polysulfone interfacial composite membranes. Journal of Membrane Science 2009, 336, $140-148$.

[36] Ramon, G. Z.; Wong, M. C.; Hoek, E. M. Transport through composite membrane, part 1: Is there an optimal support membrane? Journal of Membrane Science 2012, 415-416, $298-305$.

[37] Sotto, A.; Rashed, A.; Zhang, R.-X.; Martínez, A.; Braken, L.; Luis, P.; der Bruggen, B. V. Improved membrane structures for seawater desalination by studying the influence of sublayers. Desalination 2012, 287, 317 - 325, Special Issue in honour of Professor Takeshi Matsuura on his 75th Birthday.

[38] Jimenez-Solomon, M. F.; Gorgojo, P.; Munoz-Ibanez, M.; Livingston, A. G. Beneath the surface: Influence of supports on thin film composite membranes by interfacial polymerization for organic solvent nanofiltration. Journal of Membrane Science 2013, 448, 102 113. 
[39] Park, S.-J.; Choi, W.; Nam, S.-E.; Hong, S.; Lee, J. S.; Lee, J.-H. Fabrication of polyamide thin film composite reverse osmosis membranes via support-free interfacial polymerization. Journal of Membrane Science 2017, 526, 52 - 59.

[40] Karan, S.; Wang, Q.; Samitsu, S.; Fujii, Y.; Ichinose, I. Ultrathin free-standing membranes from metal hydroxide nanostrands. Journal of Membrane Science 2013, 448, 270 - 291.

[41] Karan, S.; Jiang, Z.; Livingston, A. G. Sub-10 nm polyamide nanofilms with ultrafast solvent transport for molecular separation. Science 2015, 348, 1347-1351.

[42] Ghosh, A. K.; Jeong, B.-H.; Huang, X.; Hoek, E. M. Impacts of reaction and curing conditions on polyamide composite reverse osmosis membrane properties. Journal of Membrane Science 2008, 311, $34-45$.

[43] Jegal, J.; Min, S. G.; Lee, K.-H. Factors affecting the interfacial polymerization of polyamide active layers for the formation of polyamide composite membranes. Journal of Applied Polymer Science 2002, 86, 2781-2787.

[44] Hu, L.; Zhang, S.; Han, R.; Jian, X. Preparation and performance of novel thermally stable polyamide/PPENK composite nanofiltration membranes. Applied Surface Science 2012, 258, 9047 - 9053.

[45] Fathizadeh, M.; Aroujalian, A.; Raisi, A. Effect of lag time in interfacial polymerization on polyamide composite membrane with different hydrophilic sub layers. Desalination 2012, 284, $32-41$.

[46] Dalwani, M.; Benes, N. E.; Bargeman, G.; Stamatialis, D.; Wessling, M. Effect of pH on the performance of polyamide/polyacrylonitrile based thin film composite membranes. Journal of Membrane Science 2011, 372, 228 - 238.

[47] Chai, G.-Y.; Krantz, W. B. Formation and characterization of polyamide membranes via interfacial polymerization. Journal of Membrane Science 1994, 93, 175 - 192.

[48] Chen, S.-H.; Chang, D.-J.; Liou, R.-M.; Hsu, C.-S.; Lin, S.-S. Preparation and separation properties of polyamide nanofiltration membrane. Journal of Applied Polymer Science 2002, 83, 1112-1118.

[49] Ahmad, A. L.; Ooi, B. S.; Mohammad, A. W.; Choudhury, J. P. Composite Nanofiltration Polyamide Membrane: A Study on the Diamine Ratio and Its Performance Evaluation. Industrial \&5 Engineering Chemistry Research 2004, 43, 8074-8082.

[50] Ahmad, A.; Ooi, B. Properties-performance of thin film composites membrane: study on trimesoyl chloride content and polymerization time. Journal of Membrane Science $\mathbf{2 0 0 5}$ $255,67-77$.

[51] Song, Y.; Sun, P.; Henry, L. L.; Sun, B. Mechanisms of structure and performance controlled thin film composite membrane formation via interfacial polymerization process. Journal of Membrane Science 2005, 251, 67 - 79 .

[52] Khorshidi, B.; Thundat, T.; Fleck, B. A.; Sadrzadeh, M. A Novel Approach Toward Fabrication of High Performance Thin Film Composite Polyamide Membranes. Scientific Reports 2016, 6, 22069.

[53] Tsonopoulos, C.; Wilson, G. M. High-temperature mutual solubilities of hydrocarbons and water. Part I: Benzene, cyclohexane and n-hexane. AIChE Journal 1983, 29, 990-999.

[54] Haschets, C. W.; Shine, A. D.; Secor, R. M. Prediction of water solubilities in hydrocarbons and polyethylene at elevated temperatures and pressures. Industrial $\&$ Engineering Chemistry Research 1994, 33, 1040-1046.

[55] Morgan, P. W.; Kwolek, S. L. Interfacial polycondensation. II. Fundamentals of polymer formation at liquid interfaces. Journal of Polymer Science Part A: Polymer Chemistry 1996, 34, 531-559.

[56] Hirose, M.; Ito, H.; Kamiyama, Y. Effect of skin layer surface structures on the flux behaviour of RO membranes. Journal of Membrane Science 1996, 121, 209 - 215.

[57] Lau, W.; Gray, S.; Matsuura, T.; Emadzadeh, D.; Chen, J. P.; Ismail, A. A review on polyamide thin film nanocomposite (TFN) membranes: History, applications, challenges and approaches. Water Research 2015, 80, $306-324$. 
[58] Zhe Yang, B. D., Jun Yin Enhancing water flux of thin-film nanocomposite (TFN) membrane by incorporation of bimodal silica nanoparticles. AIMS Environmental Science 2016, 3, 185 .

[59] Zargar, M.; Hartanto, Y.; Jin, B.; Dai, S. Understanding functionalized silica nanoparticles incorporation in thin film composite membranes: Interactions and desalination performance. Journal of Membrane Science 2017, 521, 53 - 64.

[60] Jeong, B.-H.; Hoek, E. M.; Yan, Y.; Subramani, A.; Huang, X.; Hurwitz, G.; Ghosh, A. K.; Jawor, A. Interfacial polymerization of thin film nanocomposites: A new concept for reverse osmosis membranes. Journal of Membrane Science 2007, 294, 1 - 7.

[61] Lind, M. L.; Eumine Suk, D.; Nguyen, T.-V.; Hoek, E. M. V. Tailoring the Structure of Thin Film Nanocomposite Membranes to Achieve Seawater RO Membrane Performance. Environmental Science \& Technology 2010, 44, 8230-8235.

[62] Ma, N.; Wei, J.; Liao, R.; Tang, C. Y. Zeolite-polyamide thin film nanocomposite membranes: Towards enhanced performance for forward osmosis. Journal of Membrane Science 2012, 405-406, $149-157$.

[63] Tang, B.; Zou, C.; Wu, P. Study on a novel polyester composite nanofiltration membrane by interfacial polymerization. II. The role of lithium bromide in the performance and formation of composite membrane. Journal of Membrane Science 2010, 365, 276 - 285.

[64] Chau, M. High flux semipermeable membranes. 1990; U.S. Patent 4950404.

[65] Chau, M.; Light, W.; Swamikannu, A. Chlorine-tolerant, thin-film composite membrane. 1993; U.S. Patent 5.271843.

[66] Kwak, S.-Y.; Jung, S. G.; Kim, S. H. Structure-Motion-Performance Relationship of FluxEnhanced Reverse Osmosis (RO) Membranes Composed of Aromatic Polyamide Thin Films. Environmental Science \& Technology 2001, 35, 4334-4340.

[67] Kim, S. H.; Kwak, S.-Y.; Suzuki, T. Positron Annihilation Spectroscopic Evidence to Demonstrate the Flux-Enhancement Mechanism in Morphology-Controlled Thin-FilmComposite (TFC) Membrane. Environmental Science \& Technology 2005, 39, 1764-1770.

[68] Kong, C.; Kanezashi, M.; Yamomoto, T.; Shintani, T.; Tsuru, T. Controlled synthesis of high performance polyamide membrane with thin dense layer for water desalination. Journal of Membrane Science 2010, 362, 76 - 80.

[69] Kong, C.; Shintani, T.; Kamada, T.; Freger, V.; Tsuru, T. Co-solvent-mediated synthesis of thin polyamide membranes. Journal of Membrane Science 2011, 384, 10 - 16 .

[70] Kamada, T.; Ohara, T.; Shintani, T.; Tsuru, T. Optimizing the preparation of multilayered polyamide membrane via the addition of a co-solvent. Journal of Membrane Science 2014, 453, $489-497$.

[71] Starks, C. M. Phase-transfer catalysis. I. Heterogeneous reactions involving anion transfer by quaternary ammonium and phosphonium salts. Journal of the American Chemical Society 1971, 93, 195-199.

[72] Naik, S. D.; Doraiswamy, L. K. Phase transfer catalysis: Chemistry and engineering. AIChE Journal 1998, 44, 612-646.

[73] West, C. W.; O’Brien, R. A.; Salter, E. A.; Hollingsworth, B. E.; Huynh, T. L.; Sweat, R. E.; Griffin, N. J.; Wierzbicki, A.; Davis, J. H. Impact of sulfur heteroatoms on the activity of quaternary ammonium salts as phase transfer catalysts for nucleophilic displacement reactions. Journal of Molecular Catalysis A: Chemical 2015, 398, $282-$ 288.

[74] Xiang, J.; Xie, Z.; Hoang, M.; Zhang, K. Effect of amine salt surfactants on the performance of thin film composite poly(piperazine-amide) nanofiltration membranes. Desalination 2013, 315, 156 - 163, Special Issue: Nanofiltration Membranes: Fundamentals and Applications.

[75] Xiang, J.; Xie, Z.; Hoang, M.; Ng, D.; Zhang, K. Effect of ammonium salts on the properties of poly(piperazineamide) thin film composite nanofiltration membrane. Journal of Membrane Science 2014, 465, 34 - 40.

[76] Wang, T.; Dai, L.; Zhang, Q.; Li, A.; Zhang, S. Effects of acyl chloride monomer function- 
ality on the properties of polyamide reverse osmosis (RO) membrane. Journal of Membrane Science 2013, 440, 48 - 57.

[77] Khorshidi, B.; Thundat, T.; Fleck, B. A.; Sadrzadeh, M. Thin film composite polyamide membranes: parametric study on the influence of synthesis conditions. $R S C A d v$. 2015, 5, 54985-54997.

[78] Dalwani, M.; Zheng, J.; Hempenius, M.; Raaijmakers, M. J. T.; Doherty, C. M.; Hill, A. J.; Wessling, M.; Benes, N. E. Ultra-thin hybrid polyhedral silsesquioxane-polyamide films with potentially unlimited 2D dimensions. J. Mater. Chem. 2012, 22, 14835-14838.

[79] Lee, K. P.; Zheng, J.; Bargeman, G.; Kemperman, A. J.; Benes, N. E. pH stable thin film composite polyamine nanofiltration membranes by interfacial polymerisation. Journal of Membrane Science 2015, 478, 75 - 84 .

[80] Lee, K. P.; Bargeman, G.; de Rooij, R.; Kemperman, A. J.; Benes, N. E. Interfacial polymerization of cyanuric chloride and monomeric amines: $\mathrm{pH}$ resistant thin film composite polyamine nanofiltration membranes. Journal of Membrane Science 2017, 523, 487 - 496.

[81] Ruff, F.; Farkas, Ö. Concerted SN2 mechanism for the hydrolysis of acid chlorides: comparisons of reactivities calculated by the density functional theory with experimental data. Journal of Physical Organic Chemistry 2011, 24, 480-491.

[82] Freger, V. Nanoscale Heterogeneity of Polyamide Membranes Formed by Interfacial Polymerization. Langmuir 2003, 19, 4791-4797.

[83] Kang, G.; Liu, M.; Lin, B.; Cao, Y.; Yuan, Q. A novel method of surface modification on thin-film composite reverse osmosis membrane by grafting poly(ethylene glycol). Polymer 2007, 48, $1165-1170$.

[84] Mahdavi, H.; Hosseinzade, M. T.; Shahalizade, T.; Kamyabi, A. A polyamide thin-film composite membrane modified by Michael addition grafting of hyperbranched poly(amine ester). Journal of Polymer Research 2017, 24, 109.

[85] Yin, J.; Yang, Y.; Hu, Z.; Deng, B. Attachment of silver nanoparticles (AgNPs) onto thin-film composite (TFC) membranes through covalent bonding to reduce membrane biofouling. Journal of Membrane Science 2013, 441, 73 - 82.

[86] Solomon, M. F. J.; Bhole, Y.; Livingston, A. G. High flux hydrophobic membranes for organic solvent nanofiltration (OSN)-Interfacial polymerization, surface modification and solvent activation. Journal of Membrane Science 2013, 434, 193 - 203.

[87] Kulkarni, A.; Mukherjee, D.; Gill, W. N. Flux enhancement by hydrophilization of thin film composite reverse osmosis membranes. Journal of Membrane Science 1996, 114, 39 -50 .

[88] Solomon, M. F. J.; Bhole, Y.; Livingston, A. G. High flux membranes for organic solvent nanofiltration (OSN)-Interfacial polymerization with solvent activation. Journal of Membrane Science 2012, 423-424, 371 - 382.

[89] Jimenez-Solomon, M. F.; Song, Q.; Jelfs, K. E.; Munoz-Ibanez, M.; Livingston, A. G. Polymer nanofilms with enhanced microporosity by interfacial polymerization. Nature Materials 2016, 15, $760 \mathrm{EP}-$.

[90] Hai, Y.; Zhang, J.; Shi, C.; Zhou, A.; Bian, C.; Li, W. Thin film composite nanofiltration membrane prepared by the interfacial polymerization of 1,2,4,5-benzene tetracarbonyl chloride on the mixed amines cross-linked poly(ether imide) support. Journal of Membrane Science 2016, 520, 19 - 28.

[91] Petersen, R. J. Composite reverse osmosis and nanofiltration membranes. Journal of Membrane Science 1993, 83, $81-150$.

[92] Roh, I. J.; Park, S. Y.; Kim, J. J.; Kim, C. K. Effects of the polyamide molecular structure on the performance of reverse osmosis membranes. Journal of Polymer Science Part B: Polymer Physics 1998, 36, 1821-1830.

[93] Kim, C.; Kim, J.; Roh, I.; Kim, J. The changes of membrane performance with polyamide molecular structure in the reverse osmosis process. Journal of Membrane Science 2000, $165,189-199$.

[94] Li, L.; Zhang, S.; Zhang, X.; Zheng, G. Polyamide thin film composite membranes pre- 
pared from isomeric biphenyl tetraacyl chloride and m-phenylenediamine. Journal of Membrane Science 2008, 315, 20 - 27.

[95] Verissimo, S.; Peinemann, K.-V.; Bordado, J. Influence of the diamine structure on the nanofiltration performance, surface morphology and surface charge of the composite polyamide membranes. Journal of Membrane Science 2006, 279, 266 - 275.

[96] Buch, P.; Mohan, D. J.; Reddy, A. Preparation, characterization and chlorine stability of aromatic-cycloaliphatic polyamide thin film composite membranes. Journal of Membrane Science 2008, 309, $36-44$.

[97] Yu, S.; Liu, M.; Lü, Z.; Zhou, Y.; Gao, C. Aromatic-cycloaliphatic polyamide thin-film composite membrane with improved chlorine resistance prepared from $\mathrm{m}$ phenylenediamine-4-methyl and cyclohexane-1,3,5-tricarbonyl chloride. Journal of Membrane Science 2009, 344, 155 - 164.

[98] Gupta, K. C. Synthesis and evaluation of aromatic polyamide membranes for desalination in reverse-osmosis technique. Journal of Applied Polymer Science 1997, 66, 643-653.

[99] Ahmad, A.; Ooi, B.; Choudhury, J. Preparation and characterization of co-polyamide thin film composite membrane from piperazine and 3,5-diaminobenzoic acid. Desalination 2003, 158, 101 - 108, Desalination and the Environment: Fresh Water for All.

[100] Ahmad, A. L.; Ooi, B. S.; Wahab Mohammad, A.; Choudhury, J. P. Effect of constricted polymerization time on nanofiltration membrane characteristic and performance: A study using the Donnan Steric Pore Flow Model. Journal of Applied Polymer Science 2004, 94, 394-399.

[101] Saha, N.; Joshi, S. Performance evaluation of thin film composite polyamide nanofiltration membrane with variation in monomer type. Journal of Membrane Science 2009, 342, 60 -69 .

[102] Akbari, A.; Aliyarizadeh, E.; Rostami, S. M. M.; Homayoonfal, M. Novel sulfonated polyamide thin-film composite nanofiltration membranes with improved water flux and anti-fouling properties. Desalination 2016, 377, $11-22$.

[103] Konagaya, S.; Watanabe, O. Influence of chemical structure of isophthaloyl dichloride and aliphatic, cycloaliphatic, and aromatic diamine compound polyamides on their chlorine resistance. Journal of Applied Polymer Science 2000, 76, 201-207.

[104] Konagaya, S.; Kuzumoto, H.; Watanabe, O. New reverse osmosis membrane materials with higher resistance to chlorine. Journal of Applied Polymer Science 2000, 75, 1357-1364.

[105] Li, L.; Zhang, S.; Zhang, X.; Zheng, G. Polyamide thin film composite membranes prepared from 3,4',5-biphenyl triacyl chloride, 3,3',5,5'-biphenyl tetraacyl chloride and $\mathrm{m}$ phenylenediamine. Journal of Membrane Science 2007, 289, 258 - 267.

[106] Hong, S.; Kim, I.-C.; Tak, T.; Kwon, Y.-N. Interfacially synthesized chlorine-resistant polyimide thin film composite (TFC) reverse osmosis (RO) membranes. Desalination 2013, 309, $18-26$.

[107] Qanati, O.; Ahmadi, A.; Seyed dorraji, M. S.; Rasoulifard, M. H.; Vatanpour, V. Thin-film nanofiltration membrane with monomers of 1,2,4,5-benzene tetracarbonyl chloride and ethylene diamine on electrospun support: preparation, morphology and chlorine resistance properties. Polymer Bulletin 2017,

[108] Liu, Y.; He, B.; Li, J.; Sanderson, R. D.; Li, L.; Zhang, S. Formation and structural evolution of biphenyl polyamide thin film on hollow fiber membrane during interfacial polymerization. Journal of Membrane Science 2011, 373, 98 - 106.

[109] Wang, H.; Zhang, Q.; Zhang, S. Positively charged nanofiltration membrane formed by interfacial polymerization of 3,3',5,5'-biphenyl tetraacyl chloride and piperazine on a poly(acrylonitrile) (PAN) support. Journal of Membrane Science 2011, 378, $243-249$, Membranes for a Sustainable Future Section.

[110] Wang, T.; Yang, Y.; Zheng, J.; Zhang, Q.; Zhang, S. A novel highly permeable positively charged nanofiltration membrane based on a nanoporous hyper-crosslinked polyamide barrier layer. Journal of Membrane Science 2013, 448, 180 - 189. 
[111] Verbeke, R.; Gómez, V.; Vankelecom, I. F. Chlorine-resistance of reverse osmosis (RO) polyamide membranes. Progress in Polymer Science 2017, 72, 1 - 15.

[112] Gohil, J. M.; Suresh, A. K. Chlorine attack on reverse osmosis membranes: Mechanisms and mitigation strategies. Journal of Membrane Science 2017, 541, 108 - 126.

[113] Glater, J.; kwan Hong, S.; Elimelech, M. The search for a chlorine-resistant reverse osmosis membrane. Desalination 1994, 95, 325 - 345.

[114] Barassi, G.; Borrmann, T. N-chlorination and Orton Rearrangement of Aromatic Polyamides, Revisited. Journal of Membrane Science \& Technology 2012, 2, 1-3.

[115] Shu-Sen, W.; Ai-Lian, L.; Ling-Ling, W.; Yi-Yuan, G.; Shu-Xiu, L.; Zhi-Zhou, W.; LiMing, S.; De-Kuan, K. Polysulfonamide as a membrane material. Desalination 1987, 62, 221 - 232, International Symposium on Synthetic Membrane Science and Technology.

[116] Seman, M. A.; Khayet, M.; Hilal, N. Nanofiltration thin-film composite polyester polyethersulfone-based membranes prepared by interfacial polymerization. Journal of Membrane Science 2010, 348, 109 - 116.

[117] Jimenez-Solomon, M. F.; Song, Q.; Jelfs, K. E.; Munoz-Ibanez, M.; Livingston, A. G. Polymer nanofilms with enhanced microporosity by interfacial polymerization. Nature Materials 2016, 15, 760 .

[118] Arnold, F. E.; Cantor, S.; Marvel, C. S. Aromatic polysulfonamides. Journal of Polymer Science Part A-1: Polymer Chemistry 1967, 5, 553-561.

[119] Soulier, J.-P.; Chabert, B.; Chauchard, J.; Berticat, P.; May, J.-F. Synthesis and properties of some polyamides and polysulfonamides. Journal of Applied Polymer Science 1974, 18, 2435-2447.

[120] Liu, M.; Yao, G.; Cheng, Q.; Ma, M.; Yu, S.; Gao, C. Acid stable thin-film composite membrane for nanofiltration prepared from naphthalene-1,3,6-trisulfonylchloride (NTSC) and piperazine (PIP). Journal of Membrane Science 2012, 415-416, 122 - 131.

[121] Trushinski, B.; Dickson, J.; Smyth, T.; Childs, R.; McCarry, B. Polysulfonamide thin-film composite reverse osmosis membranes. Journal of Membrane Science 1998, 143, 181 188 .

[122] Kurth, C.; Kloos, S.; Peschl, J.; Hodgins, L. Acid stable membranes for nanofiltration. 2006; U.S. Patent 7138058.

[123] Hoseinpour, H.; Peyravi, M.; Nozad, A.; Jahanshahi, M. Static and dynamic assessments of polysulfonamide and poly(amide-sulfonamide) acid-stable membranes. Journal of the Taiwan Institute of Chemical Engineers 2016, 67, 453 - 466.

[124] Parker, R. E.; Isaacs, N. S. Mechanisms Of Epoxide Reactions. Chemical Reviews 1959, 59, 737-799.

[125] Menschutkin, N. Beiträge zur Kenntnis der Affinitätskoeffizienten der Alkylhaloide und der organischen Amine. Zeitschrift für Physikalische Chemie 1890, 5, 589-600.

[126] Menschutkin, N. Über die Affinitätskoeffizienten der Alkylhaloide und der Amine. Zeitschrift für Physikalische Chemie 1890, 6, 41-57.

[127] Chattopadhyay, D.; Webster, D. C. Thermal stability and flame retardancy of polyurethanes. Progress in Polymer Science 2009, 34, 1068 - 1133.

[128] Aleksandrova, Y.; Tarakanov, O. Some kinetic relationships of the water-isocyanate reaction. Polymer Science U.S.S.R. 1972, 14, $25-32$.

[129] Ni, H.; Nash, H. A.; Worden, J. G.; Soucek, M. D. Effect of catalysts on the reaction of an aliphatic isocyanate and water. Journal of Polymer Science Part A: Polymer Chemistry 2002, 40, 1677-1688.

[130] Ichiura, H.; Yamamoto, K.-i.; Ohtani, Y. Polyurea films prepared by interfacial polymerization on a paper surface: sustained release of N,N-diethyl-3-methylbenzamide. Polymer Bulletin 2015, 72, 2621-2632.

[131] Young, P. R.; Davis, J. R. J.; Chang, A. C.; Richardson, J. N. Characterization of a thermally imidized soluble polyimide film. Journal of Polymer Science Part A: Polymer Chemistry 1990, 28, 3107-3122. 
[132] Dickinson, P. R.; Sung, C. S. P. Kinetics and mechanisms of thermal imidization studies by UV-visible and fluorescence spectroscopic techniques. Macromolecules 1992, 25, 37583768.

[133] Kailani, M. H.; Sung, C. S. P. Chemical Imidization Study by Spectroscopic Techniques. 1. Model Amic Acids. Macromolecules 1998, 31, 5771-5778.

[134] Raaijmakers, M. J. T.; Hempenius, M. A.; Schön, P. M.; Vancso, G. J.; Nijmeijer, A.; Wessling, M.; Benes, N. E. Sieving of Hot Gases by Hyper-Cross-Linked Nanoscale-Hybrid Membranes. Journal of the American Chemical Society 2014, 136, 330-335.

[135] Raaijmakers, M. J. T.; Wessling, M.; Nijmeijer, A.; Benes, N. E. Hybrid Polyhedral Oligomeric Silsesquioxanes-Imides with Tailored Intercage Spacing for Sieving of Hot Gases. Chemistry of Materials 2014, 26, 3660-3664.

[136] Yu, S.; Ma, M.; Liu, J.; Tao, J.; Liu, M.; Gao, C. Study on polyamide thin-film composite nanofiltration membrane by interfacial polymerization of polyvinylamine (PVAm) and isophthaloyl chloride (IPC). Journal of Membrane Science 2011, 379, 164 - 173.

[137] Liu, M.; Zheng, Y.; Shuai, S.; Zhou, Q.; Yu, S.; Gao, C. Thin-film composite membrane formed by interfacial polymerization of polyvinylamine (PVAm) and trimesoyl chloride (TMC) for nanofiltration. Desalination 2012, 288, 98 - 107.

[138] Hurndall, M. J.; Jacobs, E. P.; Sanderson, R. D. New composite reverse osmosis membranes made from poly-2-vinylimidazoline. Journal of Applied Polymer Science 1992, 46, $523-529$.

[139] Hurndall, M.; Jacobs, E.; Sanderson, R. Chemical composition of thin-film composite reverse osmosis membranes made from poly-2-vinylimidazoline. Journal of Membrane Science 1993, 78, $283-298$.

[140] Bartels, C. R.; Kreuz, K. L.; Wachtel, A. Structure-performance relationships of composite membranes: Porous support densification. Journal of Membrane Science 1987, 32, 291 312.

[141] Cadotte, J. E.; King, R. S.; Majerle, R. J.; Petersen, R. J. Interfacial Synthesis in the Preparation of Reverse Osmosis Membranes. Journal of Macromolecular Science: Part A - Chemistry 1981, 15, 727-755.

[142] Sun, S. P.; Hatton, T. A.; Chan, S. Y.; Chung, T.-S. Novel thin-film composite nanofiltration hollow fiber membranes with double repulsion for effective removal of emerging organic matters from water. Journal of Membrane Science 2012, 401-402, 152 - 162.

[143] Chiang, Y.-C.; Hsub, Y.-Z.; Ruaan, R.-C.; Chuang, C.-J.; Tung, K.-L. Nanofiltration membranes synthesized from hyperbranched polyethyleneimine. Journal of Membrane Science 2009, 326, $19-26$.

[144] Zuo, J.; Wang, Y.; Sun, S. P.; Chung, T.-S. Molecular design of thin film composite (TFC) hollow fiber membranes for isopropanol dehydration via pervaporation. Journal of Membrane Science 2012, 405-406, 123 - 133.

[145] Fang, W.; Shi, L.; Wang, R. Interfacially polymerized composite nanofiltration hollow fiber membranes for low-pressure water softening. Journal of Membrane Science 2013, 430, $129-139$.

[146] Wei, X.; Wang, S.; Shi, Y.; Xiang, H.; Chen, J.; Zhu, B. Characterization of a positively charged composite nanofiltration hollow fiber membrane prepared by a simplified process. Desalination 2014, 350, 44 - 52.

[147] Wu, D.; Yu, S.; Lawless, D.; Feng, X. Thin film composite nanofiltration membranes fabricated from polymeric amine polyethylenimine imbedded with monomeric amine piperazine for enhanced salt separations. Reactive and Functional Polymers 2015, 86, 168 - 183.

[148] Caminade, A.-M.; Yan, D.; Smith, D. K. Dendrimers and hyperbranched polymers. Chem. Soc. Rev. 2015, 44, 3870-3873.

[149] Boas, U.; Heegaard, P. M. H. Dendrimers in drug research. Chem. Soc. Rev. 2004, 33, $43-63$.

[150] Mintzer, M. A.; Grinstaff, M. W. Biomedical applications of dendrimers: a tutorial. Chem. Soc. Rev. 2011, 40, 173-190. 
[151] Sowinska, M.; Urbanczyk-Lipkowska, Z. Advances in the chemistry of dendrimers. New J. Chem. 2014, 38, 2168-2203.

[152] Tomalia, D. A.; Naylor, A. M.; Goddard, W. A. Starburst Dendrimers: Molecular-Level Control of Size, Shape, Surface Chemistry, Topology, and Flexibility from Atoms to Macroscopic Matter. Angewandte Chemie International Edition in English 1990, 29, $138-175$.

[153] Lianchao, L.; Baoguo, W.; Huimin, T.; Tianlu, C.; Jiping, X. A novel nanofiltration membrane prepared with PAMAM and TMC by in situ interfacial polymerization on PEK-C ultrafiltration membrane. Journal of Membrane Science 2006, 269, 84 - 93.

[154] Jin, L.; Yu, S.; Shi, W.; Yi, X.; Sun, N.; Ge, Y.; Ma, C. Synthesis of a novel composite nanofiltration membrane incorporated $\mathrm{SiO} 2$ nanoparticles for oily wastewater desalination. Polymer 2012, 53, 5295 - 5303.

[155] Zheng, Y.; Li, S.; Weng, Z.; Gao, C. Hyperbranched polymers: advances from synthesis to applications. Chem. Soc. Rev. 2015, 44, 4091-4130.

[156] Wei, X.-Z.; Zhu, L.-P.; Deng, H.-Y.; Xu, Y.-Y.; Zhu, B.-K.; Huang, Z.-M. New type of nanofiltration membrane based on crosslinked hyperbranched polymers. Journal of Membrane Science 2008, 323, 278 - 287.

[157] Wei, X.; Kong, X.; Yang, J.; Zhang, G.; Chen, J.; Wang, J. Structure influence of hyperbranched polyester on structure and properties of synthesized nanofiltration membranes. Journal of Membrane Science 2013, 440, 67 - 76

[158] Han, R. Formation and characterization of (melamine-TMC) based thin film composite NF membranes for improved thermal and chlorine resistances. Journal of Membrane Science 2013, 425-426, $176-181$.

[159] Chapman, R. P.; Averell, P. R.; Harris, R. R. Solubility of Melamine in Water. Industrial G Engineering Chemistry 1943, 35, 137-138.

[160] Thurston, J. T.; Dudley, J. R.; Kaiser, D. W.; Hechenbleikner, I.; Schaefer, F. C.; Holm-Hansen, D. Cyanuric Chloride Derivatives. I. Aminochloro-s-triazines. Journal of the American Chemical Society 1951, 73, 2981-2983.

[161] Afonso, C. A. M.; Lourenco, N. M. T.; Rosatella, A. d. A. Synthesis of 2,4,6-Trisubstituted-1,3,5-Triazines. Molecules 2006, 11, 81-102.

[162] Mooibroek, T. J.; Gamez, P. The s-triazine ring, a remarkable unit to generate supramolecular interactions. Inorganica Chimica Acta 2007, 360, 381 - 404, Inorganic Chemistry The Next Generation.

[163] Cordes, D. B.; Lickiss, P. D.; Rataboul, F. Recent Developments in the Chemistry of Cubic Polyhedral Oligosilsesquioxanes. Chemical Reviews 2010, 110, 2081-2173.

[164] Tanaka, K.; Chujo, Y. Advanced functional materials based on polyhedral oligomeric silsesquioxane (POSS). J. Mater. Chem. 2012, 22, 1733-1746.

[165] Kuo, S.-W.; Chang, F.-C. POSS related polymer nanocomposites. Progress in Polymer Science 2011, 36, 1649 - 1696.

[166] Zhang, W.; Camino, G.; Yang, R. Polymer/polyhedral oligomeric silsesquioxane (POSS) nanocomposites: An overview of fire retardance. Progress in Polymer Science 2017, 67, 77 - 125, Topical Volume on Nanocomposites.

[167] Marciniec, B. Hydrosilylation: A Comprehensive Review on Recent Advances; Springer Netherlands: Dordrecht, 2009; pp 3-51.

[168] Rikowski, E.; Marsmann, H. C. Cage-rearrangement of silsesquioxanes. Polyhedron 1997, $16,3357-3361$.

[169] J. Feher, F.; D. Wyndham, K.; Soulivong, D.; Nguyen, F. Syntheses of highly functionalized cube-octameric polyhedral oligosilsesquioxanes (R8Si8O12). J. Chem. Soc., Dalton Trans. 1999, 1491-1498.

[170] J. Feher, F.; D. Wyndham, K. Amine and ester-substituted silsesquioxanes: synthesis, characterization and use as a core for starburst dendrimers. Chem. Commun. 1998, 323324 
[171] Zhang, T.; Cai, Q.; Wu, D.-Z.; Jin, R.-G. Phosphazene cyclomatrix network polymers: Some aspects of the synthesis, characterization, and flame-retardant mechanisms of polymer. Journal of Applied Polymer Science 2005, 95, 880-889.

[172] Tao, K.; Li, J.; Xu, L.; Zhao, X.; Xue, L.; Fan, X.; Yan, Q. A novel phosphazene cyclomatrix network polymer: Design, synthesis and application in flame retardant polylactide. Polymer Degradation and Stability 2011, 96, 1248 - 1254.

[173] Allcock, H. R. Hybrids of hybrids: nano-scale combinations of polyphosphazenes with other materials. Applied Organometallic Chemistry 2010, 24, 600-607.

[174] Allcock, H. R. Polyphosphazene elastomers, gels, and other soft materials. Soft Matter 2012, 8, 7521-7532.

[175] Allcock, H. R.; Morozowich, N. L. Bioerodible polyphosphazenes and their medical potential. Polym. Chem. 2012, 3, 578-590.

[176] Jaeger, R.; Debowski, M.; Manners, I.; Vancso, G. J. Study of the Molecular Geometry, Electronic Structure, and Thermal Stability of Phosphazene and Heterophosphazene Rings with ab Initio Molecular Orbital Calculations. Inorganic Chemistry 1999, 38, 1153-1159.

[177] Wang, Z.; Manners, I. Synthesis and Characterization of Water-Soluble Cationic and Anionic Polythionylphosphazene Polyelectrolytes. Macromolecules 2005, 38, 5047-5054.

[178] Chandrasekhar, V. Inorganic and Organometallic Polymers; Springer Berlin Heidelberg, 2005.

[179] Manners, I.; Allcock, H. R.; Renner, G.; Nuyken, O. Poly(carbophosphazenes): a new class of inorganic-organic macromolecules. Journal of the American Chemical Society 1989, 111, 5478-5480.

[180] Allcock, H. R.; Coley, S. M.; Manners, I.; Nuyken, O.; Renner, G. Poly[(aryloxy)carbophosphazenes]: synthesis, properties, and thermal transition behavior. Macromolecules 1991, 24, 2024-2028.

[181] Allcock, H. R.; Coley, S. M.; Manners, I.; Visscher, K. B.; Parvez, M.; Nuyken, O.; Renner, G. Reactivity and polymerization behavior of a pentachlorocyclocarbophosphazene, N3P2CCl5. Inorganic Chemistry 1993, 32, 5088-5094.

[182] Allcock, H. R.; Coley, S. M.; Morrissey, C. T. Synthesis and Properties of Poly(aminocarbophosphazenes). Macromolecules 1994, 27, 2904-2911.

[183] Allcock, H. R.; Dodge, J. A.; Manners, I. Poly(thiophosphazenes): new inorganic backbone polymers. Macromolecules 1993, 26, 11-16.

[184] Dodge, J. A.; Manners, I.; Allcock, H. R.; Renner, G.; Nuyken, O. Poly(thiophosphazenes): new inorganic macromolecules with backbones composed of phosphorus, nitrogen, and sulfur atoms. Journal of the American Chemical Society 1990, 112, 1268-1269.

[185] Ni, Y.; Park, P.; Liang, M.; Massey, J.; Waddling, C.; Manners, I. Polymers with Sulfur(VI)-Nitrogen-Phosphorus Backbones: Synthesis, Characterization, and Properties of Atactic Poly[(amino)thionylphosphazenes]. Macromolecules 1996, 29, 3401-3408.

[186] Nobis, M. N.; McWilliams, A. R.; Nuyken, O.; Manners, I. Polymers with Sulfur(VI)Nitrogen-Phosphorus Backbones: Synthesis, Characterization, and Properties of Poly[(dialkylamino)thionylphosphazenes]. Macromolecules 2000, 33, 7707-7712.

[187] Liang, M.; Manners, I. Poly(thionylphosphazenes): a new class of inorganic polymers with skeletal phosphorus, nitrogen, and sulfur(VI) atoms. Journal of the American Chemical Society 1991, 113, 4044-4045. 



\section{Chapter 2}

\section{The use of a star-shaped trifunctional acyl chloride for the preparation of polyamide thin film composite membranes}

This chapter is adapted from:

Evelien Maaskant, Wouter Vogel, Theo J. Dingemans, and Nieck E. Benes, The use of a star-shaped trifunctional acyl chloride for the preparation of polyamide thin film composite membranes, Submitted for publication 

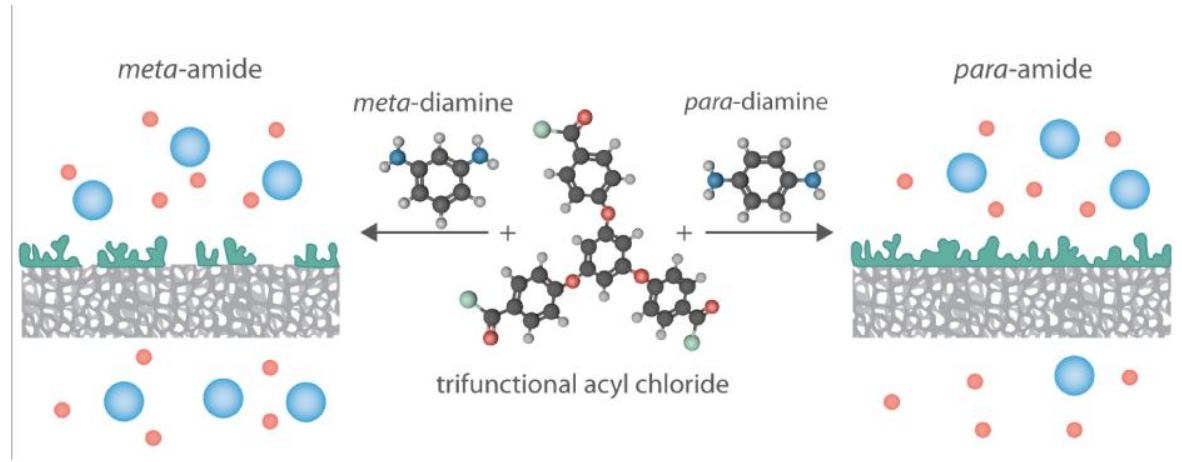

\begin{abstract}
A star-shaped trifunctional acyl chloride bearing ether linkages was synthesized as an alternative to the commonly used trimesoyl chloride (TMC) in the preparation of polyamide thin film composite membranes (TFC). Although this star-shaped acyl chloride has the same functionality as TMC, it is larger in size and its acyl chloride groups are less reactive due to the electron donating ether linkages. In this work, we prepared TFC membranes by the interfacial polymerization of both this star-shaped acyl chloride and TMC with either one of the two structural isomers: $m$-phenylenediamine (MPD) or $p$-phenylenediamine (PPD). No significant effect was observed of the substitution pattern of the aromatic diamine on the membrane formation with TMC, due to the high reactivity of the acyl chloride groups of TMC. In contrast, the lower reactivity of the star-shaped acyl chloride results in significant differences in the formed TFC membrane depending on the use of MPD or PPD. Where TMC-MPD membranes are well-known for their excellent retention, we could not obtain defect-free membranes prepared from MPD and this star-shaped triacyl chloride $\left(R_{\text {rose bengal }}<77 \%\right)$. The use of PPD instead of MPD, however, did result in defect-free membranes $\left(R_{\text {rose bengal }}>97 \%\right)$ with an acceptable clean water permeance $\left(2.5 \mathrm{~L} \mathrm{~m}^{-2} \mathrm{~h}^{-1} \mathrm{bar}^{-1}\right)$.
\end{abstract}




\section{$2.1 \quad$ Introduction}

Thin film composite (TFC) membranes are nowadays the industrial standard for, e.g., reverse osmosis (RO). These TFC membranes consist of a thin dense top layer that is the actual separating layer, and a porous support that provides mechanical strength $^{[1]}$. The first TFC membranes were developed by John Cadotte ${ }^{[2]}$, who reported on a method to make these TFC membranes by interfacial polymerization (IP). Membranes prepared by IP showed to have a higher water flux and salt rejection as compared to membranes prepared by the Loeb-Sourirajan process. In a typical IP reaction, a bifunctional amine is dissolved into the aqueous phase, and a trifunctional acyl chloride is dissolved into the organic phase ${ }^{[3]}$. These two monomers form a dense top layer at the interface of the two immiscible phases. The all-aromatic, highly cross-linked polyamide prepared from $m$-phenylenediamine (MPD) and trimesoyl chloride (TMC) ${ }^{[4]}$, developed by John Cadotte, is used for the preparation of most commercial TFC membranes.

Alternative chemical structures to the commonly used MPD and TMC monomers have been published in literature ${ }^{[5]}$. All aim for improved membrane properties, such as enhanced permeability, salt rejection, stability, or fouling resistance. It was found that the substitution patterns of the aromatic rings of both the amine and the acyl chloride monomer have a strong effect on the rejection of the resulting membranes ${ }^{[6,7]}$. For example, the performance of membranes prepared from either MPD or $p$-phenylenediamine (PPD) by the interfacial polymerization with TMC has been studied extensively ${ }^{[8-10]}$. It was found that TMC-MPD membranes have a more flexible chain structure as compared to TMC-PPD membranes ${ }^{[11]}$, and hence have a higher water flux while retaining a similar salt rejection.

In addition to the trifunctional monomer TMC, membranes have been prepared from the bifunctional acyl chlorides isophthaloyl chloride (IPC) ${ }^{[6,12,13]}$ or terephthaloyl chloride (TPC) ${ }^{[6]}$. The use of these bifunctional acyl chlorides reduces the amount of unreacted acyl chloride groups, but also reduces the degree of crosslinking when reacted with diamines. As compared to TMC-based membranes, the lower degree of cross-linking of IPC and TPC derived membranes results in a lower salt rejection ${ }^{[7,14]}$ and potentially in an increased swelling propensity. Therefore, one can claim that to be able to obtain highly cross-linked and stable top layers, the acyl chloride used should have a functionality of at least three.

A possible method to increase the acyl chloride functionality is to decorate a biphenyl with acyl chloride groups. A series of acyl chloride biphenyls with varying functionalities has been reported in literature by various authors. For example, the trifunctional 3,4',5-biphenyl triacyl chloride (BTRC) and the tetrafunctional $3,3^{\prime}, 5,5^{\prime}$-biphenyl tetraacyl chloride ( $\mathrm{mm}$-BTEC) have been used in the preparation of TFC membranes ${ }^{[15]}$. These membranes were prepared from the interfacial polymerization of MPD with either BTRC or $m m$-BTEC. The performance of these membranes was compared to that of classical TMC-MPD membranes. BTRC-MPD membranes showed to have a higher cross-linking degree as compared to TMC-MPD membranes, resulting in a lower water permeance and higher 
salt rejection. Introducing the tetraacyl chloride $m m$-BTEC resulted in a further decrease of water permeance and increase in salt rejection. Further studies revealed that the use of BTEC structural isomers has a strong influence on the membrane performance. Membranes prepared from MPD and either om-BTEC or $o p$-BTEC showed a significant increase in water permeance, while the rejection remained almost identical to $\mathrm{mm}$-BTEC derived membranes ${ }^{[16]}$.

In addition, membranes prepared from the pentafunctional biphenyl pentaacyl chloride $^{[17]}$ and the hexafunctional biphenyl hexaacyl chloride ${ }^{[18]}$ have been reported in literature. The membranes prepared from these acyl chlorides with MPD follow the same trend as found for the tri- and tetrafunctional biphenyl acyl chlorides ( $\mathrm{Li}$ et al.); a higher acyl chloride functionality lowers the water permeance. The salt rejection, however, was found to be independent on the acyl chloride functionality.

In summary, most structural variations to the commonly used TMC monomer, that are reported on in literature, are based on small rigid biphenyls with varying acyl chloride functionality $(3 \geq f \leq 6)$. In this work, we did the opposite and synthesized the larger and more flexible acyl chloride, 4,4',4"-[benzene-1,3,5-triyltris(oxy)] tribenzoyl chloride (3, Scheme 2.1$)$, which has three acyl chloride groups. This acyl chloride has the same functionality as TMC, but is significantly larger. We expect that the use of such a large and flexible acyl chloride will have an effect on the free volume, the flexibility, and the morphology of the resulting TFC membranes. These TFC membranes were prepared by the interfacial polymerization of 3 with either MPD or PPD. The influence of this acyl chloride (3) and the diamine isomerism on the surface characteristics and membrane performance of the resulting membranes were compared to those of the commonly used TMC-MPD and TMC-PPD membranes.

\subsection{Experimental}

\subsubsection{Materials}

Phloroglucinol ( $\geq 99 \%)$, 4-fluorobenzonitrile (99\%), thionyl chloride ( $\geq 98 \%)$, $m$-phenylenediamine (MPD, 99\%), $p$-phenylenediamine (PPD, $\geq 99 \%$ ), and trimesoyl chloride (TMC, 98\%) were obtained from Sigma-Aldrich (The Netherlands). Dried toluene was obtained from Merck (Germany) and Alfa Aesar (Germany). All chemicals and solvents were used as received.

\subsubsection{Synthesis of $4,4^{\prime}, 4^{\prime \prime}$-[benzene-1,3,5-triyltris(oxy)]tri- benzoic acid (2)}

Compound $\mathbf{2}$ was synthesized from phloroglucinol and 4-fluorobenzonitrile, with compound $\mathbf{1}$ as intermediate, according to the procedure described by 
<smiles>N#Cc1ccc(F)cc1</smiles><smiles>N#Cc1ccc(Oc2cc(Oc3ccc(C#N)cc3)cc(Oc3ccc(C#N)cc3)c2)cc1</smiles>

1

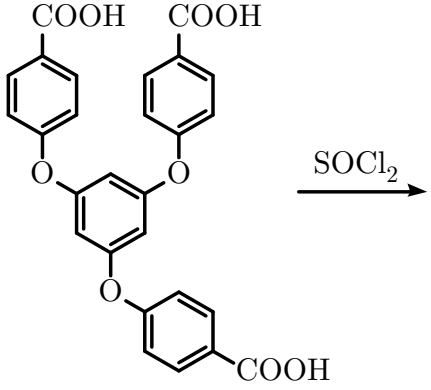

2<smiles>O=C(Cl)c1ccc(Oc2cc(Oc3ccc(C(=O)Cl)cc3)cc(Oc3ccc(C(=O)Cl)cc3)c2)cc1</smiles>

3

Scheme 2.1: Synthesis of the star-shaped trifunctional acyl chloride monomer 4,4',4"[benzene-1,3,5-triyltris(oxy)] tribenzoyl chloride (3).

Matsumoto et al. ${ }^{[19]}$. ATR-FTIR $\left(\nu, \mathrm{cm}^{-1}\right): 1675(\mathrm{C}=\mathrm{O}), 1230$, and 1004 (C-O-C). ${ }^{1} \mathrm{H}-\mathrm{NMR}$ (DMSO, $\left.\delta, \mathrm{ppm}\right): 12.91$ (s, 3H), 7.97 (d, 6H, J = $9 \mathrm{~Hz}$ ), $7.17(\mathrm{~d}, 6 \mathrm{H}, \mathrm{J}=9 \mathrm{~Hz}), 6.67(\mathrm{~s}, 3 \mathrm{H})$.

\subsubsection{Synthesis of $4,4^{\prime}, 4$ "-[benzene-1,3,5-triyltris(oxy)]tri- benzoyl chloride (3)}

Compound 2 (5.03 g, $0.01 \mathrm{~mol})$ was dissolved in $40 \mathrm{~mL}$ of thionyl chloride under argon atmosphere. The mixture was heated to $80{ }^{\circ} \mathrm{C}$ and refluxed for $17 \mathrm{~h}$. Excess thionyl chloride was removed by vacuum distillation, to yield an off-white powder (5.60 g, 100\%). MP: $210{ }^{\circ} \mathrm{C}$. ATR-FTIR $\left(\nu, \mathrm{cm}^{-1}\right): 1740(\mathrm{C}=\mathrm{O}), 1230$, and 999 $(\mathrm{C}-\mathrm{O}-\mathrm{C}) .{ }^{1} \mathrm{H}-\mathrm{NMR}\left(\mathrm{CDCl}_{3}, \delta, \mathrm{ppm}\right): 8.13(\mathrm{~d}, 6 \mathrm{H}, \mathrm{J}=9 \mathrm{~Hz}), 7.11(\mathrm{~d}, 6 \mathrm{H}, \mathrm{J}=9$ $\mathrm{Hz}), 6.66$ (s, 3H). ${ }^{13} \mathrm{C}-\mathrm{NMR}\left(\mathrm{CDCl}_{3}, \delta, \mathrm{ppm}\right): 167,162,158,134,128,118,108$, 50 . 


\subsubsection{Synthesis of polyamide powders}

Polyamide powders were prepared by vigorously stirring $20 \mathrm{~mL}$ of MPD or PPD $\left(2 \mathrm{w} / \mathrm{v} \%\right.$ in $\mathrm{H}_{2} \mathrm{O}$, i.e., $2 \mathrm{~g}$ in $\left.100 \mathrm{~mL}\right)$ with $20 \mathrm{~mL}$ of acyl chloride $(0.1 \mathrm{w} / \mathrm{v} \% \mathrm{TMC}$ or $0.2 \mathrm{w} / \mathrm{v} \% 3$ in toluene, i.e., 0.1 or $0.2 \mathrm{~g}$ in $100 \mathrm{~mL}$ ) for 15 minutes. The solids were filtered, washed with water and subsequently with acetone, and dried in a vacuum oven at $50{ }^{\circ} \mathrm{C}$.

\subsubsection{Preparation of polyamide films on silicon wafers}

A silicon wafer $\left(1.5 \times 1.5 \mathrm{~cm}^{2}\right)$ was placed at the bottom of a petri dish $(\varnothing 2.5 \mathrm{~cm})$. $5 \mathrm{~mL}$ of aqueous phase $(2 \mathrm{w} / \mathrm{v} \%$ amine $)$ was poured into the petri dish. Subsequently, $3 \mathrm{~mL}$ of organic phase (acyl chloride in toluene) was poured on top of the aqueous phase. After $20 \mathrm{~s}$ both phases were removed with a pipette, while making sure that the forming freestanding film hit the surface of the wafer at $30 \mathrm{~s}$. The film was carefully rinsed with water at least three times. The films were dried in a vacuum oven at $50{ }^{\circ} \mathrm{C}$.

\subsubsection{Synthesis of thin film composite membranes by inter- facial polymerization}

Thin film composite (TFC) membranes were prepared by the interfacial polymerization of 3 with either MPD or PPD on porous polyacrylonitrile (PAN) ultrafiltration supports (Solsep, the Netherlands). For comparison, membranes with TMC were prepared using a similar procedure. The structure of the polyamide obtained from the reaction of MPD or PPD with an acyl chloride is shown in Scheme 2.2. Because of the insufficient solubility of $\mathbf{3}$ in linear alkanes, such as $n$-hexane, toluene was chosen as organic phase. All TMC-based membranes were prepared with $0.1 \mathrm{w} / \mathrm{v} \% \mathrm{TMC}^{[20,21]}$. The concentration of $\mathbf{3}$ was varied between $0.1-0.3 \mathrm{w} / \mathrm{v} \%$. The reaction time was kept constant at $30 \mathrm{~s}$ for all TFC membranes.

A typical procedure for the TFC preparation is given. The PAN support was clamped in a custom-built aluminum frame and $10 \mathrm{~mL}$ of aqueous solution $(2 \mathrm{w} / \mathrm{v} \%$ MPD or PPD in water) was poured into the frame atop of the PAN support, and the support was soaked for 5 minutes. The excess solution was drained off, and the frame was placed in a closed box which was flushed with nitrogen $(<5 \%$ relative humidity). After 6 minutes of drying, the frame was removed from the box, and $10 \mathrm{~mL}$ of organic phase $(0.1 \mathrm{w} / \mathrm{v} \% \mathrm{TMC}$ or $0.1-0.3 \mathrm{w} / \mathrm{v} \% 3$ in toluene) was carefully poured into the frame. After a reaction time of 30 seconds, the organic phase was removed and the TFC membrane was washed with toluene. The membrane was air-dried for 5 minutes, and stored in deionized water until use. 

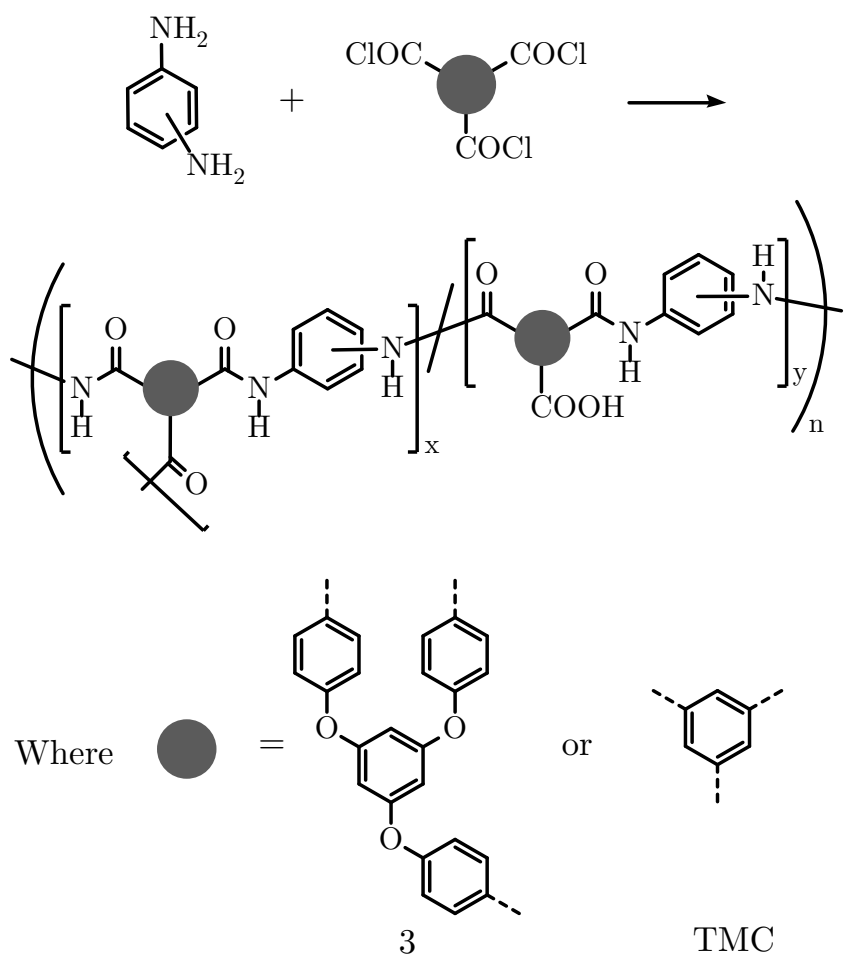

Scheme 2.2: The formation of a cross-linked network by the interfacial polymerization of a triacyl chloride (3 or TMC) with MPD or PPD resulting in linear and cross-linked repeating units. The resulting polyamide networks contains carboxylic acid end-groups due to the hydrolysis of unreacted acyl chloride moieties.

\subsubsection{Characterization}

The chemical structures of the membranes were analyzed by Fourier transform infrared spectroscopy (FTIR) in attenuated total reflectance (ATR) mode on an ALPHA spectrometer (Bruker, Germany). Dried samples were pressed onto the diamond crystal without further sample preparation.

Thermal gravimetric analysis (TGA) measurements were performed with a Perkin Elmer TGA 4000 at $10{ }^{\circ} \mathrm{C} \mathrm{min}^{-1}$ under nitrogen purge in aluminum pans. Combined thermogravimetric analysis (TGA) and mass spectroscopy (MS) measurements were performed using an STA 449 F3 Jupiter TGA with an alumina sample cup (Netzsch, Germany) and QMS 403 D Aeolos MS (Netzsch, Germany). The methods used for these combined TGA-MS measurements are described elsewhere ${ }^{[22]}$. Mass loss measurements were performed from 50 to $600{ }^{\circ} \mathrm{C}$ with a heating rate of $10{ }^{\circ} \mathrm{C} \mathrm{min}{ }^{-1}$ under a nitrogen atmosphere. 
Scanning electron micrographs were taken with a JEOL JSM-7610 field emission scanning electron microscope (FE-SEM). Samples were coated with a $5 \mathrm{~nm}$ chromium layer (Quorum Q150T ES) prior to imaging.

Streaming current measurements were performed on a SurPASS analyzer (Anton Paar, Austria) equipped with an adjustable gap cell. The TFC membranes were fastened to the PDMS blocks $\left(2 \times 1 \mathrm{~cm}^{2}\right)$ of the cell with double sided adhesive tape (Tesa $\left.{ }^{\circledR} 4965\right)$. The $\mathrm{pH}$ of the electrolyte solution $\left(5 \mathrm{mM} \mathrm{KCl}, \mathrm{pH}_{\text {start }} \approx 3.5\right)$ was automatically adjusted using $0.1 \mathrm{M} \mathrm{NaOH}$. The zeta potential of two different membranes was determined for each composition. From the streaming current, the zeta potential could be derived using Equation 4.4:

$$
\zeta=\frac{\mathrm{d} I}{\mathrm{~d} P} \cdot \frac{\eta}{\epsilon \cdot \epsilon_{0}} \cdot \frac{L}{A_{\text {channel }}}
$$

where: $\zeta$ is the zeta potential, $\frac{\mathrm{d} I}{\mathrm{~d} P}$ is the slope of the streaming current versus pressure, $\eta$ and $\epsilon$ are the viscosity and dielectric constant of the electrolyte, here taken as that of water, $\epsilon_{0}$ is the permittivity of vacuum, $L$ is the length of the streaming channel, and $A_{\text {channel }}$ is the cross sectional area of the channel.

The surface hydrophilicity of polyamide films deposited on silicon wafers was measured by static contact angle measurements using the sessile drop method (OCA 15, Dataphysics, Germany). Five separate water drops $(1 \mu \mathrm{L})$ were deposited, and an image capturing the droplet was taken $3 \mathrm{~s}$ after the deposition.

The thickness of polyamide films deposited on silicon wafers was measured with an M2000X ellipsometer (J.A. Woollam Co., US) equipped with focusing probes. Spectra were recorded at three incident angles: $65^{\circ}, 70^{\circ}$, and $75^{\circ}$. The film thickness was modeled (CompleteEase v4.86, J.A. Woollam Co., US) by a Cauchy layer atop of a silicon wafer bearing a $2 \mathrm{~nm}$ native oxide layer (fit parameters: $A, B, k$, and thickness).

Clean water fluxes were measured on a custom-built setup (Convergence, the Netherlands). All measurements were performed in cross-flow operation at a feed temperature of $25{ }^{\circ} \mathrm{C}$ with a membrane area of $46 \mathrm{~cm}^{2}$. Permeate fluxes were measured using an M12 or M13 mini-Coriflow Coriolis mass-flow meter (Bronkhorst, the Netherlands).

Retention measurements were performed on a custom-built dead-end filtration setup. The membrane coupon ( $\varnothing 39 \mathrm{~mm}$ ), supported by a porous stainless steel disk, was mounted at the bottom of a stainless steel feed vessel. This vessel was pressurized to 15 bar with nitrogen gas. The feed was stirred with an overhead stirrer at $600 \mathrm{rpm}$ to suppress concentration polarization. The first $20 \mathrm{~mL}$ of permeate was discarded from analysis.

The retention of two different solutes was determined: a $2000 \mathrm{pm}$ aqueous $\mathrm{NaCl}$ solution and a $35 \mu \mathrm{M}$ aqueous rose bengal solution (dye, $1017 \mathrm{~g} \mathrm{~mol}^{-1}$ ). The concentration of the $\mathrm{NaCl}$ feed and permeate were analyzed by measuring the 
conductivity and temperature of the samples using a Cond 3310 conductivity meter (WTW, Germany). The concentration of the rose bengal feed and permeate was determined by measuring the UV-VIS absorbance of the samples at a wavelength of $549 \mathrm{~nm}$ (Shimadzu UV-1800 UV-spectrophotometer).

The retention $R$ is defined as:

$$
R=\frac{c_{\text {feed }}-c_{\text {permeate }}}{c_{\text {feed }}} \cdot 100 \%
$$

where $c_{\text {feed }}$ is the concentration of the solute in the feed, and $c_{\text {permeate }}$ the concentration in the permeate. All retention experiments were carried out in dead-end mode. As a result, the concentration of the feed changes slightly over time. To compensate for this, the concentration of the solute in the feed was taken as the average of the original feed and the final retentate composition.

\subsection{Results and discussion}

\subsubsection{Synthesis of the star-shaped trifunctional acyl chloride monomer}

A star-shaped trifunctional acyl chloride monomer was prepared as outlined in Scheme 2.1. 4,4',4"-[Benzene-1,3,5-triyltris(oxy)]tribenzoyl chloride (3) was prepared from the reaction of phloroglucinol and 4-fluorobenzonitrile, followed by hydrolysis and subsequent chlorination with thionyl chloride. The chemical analysis of compound $\mathbf{3}$ can be found in the supporting information.

\subsubsection{Membrane synthesis and characterization}

Polyamide TFC membranes have been prepared from a flexible acyl chloride and the aromatic diamines MPD and PPD. Scheme 2.2 shows the chemical structure of the resulting polyamides. ATR-FTIR spectra of TFC membranes prepared on PAN supports are given in Figure 2.1. All spectra are normalized to the PAN CN stretching at $2240 \mathrm{~cm}^{-1}$. A strong amide $\mathrm{I}(\mathrm{C}=\mathrm{O}$ stretching $)$ absorbance peak is present around $1661 \mathrm{~cm}^{-1}$ (Figure 2.1a) in the spectra of the TFC membranes prepared with TMC. Additionally, the TMC-MPD membrane shows a strong amide II ( $\mathrm{N}-\mathrm{H}$ bending) absorbance peak at $1537 \mathrm{~cm}^{-1}$. The TMC-PPD membrane shows a shoulder at this position and a strong absorbance peak at $1513 \mathrm{~cm}^{-1}$. Both TMCMPD and TMC-PPD membranes show aromatic $\mathrm{C}=\mathrm{C}$ stretching absorbance peaks at $1610 \mathrm{~cm}^{-1}$ and $1451 \mathrm{~cm}^{-1}$.

The spectra of the $\mathbf{3}$-based membranes prepared with various concentrations of $\mathbf{3}$ are shown in Figure 2.1b-d. While the ATR-FTIR spectrum of the acyl chloride 3 shows an absorbance peak due to the $\mathrm{C}=\mathrm{O}$ stretching of the acyl chloride at 

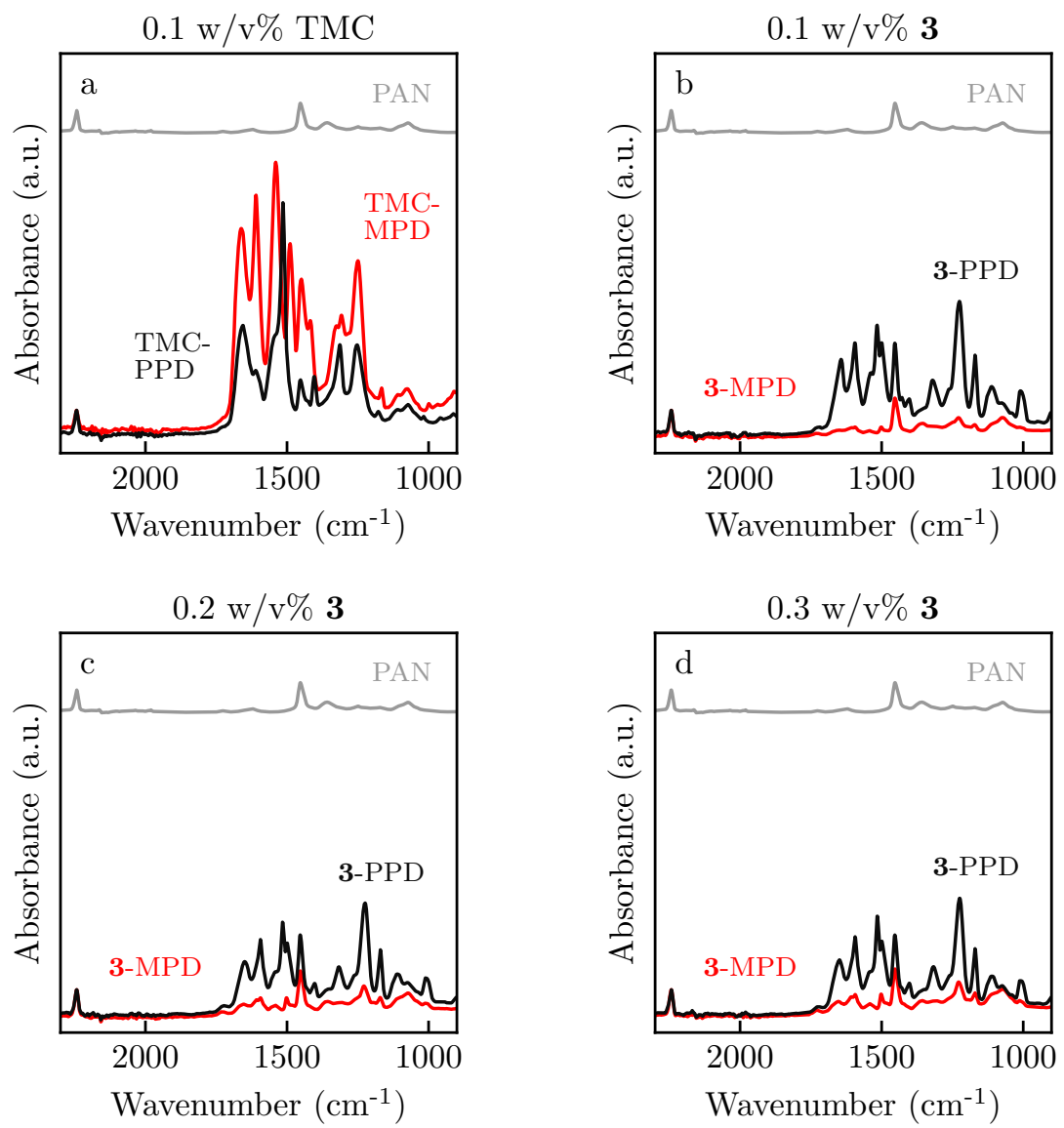

Figure 2.1: ATR-FTIR spectra of membranes prepared with (a) $0.1 \mathrm{w} / \mathrm{v} \%$ TMC, (b) 0.1 $\mathrm{w} / \mathrm{v} \% 3$, (c) $0.2 \mathrm{w} / \mathrm{v} \% 3$, and (d) $0.3 \mathrm{w} / \mathrm{v} \% 3$. All membranes were prepared on porous PAN supports by applying a reaction time of $30 \mathrm{~s}$. All spectra are normalized to the absorbance peak at $2240 \mathrm{~cm}^{-1}$, originating from the CN stretching of PAN. The spectrum of the bare PAN support is given at the top as a reference (gray, - ). MPD-based membranes are represented in red (-), and PPD-based membranes in black (-). A peak originating from the $\mathrm{C}-\mathrm{O}-\mathrm{C}$ bond at $1000 \mathrm{~cm}^{-1}$ is only present in the 3-based membranes. 
1740-1770 $\mathrm{cm}^{-1}$ (see supporting information), this peak has disappeared in the spectra of the 3-based membranes. Instead, unreacted acyl chloride bonds hydrolyze towards carboxyl acids resulting in a small absorbance peak present at $1725 \mathrm{~cm}^{-1}$ belonging to the $\mathrm{C}=\mathrm{O}$ stretch of the carboxylic acid.

The 3-PPD membranes show a strong amide I stretching around $1638 \mathrm{~cm}^{-1}$, and the amide II bending around $1516 \mathrm{~cm}^{-1}$, independent of the concentration $\mathbf{3}$ used. The aromatic $\mathrm{C}=\mathrm{C}$ stretching is present at $1591 \mathrm{~cm}^{-1}$ and $1496 \mathrm{~cm}^{-1}$ for these membranes. An additional peak compared to the TMC-based membranes is present at $1009 \mathrm{~cm}^{-1}$. This peak originates from the $\mathrm{C}-\mathrm{O}-\mathrm{C}$ stretching of the ether linkage present in $\mathbf{3}$. In contrast to the strong polyamide peaks present in TMC-MPD and 3-PPD, 3-MPD shows only very small polyamide peaks, and a small peak around $1008 \mathrm{~cm}^{-1}$ originating from the $\mathrm{C}-\mathrm{O}-\mathrm{C}$ stretching. The ratio of the polyamide to PAN peaks increases slightly with $\mathbf{3}$ concentration, but stays extremely small compared to the other polyamide membranes. This indicates that relative to the $\mathbf{3}$ PPD membranes, there is not much 3-MPD material present. This can be caused by either an extremely thin or a discontinuous top layer.

Unreacted acyl chloride groups present in the linear polyamide units hydrolyze into carboxylic acid groups upon contact with water. These carboxylic acid groups result in the negative surface charge which is common for polyamide membranes. Streaming current measurements were performed on all membranes, from which the zeta potential of the membrane's surface could be obtained (Figure 2.2). Figure $2.2 \mathrm{a}$ shows the zeta potential for TMC-based membranes and Figure 2.2b-d for 3 -based membranes prepared with $0.1,0.2$, and $0.3 \mathrm{w} / \mathrm{v} \%$ acyl chloride, respectively.

As expected, the TMC-based membranes show a negative surface charge over the whole $\mathrm{pH}$ range due to free carboxylic acid end-groups. In contrast to TMC, we expected that the use of the larger acyl chloride 3 would result in a reduction of the amide and carboxylic acid groups per unit of volume, and hence a more positively charged surface. However, from the zeta potential measurements, no significant increase in surface charge for the $\mathbf{3}$-membranes as compared to the TMC-based membranes could be observed. 

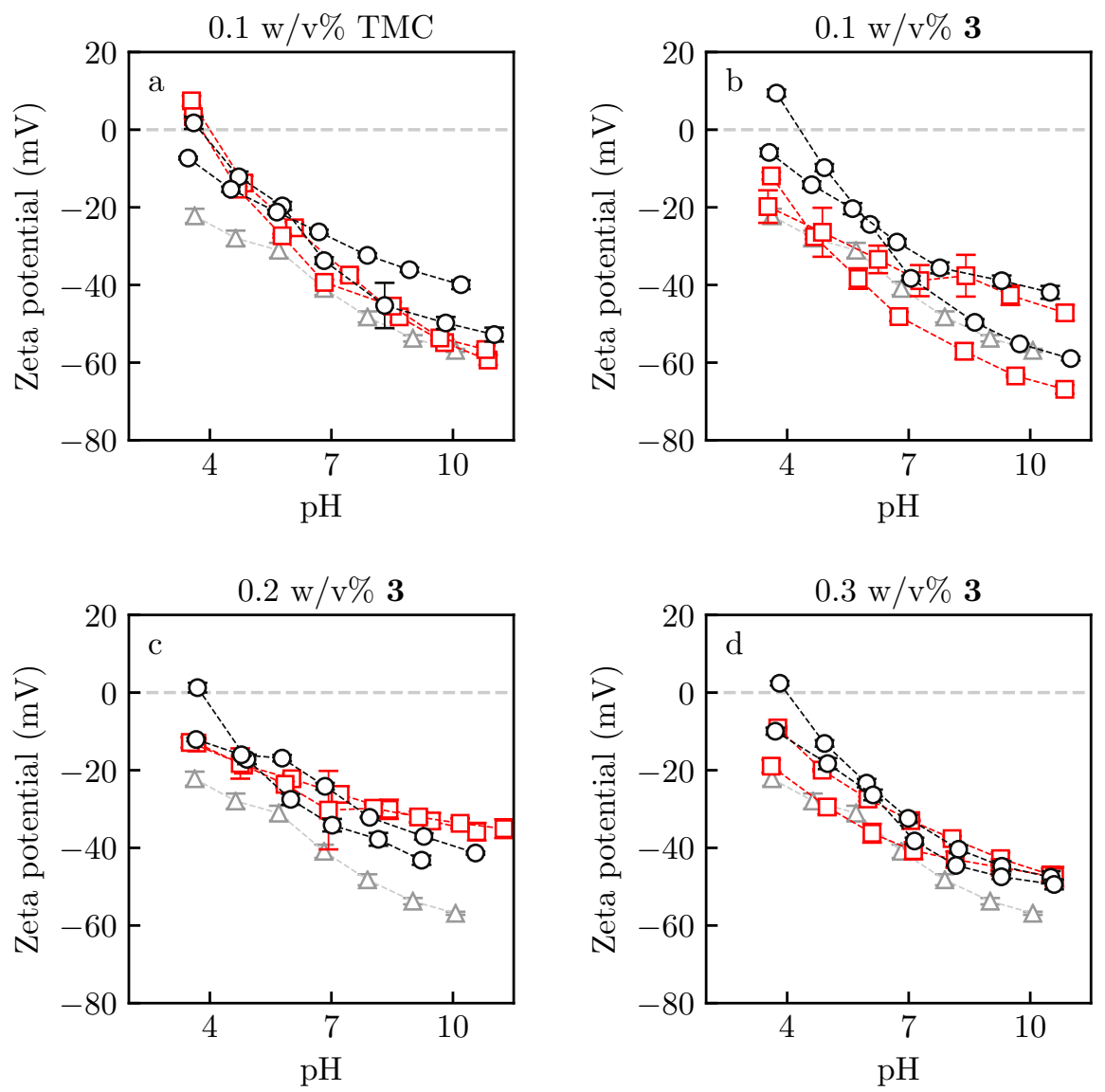

Figure 2.2: The zeta potential as function of $\mathrm{pH}$ of TFC membranes prepared with (a) 0.1 $\mathrm{w} / \mathrm{v} \%$ TMC, (b) $0.1 \mathrm{w} / \mathrm{v} \% 3$, (c) $0.2 \mathrm{w} / \mathrm{v} \% 3$, and (d) $0.3 \mathrm{w} / \mathrm{v} \% 3$. All membranes were prepared on PAN supports by applying a $30 \mathrm{~s}$ reaction time. MPD-based polyamides are represented by red squares ( $\square$ ), and PPD-based polyamides by black circles (O). The zeta potential of a bare PAN support is added as a reference (gray triangles, $\triangle$ ). 


\subsubsection{Membrane structure and morphology}

The membrane structure and morphology were examined by top-view FE-SEM imaging. Figure 2.3 shows the results for the MPD-based membranes, and Figure 2.4 shows the results for the PPD-based membranes.

The surface morphology of TMC-MPD and TMC-PPD membranes is frequently reported in literature. For example, Kwak et al. ${ }^{[9]}$ reported FE-SEM micrographs for MPD-TMC and PPD-TMC membranes, respectively. The authors found a typical ridge-and-valley structure ${ }^{[23]}$ with a tightly packed globular structure underneath for TMC-MPD membranes. In contrast, the surface morphology of TMC-PPD membranes looked more like a dense, finely dispersed nodular structure. Figure 2.3a-c shows a similar surface morphology of TMC-MPD membranes as to that reported by Kwak et al.. The TMC-MPD membranes have a nodular structure with ridge-and-valley features on top. The TMC-PPD membranes (Figure 2.4a-c) prepared in this study show a significantly reduction in the ridge-andvalley structure, whereas the nodular structure is clearly visible. These findings correspond relatively well to those reported by Kwak et al..

The substitution of TMC by compound $\mathbf{3}$ has a significant impact on the surface morphology of the polyamide formed. The nodular structure with ridge-and-valley features has disappeared. Instead, 3-MPD membranes are found to have a polymer film-like structure that strongly depends on the concentration of acyl chloride. From Figure $2.3 \mathrm{e}$, it can be clearly seen that $0.1 \mathrm{w} / \mathrm{v} \%$ of 3 results in a very open polymer structure that only partially covers the PAN support (FE-SEM images of the PAN support can be found in the supporting information). Increasing the acyl chloride concentration to 0.2 or $0.3 \mathrm{w} / \mathrm{v} \%$ results in a more densely packed polymer film that is still relatively smooth compared to the TMC-MPD membrane. The difference in surface roughness can be seen more clearly from Figure 2.3c,f,i,l where the sample stage was rotated at an angle of $45^{\circ}$.

The surface morphology of TMC-MPD and TMC-PPD membranes are found to have similar characteristics. In contrast, the surface morphology of 3-based membranes depends strongly on the chemical structure of the diamine. The use of PPD results in a rough and grain-like surface morphology (Figure 2.4e,h,k). In contrast to 3-MPD membranes, no strong influence of the concentration of acyl chloride on the surface morphology of $\mathbf{3}$-PPD membranes is observed. 
$0.1 \mathrm{w} / \mathrm{v} \% \mathrm{TMC}$
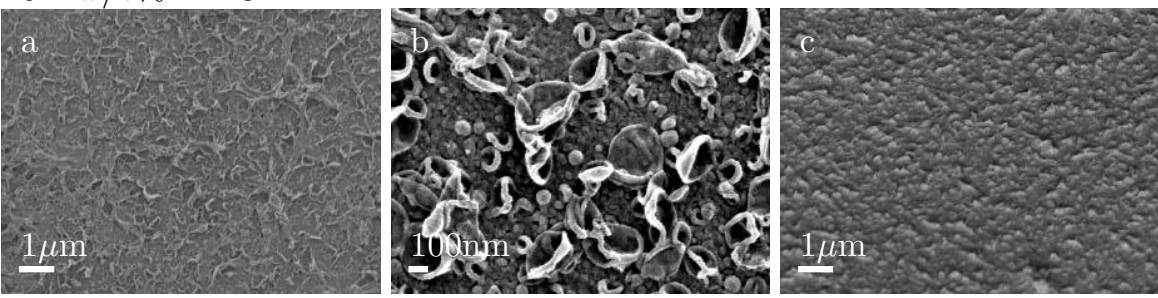

$0.1 \mathrm{w} / \mathrm{v} \% 3$
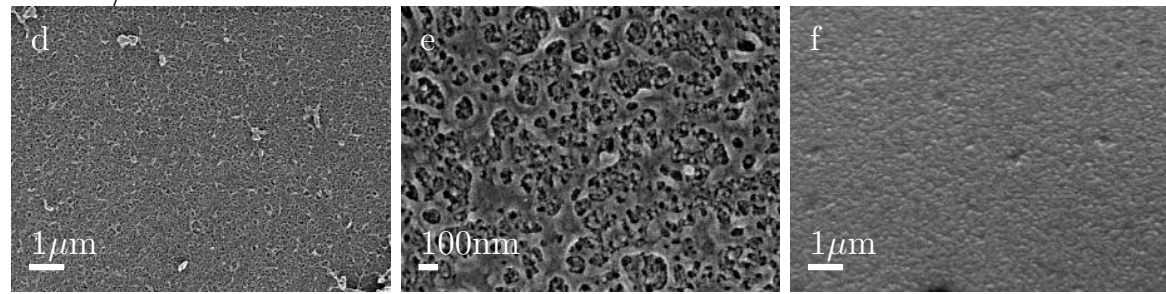

$0.2 \mathrm{w} / \mathrm{v} \% 3$
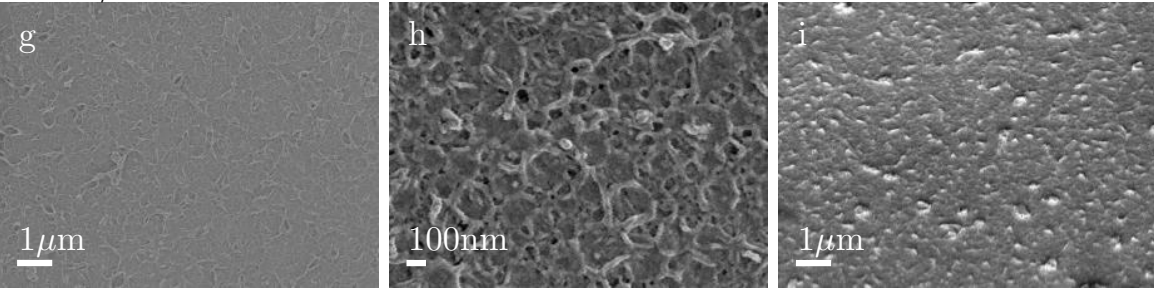

$0.3 \mathrm{w} / \mathrm{v} \% \mathbf{3}$
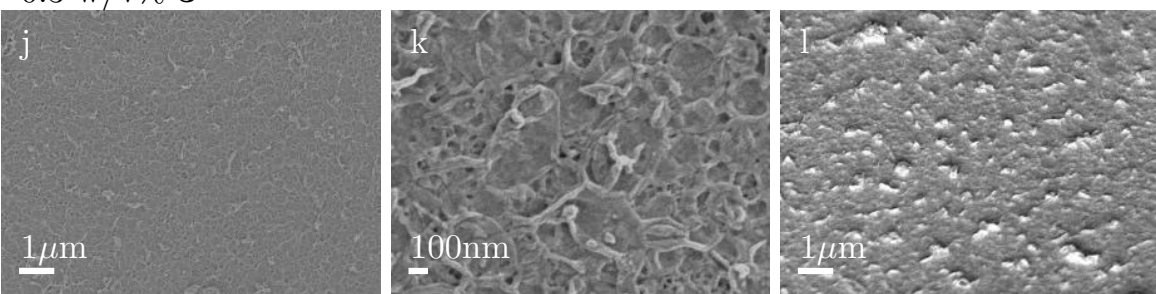

Figure 2.3: Top-view scanning electron micrographs of MPD-based membranes prepared with TMC (a-d) or various concentrations $3(d-l)$. (a,d,g,j) 10,000x magnification, (b,e,h,k) $50,000 \times$ magnification, and $(c, f, i, I) 10,000 x$ magnification with a stage angle of $45^{\circ}$. 
$0.1 \mathrm{w} / \mathrm{v} \% \mathrm{TMC}$
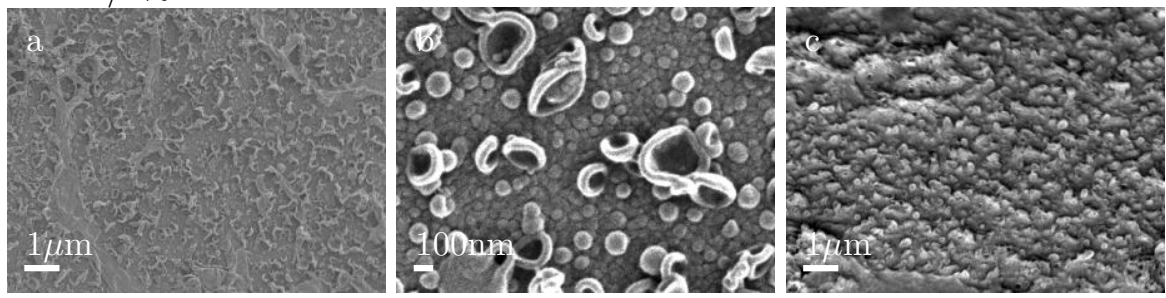

$0.1 \mathrm{w} / \mathrm{v} \% 3$
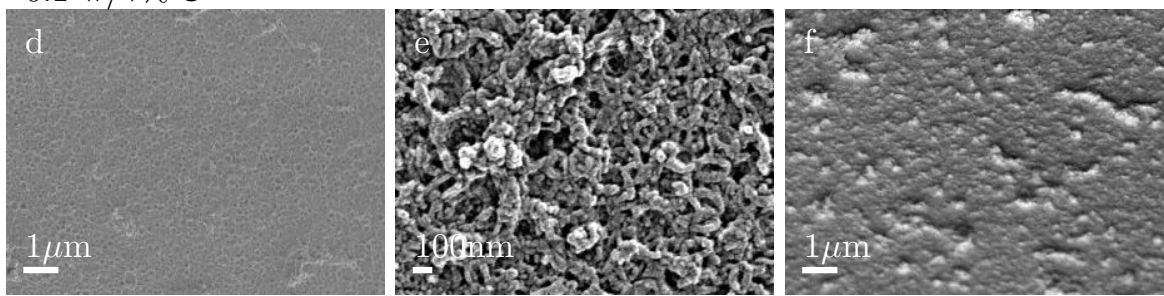

$0.2 \mathrm{w} / \mathrm{v} \% 3$
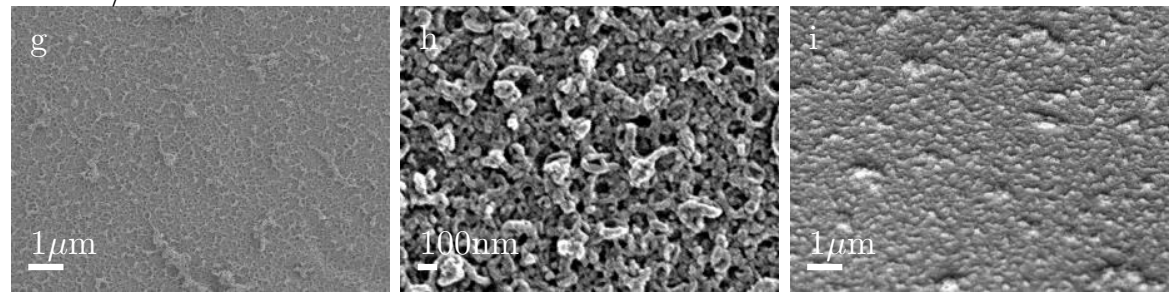

\section{$0.3 \mathrm{w} / \mathrm{v} \% \mathbf{3}$}
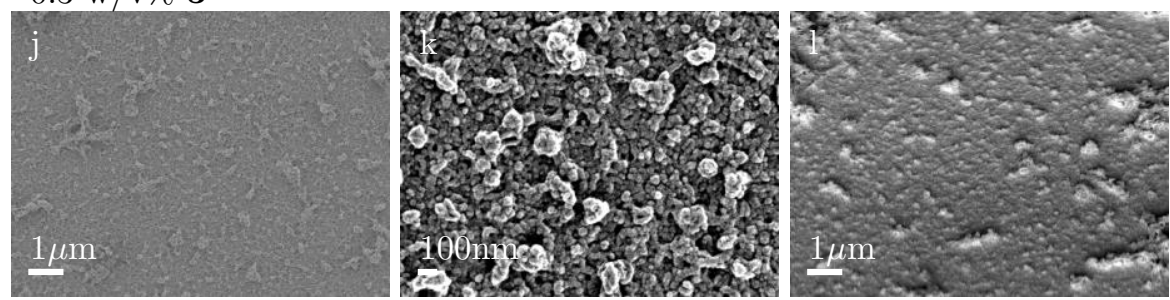

Figure 2.4: Top-view scanning electron micrographs of PPD-based membranes prepared with TMC (a-d) or various concentrations $3(d-l)$. (a,d,g,j) 10,000x magnification, (b,e,h,k) $50,000 \times$ magnification, and $(c, f, i, I) 10,000 \times$ magnification with a stage angle of $45^{\circ}$. 


\subsubsection{The effect of chemical structure on the reactivity}

From the FTIR and FE-SEM results it can be concluded that there is a significant difference in the reaction kinetics of the polyamide formation when either MPD or PPD is used in the interfacial polymerization with the acyl chloride 3 . The morphology of a membrane prepared by interfacial polymerization is greatly influenced by the diffusivity and solubility of the diamine monomer into the organic phase ${ }^{[24,25]}$. However, we expect the diffusion rate and solubility of MPD and PPD to be similar, evidenced by the minor morphological differences found for TMC-based membranes. Therefore the difference in reaction kinetics must be explained by another parameter.

Both PPD and MPD have electron donating amine groups, but due to resonance effects they have a $\delta^{-}$charge on different locations as depicted in Figure 2.5. MPD has permanent $\delta^{-}$charges in the aromatic ring. In contrast, PPD has a net zero charge in the aromatic ring due to resonance effects that cancel each other out. The $\delta^{-}$charges present in MPD, reduce the nucleophilicity of the amine groups and therefore reduces the reactivity as well. This reduction in reactivity of the amine groups is not present in PPD because of the net zero charge.

So far, it can be concluded that MPD can be considered to be less reactive compared to PPD regarding the substitution of the first amine group. However, the reaction with an acyl chloride, and thus amide formation, has a strong effect on the reactivity of the remaining amine group. The resonance effects in the aromatic ring change by the conversion of one amine group to an amide group, and therefore influence the further development of the polymerization. An amide group is a moderately electron donating, and thus moderately activating, group. It donates some of its electron density into the aromatic ring, and makes the amine group more electron rich and nucleophilic. This will increase the reactivity of the remaining amine group. The $\delta^{-}$charges present when one amine group has reacted towards an amide group are shown in Figure 2.6.

From Figure 2.6 it can be seen that an amide bond has a different effect on the reactivity of the remaining amine group in MPD or in PPD. The electron density of an meta-amide towards the amine group is unchanged compared to MPD. In

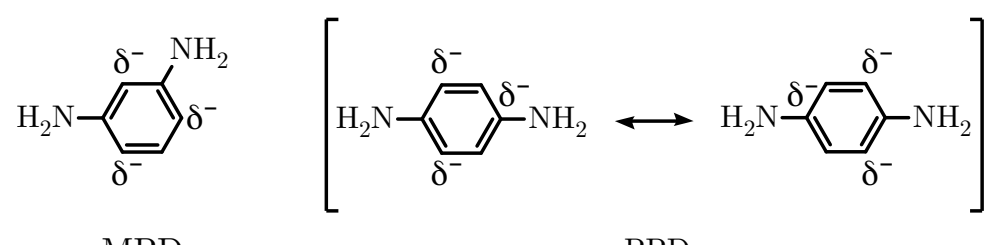

MPD

PPD

Figure 2.5: MPD and PPD have charge localization on different positions on the aromatic ring. 


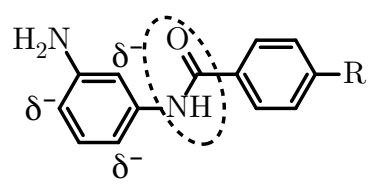

meta-amide: no advantage

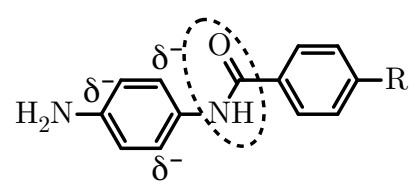

para-amide:

benificial

Figure 2.6: Formation of moderately activating amide bonds will, depending on the substitution pattern of the aromatic diamine, enhance the reactivity of the remaining amine group.

contrast, the electron density towards the amine group is increased in an paraamide, and thus making this para-amide a better nucleophile.

Thus MPD can be considered to be less reactive towards the first amine substitution, and in addition the second amine substitution is not aided by the resonance effects that are induced by the amide group. For PPD, the formed amide bond results into a more nucleophilic amine group upon polymerization. This can explain the differences in reaction kinetics of $\mathbf{3}$ with MPD or PPD as found in the previous sections. For TMC-based membranes no differences in reactivity are observed between MPD and PPD. This is due to the higher reactivity of TMC as compared to $\mathbf{3}$, in which the strongly electron donating ether groups render the acyl chloride groups less electrophilic.

\subsubsection{Membrane performance}

Table 2.1 shows the clean water permeance (CWP), NaCl retention, and rose bengal retention for all membranes prepared in this study. The CWP of 3-based membranes is strongly dependent on the concentration of the acyl chloride, and more or less independent on the isomerism of the diamine. An acyl chloride concentration of $0.1 \mathrm{w} / \mathrm{v} \%$ results in a very open top layer with a high CWP (50-65 $\left.\mathrm{L} \mathrm{m}^{-2} \mathrm{~h}^{-1} \mathrm{bar}^{-1}\right)$. Increasing the acyl chloride concentration to $0.2 \mathrm{w} / \mathrm{v} \%$ significantly reduces the CWP to the order of $4-10 \mathrm{~L} \mathrm{~m}^{-2} \mathrm{~h}^{-1} \mathrm{bar}^{-1}$. A further increase in acyl chloride concentration to $0.3 \mathrm{w} / \mathrm{v} \%$ reduces the CWP further to 2-4 $\mathrm{L} \mathrm{m}^{-2} \mathrm{~h}^{-1}$ bar $^{-1}$.

The $\mathrm{NaCl}$ and rose bengal retention follow the same trend as the CWP. However, membranes prepared with PPD are found to have a significantly higher $\mathrm{NaCl}$ retention as compared to membranes prepared with MPD. This fits well with our hypothesis that the monomer PPD can be considered to be more reactive compared to MPD. When comparing the retention to that of the classical TMCMPD membranes, all 3-based membranes show a very low $\mathrm{NaCl}$ retention. This 


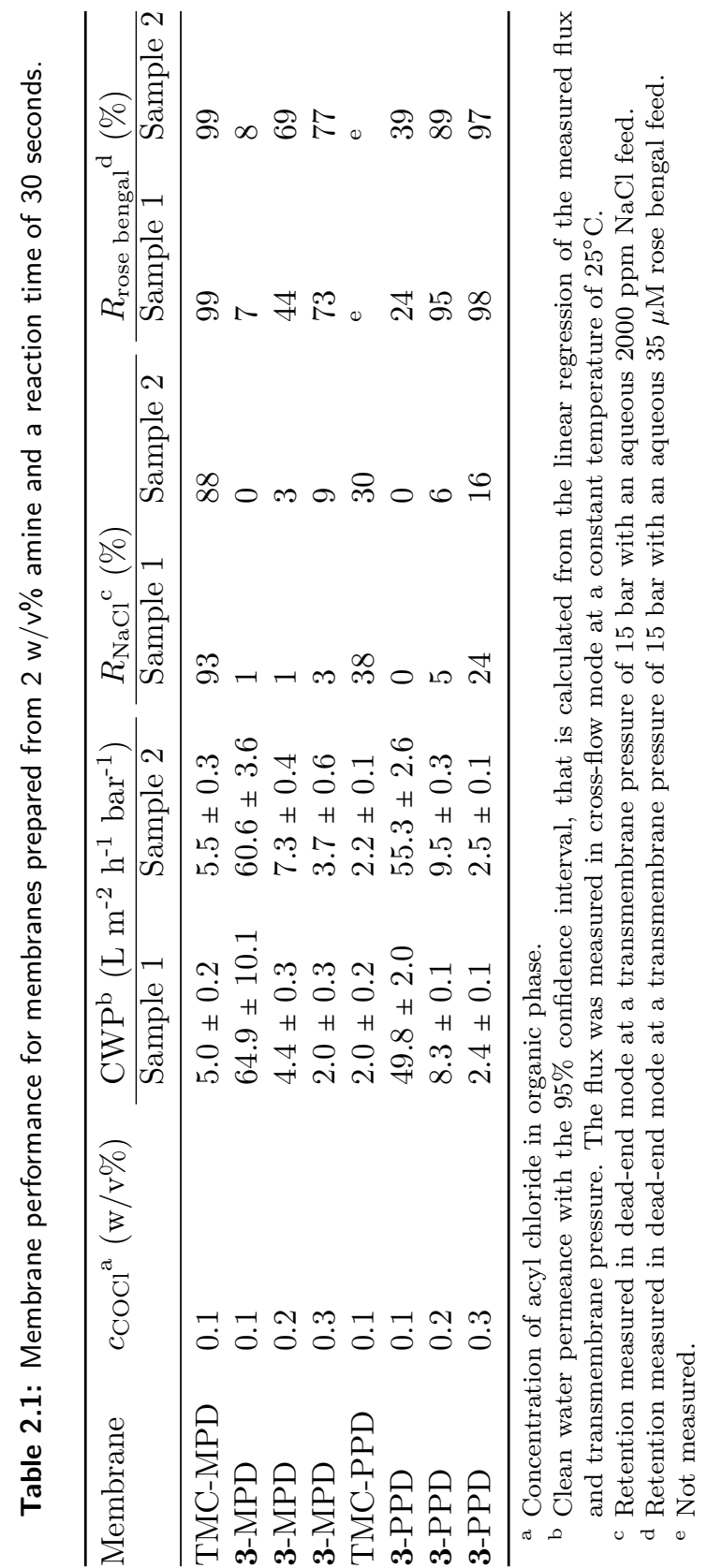


is probably caused by the larger size of the $\mathbf{3}$ monomer, and thereby a larger d-spacing of the top layer.

The retention of rose bengal $\left(1017 \mathrm{~g} \mathrm{~mol}^{-1}\right)$ can be considered as an indicator for a defect-free top layer. Again, higher retentions are obtained with higher concentration of acyl chloride, and retentions for PPD-based membranes are higher than those for MPD-based membranes. Membranes prepared with $0.3 \mathrm{w} / \mathrm{v} \% \mathbf{3}$ and $2 \mathrm{w} / \mathrm{v} \%$ PPD have a defect-free top layer with a rose bengal retention of $>97 \%$.

\subsection{Conclusion}

Here, we reported on the synthesis of a new star-shaped trifunctional acyl chloride that could be used in the interfacial polymerization with aromatic diamines to form polyamide TFC membranes. We found that the structural isomerism of the aromatic diamine has a great effect on the reaction kinetics, and thus on the performance of the resulting membranes. The TFC membrane prepared from the para-substituted diamine PPD showed to have superior membrane performance over the meta-substituted diamine MPD. This effect could be explained by a combination of the lower reactivity of the MPD monomer and a lower reactivity of the acyl chloride groups of the trifunctional acyl chloride as compared to the acyl chloride groups of the commonly used TMC. Defect-free $\left(R_{\text {rose bengal }}>97 \%\right)$ membranes could be obtained by the interfacial polymerization of the star-shaped trifunctional acyl chloride and PPD. These membranes are found to have a clean water permeance of $2.5 \mathrm{~L} \mathrm{~m}^{-2} \mathrm{~h}^{-1}$ bar $^{-1}$, and a maximum $\mathrm{NaCl}$ retention of $24 \%$.

\subsection{Acknowledgements}

This work took place within the framework of the Institute for Sustainable Process Technology (ISPT, project BL-20-02) and within The Dutch Polymer Institute under project \#718. 


\subsection{References}

[1] Roh, I. J.; Greenberg, A. R.; Khare, V. P. Synthesis and characterization of interfacially polymerized polyamide thin films. Desalination 2006, 191, $279-290$.

[2] Li, D.; Wang, H. Recent developments in reverse osmosis desalination membranes. J. Mater. Chem. 2010, 20, 4551-4566.

[3] Petersen, R. J. Composite reverse osmosis and nanofiltration membranes. Journal of Membrane Science 1993, 83, $81-150$.

[4] Cadotte, J. E. Interfacially Synthesized Reverse Osmosis Membrane. 1981; U.S. Patent 4 227344

[5] Lau, W.; Ismail, A.; Misdan, N.; Kassim, M. A recent progress in thin film composite membrane: A review. Desalination 2012, 287, 190 - 199.

[6] Roh, I. J.; Park, S. Y.; Kim, J. J.; Kim, C. K. Effects of the polyamide molecular structure on the performance of reverse osmosis membranes. Journal of Polymer Science Part B: Polymer Physics 1998, 36, 1821-1830.

[7] Kim, C.; Kim, J.; Roh, I.; Kim, J. The changes of membrane performance with polyamide molecular structure in the reverse osmosis process. Journal of Membrane Science 2000, $165,189-199$.

[8] Choi, W.; Gu, J.-E.; Park, S.-H.; Kim, S.; Bang, J.; Baek, K.-Y.; Park, B.; Lee, J. S.; Chan, E. P.; Lee, J.-H. Tailor-Made Polyamide Membranes for Water Desalination. ACS Nano 2015, 9, 345-355, PMID: 25548959.

[9] Kwak, S.-Y.; Jung, S. G.; Yoon, Y. S.; Ihm, D. W. Details of surface features in aromatic polyamide reverse osmosis membranes characterized by scanning electron and atomic force microscopy. Journal of Polymer Science Part B: Polymer Physics 1999, 37, 1429-1440.

[10] Juhn Roh, I. Effect of the physicochemical properties on the permeation performance in fully aromatic crosslinked polyamide thin films. Journal of Applied Polymer Science 2003, 87, 569-576.

[11] Kwak, S.-Y. Relationship of relaxation property to reverse osmosis permeability in aromatic polyamide thin-film-composite membranes. Polymer 1999, 40,6361-6368.

[12] Mo, Y.; Tiraferri, A.; Yip, N. Y.; Adout, A.; Huang, X.; Elimelech, M. Improved Antifouling Properties of Polyamide Nanofiltration Membranes by Reducing the Density of Surface Carboxyl Groups. Environmental Science \&6 Technology 2012, 46, 13253-13261, PMID: 23205860 .

[13] Cadotte, J. E.; King, R. S.; Majerle, R. J.; Petersen, R. J. Interfacial Synthesis in the Preparation of Reverse Osmosis Membranes. Journal of Macromolecular Science: Part A - Chemistry 1981, 15, 727-755.

[14] Saha, N.; Joshi, S. Performance evaluation of thin film composite polyamide nanofiltration membrane with variation in monomer type. Journal of Membrane Science 2009, 342, 60 $-69$.

[15] Li, L.; Zhang, S.; Zhang, X.; Zheng, G. Polyamide thin film composite membranes prepared from 3,4',5-biphenyl triacyl chloride, 3,3',5,5'-biphenyl tetraacyl chloride and $\mathrm{m}$ phenylenediamine. Journal of Membrane Science 2007, 289, 258 - 267.

[16] Li, L.; Zhang, S.; Zhang, X.; Zheng, G. Polyamide thin film composite membranes prepared from isomeric biphenyl tetraacyl chloride and m-phenylenediamine. Journal of Membrane Science 2008, 315, $20-27$.

[17] Wang, T.; Dai, L.; Zhang, Q.; Li, A.; Zhang, S. Effects of acyl chloride monomer functionality on the properties of polyamide reverse osmosis (RO) membrane. Journal of Membrane Science 2013, 440, $48-57$.

[18] Wang, T.; Yang, Y.; Zheng, J.; Zhang, Q.; Zhang, S. A novel highly permeable positively charged nanofiltration membrane based on a nanoporous hyper-crosslinked polyamide barrier layer. Journal of Membrane Science 2013, 448, 180 - 189.

[19] Matsumoto, K.; Higashihara, T.; Ueda, M. Star-Shaped Sulfonated Block Copoly(ether ketone)s as Proton Exchange Membranes. Macromolecules 2008, 41, 7560-7565. 
[20] Ahmad, A.; Ooi, B. Properties-performance of thin film composites membrane: study on trimesoyl chloride content and polymerization time. Journal of Membrane Science 2005, $255,67-77$.

[21] Klaysom, C.; Hermans, S.; Gahlaut, A.; Craenenbroeck, S. V.; Vankelecom, I. F. Polyamide/Polyacrylonitrile (PA/PAN) thin film composite osmosis membranes: Film optimization, characterization and performance evaluation. Journal of Membrane Science 2013, 445, $25-33$.

[22] Raaijmakers, M. J. T.; Kappert, E. J.; Nijmeijer, A.; Benes, N. E. Thermal Imidization Kinetics of Ultrathin Films of Hybrid Poly(POSS-imide)s. Macromolecules 2015, 48, 30313039.

[23] Xu, J.; Yan, H.; Zhang, Y.; Pan, G.; Liu, Y. The morphology of fully-aromatic polyamide separation layer and its relationship with separation performance of TFC membranes. Journal of Membrane Science 2017, 541, 174 - 188.

[24] Ghosh, A. K.; Jeong, B.-H.; Huang, X.; Hoek, E. M. Impacts of reaction and curing conditions on polyamide composite reverse osmosis membrane properties. Journal of Membrane Science 2008, 311, $34-45$.

[25] Khorshidi, B.; Thundat, T.; Fleck, B. A.; Sadrzadeh, M. A Novel Approach Toward Fabrication of High Performance Thin Film Composite Polyamide Membranes. Scientific Reports 2016, 6, 22069.

[26] Kao, S.-T.; Huang, S.-H.; Liaw, D.-J.; Chao, W.-C.; Hu, C.-C.; Li, C.-L.; Wang, D.-M.; Lee, K.-R.; Lai, J.-Y. Interfacially polymerized thin-film composite polyamide membrane: positron annihilation spectroscopic study, characterization and pervaporation performance. Polymer Journal 2010, 42, 242 EP -. 


\subsection{Supplementary information}

\subsubsection{NMR spectra}

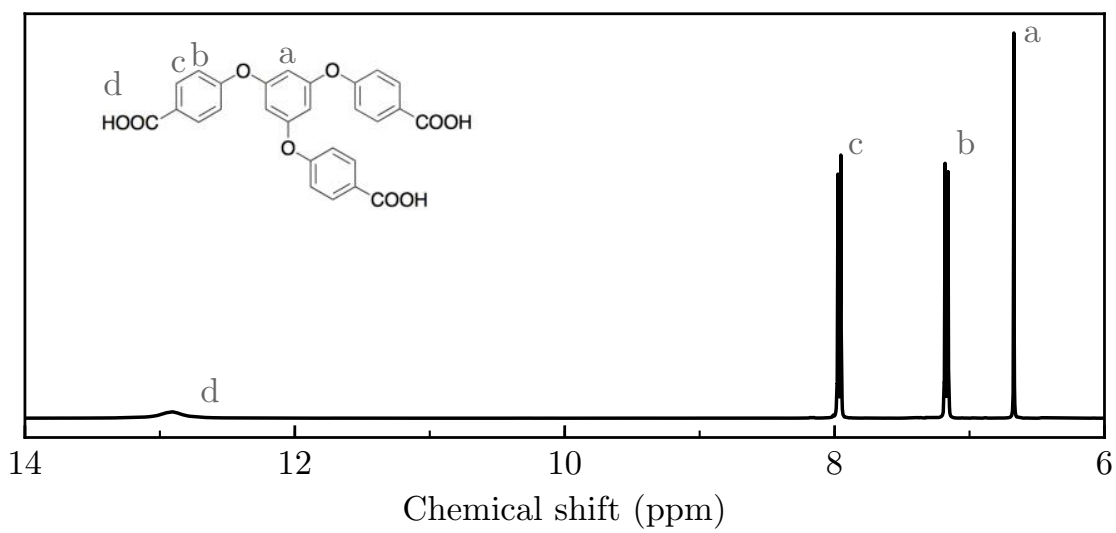

Figure 2.7: ${ }^{1} \mathrm{H}-\mathrm{NMR}$ spectrum of 2 recorded in DMSO-d6.

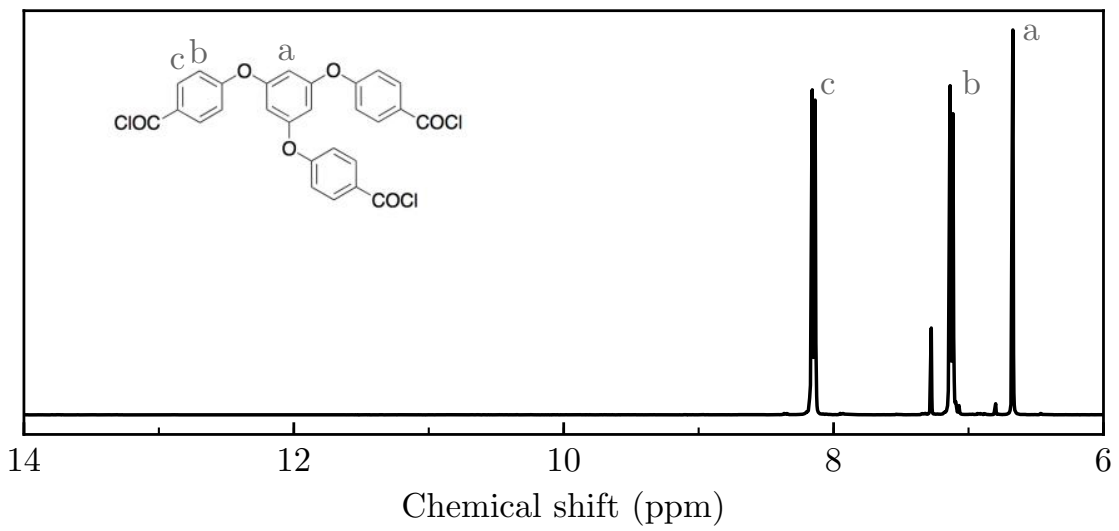

Figure 2.8: ${ }^{1} \mathrm{H}-\mathrm{NMR}$ spectrum of 3 recorded in $\mathrm{CDCl}_{3}$. 


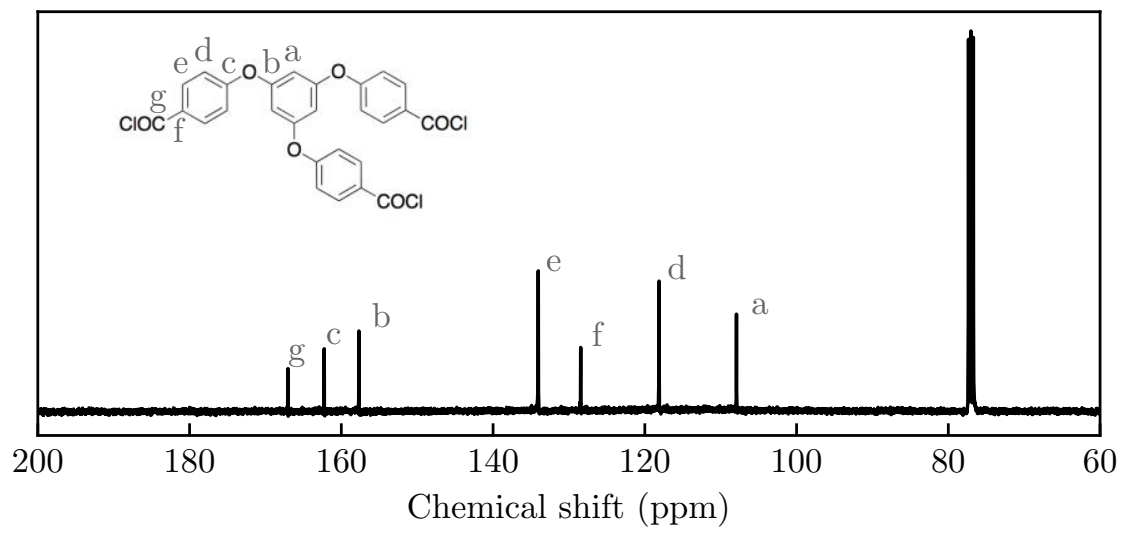

Figure 2.9: ${ }^{13} \mathrm{C}-\mathrm{NMR}$ spectrum of 3 recorded in $\mathrm{CDCl}_{3}$.

\subsubsection{FTIR spectra}

The ATR-FTIR spectra of the monomers $\mathbf{2}$ and $\mathbf{3}$ are given in Figure 2.10. The spectrum of $\mathbf{2}$ shows a sharp absorbance peak originating from the $\mathrm{C}=\mathrm{O}$ stretching of the carboxylic acid at $1675 \mathrm{~cm}^{-1}$. In addition, a broad absorbance peak is observed around $2800 \mathrm{~cm}^{-1}$, which originates from the $\mathrm{OH}$ stretching of the carboxylic acid.

The carboxylic acid groups of $\mathbf{2}$ are converted into acyl chloride groups upon treatment with thionyl chloride $\left(\mathrm{SOCl}_{2}\right)$ revealing monomer 3. The $\mathrm{C}=\mathrm{O}$ stretching of the acyl chloride shifts to $1740 \mathrm{~cm}^{-1}$ in the spectrum of $\mathbf{3}$.

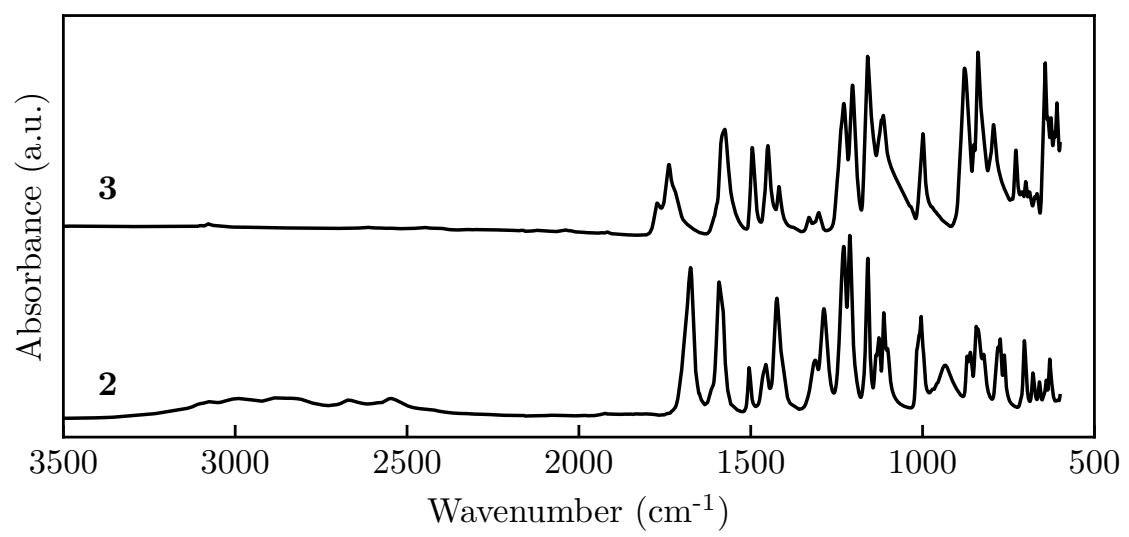

Figure 2.10: ATR-FTIR spectra of 2 and 3. 


\subsubsection{Contact angle}

The contact angles of the prepared polyamide films are shown in Figure 2.11. Interestingly, the measured contact angle for our TMC-MPD film is much lower as compared to values reported in literature, that vary between $60-80^{\circ}[15,17,26]$. These literature values are measured on TMC-MPD films deposited on a porous polymeric support, whereas here the films are supported by a silicon wafer.

The 3-MPD films prepared with $0.1 \mathrm{w} / \mathrm{v} \%$ acyl chloride seem to have a relatively high contact angle as compared to all other polyamide films. However, all films were washed with excess water after synthesis, except for these films. Due to their fragility these films could not be washed with water, and therefore their contact angle could be overestimated.

In general, the films prepared from both 3-MPD and 3-PPD show to have a lower contact angle as compared to their TMC-based analogues. This is surprising, considering the increased monomer size, and thus reduced amount of amide groups per unit volume for 3 -based polyamides. The lower contact angle can be explained by a higher amount of unreacted end-groups, and thus a lower cross-linking density.

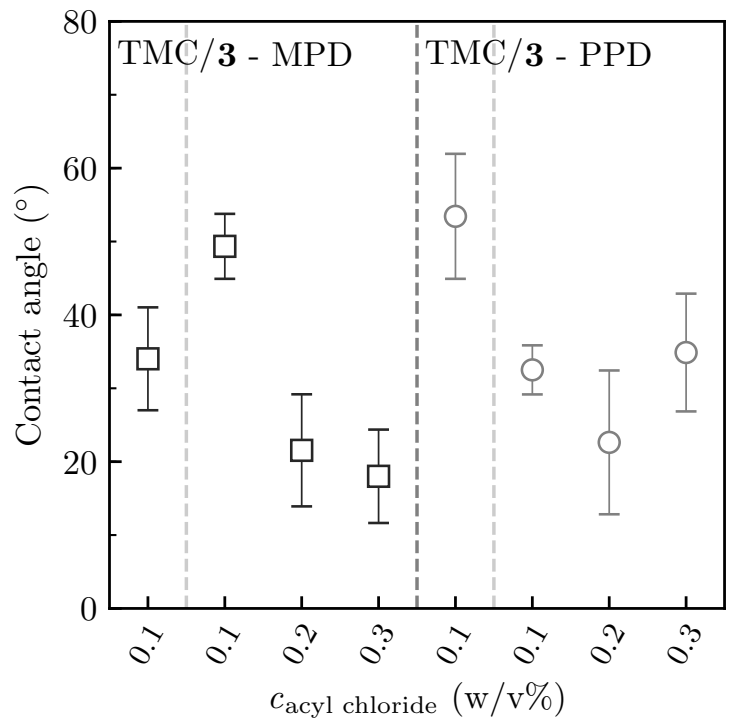

Figure 2.11: Contact angle of polyamide films on silicon wafers. MPD-based polyamides are represented by black squares ( $\square$ ), and PPD-based polyamides by gray circles $(\bigcirc)$. The error bars represent the $95 \%$ confidence interval calculated from 5 measurements. 


\subsubsection{Thermogravimetric analysis}

Figure 2.12 shows the mass loss as function of temperature for the monomers $\mathbf{2}$ and 3. The mass loss as a function of temperature and the corresponding gases evolved for the polyamide powders is given in Figure 2.13 for MPD-based polyamides, and in Figure 2.14 for PPD-based polyamides.

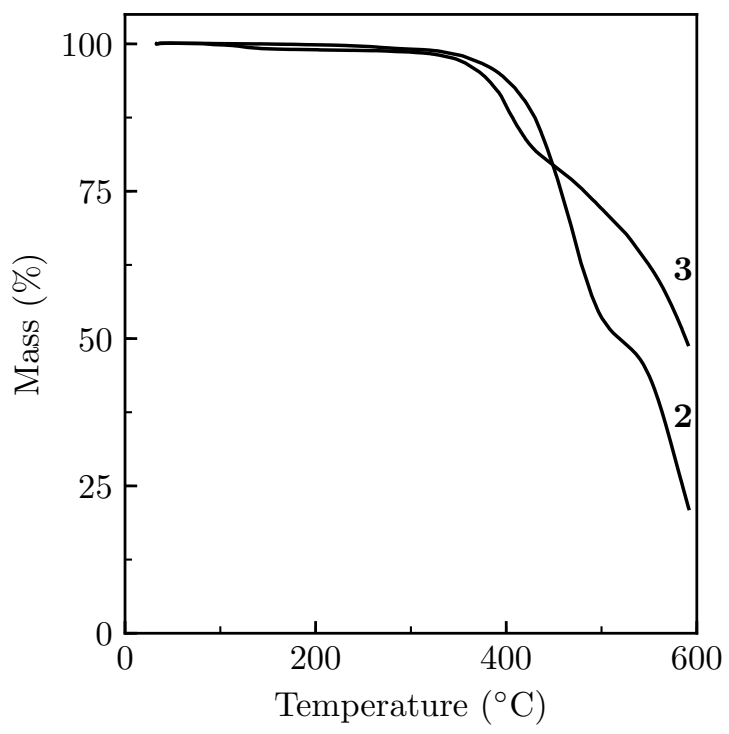

Figure 2.12: Mass loss as function of temperature for 2 and 3. All traces were obtained under a nitrogen atmosphere, with a heating rate of $10{ }^{\circ} \mathrm{C} \mathrm{min}^{-1}$. 

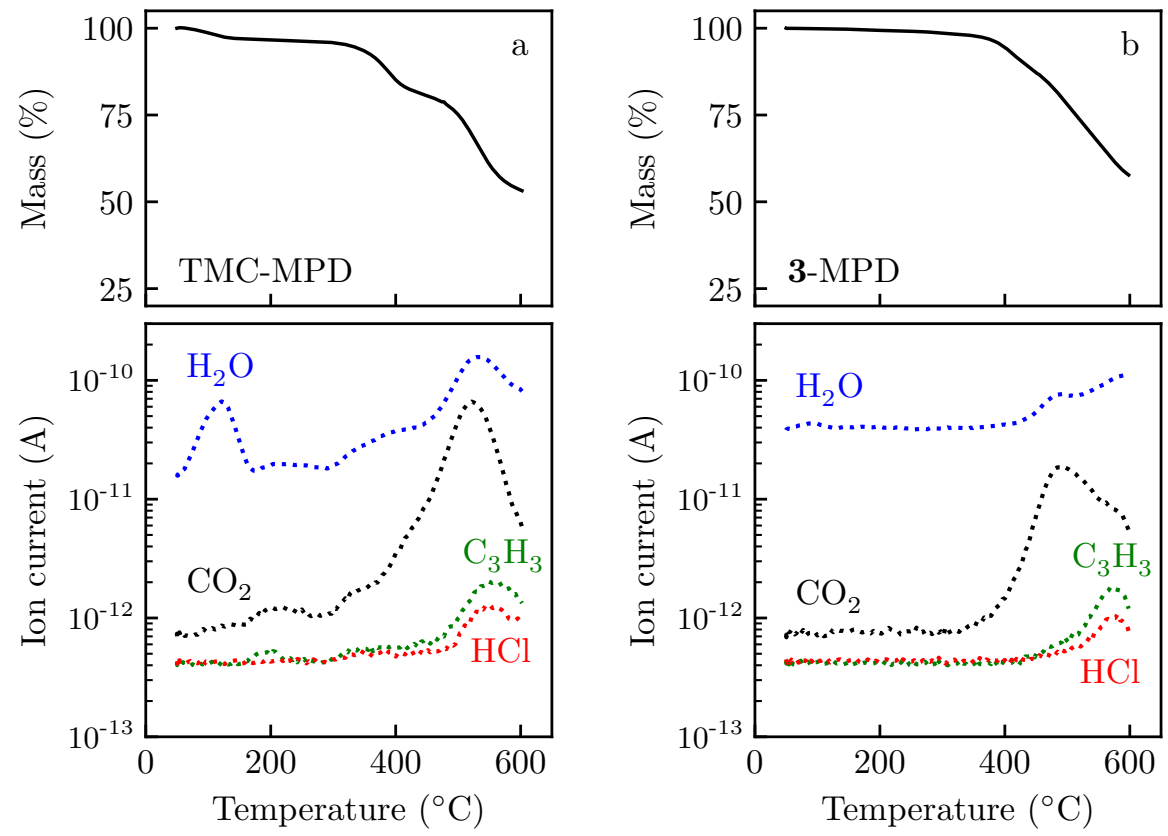

Figure 2.13: TGA-MS spectra of (a) TMC-MPD and (b) 2-MPD powder obtained under a nitrogen atmosphere with a heating rate of $10{ }^{\circ} \mathrm{C} \mathrm{min}^{-1}$. The top graphs show the mass loss as function of temperature. The bottom graphs show the evolved gases. The tracked $m / z$ values are $\mathrm{H}_{2} \mathrm{O}(m / z=18$, blue, -$), \mathrm{HCl}(m / z=38$, red, -$), \mathrm{C}_{3} \mathrm{H}_{3}(m / z=39$, fragment originating from aromatic ring, green, -$)$, and $\mathrm{CO}_{2}(m / z=44$, black, -$)$. 

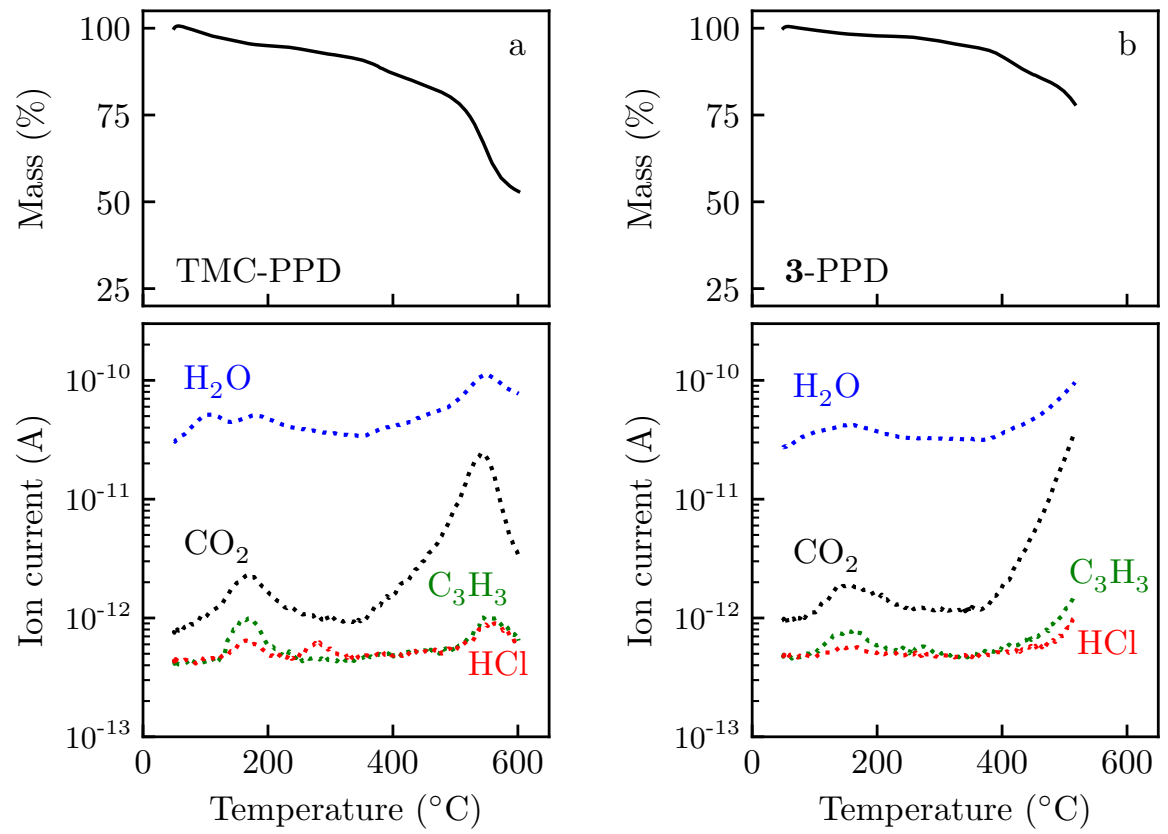

Figure 2.14: TGA-MS spectra of (a) TMC-PPD and (b) 2-PPD powder obtained under a nitrogen atmosphere with a heating rate of $10{ }^{\circ} \mathrm{C} \mathrm{min}^{-1}$. The top graphs show the mass loss as function of temperature. The bottom graphs show the evolved gases. The tracked $\mathrm{m} / \mathrm{z}$ values are $\mathrm{H}_{2} \mathrm{O}(m / z=18$, blue, -$), \mathrm{HCl}(m / z=38$, red, -$), \mathrm{C}_{3} \mathrm{H}_{3}(m / z=39$, fragment originating from aromatic ring, green, -$)$, and $\mathrm{CO}_{2}(m / z=44$, black, - ). 


\subsubsection{Film thickness}

The film thickness of the polyamide films prepared on silicon wafers is shown in Figure 2.15. All films showed to have a low light reflectivity, and therefore an extremely low intensity. In combination with a high surface roughness, the fitting of the ellipsometric spectra gives raise to a high error in these measurements.

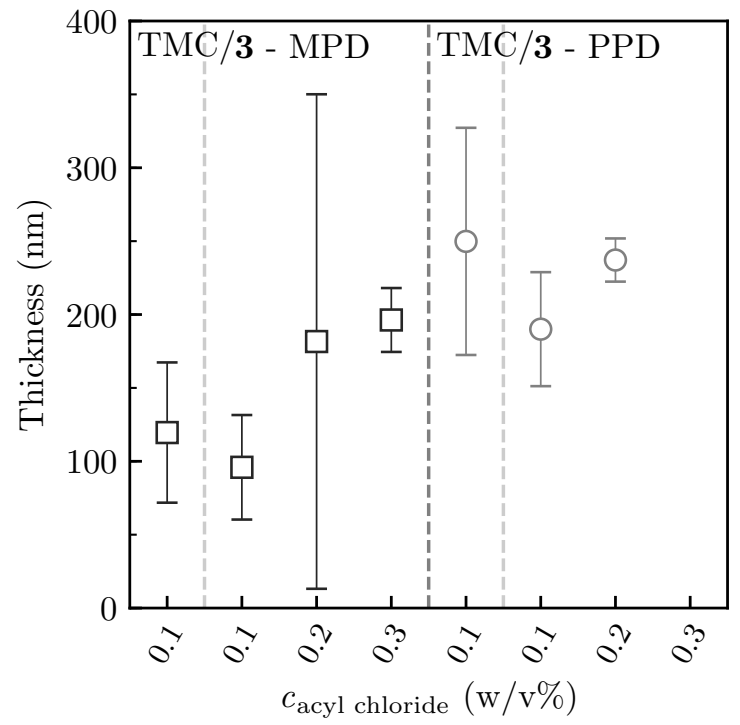

Figure 2.15: The film thickness of polyamide films on silicon wafers. MPD-based polyamides are represented by black squares ( $\square$ ), and PPD-based polyamides by gray circles $(\bigcirc)$. The error bars represent the $95 \%$ confidence interval calculated from 3-5 measurements. 


\subsubsection{Scanning electron microscopy}

Top-view scanning electron micrographs of a PAN ultrafiltration support are given in Figure 2.16.
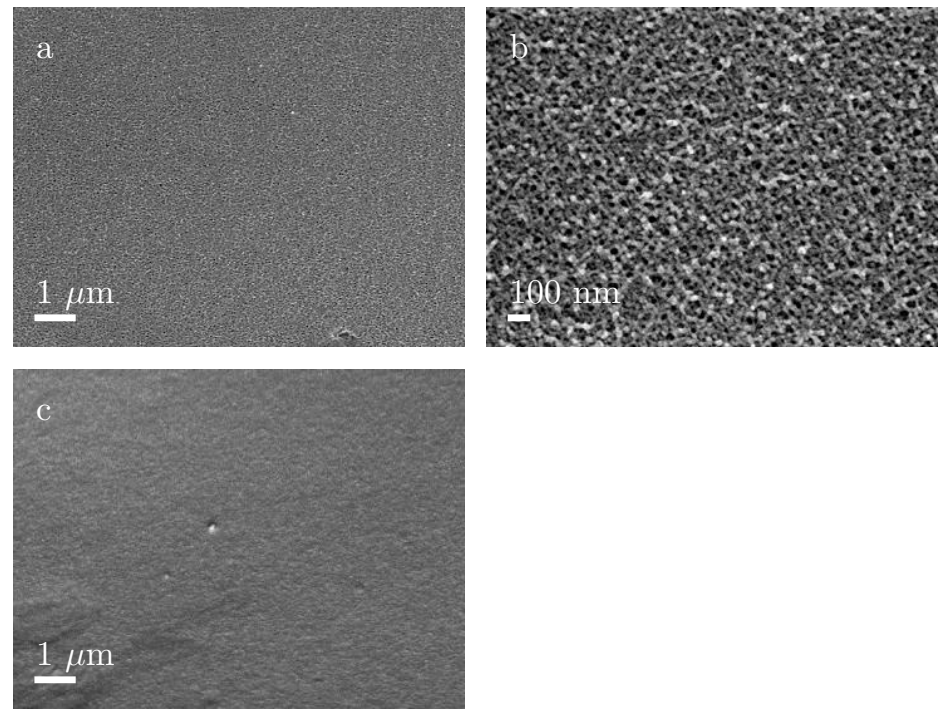

Figure 2.16: Top-view scanning electron micrographs of a PAN ultrafiltration support. (a) $10.000 \times$ magnification, (b) 50.000x magnification, and (c) 10.000x magnification with a stage angle of $45^{\circ}$. 


\subsubsection{Clean water permeance}

Figure 2.17 shows the water flux as function of transmembrane pressure (TMP) for all membranes. All membranes show a linear dependence of the flux on the TMP, where all fits pass through the origin.
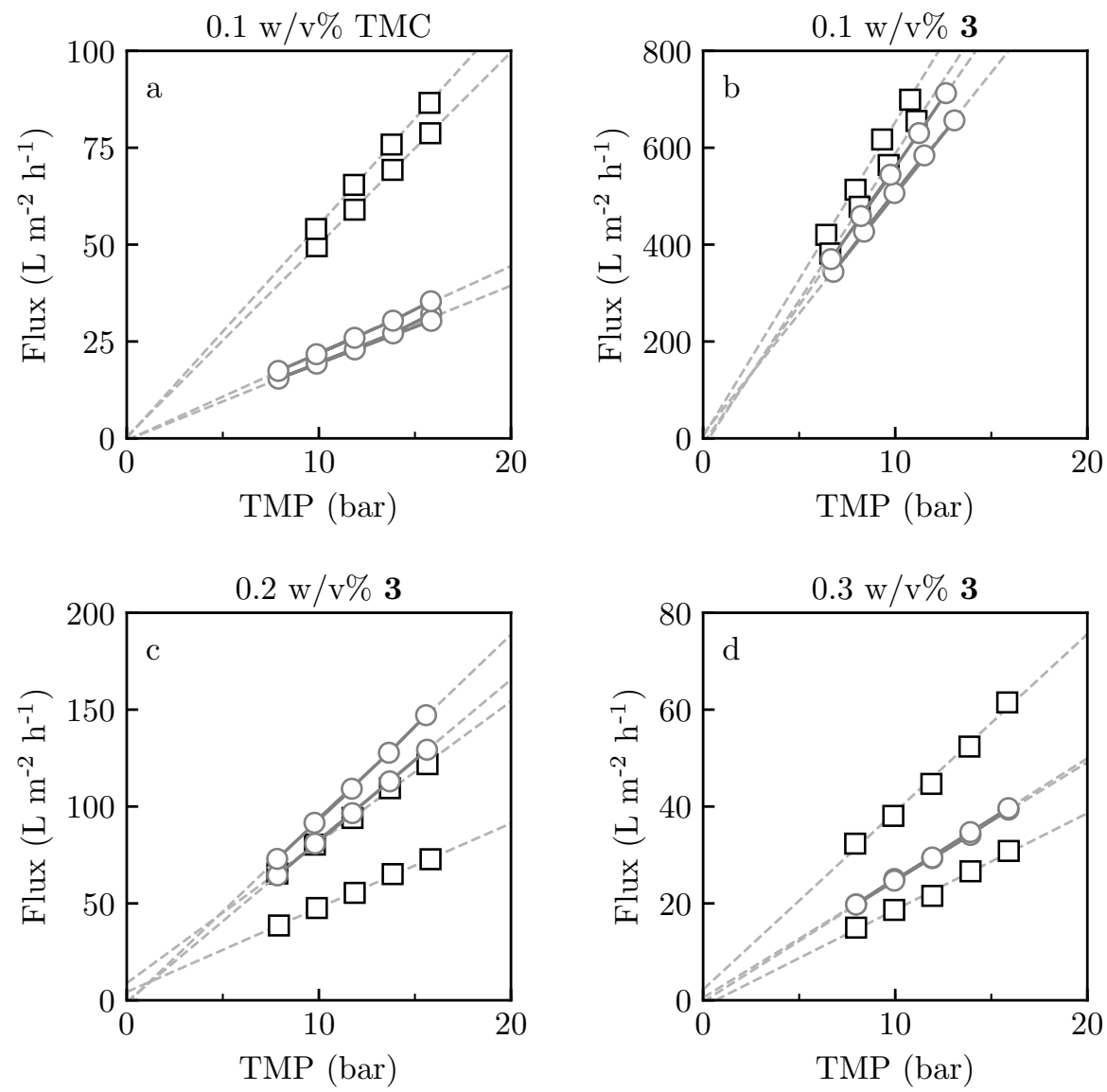

Figure 2.17: The clean water permeance for membranes prepared from (a) $0.1 \mathrm{w} / \mathrm{v} \%$ TMC, (b) $0.1 \mathrm{w} / \mathrm{v} \% 3$, (c) $0.2 \mathrm{w} / \mathrm{v} \% 3$, and (d) $0.3 \mathrm{w} / \mathrm{v} \% 3$. MPD-based membranes are represented by black squares $(\square)$ and PPD-based membranes by gray circles $(\bigcirc)$. 


\section{Chapter 3}

\section{Hyper-cross-linked thin polydimethylsiloxane films}

This chapter is adapted from:

Evelien Maaskant, Kristianne Tempelman, and Nieck E. Benes, Hyper-cross-linked thin polydimethylsiloxane films, Submitted for publication 


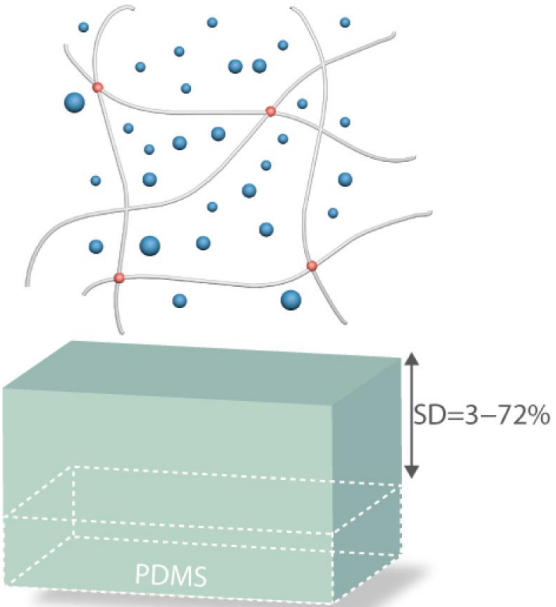

Hexane $>$ Ethyl acetate $>$ Ethanol
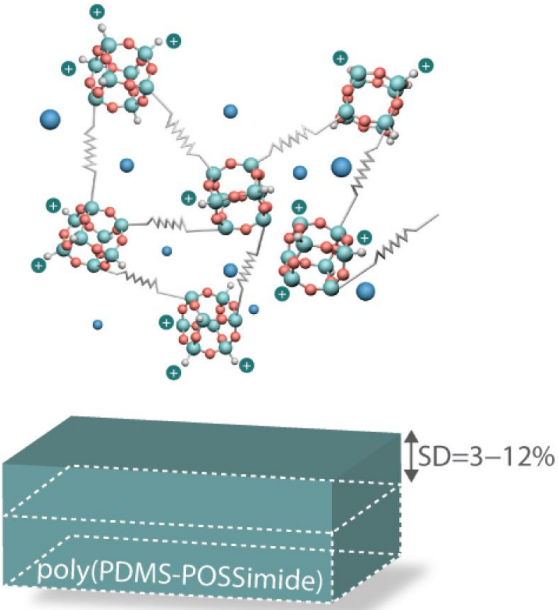

Ethanol $>$ Hexane $=$ Ethyl acetate

\section{Abstract}

Polydimethylsiloxane (PDMS) films are widely used in many applications, such as in microfluidic devices or as membranes. These slightly cross-linked films suffer from severe swelling upon contact with, especially non-polar, organic solvents, thereby drastically reducing the performance of the device. Here, we report on a new method to prepare ultra-thin, highly cross-linked PDMS films in a localized fashion by the interfacial polymerization of PDMS with polyhedral oligomeric silsesquioxane (POSS). The resulting thin poly(PDMS-POSSimide) films ( 150 nm) showed to have a drastic reduction in swelling upon contact with $n$ hexane vapor ( 15 fold decrease) and ethyl acetate vapor ( 5 fold decrease). These poly(PDMS-POSSimide) films showed an increase in swelling upon contact with ethanol vapor (up to a 4 fold increase) as compared to conventional PDMS. We attribute this increase in swelling to the enhanced affinity for polar solvents of these poly(PDMS-POSSimide) films due to the presence of positively charged ammonium groups. Despite the highest swelling in ethanol, the poly(PDMS-POSSimide) films are found to have extremely low ethanol permeances $\left(<0.1 \mathrm{~L} \mathrm{~m}^{-2} \mathrm{~h}^{-1} \mathrm{bar}^{-1}\right)$, thereby making them potential barrier materials. 


\subsection{Introduction}

Polydimethylsiloxane (PDMS) is an organosilicon polymer, that has the general formula $\left[\mathrm{Si}\left(\mathrm{CH}_{3}\right)_{2} \mathrm{O}\right]_{\mathrm{n}}$. PDMS is widely used because it is optically transparent, flexible, inert, bio-compatible, and non-flammable. Most applications require the cross-linking of PDMS chains. Typically, cross-linked PDMS is prepared from the hydrosilylation of a liquid divinyl-terminated PDMS prepolymer, with a multifunctional organosilane cross-linker, followed by a (thermal) curing step ${ }^{[1]}$. The reaction rate of this cross-linking reaction at ambient conditions is sufficiently low to allow for processing the PDMS by methods such as spin-coating, molding, or casting.

Example application areas of PDMS are sensors, medical devices, microfluidics, or membranes ${ }^{[2,3]}$. In microfluidic devices, thin PDMS films are commonly applied as, e.g., microlenses ${ }^{[4-6]}$, valves ${ }^{[7,8]}$, or actuators ${ }^{[9,10]}$. In addition, thin PDMS films are used as membranes in organic solvent nanofiltration (OSN), or as gas separation membranes ${ }^{[11]}$.

Although PDMS is widely used in many applications, it has some major drawbacks in the presence of organic solvents. The high affinity of PDMS for non-polar solvents and the rubbery nature of PDMS, causes PDMS to swell substantially, especially in non-polar solvents. This severe swelling could significantly reduce the performance of any PDMS-based device. For example, PDMS membranes can suffer from the loss of selectivity in organic solvents since high molecular weight solutes can permeate through the swollen membrane. In an extreme case, the selective PDMS layer can be peeled off from the support due to severe swelling of the PDMS.

It is for the above mentioned reasons, often desirable to reduce the swelling of PDMS in organic solvents. Several approaches focusing on the reduction of swelling in membranes can be found in literature. These methods could also be applied to other PDMS-based devices. One of these methods is the inclusion of inorganic nanofillers in the PDMS matrix, e.g. silica particles ${ }^{[12,13]}$, zeolites ${ }^{[14]}$, carbon nanotubes $^{[15]}$, or carbon nanoparticles ${ }^{[16]}$. These nanofillers physically interact with the PDMS matrix, thereby restricting the swelling of PDMS ${ }^{[11]}$. However, the use of inorganic nanofillers can result in phase separation, or particle agglomeration, which can reduce the performance of the device ${ }^{[17]}$.

An improved control over the swelling of the PDMS network could be obtained when the nanofiller is covalently bound to the PDMS matrix. An interesting nanofiller that could be covalently cross-linked to PDMS is polyhedral oligomeric silsesquioxane (POSS). Typical POSS molecules have a cage structure with the general formula $\mathrm{R}_{8} \mathrm{Si}_{8} \mathrm{O}_{12}$, where the organic end-groups $\mathrm{R}$ can be tailored ${ }^{[18]}$. POSS is of high interest due to its excellent thermal and chemical stability of the inorganic core, and flexible end-group chemistry. Many examples of the crosslinking of PDMS with partially condensed ${ }^{[19,20]}$ or fully condensed ${ }^{[20-24]}$ POSS cages can be found in literature. These PDMS-POSS nanocomposites are even 
used as membranes for gas separation, although the preparation of these membranes by casting ${ }^{[25]}$ results in relatively thick $(200-250 \mu \mathrm{m})$ PDMS layers ${ }^{[20]}$.

Here, we show the preparation of ultra-thin ( 150 nm) hyper-cross-linked PDMSPOSS films by interfacial polymerization (IP). IP is the localized polycondensation of two or more monomers at the interface of two immiscible solvents ${ }^{[1,26,27]}$ resulting in a perfectly alternating cross-linked polymeric film. POSS has already been successfully used in the preparation of hybrid polyamide ${ }^{[28,29]}$, or polyimide ${ }^{[30]}$ films, prepared from POSS and small organic monomers. However, POSS has not yet been applied in the preparation of cross-linked PDMS films by interfacial polymerization.

To prepare these cross-linked PDMS films, octaAmmonium-POSS was deprotonated to form its reactive free amine, and subsequently reacted with succinic anhydride terminated PDMS resulting in a poly(PDMS-POSSamic acid). This poly(amic acid) was thermally imidized in the corresponding poly(PDMSPOSSimide) (Figure 3.1). The swelling of these poly(PDMS-POSSimide)s was studied by spectroscopic ellipsometry, and compared to the swelling of conventional PDMS.

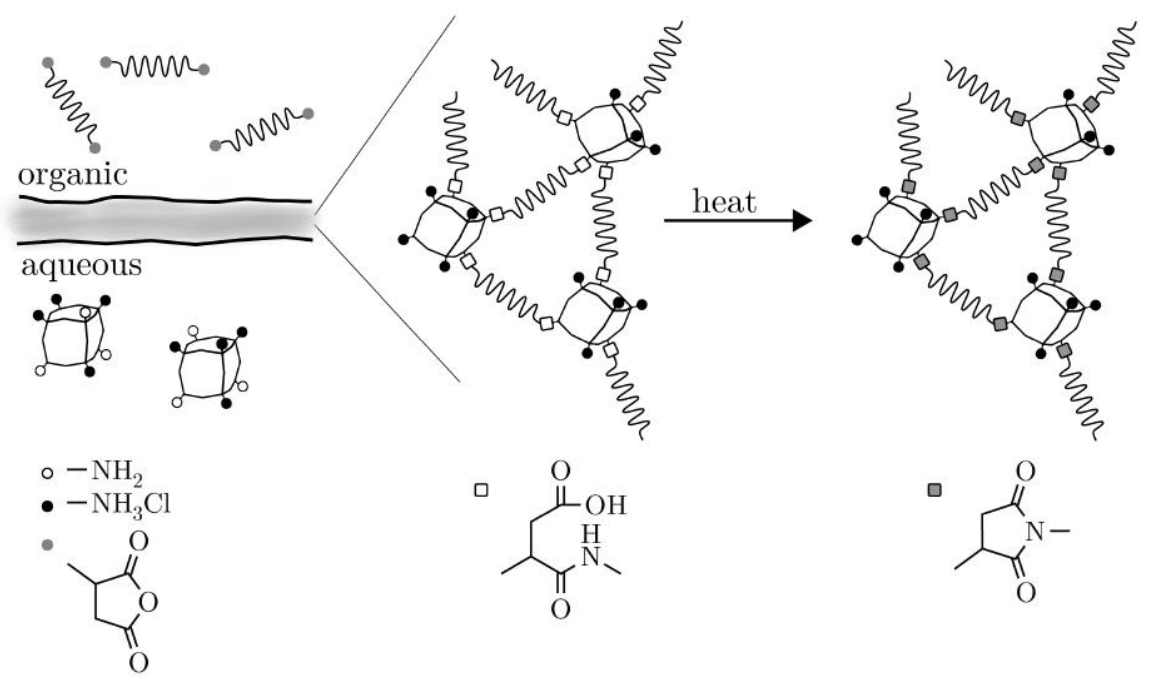

Figure 3.1: The synthesis of hyper-cross-linked poly(PDMS-POSSimide) by interfacial polymerization of amine functionalized POSS with succinic anhydride functionalized PDMS. After film formation, the resulting poly(PDMS-POSSamic acid) was thermally imidized to the stable poly(PDMS-POSS imide). 


\section{$3.2 \quad$ Experimental}

\subsubsection{Materials}

OctaAmmonium POSS (POSS) was obtained from Hybrid Plastics, USA, Polydimethylsiloxane, succinic anhydride terminated; viscosity 75-100 cSt (PDMS) was obtained from ABCR, Germany. Ethanol (absolute) was obtained from Merck. Sodium hydroxide ( $\mathrm{NaOH},>98 \%$ ), toluene (anhydrous, 99.8\%), and ethyl acetate (anhydrous, 99.8\%) were obtained from Sigma-Aldrich (The Netherlands). PDMS, Permacol RTV 615 A/B type was obtained from Permacol B.V. as a two component system, consisting of a vinyl-terminated pre-polymer (RTV A) and a crosslinker containing several hydrosilane groups (RTV B).

\subsubsection{Preparation of PDMS films}

Thin PDMS films were prepared on silicon wafers by spin-coating a prepolymer solution ( $2.5 \mathrm{wt} \%$ in $n$-hexane) containing the cross-linker in a ratio of RTV A/RTV B of 10:1 at $3000 \mathrm{rpm}$ for 30 seconds. To facilitate the cross-linking, the thin films were were placed in a chamber oven (Carbolite HTMA 5/28) under a nitrogen flow $\left(5 \mathrm{~mL} \mathrm{~min}{ }^{-1}\right)$. The samples were heated to $80{ }^{\circ} \mathrm{C}$ for $8 \mathrm{~h}$.

\subsubsection{Synthesis of poly(PDMS-POSSamic acid) networks by interfacial polymerization}

Both powdered and supported poly(PDMS-POSSamic acid) networks were prepared by interfacial polymerization (IP). For both, POSS was dissolved in Milli-Q grade water, and the $\mathrm{pH}$ of the solution was adjusted to $\mathrm{pH} 8.5$ or 9.5 using $1.5 \mathrm{M} \mathrm{NaOH}$. Powdered poly(PDMS-POSSamic acid) was prepared by vigorously stirring equal amounts of an aqueous solution of POSS (0.9 wt\%) and an organic solution of PDMS ( $0.5 \mathrm{wt} \%$ in toluene) for 1 hour. The formed solids were filtered and washed with excess water and toluene, respectively. The precipitate was dried overnight in a vacuum oven at $50{ }^{\circ} \mathrm{C}$, and ground to a fine powder. The powder was stored under nitrogen until further use.

poly(PDMS-POSSamic acid) membranes were prepared by interfacial polymerization on top of porous $\alpha$-alumina disks, coated with two layers of $\gamma$-alumina (Pervatech, The Netherlands). The support was soaked with aqueous POSS solution $(0.9 \mathrm{wt} \%)$ and dried for 15 minutes to remove excess aqueous solution. Afterwards, the organic solution of PDMS (0.5 wt\% in toluene) was poured onto the porous disk. After 5 minutes reaction time, the toluene solution was removed, and the membrane surface was washed with toluene.

Thin poly(PDMS-POSSamic acid) films deposited on silicon wafers were prepared for spectroscopic ellipsometry experiments. A silicon wafer was fixed in the middle 
of a petri dish and aqueous POSS solution (0.9 wt\%, $\mathrm{pH}=9.5)$ was poured into the petri dish, just covering the wafer. Then PDMS solution ( $0.5 \mathrm{wt} \%$ in toluene) was gently poured from the side over the POSS solution, allowing it to float on top of the aqueous solution. A thin film formed immediately. After ten minutes reaction time, most of the toluene was removed with a pipet and the petri dish was slowly decanted, allowing for the water solution to flow out of the petri dish, and the formed poly(PDMS-POSSamic acid) film was carefully deposited on the fixed wafer. The wafer with the poly(PDMS-POSSamic acid) film was removed from the petri dish and air dried. Once dried, the wafer with the film was carefully placed in a petri dish filled with ethanol, to remove unreacted monomers.

\subsubsection{Imidization of poly(PDMS-POSSamic acid) networks}

Both poly(PDMS-POSSamic acid) powder and supported films were placed in a

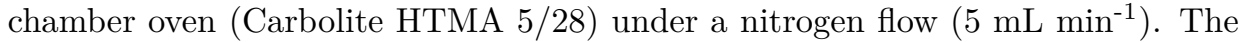
samples were heated to $100{ }^{\circ} \mathrm{C}$ for $1 \mathrm{~h}$, followed by a 18 minutes dwell at $250{ }^{\circ} \mathrm{C}$ with a heating rate of $10{ }^{\circ} \mathrm{C} \mathrm{min}^{-1}$. The imidization time and temperature were determined from combined TGA-MS experiments. The samples were cooled to room temperature without a specified cooling rate.

\subsubsection{Characterization}

The chemical structure of poly(PDMS-POSSamic acid) and poly(PDMSPOSSimide) powders was analyzed by Fourier transform infrared spectroscopy (FTIR) in attenuated total reflectance (ATR) mode on an ALPHA spectrometer (Bruker, Germany). All powders were used without further sample preparation.

Combined thermogravimetric analysis (TGA) and mass spectroscopy (MS) measurements were performed on poly(PDMS-POSSamic acid) powders using an STA 449 F3 Jupiter TGA with an aluminum sample cup (Netzsch, Germany) and QMS 403 D Aeolos MS (Netzsch, Germany). Mass loss measurements were performed from 50 to $1000{ }^{\circ} \mathrm{C}$ with a heating rate of $20{ }^{\circ} \mathrm{C} \mathrm{min}{ }^{-1}$ under both air and nitrogen atmospheres. Isothermal analysis was performed at $250{ }^{\circ} \mathrm{C}$ with a heating rate of $10{ }^{\circ} \mathrm{C} \mathrm{min}^{-1}$ under nitrogen atmosphere.

Streaming current measurements were performed on a SurPASS analyzer (Anton Paar, Austria) equipped with an adjustable gap cell. Poly(PDMS-POSSimide) films were deposited on silicon wafers of $1 \times 2 \mathrm{~cm}^{2}$. The wafers were attached to the adjustable gap cell by double sided adhesive tape (Tesa ${ }^{\circledR} 4965$ ). The pH of the electrolyte solution $(5 \mathrm{mM} \mathrm{KCl})$ was automatically adjusted using $0.1 \mathrm{M} \mathrm{NaOH}$. 
From the streaming current, the zeta potential could be derived using Equation 3.1:

$$
\zeta=\frac{d I}{d P} \cdot \frac{\eta}{\epsilon \cdot \epsilon_{0}} \cdot \frac{L}{A_{\text {channel }}}
$$

where $\zeta$ is the zeta potential, $\frac{\mathrm{d} I}{\mathrm{~d} P}$ is the slope of the streaming current versus pressure, $\eta$ and $\epsilon$ are the viscosity and dielectric constant of the electrolyte, here taken as that of water, $\epsilon_{0}$ is the permittivity of vacuum, $L$ is the length of the streaming channel, and $A_{\text {channel }}$ is the cross sectional area of the channel.

The contact angle of poly(PDMS-POSSimide) films deposited on silicon wafers was measured with an OKA 15 (DataPhysics, Germany) set-up by applying the sessile drop method. A Milli-Q water droplet $(V=1 \mu \mathrm{L})$ was deposited onto the surface and the contact angle was obtained $3 \mathrm{~s}$ after deposition. The average contact angle and $95 \%$ confidence interval were calculated from 5 individual measurements.

Ethanol permeation measurements were performed on a custom-built dead-end permeation setup. A feed vessel was pressurized to 20 bar using ultra pure $\mathrm{N}_{2}$. Permeate streams were measured with a mass balance.

\subsubsection{In-situ spectroscopic ellipsometry}

Thickness and refractive index measurements of films were done with spectroscopic ellipsometry on an M2000X spectroscopic ellipsometer (J.A. Woollam Co.), with focusing probes. In-situ data was recorded at least once every 15 seconds. The data was modeled using the CompleteEase software package (J.A. Woollam Co.) in the wavelength range of $370-1000 \mathrm{~nm}$. The substrate was modeled using the built-in temperature-dependent optical properties of silicon, on top of which a $2 \mathrm{~nm}$ native oxide layer was modeled. The refractive index of the poly(PDMSPOSS) film was modeled at $632.8 \mathrm{~nm}$ wavelength using a Cauchy dispersion (fit parameters: $A, B, k$, and thickness).

The ellipsometry data for imidization was collected with a Linkam heating stage with quartz windows with an incident angle of $70^{\circ}$. The non-imidized films, used for imidization measurements with ellipsometry, were stripped of residual solvents in a furnace at $110{ }^{\circ} \mathrm{C}$ for 20 minutes. The temperature measurements were performed under ultra pure $\mathrm{N}_{2}$ at a flow rate of $100 \mathrm{~mL} \mathrm{~min}{ }^{-1}$. A temperature correction was performed according to the procedure described by Kappert et al. ${ }^{[31]}$ (the difference between set point and actual temperature was less than $1{ }^{\circ} \mathrm{C}$ ). The optical retardance of the windows of the measurement cell was included using calibrated delta off-sets. Prior to heating, the samples were flushed at $25{ }^{\circ} \mathrm{C}$ under $\mathrm{N}_{2}$ flow for 30 minutes. Then, the samples were heated to $250{ }^{\circ} \mathrm{C}$ at $5{ }^{\circ} \mathrm{C} \mathrm{min}{ }^{-1}$ and remained at $250{ }^{\circ} \mathrm{C}$ for 20 minutes. The samples were cooled down with a cooling rate of $20^{\circ} \mathrm{C} \mathrm{min}^{-1}$. 
The relative thickness $\left(d_{\text {relative }}\right)$ at any point in time during the heat stage measurements was calculated using Equation 3.2.

$$
d_{\text {relative }}=\frac{d_{t}}{d_{0}}
$$

Where $d_{0}$ and $d_{t}$ are the thicknesses of the film at the starting time $(t=0)$ or at a certain point in time $(t=t)$, respectively. The relative refractive index was obtained similarly from the refractive index at the starting time and at a certain point of time for the heat stage measurements.

Swelling measurements by spectroscopic ellipsometry were performed with a custom-built Teflon liquid flow cell with quartz windows with an incident angle of $70^{\circ}$. The cell volume was $25.5 \mathrm{~cm}^{3}$. The cell temperature was controlled with an external water bath (LAUDA-Brinkmann, LP.), allowing water at $25{ }^{\circ} \mathrm{C}$ to flow through the outer walls of the cell. The optical retardance of the windows of the measurement cell was corrected for using calibrated delta offsets. The solvent vapor flow was generated using two identical bubblers in series, both at $25{ }^{\circ} \mathrm{C}$. The carrier gas was a ultra pure $\mathrm{N}_{2}$ gas, with a gas flow of $100 \mathrm{~mL} \mathrm{~min}{ }^{-1}$. The dry sample thickness and refractive index were based on the last ten data points before the solvent vapor was introduced into the cell.

The swelling degree (SD) of a polymer film upon swelling in solvents was calculated using Equation 3.3.

$$
\mathrm{SD}=\left(\frac{d_{\text {swollen }}}{d_{\text {dry }}}-1\right) \cdot 100 \%
$$

Where $d_{\text {dry }}$ and $d_{\text {swollen }}$ are the dry and swollen thickness of the film, respectively. The normalized refractive index upon swelling in solvents was calculated using Equation 3.4.

$$
\eta_{\text {norm }}=\frac{\eta_{\text {swollen }}-\eta_{\text {solvent }}}{\eta_{\text {dry }}-\eta_{\text {solvent }}}
$$

Where $\eta_{\text {norm }}$ is the normalized refractive index, $\eta_{\text {dry }}$ is the refractive index of the unswollen polymer film, $\eta_{\text {swollen }}$ is the refractive index of the swollen polymer film in a solvent, and $\eta_{\text {solvent }}$ is the refractive index of the pure solvent.

The poly(PDMS-POSSimide) films show a significant spread in the refractive index, that can originate from the preparation of the films on a silicon wafer. The preparation involves a free standing film that is deposited onto the silicon wafer by decanting the solutions. As a result, an inhomogeneous thin film was deposited 
onto the wafer, with different thicknesses and refractive indices, depending on the local reaction time. As a result of the inhomogeneity of the poly(PDMSPOSSimide) films, the refractive index is considered to be less reliable. The behavior of the refractive index is, however, given in the supplementary information.

The apparent solvent activity in the cell was determined by assuming the solvent cell as a continuous ideally stirred tank reactor (CISTR), with the boundary condition at time $t=0$, the apparent activity $a$ is 0 and the activity of the in-going stream equal to 1 . As a consequence, $\lim _{t \rightarrow \infty} a(t)=1$. The apparent solvent activity at time $t$ can be calculated using Equation 3.5.

$$
a=1-\exp \left(-\frac{t}{\tau}\right)
$$

Where $a$ is the apparent solvent activity, and $\tau$ is the residence time which can be determined as:

$$
\tau=\frac{V_{\text {cell }}}{\Phi_{\text {gas }}}
$$

where $V_{\text {cell }}$ is the volume of the cell $\left(25.5 \mathrm{~cm}^{3}\right)$, and $\Phi_{\text {gas }}$ is the flow of the solvent vapor into the cell.

\subsection{Results and discussion}

\subsubsection{Imidization of poly(PDMS-POSSamic acid)}

The imidization of poly(PDMS-POSSamic acid) to poly(PDMS-POSSimide) is an important step to ensure stability of the material against hydrolysis. Poly(PDMSPOSSamic acid) powder has been thermally treated during a thermogravimetric analysis combined with mass spectroscopy (TGA-MS) to study the onset of imidization and the stability of the material during thermal treatment. Figure 3.2 shows the mass loss as function of temperature (top graph) and the corresponding gases evolved (bottom graph). During imidization, the amic acid ring is closed while water is eliminated (Figure 3.1). Thus the onset of imidization can be determined from the $m / z=18$ MS signal.

From Figure 3.2 it can be concluded that the imidization of this poly(PDMSPOSSamic acid) starts at $150{ }^{\circ} \mathrm{C}$, with a peak in water release at $195{ }^{\circ} \mathrm{C}$. Above $250{ }^{\circ} \mathrm{C}$ no more water is released, indicating that the imidization is finished at this temperature. The most significant mass loss and the release of decomposition products (e.g. $\mathrm{CO}_{2}, \mathrm{CH}_{4}$, and $\mathrm{NO}$ ) starts at temperatures above $400{ }^{\circ} \mathrm{C}$, indicating the excellent thermal stability of the poly(PDMS-POSSimide) material. 


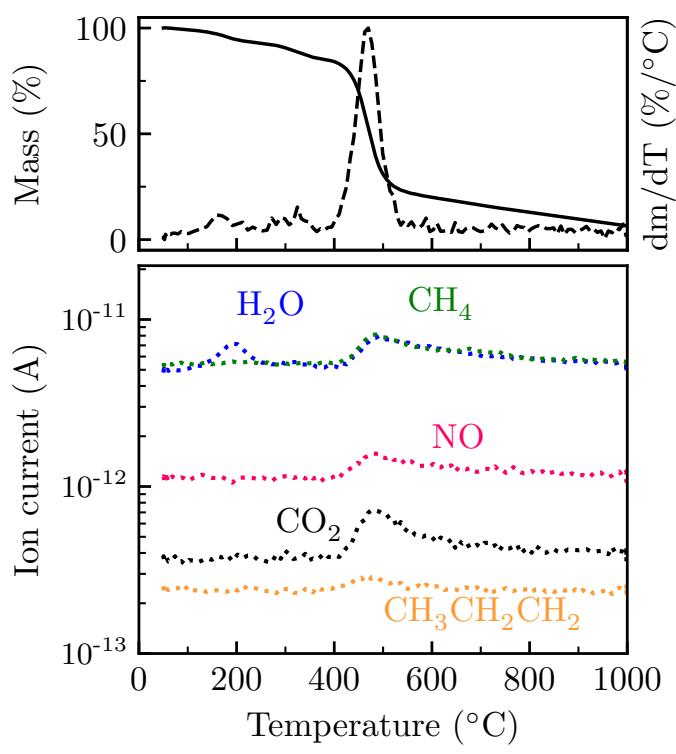

Figure 3.2: Combined TGA-MS analysis under nitrogen atmosphere of poly(PDMSPOSSamic acid) powder. The top graph shows the mass loss as function of temperature. The bottom graph shows the evolved gases during heating. The following gases are traced: $\mathrm{CH}_{4}(m / z=15$, green, -$), \mathrm{H}_{2} \mathrm{O}(\mathrm{m} / z=18$, blue, -$), \mathrm{NO}(\mathrm{m} / z=30$, pink, -$), \mathrm{CH}_{3} \mathrm{CH}_{2} \mathrm{CH}_{2}$ $(m / z=43$, orange, -$)$, and $\mathrm{CO}_{2}(m / z=44$, black, -$)$.

Figure 3.3 shows the infrared spectrum of poly(PDMS-POSS) powder before (bottom) and after (top) the imidization step. Sharp absorbance peaks at $795 \mathrm{~cm}^{-1}$ and $1260 \mathrm{~cm}^{-1}$ can be observed in both spectra, indicating the presence of $\mathrm{Si}-\mathrm{CH}_{3}$ bonds, and thus the presence of PDMS. Absorbance peaks at $1015 \mathrm{~cm}^{-1}$ and $1080 \mathrm{~cm}^{-1}$ can be attributed to the asymmetric stretching of $\mathrm{Si}-\mathrm{O}-\mathrm{Si}$, a bond that is present in both PDMS and in POSS.

The spectrum of the poly(PDMS-POSSamic acid) shows peaks at $1640 \mathrm{~cm}^{-1}$ and $1530 \mathrm{~cm}^{-1}$, which are assigned to the $\mathrm{N}-\mathrm{H}$ bending and $\mathrm{C}=\mathrm{O}$ stretching of the amic acid, respectively. These peaks vanish after the thermal treatment, indicating the conversion of amic acid bonds into imide bonds. Peaks at $1700 \mathrm{~cm}^{-1}$ and $1670 \mathrm{~cm}^{-1}$ appear after this thermal treatment. These peaks are assigned to the $\mathrm{C}=\mathrm{O}$ symmetric and asymmetric stretching present in the poly(PDMSPOSSimide). In addition, a small peak at $1780 \mathrm{~cm}^{-1}$ can be observed in the spectrum of the poly(PDMS-POSSimide). This peak can be attributed to a small fraction of isoimide bonds formed during imidization. 


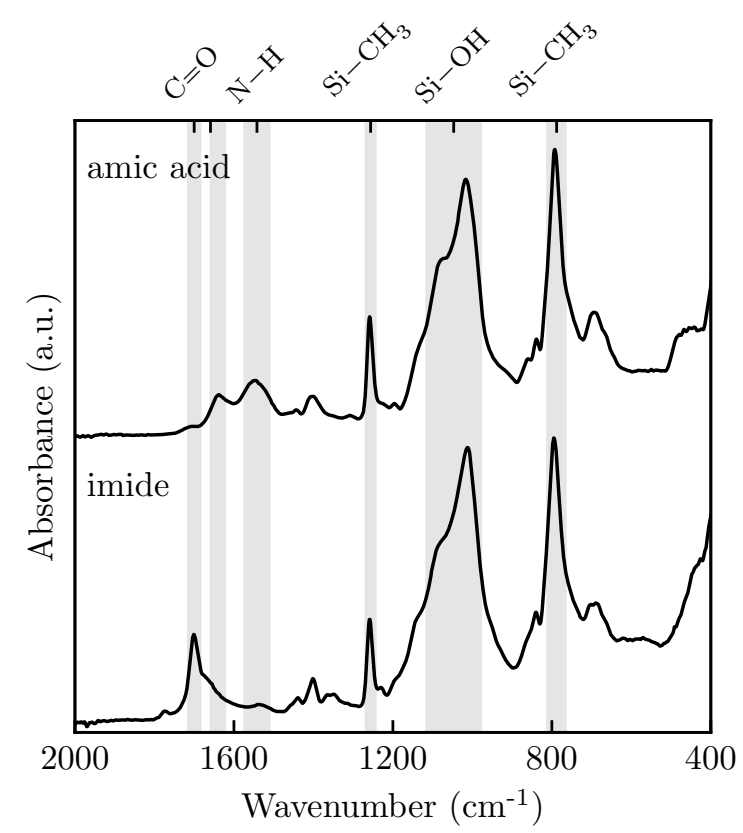

Figure 3.3: ATR-FTIR spectra of poly(PDMS-POSSamic acid) (bottom) and the corresponding poly(PDMS-POSSimide) (top). The characteristic amic acid absorbance peaks have been replaced by characteristic imide absorbance peaks upon thermal imidization. The absorbance peaks characteristic for both PDMS and POSS (i.e., absorbance peaks caused by $\mathrm{Si}-\mathrm{O}-\mathrm{Si}$ and $\mathrm{Si}-\mathrm{CH}_{3}$ bonds) stayed unchanged, indicating the thermal stability of the network during the thermal treatment.

In addition to the TGA-MS experiments, the imidization process of a thin poly(PDMS-POSSamic acid) film has been studied by spectroscopic ellipsometry. Figure 3.4 shows the relative thickness $(a, b)$ and relative refractive index $(\mathrm{c}, \mathrm{d})$ as a function of temperature and time. Three regimes can be distinguished when looking at the thickness of the film during the heating phase. First, a small decrease in film thickness is observed at temperatures up to $50{ }^{\circ} \mathrm{C}$. This decrease can be attributed to the drying of the film, and thus the release of physically bound water. The second stage is characterized by a plateau in the film thickness. At this stage the thermal expansion of the film more or less equals the mass loss due to the release of water. However, the refractive index decreases at this stage, indicating a change in chemical composition of the material. The last stage can be defined as the onset of imidization, starting from $180{ }^{\circ} \mathrm{C}$ with a significant decrease in film thickness. This decrease can be attributed to reorganization of the polymer network, while the decrease in index can be attributed to the conversion of the amic acid groups into imide groups ${ }^{[32]}$. 
At the isothermal stage (Figure 3.4b,d) both the thickness and refractive index keep decreasing over time. Since there is no more thermal expansion of the material, the decrease in both thickness and refractive index is attributed to the continuing imidization. During the imidization, progressively less amic acid groups remain, and thereby the decrease in thickness levels off.
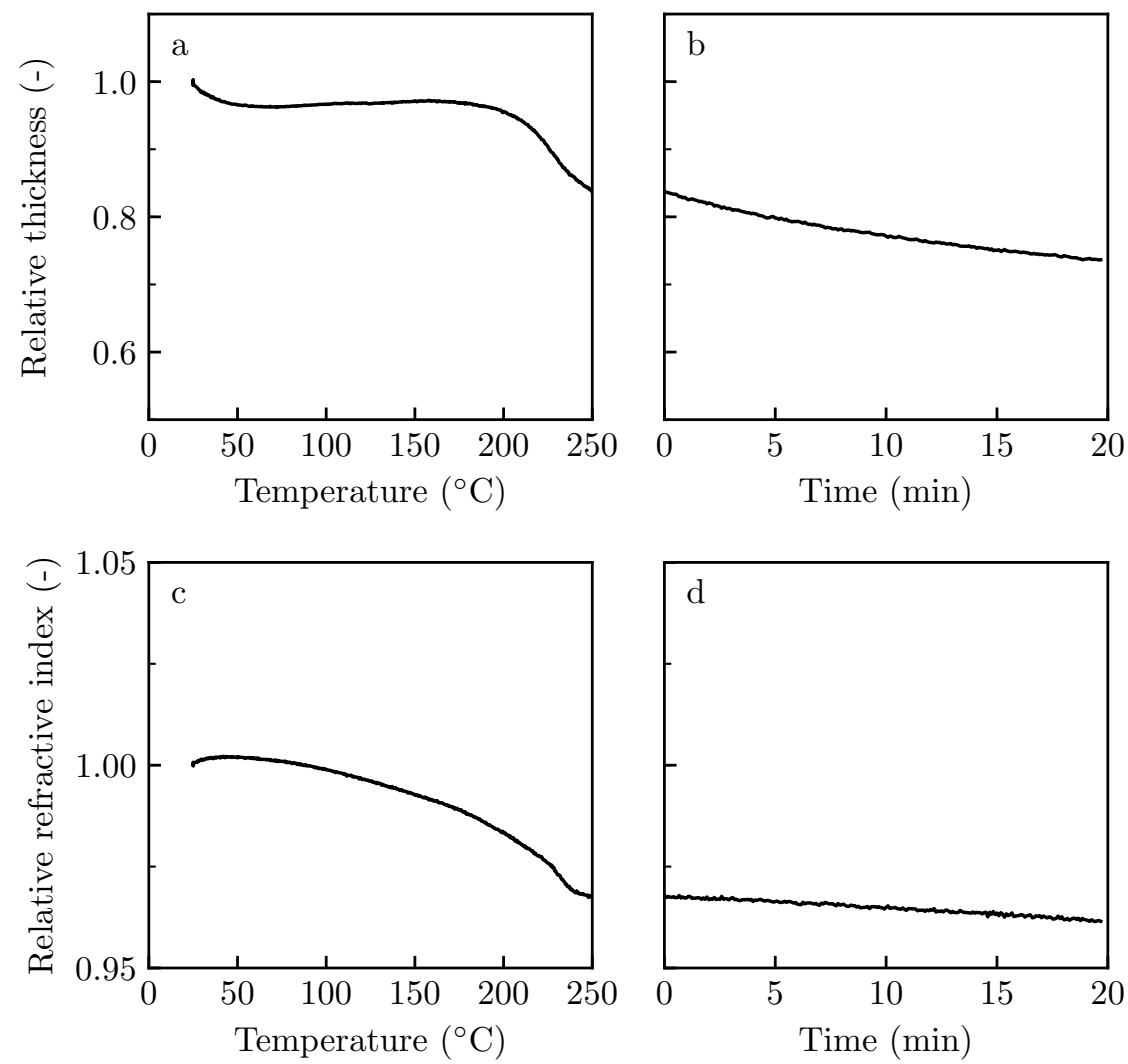

Figure 3.4: The relative thickness and refractive index of poly(PDMS-POSSamic acid) films during imidization studied by spectroscopic ellipsometry. (a) The relative thickness during heating to $250{ }^{\circ} \mathrm{C}$ as function of temperature. (b) The relative thickness during the isothermal stage as function of time. (c) The relative refractive index during heating to $250{ }^{\circ} \mathrm{C}$ as function of temperature. (d) The relative refractive index during the isothermal stage as function of time. 


\subsubsection{Swelling in organic solvents}

In this work we have studied the swelling of both conventional PDMS films and poly(PDMS-POSSimide) films, in $n$-hexane, ethyl acetate, and ethanol vapors. Figure 3.5 shows the swelling behavior of a conventional PDMS film as function of the "apparent solvent activity". The extent of solvent induced swelling of a PDMS film is correlated to the affinity of the PDMS chains for the solvent. The conventional PDMS film has the highest swelling degree for $n$-hexane, with a stable value reached at $72 \%$. The second highest swelling degree is observed for ethyl acetate $(25 \%)$, and the lowest for ethanol $(3 \%)$. This order of the swelling degrees correspond well with the affinity of PDMS for organic solvents, based on Hildebrand solubility parameters (see Table 3.1), and the shape of the isotherms is consistent with the Flory-Huggins theory. The absolute magnitude of swelling is substantially lower for the swelling in vapors than for the pure liquid solvents ${ }^{[33-35]}$. This indicates that in our experimental method the $\mathrm{N}_{2}$ stream is not completely saturated with the vapor. The use of vapors rather than liquids allows for a higher optical contrast; highly swollen films have a refractive index that is relatively similar to that of the liquid ambient, whereas for vapors the ambient refractive index remains close to unity. A drawback of the use of vapors is that the quantitative control of the activity is generally less accurate, while in particular close to an activity of one the extent of swelling is a strong function of the activity. Moreover, for ethyl acetate the swelling monotonically increases with time over a period of more than
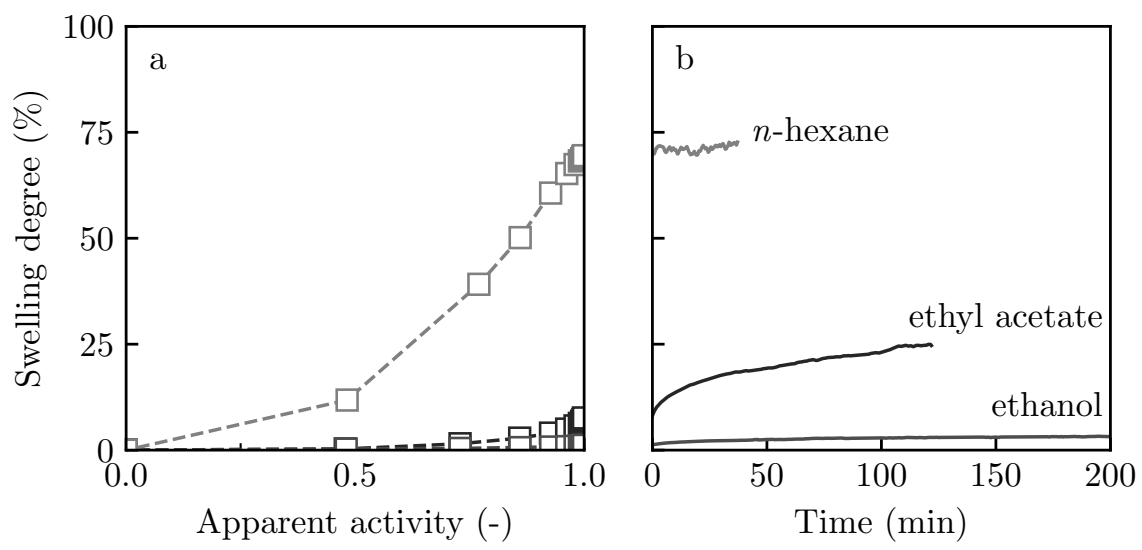

Figure 3.5: (a) The swelling degree of pure PDMS as a function of solvent vapor activity in the cell. (b) The swelling degree as function of time at an apparent activity of 1 . The swelling degree of PDMS is the highest for $n$-hexane $(72 \%)$, followed by ethyl acetate $(25 \%)$, and ethanol $(3 \%)$. 
Table 3.1: Solubility parameters of the solvents used in this study, the solubility parameter of PDMS is $7.3 \mathrm{cal}^{1 / 2} \mathrm{~cm}^{-3 / 2[35]}$.

\begin{tabular}{ll}
\hline Solvent & $\delta\left(\mathrm{cal}^{1 / 2} \mathrm{~cm}^{-3 / 2}\right)$ \\
\hline$n$-hexane & 7.3 \\
ethyl acetate & 9.0 \\
ethanol & 12.7 \\
\hline
\end{tabular}

an hour. The dynamics of swelling of the rubbery PDMS by organic solvents are very fast as compared to the time-scale of this increase in swelling, indicating that for the ethyl acetate measurement the apparent activity of the vapor in the cell only slowly increases in time.

The poly(PDMS-POSSimide) films show much less swelling as compared to conventional PDMS for $n$-hexane and ethyl acetate (Figure 3.6a-d). Surprisingly, the most polar solvent ethanol swells the poly(PDMS-POSSimide) films much more that the least polar solvent $n$-hexane (Figure 3.6e-f). In addition, all poly(PDMSPOSSimide) films show a similar trend with respect to the value of the refractive index of the dry films, which get more pronounced with solvent polarity. A lower refractive index corresponds to more extensive swelling, and therefore a lower refractive index indicates a lower cross-link density, and thus more unreacted functional groups of the POSS cages.

Poly(PDMS-POSSimide)s films show a stable swelling degree of $4-6 \%$ in $n$-hexane, where the swelling is correlated to the refractive index of the film. This swelling degree is approximately fifteen times lower compared to that of the conventional PDMS. This can be caused by the successful cross-linking of the PDMS chains, as well as by the reduced affinity for $n$-hexane due to the inclusion of the POSS molecules.

The swelling degree of poly(PDMS-POSSimide) films in ethyl acetate $(3-7 \%)$ is comparable to that obtained for $n$-hexane. This swelling degree is approximately 5 times lower compared to that of conventional PDMS in ethyl acetate. In addition, the correlation of the swelling degree to the refractive index of the poly(PDMSPOSSimide) film is more strongly confirmed as compared to swelling in $n$-hexane.

The effect of refractive index of the poly(PDMS-POSSimide) film on swelling degree is even more pronounced when the films were swollen in ethanol. Where PDMS showed a swelling degree of $3 \%$, the swelling degree of poly(PDMSPOSSimide) films varied from $4-12 \%$, with again the highest swelling degree for the lowest refractive index, and thus lowest cross-link density. This higher swelling degree, and more pronounced effect of refractive index can be related to the affinity of the poly(PDMS-POSSimide) matrix to the solvent. 

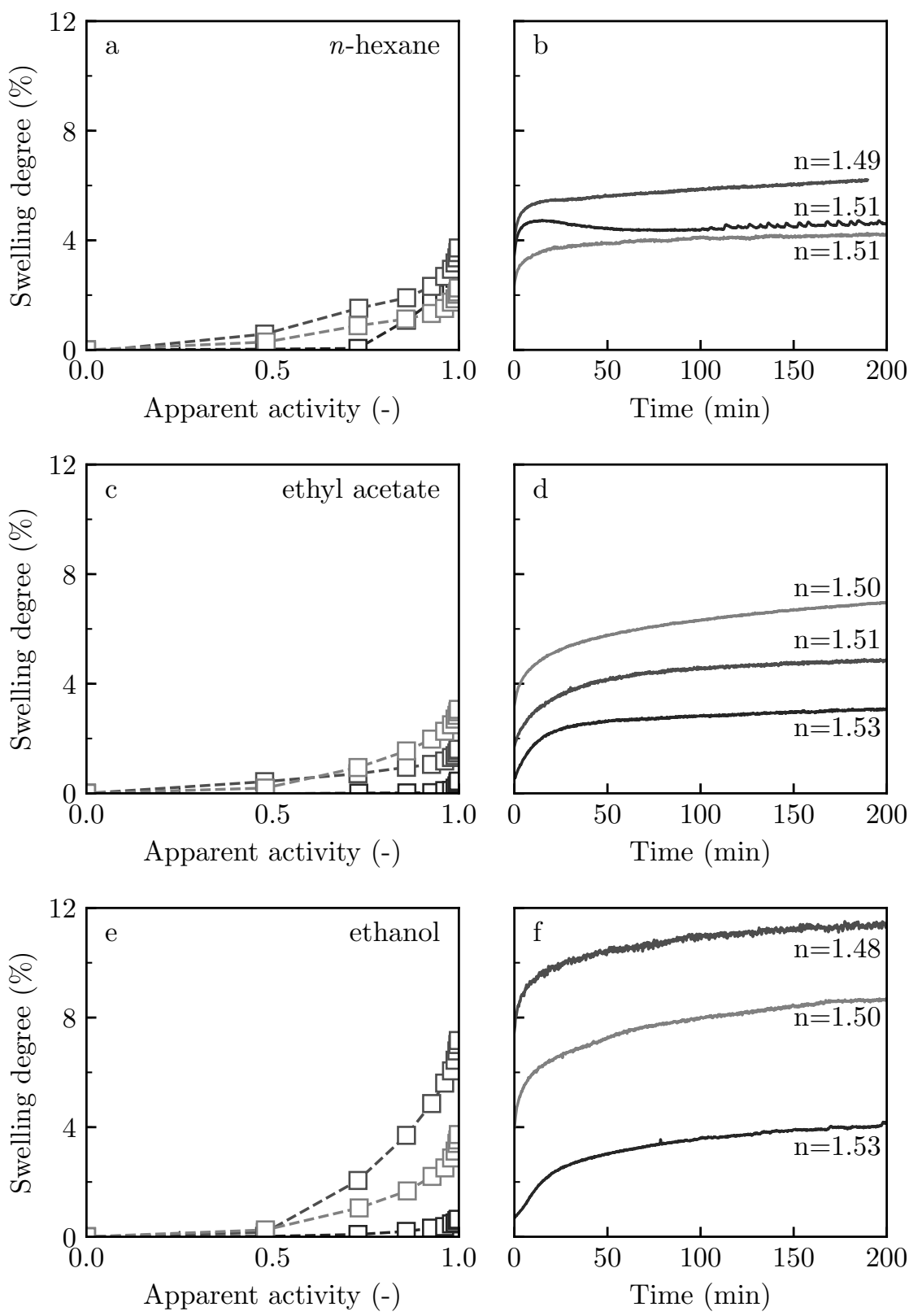

Figure 3.6: The swelling degree of poly(PDMS-POSSimide) films measured by spectroscopic ellipsometry for $(a, b) n$-hexane, (c,d) ethyl acetate, and (e,f) ethanol vapors. $(a, c, e)$ The swelling degree as function of the apparent solvent vapor activity in the cell, and $(b, d, f)$ the swelling degree as function of time at an apparent activity of one. For every solvent, three different samples with varying refractive indices were measured. 
The PDMS chains are cross-linked by POSS containing ammonium side-groups. These side-groups are partially deprotonated towards the reactive free amine groups prior to interfacial polymerization. However, only 3-4 ammonium groups are converted at the $\mathrm{pH}$ of the aqueous solution $(\mathrm{pH}=9.5)$, and thus POSS is a positively charged monomer at these conditions. Figure 3.7 shows the zeta potential of a poly(PDMS-POSSimide) film supported on a silicon wafer, proving the positive charge of the poly(PDMS-POSSimide) film at neutral $\mathrm{pH}$. Therefore, the higher swelling degree of poly(PDMS-POSSimide) films in ethanol could be explained by the presence of positively charged ammonium groups. Despite the positively charged surface, the poly(PDMS-POSSimide) films show to have an average contact angle of $110^{\circ} \pm 6^{\circ}$ and can therefore be considered as hydrophobic.

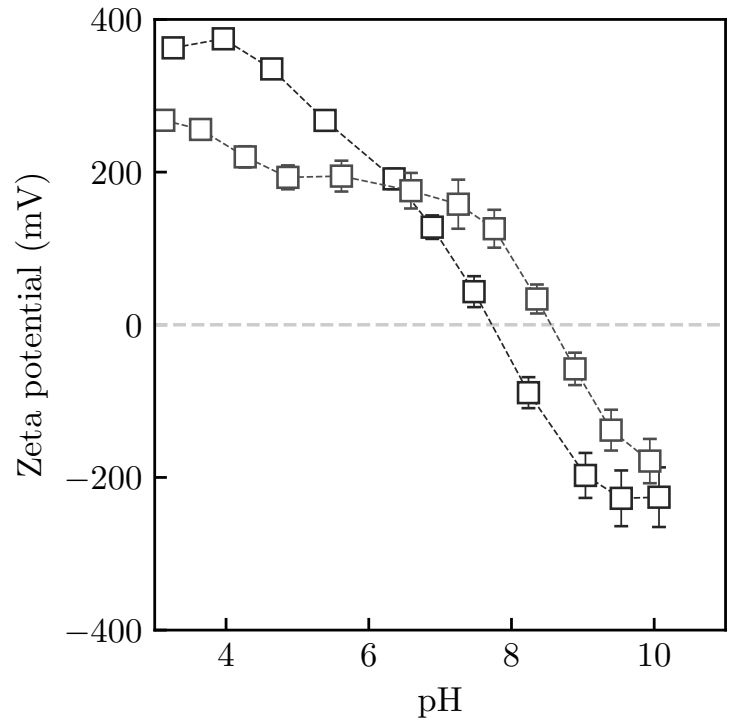

Figure 3.7: Zeta potential of poly(PDMS-POSSimide) films supported by silicon wafers, measured in duplicate. 


\subsubsection{Barrier properties}

poly(PDMS-POSSimide) films were prepared by interfacial polymerization on top of $\gamma$-alumina coated porous $\alpha$-alumina supports. The use of these ceramic supports allow for the imidization at $250{ }^{\circ} \mathrm{C}$. Due to the hydrophilic nature of the support, only polar solvents will be permeating through the support. Clean ethanol fluxes were measured for three separate membranes in dead-end mode at 20 bar transmembrane pressure for at least 27 hours. All membranes showed almost no permeation, with ethanol permeances between 0.004 and $0.011 \mathrm{~L} \mathrm{~m}^{-2} \mathrm{~h}^{-1}$ bar- $^{-1}$ (Figure 3.8), which is surprising regarding the substantial swelling in ethanol observed for films with a lower cross-linking degree. The extremely low ethanol permeance of the poly(PDMS-POSSimide) membrane could be explained by a combination of a high cross-link density, and the relatively short PDMS oligomer used $\left(\mathrm{M}_{\mathrm{n}} \approx 900 \mathrm{~g} \mathrm{~mol}^{-1}\right.$ as determined by $\left.{ }^{1} \mathrm{H}-\mathrm{NMR}\right)$. The low permeance of these poly(PDMS-POSSimide) films could be of benefit when applied in microfluidic devices.

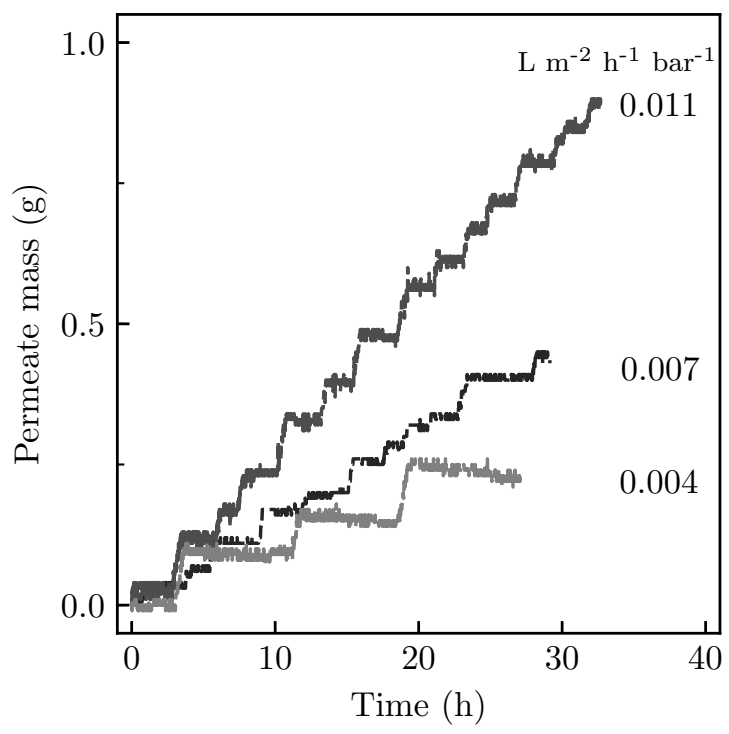

Figure 3.8: The permeate mass increase during ethanol permeation at 20 bar in dead-end mode. The steps are caused by dripping of the permeate onto the mass balance. 


\subsection{Conclusion}

Here, we showed the preparation of hyper-cross-linked poly(PDMS-POSSimide) films. Swelling measurements in $n$-hexane, ethyl acetate and ethanol vapors show that the presence of the hybrid cross-links restricts the swelling of poly(PDMSPOSSimide) films in $n$-hexane and ethyl acetate significantly as compared to conventional PDMS. A $\sim 15$ fold decrease in swelling in $n$-hexane vapor, and a $\sim 5$ fold decrease in ethyl acetate vapor was observed for these poly(PDMS-POSSimide) films. The presence of unreacted positively charged ammonium groups promote a slightly higher swelling of poly(PDMS-POSSimide) films in ethanol compared to PDMS (similar up to a 4 fold increase). In general, the swelling of these hypercross-linked poly(PDMS-POSSimide) films is limited to less than $12 \%$, showing that these films are stable in a wide variety of solvents.

Despite the substantial swelling in ethanol, poly(PDMS-POSSimide) films did not show ethanol permeance $\left(<0.1 \mathrm{~L} \mathrm{~m}^{-2} \mathrm{~h}^{-1} \mathrm{bar}^{-1}\right)$. This low permeance can be attributed to a combination of a high cross-linking degree and the relatively short PDMS oligomer used.

\subsection{Acknowledgements}

This work took place within the framework of the Institute for Sustainable Process Technology (ISPT, project BL-20-02) and the research program TA-ISPT Fundamentals with project number 731.014.203, which is (partly) financed by the Netherlands Organization for Scientific Research (NWO). 


\subsection{References}

[1] Esteves, A.; Brokken-Zijp, J.; Laven, J.; Huinink, H.; Reuvers, N.; Van, M.; de With, G. Influence of cross-linker concentration on the cross-linking of PDMS and the network structures formed. Polymer 2009, 50, 3955 - 3966.

[2] Sia, S. K.; Whitesides, G. M. Microfluidic devices fabricated in Poly(dimethylsiloxane) for biological studies. ELECTROPHORESIS 2003, 24, 3563-3576.

[3] Firpo, G.; Angeli, E.; Repetto, L.; Valbusa, U. Permeability thickness dependence of polydimethylsiloxane (PDMS) membranes. Journal of Membrane Science 2015, 481, 1 - 8.

[4] Werber, A.; Zappe, H. Tunable microfluidic microlenses. Appl. Opt. 2005, 44, 3238-3245.

[5] Shih, T.-K.; Chen, C.-F.; Ho, J.-R.; Chuang, F.-T. Fabrication of PDMS (polydimethylsiloxane) microlens and diffuser using replica molding. Microelectronic Engineering 2006, 83, 2499 - 2503, Materials for Advanced Metallization (MAM 2006).

[6] Zeng, X.; Jiang, H. Polydimethylsiloxane Microlens Arrays Fabricated Through LiquidPhase Photopolymerization and Molding. Journal of Microelectromechanical Systems 2008, 17, 1210-1217.

[7] Unger, M. A.; Chou, H.-P.; Thorsen, T.; Scherer, A.; Quake, S. R. Monolithic Microfabricated Valves and Pumps by Multilayer Soft Lithography. Science 2000, 288, 113-116.

[8] Sugiura, Y.; Hirama, H.; Torii, T. Fabrication of Microfluidic Valves Using a Hydrogel Molding Method. Scientific Reports 2015, 5, 13375 EP -.

[9] Tung, Y.-C.; Kurabayashi, K. A single-layer PDMS-on-silicon hybrid microactuator with multi-axis out-of-plane motion capabilities-Part i: design and analysis. Journal of Microelectromechanical Systems 2005, 14, 548-557.

[10] Rosset, S.; Niklaus, M.; Dubois, P.; Shea, H. R. Large-Stroke Dielectric Elastomer Actuators With Ion-Implanted Electrodes. Journal of Microelectromechanical Systems 2009, 18, 1300-1308.

[11] Vandezande, P.; Gevers, L. E. M.; Vankelecom, I. F. J. Solvent resistant nanofiltration: separating on a molecular level. Chem. Soc. Rev. 2008, 37, 365-405.

[12] Vanherck, K.; Aerts, A.; Martens, J.; Vankelecom, I. Hollow filler based mixed matrix membranes. Chem. Commun. 2010, 46, 2492-2494.

[13] Rezakazemi, M.; Vatani, A.; Mohammadi, T. Synergistic interactions between POSS and fumed silica and their effect on the properties of crosslinked PDMS nanocomposite membranes. RSC Adv. 2015, 5, 82460-82470.

[14] Gevers, L. E. M.; Vankelecom, I. F. J.; Jacobs, P. A. Zeolite filled polydimethylsiloxane (PDMS) as an improved membrane for solvent-resistant nanofiltration (SRNF). Chem. Commun. 2005, 2500-2502.

[15] Xue, C.; Du, G.-Q.; Chen, L.-J.; Ren, J.-G.; Sun, J.-X.; Bai, F.-W.; Yang, S.-T. A carbon nanotube filled polydimethylsiloxane hybrid membrane for enhanced butanol recovery. Scientific Reports 2014, 4, $5925 \mathrm{EP}-$.

[16] Azimi, H.; Tezel, F. H.; Thibault, J. Effect of embedded activated carbon nanoparticles on the performance of polydimethylsiloxane (PDMS) membrane for pervaporation separation of butanol. Journal of Chemical Technology \& Biotechnology 2017, 92, 2901-2911.

[17] Kickelbick, G. Concepts for the incorporation of inorganic building blocks into organic polymers on a nanoscale. Progress in Polymer Science 2003, 28, 83 - 114.

[18] Cordes, D. B.; Lickiss, P. D.; Rataboul, F. Recent Developments in the Chemistry of Cubic Polyhedral Oligosilsesquioxanes. Chemical Reviews 2010, 110, 2081-2173, PMID: 20225901.

[19] Shi, Y.; Gao, X.; Zhang, D.; Liu, Y.; Huang, G. Synthesis and thermal properties of modified room temperature vulcanized (RTV) silicone rubber using polyhedral oligomeric silsesquioxane (POSS) as a cross linking agent. $R S C A d v \mathbf{2 0 1 4}$, 4, 41453-41460.

[20] Madhavan, K.; Reddy, B. Structure-gas transport property relationships of 
poly(dimethylsiloxane-urethane) nanocomposite membranes. Journal of Membrane Science 2009, 342, $291-299$.

[21] Chen, D.; Huang, C.; Hu, X. Preparation and characterization of novel polydimethylsiloxane composites used POSS as cross-linker and fumed silica as reinforcing filler. Polymer Composites 2013, 34, 1041-1050.

[22] Chen, D.; Liu, Y.; Zhang, H.; Zhou, Y.; Huang, C.; Xiong, C. Influence of Polyhedral Oligomeric Silsesquioxanes (POSS) on Thermal and Mechanical Properties of Polydimethylsiloxane (PDMS) Composites Filled with Fumed Silica. Journal of Inorganic and Organometallic Polymers and Materials 2013, 23, 1375-1382.

[23] Baumann, T. F.; Jones, T. V.; Wilson, T.; Saab, A. P.; Maxwell, R. S. Synthesis and characterization of novel PDMS nanocomposites using POSS derivatives as cross-linking filler. Journal of Polymer Science Part A: Polymer Chemistry 2009, 47, 2589-2596.

[24] chao Huang, J.; bin He, C.; Xiao, Y.; Mya, K. Y.; Dai, J.; Siow, Y. P. Polyimide/POSS nanocomposites: interfacial interaction, thermal properties and mechanical properties. Polymer 2003, 44, 4491 - 4499.

[25] Marchetti, P.; Jimenez Solomon, M. F.; Szekely, G.; Livingston, A. G. Molecular Separation with Organic Solvent Nanofiltration: A Critical Review. Chemical Reviews 2014, 114, 10735-10806, PMID: 25333504.

[26] Lau, W.; Ismail, A.; Misdan, N.; Kassim, M. A recent progress in thin film composite membrane: A review. Desalination 2012, 287, 190 - 199, Special Issue in honour of Professor Takeshi Matsuura on his 75th Birthday.

[27] Raaijmakers, M. J.; Benes, N. E. Current trends in interfacial polymerization chemistry. Progress in Polymer Science 2016, 63, 86 - 142.

[28] Dalwani, M.; Zheng, J.; Hempenius, M.; Raaijmakers, M. J. T.; Doherty, C. M.; Hill, A. J.; Wessling, M.; Benes, N. E. Ultra-thin hybrid polyhedral silsesquioxane-polyamide films with potentially unlimited 2D dimensions. J. Mater. Chem. 2012, 22, 14835-14838.

[29] Duan, J.; Litwiller, E.; Pinnau, I. Preparation and water desalination properties of POSSpolyamide nanocomposite reverse osmosis membranes. Journal of Membrane Science $\mathbf{2 0 1 5}$, 473, $157-164$.

[30] Raaijmakers, M. J. T.; Hempenius, M. A.; Schön, P. M.; Vancso, G. J.; Nijmeijer, A.; Wessling, M.; Benes, N. E. Sieving of Hot Gases by Hyper-Cross-Linked NanoscaleHybrid Membranes. Journal of the American Chemical Society 2014, 136, 330-335, PMID: 24308639.

[31] Kappert, E. J.; Raaijmakers, M. J.; Ogieglo, W.; Nijmeijer, A.; Huiskes, C.; Benes, N. E. Temperature calibration procedure for thin film substrates for thermo-ellipsometric analysis using melting point standards. Thermochimica Acta 2015, 601, 29 - 32.

[32] Raaijmakers, M. J. T.; Kappert, E. J.; Nijmeijer, A.; Benes, N. E. Thermal Imidization Kinetics of Ultrathin Films of Hybrid Poly(POSS-imide)s. Macromolecules 2015, 48, 30313039.

[33] Stafie, N.; Stamatialis, D.; Wessling, M. Effect of $\{$ PDMS $\}$ cross-linking degree on the permeation performance of PAN/PDMS composite nanofiltration membranes. Separation and Purification Technology 2005, 45, 220 - 231.

[34] Rumens, C. V.; Ziai, M. A.; Belsey, K. E.; Batchelor, J. C.; Holder, S. J. Swelling of PDMS networks in solvent vapours; applications for passive RFID wireless sensors. J. Mater. Chem. C 2015, 3, 10091-10098.

[35] Lee, J. N.; Park, C.; Whitesides, G. M. Solvent Compatibility of Poly(dimethylsiloxane)Based Microfluidic Devices. Analytical Chemistry 2003, 75, 6544-6554, PMID: 14640726.

[36] Camino, G.; Lomakin, S.; Lazzari, M. Polydimethylsiloxane thermal degradation Part 1. Kinetic aspects. Polymer 2001, 42, $2395-2402$.

[37] Camino, G.; Lomakin, S.; Lageard, M. Thermal polydimethylsiloxane degradation. Part 2. The degradation mechanisms. Polymer 2002, 43, $2011-2015$. 


\subsection{Supplementary information}

\subsubsection{Synthesis of poly(PDMS-POSSimide) networks}

Ultra-thin poly(PDMS-POSSimide) films were made by the interfacial polymerization of octaAmmonium POSS and succinic anhydride terminated PDMS. To partially activate the eight available ammonium groups, the POSS was treated with sodium hydroxide. The number of converted ammonium groups to primary amine groups depends on the amount of sodium hydroxide added, and is thus dependent on the $\mathrm{pH}$ of the aqueous solution. Dalwani et al. ${ }^{[28]}$ showed that below $\mathrm{pH} 7$ there is no significant conversion of ammonium groups. With increasing $\mathrm{pH}$, the number of converted ammonium groups increases. At a $\mathrm{pH}$ value of 9-10, about 4 to 5 amine groups have been formed. At increasing $\mathrm{pH}$ simultaneous hydrolysis of the $\mathrm{Si}-\mathrm{O}-\mathrm{Si}$ bonds occurs.

Figure 3.9 shows FTIR spectra of poly(PDMS-POSSamic acid) powders from $1800 \mathrm{~cm}^{-1}$ to $1400 \mathrm{~cm}^{-1}$. All spectra are normalized to the absorbance peak at $1530 \mathrm{~cm}^{-1}$. Poly(PDMS-POSSamic acid) powders were prepared with various $\mathrm{pH}$ values of the aqueous solution. The absorbance peaks of the $\mathrm{N}-\mathrm{H}$ bending and $\mathrm{C}=\mathrm{O}$ stretching, originating from the amic acid bonds, can be clearly distinguished at $1640 \mathrm{~cm}^{-1}$ and $1530 \mathrm{~cm}^{-1}$, respectively. In addition to these characteristic amic acid peaks, a small absorbance peak, of which the magnitude is dependent on the

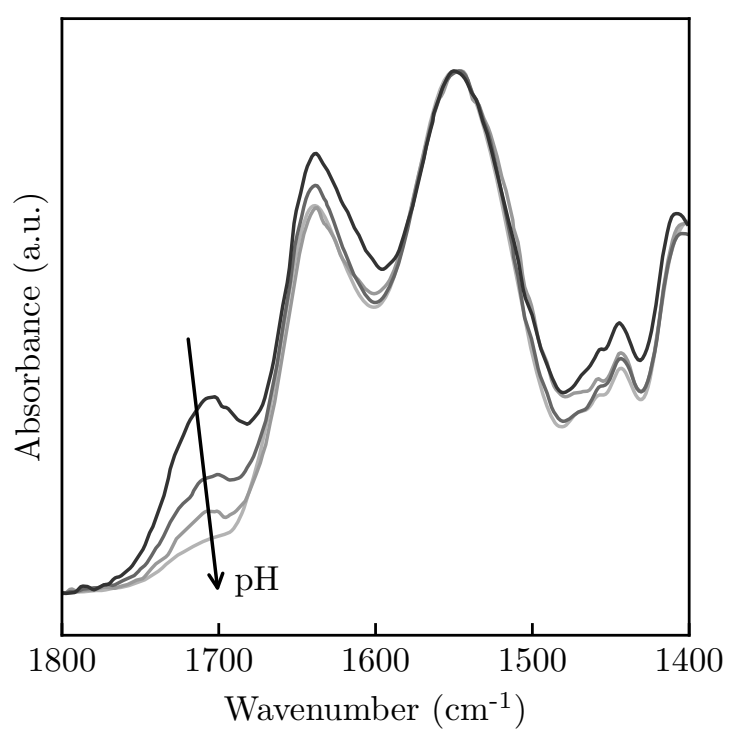

Figure 3.9: ATR-FTIR spectra for poly(PDMS-POSSamic acid) powders from $1800 \mathrm{~cm}^{-1}$ to $1400 \mathrm{~cm}^{-1}$. The $\mathrm{pH}$ of the aqueous solution was varied from $\mathrm{pH} 8.3$ to 9.5 . 
synthesis $\mathrm{pH}$, appears at $1705 \mathrm{~cm}^{-1}$. This peak can be assigned to the $\mathrm{C}=\mathrm{O}$ stretching of a carboxylic acid. This carboxylic acid can be formed by the reaction of a succinic anhydride group with water. A relatively high amount of these carboxylic acid groups is present at a "low" $\mathrm{pH}(\mathrm{pH}$ 8.3), while a "high" $\mathrm{pH}(\mathrm{pH}$ 9.5) results in almost none of these carboxylic acid groups. This corresponds perfectly well to the amount of available reactive amine groups at a certain $\mathrm{pH}$. To conclude, a "low" $\mathrm{pH}$ of the aqueous phase results in relatively few reactive amine groups, and thus a high amount of unreacted succinic anhydride groups that eventually convert into carboxylic acid groups.

\subsubsection{Thermogravimetric analysis of poly(PDMS-POSS- amic acid) powders}

Figure 3.10 shows the TGA-MS graphs of poly(PDMS-POSSamic acid) powders. The top graphs show the mass loss as a function of temperature, while the bottom graphs show the corresponding gases evolved tracked with a MS.

The imidization and thermal degradation of a poly(PDMS-POSSamic acid) powder in an air atmosphere is shown in Figure 3.10a, and that in a nitrogen atmosphere is shown in Figure 3.10b. Both in an air and in a nitrogen atmosphere, the peak in water evolved associated with imidization is present at $215{ }^{\circ} \mathrm{C}$. However, when the imidization is carried out in air, almost immediately after this imidization peak, a significant release of $\mathrm{CO}_{2}$ and more $\mathrm{H}_{2} \mathrm{O}$ is detected. Those are typical degradation products under air atmosphere. Thus, although the onset of imidization does not seem to depend on the atmosphere, the onset of thermal degradation strongly does $\left(250{ }^{\circ} \mathrm{C}\right.$ in air, $400{ }^{\circ} \mathrm{C}$ in nitrogen). To avoid thermal degradation of the material during imidization, the imidization temperature chosen should be well below the onset of thermal degradation. This can only be achieved when imidization is carried out in a nitrogen atmosphere.

In addition to the onset of thermal degradation, the mass loss pattern of the poly(PDMS-POSSimide) powders strongly depends on the atmosphere as well. This dependence of atmosphere is similar to that found for conventional PDMS ${ }^{[36]}$. Thermal degradation in air occurs in multiple steps, with a stable weight of $50 \%$ of the original mass reached at $500{ }^{\circ} \mathrm{C}$. In contrast, the main degradation in nitrogen occurs in a single step at $470{ }^{\circ} \mathrm{C}$, after which the mass slowly decreases further with increasing temperature. A residual mass of less than $10 \%$ is found at $1000{ }^{\circ} \mathrm{C}$.

Camino et al. ${ }^{[36,37]}$ report that conventional PDMS degrades to volatile cyclic oligomers upon heating by the scission of $\mathrm{Si}-\mathrm{O}$ bonds. The authors state that oxygen can catalyze this depolymerization reaction, resulting in a reduced temperature of the first weight loss observed in air. The higher residual weight in air can be a result of further cross-linking of the PDMS chains in the presence of oxygen, and thereby stabilizing the material against thermal degradation. The poly(PDMS-POSSimide) networks prepared in this work are prepared with a relatively low molecular weight PDMS $\left(\mathrm{M}_{\mathrm{n}} \approx 900 \mathrm{~g} \mathrm{~mol}^{-1}\right)$, making the formation 

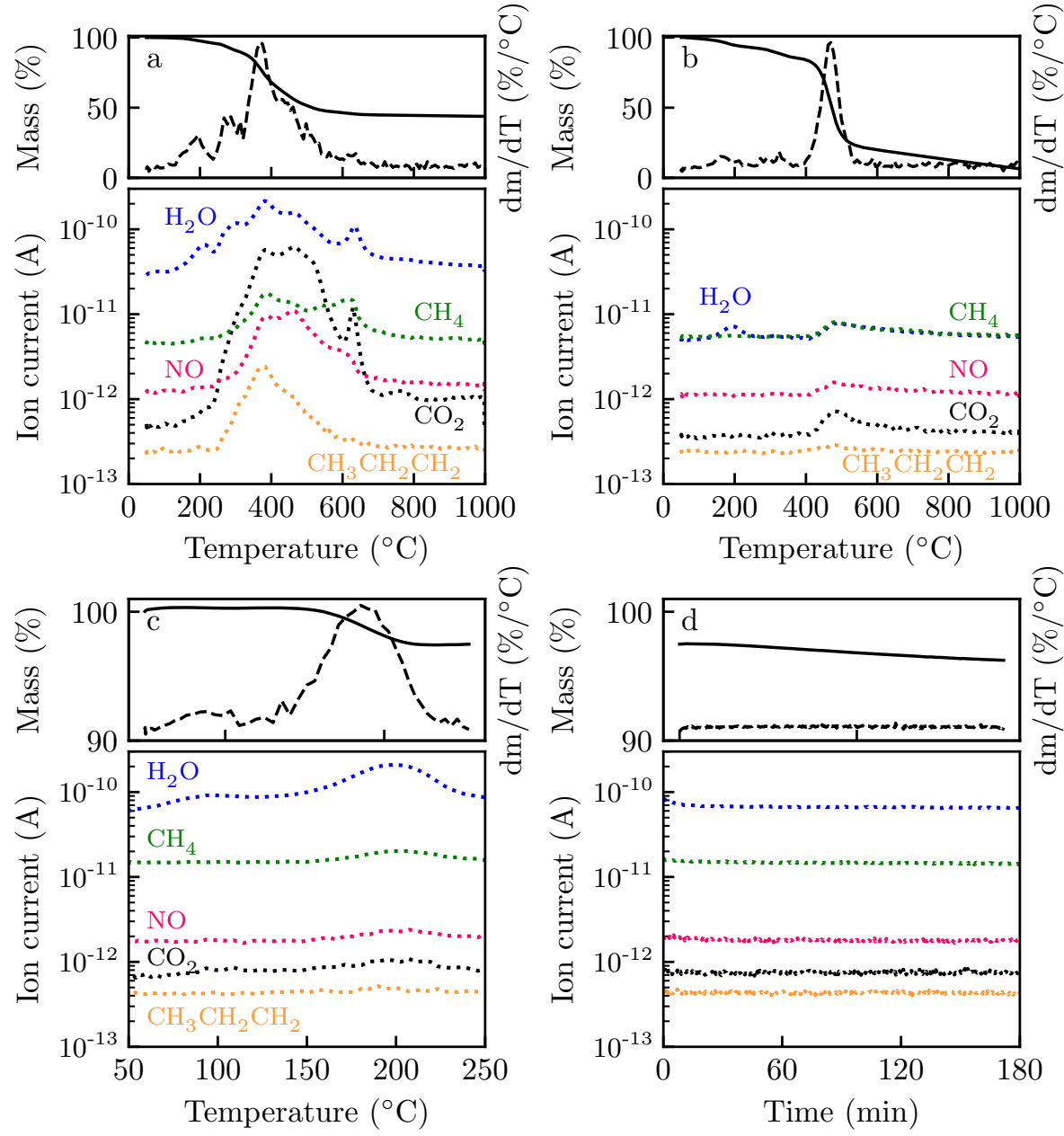

Figure 3.10: TGA-MS data for poly(PDMS-POSSamic acid) powders. (a) Imidization and thermal degradation in an air atmosphere. (b) Imidization and thermal degradation in a nitrogen atmosphere. (c) The imidization in a nitrogen atmosphere. (d) Isothermal analysis of the imidization under nitrogen atmosphere. All top graphs show the mass loss as function of temperature. All bottom graphs show the evolved gases during heating. The following gases are traced: $\mathrm{CH}_{4}(m / z=15$, green, -$), \mathrm{H}_{2} \mathrm{O}(m / z=18$, blue, -$)$, $\mathrm{NO}(m / z=30$, pink, $-), \mathrm{CH}_{3} \mathrm{CH}_{2} \mathrm{CH}_{2}(m / z=43$, orange, -$)$, and $\mathrm{CO}_{2}(m / z=44$, black, -$)$. 
of volatile cyclic compounds less likely. However, the further cross-linking of the PDMS chains in the presence of oxygen can still occur, and can thus explain the dependence of degradation behavior on the atmosphere.

In addition to the imidization temperature, the imidization time could be determined from the TGA-MS experiments. Figure 3.10c and d show the heating and isothermal stage of the imidization, respectively. Some minor traces of $\mathrm{H}_{2} \mathrm{O}$ are observed around $90{ }^{\circ} \mathrm{C}$. This can be attributed to the release of physically bound water. The release of $\mathrm{H}_{2} \mathrm{O}$ due to the imidization process starts at $150{ }^{\circ} \mathrm{C}$, with a peak around $195{ }^{\circ} \mathrm{C}$. Besides imidization, $\mathrm{H}_{2} \mathrm{O}$ can be released because of silanol condensation ${ }^{[32]}$. Simultaneously, small traces of $\mathrm{CO}_{2}, \mathrm{CH}_{4}$, and $\mathrm{NO}$ are detected. The release of $\mathrm{CO}_{2}$ can be caused by the decarboxylation reaction of unreacted carboxylic acid groups ${ }^{[32]}$. Despite these minor peaks of decomposition gasses, the network is considered to be stable at this imidization process. This is proven by the lack of a signal originating from the $\mathrm{CH}_{3} \mathrm{CH}_{2} \mathrm{CH}_{2}$ fragment. Due to the $\mathrm{sp}^{3}$ hybridization, the propyl groups are considered to be the thermally weakest links.

The isothermal analysis (Figure 3.10d) reveals that after 18 minutes at $250{ }^{\circ} \mathrm{C}$, there is no more loss of $\mathrm{H}_{2} \mathrm{O}$ detected. That means that after 18 minutes the imidization process is finished, and therefore the imidization of poly(PDMSPOSSamic acid) is performed at $250{ }^{\circ} \mathrm{C}$ for 18 minutes.

\subsubsection{The refractive index of poly(PDMS-POSSimide) films upon solvent swelling}

From spectroscopic ellipsometry both the film thickness and refractive index could be obtained. The change in normalized refractive index for conventional PDMS upon swelling in solvent vapor is shown in Figure 3.11. Figure 3.11a shows the normalized refractive index as function of apparent solvent activity, while Figure $3.11 \mathrm{~b}$ shows the normalized refractive index (hereafter called "index") at activity 1 as function of time. The index of PDMS decreases upon exposure to solvents, which fits perfectly well with the swelling measured. Upon solvent swelling, the PDMS matrix gets diluted with the solvent that has a lower refractive index than the PDMS matrix, thereby decreasing the index of the swollen film. The extent of this reduction of the index is directly related to the swelling degree in the specific solvent. A higher swelling degree results in more solvent in the polymer matrix, and thus a lower index.

The index upon solvent swelling was also obtained for poly(PDMS-POSSimide) films. However, the accuracy and thus reliability of the index is low for these poly(PDMS-POSSimide) films due to the use of focusing probes and a high surface inhomogeneity of the samples. Additionally, the low swelling degrees in all solvents results in extremely small changes in refractive index $(<1 \%$ ) further reducing the accuracy.

Figure 3.12 shows the index for poly(PDMS-POSSimide) films in $n$-hexane (Figure 3.12a-b), ethyl acetate (Figure 3.12c-d), and ethanol (Figure 3.12e-f). With 


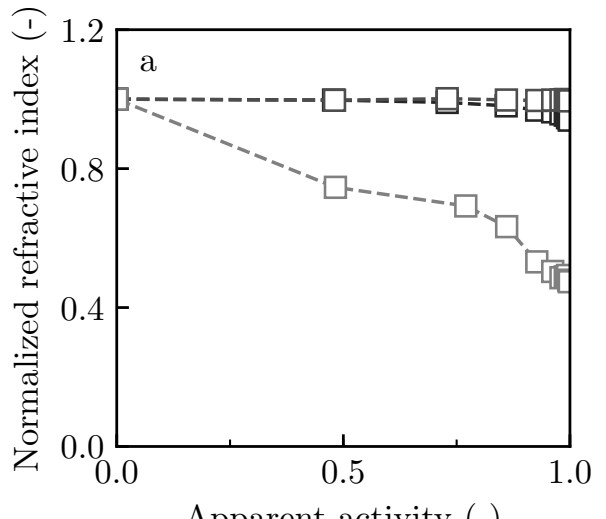

Apparent activity (-)

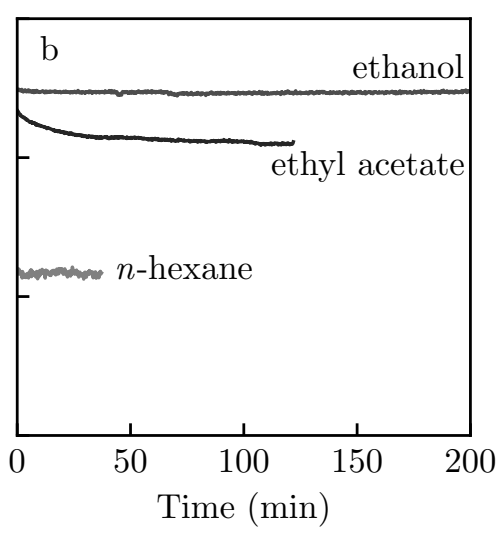

Figure 3.11: The normalized refractive index of PDMS in solvent vapors (a) as a function of the apparent solvent activity in the cell, and (b) as a function of time at an constant activity of 1 .

increasing solvent activity, some of the films show an initial increase in index. In general, this phenomenon is observed for films with a higher dry index $(n>1.50)$. These higher dry indices could be attributed to a higher cross-link density. This higher cross-link density makes the films more rigid, thereby allowing for some frozen-in excess free volume between the network. Upon exposure to a solvent, the solvent will replace the frozen-in void. As a result of this, the index of the system will initially increase, because the refractive index of the solvent is higher compared to the refractive index of void $(n=1)$. Eventually, the index will decrease by a similar mechanism as reported for conventional PDMS. 

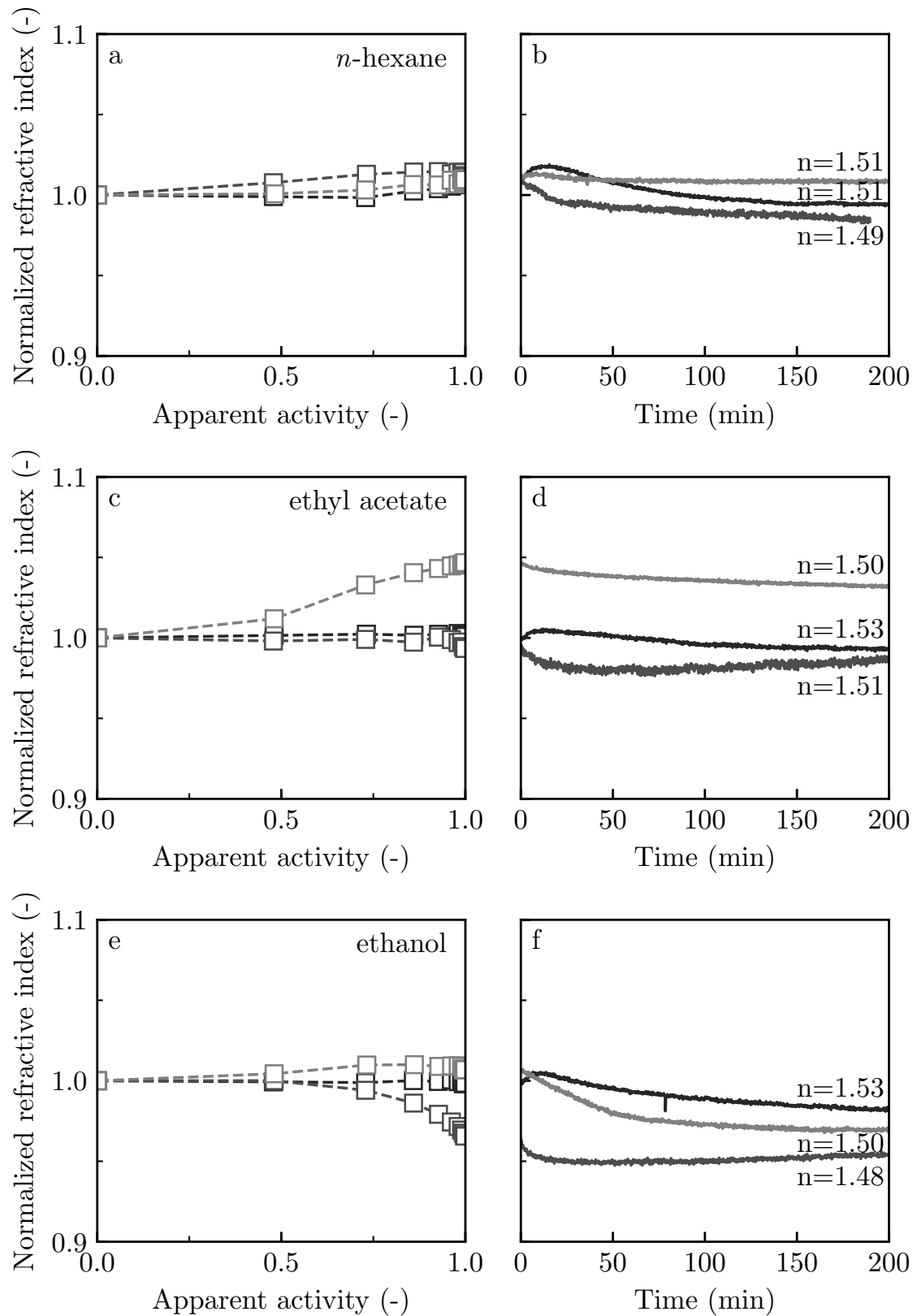

Figure 3.12: The normalized refractive index of poly(PDMS-POSSimide) films measured by spectroscopic ellipsometry for $(a, b) n$-hexane, $(c, d)$ ethyl acetate, and $(e, f)$ ethanol vapors. $(a, c, e)$ The normalized refractive index as function of the apparent solvent vapor activity in the cell, and $(b, d, f)$ the normalized refractive index as function of time at an apparent activity of one. For every solvent, three different samples with varying refractive indices were measured. 


\section{Chapter 4}

\section{Thin cyclomatrix polyphosphazene films: Interfacial polymerization of hexachlorocyclotriphosphazene with aromatic biphenols}

This chapter is adapted from:

Evelien Maaskant, Hubert Gojzewski, Mark A. Hempenius, G. Julius Vancso, Nieck E. Benes, Thin cyclomatrix polyphosphazene films: Interfacial polymerization of hexachlorocyclotriphosphazenes with aromatic biphenols, Polymer Chemistry 2018, accepted manuscript, DOI: 10.1039/c8py00444g 


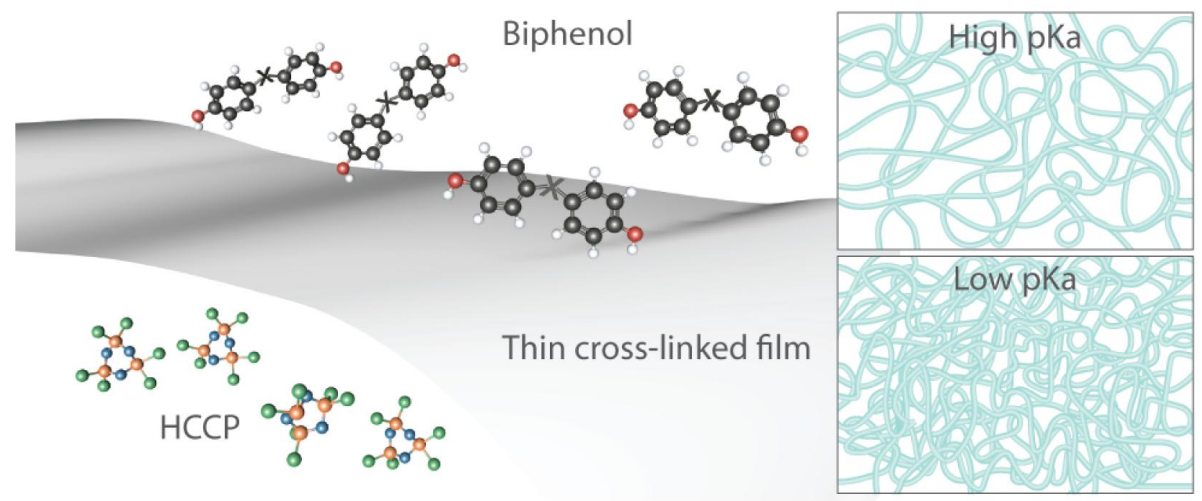

\section{Abstract}

A series of thin cyclomatrix polyphosphazene films has been prepared by interfacial polymerization of hexachlorocyclotriphosphazene (HCCP) with an aromatic biphenol. The pKa values of the biphenol used strongly influence the properties of the hyper-cross-linked films formed. 4,4'-Dihydroxybiphenyl (BPH) and 4,4'-dihydroxydiphenyl ether (DHPE) possess pKa values in the range of 9.4-9.6 \& 10.0-10.3 for the mono- and di-ionized forms, respectively, and produce films with a lower cross-link density, whereas 4,4'-dihydroxybenzophenone (DHBP) and 4,4'-sulfonyldiphenol (BPS) feature lower pKa values (7.4-7.6 \& 8.0-8.2), resulting in films with a higher cross-link density. The difference in cross-link density is reflected in, e.g., the surface morphology and mechanical properties of the films. Mechanical stiffness has been quantitatively assessed by PeakForce QNM AFM. Lower cross-link densities result in Young's moduli with average values of 44-69 $\mathrm{MPa}$, with a sharp distribution, while higher cross-link densities yield broadly distributed Young's moduli with average values of 255-306 MPa, depending on the choice of the biphenol. All films, obtained by interfacial polymerization, show good thermal stability to temperatures up to $450{ }^{\circ} \mathrm{C}$, with residual masses of more than $60 \%$ at $600{ }^{\circ} \mathrm{C}$. 


\subsection{Introduction}

Hybrid materials gained much interest over the last decades, as the combination of organic and inorganic matter within a hybrid material often leads to enhanced, or even novel, properties compared to those of the pure organic and inorganic constituents $^{[1]}$. For example, hybrid materials may display higher flexibility and greater mechanical strength, usability over a broader temperature range, as well as greater durability ${ }^{[2]}$. The class of polyphosphazenes holds fascinating examples of inorganic-organic (hybrid) materials ${ }^{[3]}$. Polyphosphazenes can be regarded as molecular level hybrids as they consist of an inorganic backbone, composed of alternating phosphorous and nitrogen atoms, usually with two organic substituents linked to each phosphorous atom ${ }^{[4,5]}$. Heteroatoms, such as carbon or sulfur, could be introduced into the polymers backbone resulting in polyheterophosphazenes ${ }^{[6-8]}$. Besides linear polyphosphazenes, star, dendritic, block copolymeric, cyclolinear, and cyclomatrix architectures have been synthesized ${ }^{[9,10]}$.

A versatile building block for the preparation of materials based on phosphazenes is the cyclic phosphazene trimer hexachlorocyclotriphosphazene $\left[\mathrm{NPCl}_{2}\right]_{3}, \mathrm{HCCP}$. Covalent linkages can be formed between nucleophiles, such as alkylamines, and the phosphorous atoms, with chloride as the leaving group. In cyclolinear polymers, only two of the six reactive sites of the phosphazene rings are linked via difunctional exocyclic groups to form linear chains. When a larger number of reactive sites are involved in bond formation, cyclomatrix structures result, which are cross-linked materials. Precipitation polycondensation reactions under such conditions (where multiple HCCP sites reacted with organic small molecules, or polymers having at least two hydroxyl or amine groups) have yielded cyclomatrix polyphosphazene microspheres ${ }^{[11]}$. These cyclomatrix materials are mainly known for their excellent flame retardant properties ${ }^{[12,13]}$, but are also used for biocompatible coatings ${ }^{[14]}$, sensing applications ${ }^{[15]}$, adhesives ${ }^{[16]}$, or super-hydrophobic coatings ${ }^{[17]}$. Aromatic organic building blocks were commonly used, though aliphatic diamines ${ }^{[18]}$ or polymers ${ }^{[11]}$ were reported as well.

Conventional methods to prepare films, e.g., doctor-blade casting, drop casting, or spin coating result in relatively thick films in the order of a few hundred microns. Here, we have prepared thin films of a cyclomatrix polyphosphazene material by interfacial polymerization (IP). IP most often involves a polycondensation reaction of two or more monomers at the interface of two immiscible phases. When at least one of the monomers has a higher functionality than two, an insoluble thin crosslinked film is formed at the interface. These films possess much higher stability in aggressive environments compared to their uncross-linked analogues. Due to the localized nature of the reaction, thin, defect-free films could be obtained ${ }^{[19-21]}$.

Interestingly, IP has been successfully employed in the preparation of several HCCP-based molecules. Thompson et al. ${ }^{[22]}$ achieved selective disubstitution of HCCP with bisphenol A, yielding di(bisphenol A)tetrachlorocyclotriphosphazene. Chen-Yang et al. ${ }^{[23]}$ prepared mono- through hexa-substituted 


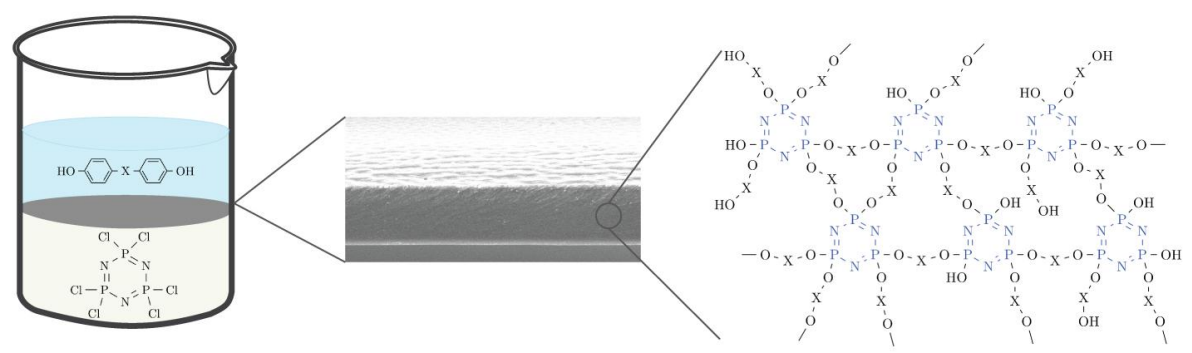

Figure 4.1: The preparation of cyclomatrix polyphosphazenes by interfacial polymerization.

(phenoxy)cyclotriphosphazenes by interfacial condensation of HCCP with phenol. These authors showed that the highest reaction rates could be obtained using chlorinated solvents, which reduce the hydrolysis of HCCP chlorine groups upon contact with water, due to the low solubility of water in these media.

Here we report, to our knowledge, on the first examples of cyclomatrix thin $(2-5 \mu \mathrm{m})$ polyphosphazene films prepared by IP (Figure 4.1). These films were obtained by the interfacial polycondensation of HCCP with the aromatic biphenols 4,4'-dihydroxybiphenyl (BPH), 4,4'-dihydroxydiphenyl ether (DHPE), 4,4'-dihydroxybenzophenone (DHBP), and 4,4'-sulfonyldiphenol (BPS). We note, that cyclomatrix polyphosphazenes based on BPS are well described in the literature when prepared in a single solvent ${ }^{[24-28]}$.

The chemical structure of the aromatic biphenol has a strong influence on the stiffness (Young's modulus) and thermal stability of the corresponding thin film, originating from differences in the cross-link density. The properties of the final films seem to depend strongly on the pKa values of the aromatic biphenol used. Judicious selection of the aromatic biphenol therefore allows facile tuning of the properties of the cyclomatrix thin polyphosphazene film.

\subsection{Experimental}

\subsubsection{Materials}

Hexachlorocyclotriphosphazene (HCCP, 99\%), sodium hydroxide ( $\mathrm{NaOH},>98 \%$ ), dichloromethane (DCM, ACS reagent, $\geq 99.5 \%$ ), 4,4'-dihydroxybiphenyl (BPH, 97\%), 4,4'-dihydroxybenzophenone (DHBP, 99\%), 4,4'-sulfonyldiphenol (BPS, $98 \%$ ), and tricaprylylmethylammonium chloride (Aliquat ${ }^{\circledR} 128$ ) were obtained from Sigma-Aldrich (the Netherlands). 4,4'-Dihydroxydiphenyl ether (DHPE, $>98 \%$ ) was obtained from TCI Europe. Sylgard 184 was obtained from DOWCorning. All chemicals were used as received. 


\subsubsection{Preparation of hyper-cross-linked polyphosphazenes}

The reaction conditions of the interfacial polycondensation of HCCP with an aromatic biphenol are based on the work of Chen-Yang et al. ${ }^{[23]}$. HCCP $(0.70 \mathrm{~g}$, $2 \mathrm{mmol}$ ) and Aliquat ${ }^{\circledR} 128$ (a phase transfer catalyst) (0.42 g, $1 \mathrm{mmol}$ ) were dissolved in DCM $(20 \mathrm{~mL})$. Biphenol $(10 \mathrm{mmol})$ and $\mathrm{NaOH}(1.6 \mathrm{~g}, 40 \mathrm{mmol})$ were dissolved in Milli-Q water $(20 \mathrm{~mL})$. The aqueous phase was added to the organic phase, and the mixture was stirred vigorously for 10 minutes. The formed suspension was filtered and washed with water and ethanol, respectively, and dried in a vacuum oven at $60{ }^{\circ} \mathrm{C}$ overnight. The resulting solid was ground to a fine powder. Unreacted monomers and impurities were extracted with ethanol in a Soxhlet apparatus. The remaining solids were dried under vacuum.

\subsubsection{Thin polyphosphazene films on PDMS slabs}

A $1 \mathrm{~cm}$ thick PDMS layer was casted in a petri dish using Sylgard 184 (DOW-Corning). Both Sylgard components were mixed according the manufacturer's instructions, and centrifuged at $4000 \mathrm{rpm}$ for 15 minutes to remove air bubbles. The PDMS was poured in a petri dish and cured at $80{ }^{\circ} \mathrm{C}$ for 3 hours. A piece of PDMS was soaked into the DCM-phase (same composition as described above) for at least 10 minutes. The swollen PDMS was put on a piece of paper to remove the excess DCM from the surface, and immediately placed in the aqueous phase (same composition as described above) for 5 minutes to allow for film formation at the PDMS surface. The PDMS slabs were dipped in Milli-Q water to remove any unreacted monomers. See Figure 4.2 for a schematic representation of the synthesis procedure. After drying overnight at ambient conditions, the HCCPbiphenol film could be easily removed from the PDMS surface. After removal from the PDMS, the films were washed with subsequently water and ethanol.

\subsubsection{Characterization}

Attenuated total reflection Fourier transform infrared spectroscopy (FTIR-ATR) spectra were recorded on an ALPHA spectrometer equipped with an ATR platinum diamond crystal (Bruker, Germany). The powders were pressed onto the crystal without further sample preparation. Spectra were averaged over 64 scans with a resolution of $4 \mathrm{~cm}^{-1}$. Prior to measurements, a background spectrum was recorded at ambient conditions.

Scanning electron micrographs were taken with a JEOL-JSM6010 scanning electron microscope. Samples were coated with a $5 \mathrm{~nm}$ chromium layer (Quorum Q150T ES) prior to imaging. Film thicknesses were measured using the image processing program ImageJ (v1.50) software.

Quantitative mapping of Young's modulus and adhesion force by atomic force microscopy (AFM) was performed on HCCP-biphenol films ${ }^{[29,30]}$. Films were 


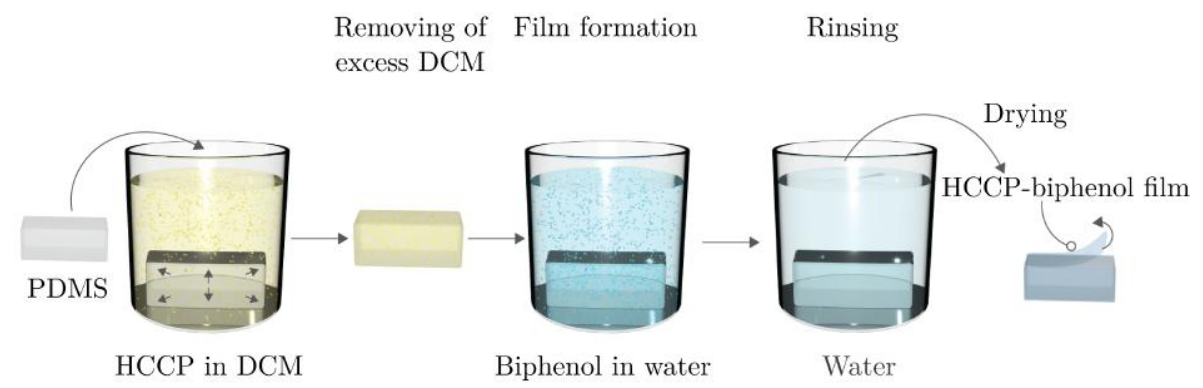

Figure 4.2: Preparation of hyper-cross-linked polyphosphazene films on the surface of PDMS slabs. A PDMS slab is soaked into the organic phase containing the monomer HCCP, and a phase transfer catalyst Aliquat ${ }^{\circledR} 128$. Note that the organic phase used here (DCM) has a higher density than the aqueous one. The excess DCM is removed from the surface of the PDMS. The swollen slab of PDMS is immediately placed in the aqueous phase. A thin film is formed at the surface of the PDMS due to the solvents' immiscibility. After 5 minutes reaction time, the PDMS slab is removed from the aqueous solution, dipped immediately in water, and dried overnight at ambient conditions. During drying the DCM evaporates, and the PDMS will slowly return to its original shape. Due to this gradual shrinkage of the support, the HCCP-biphenol film does not tear upon drying. The film is not covalently bound to the PDMS and can be easily removed with tweezers.

fastened using a two-component epoxy glue to a metal sample holder and left for $24 \mathrm{~h}$ to cure the epoxy. Specimens were measured in the PeakForce QNM (Quantitative Nanomechanical Mapping) working mode using the Multimode 8 AFM controlled by the NanoScope V control unit (Bruker, USA). Soft ScanAsystAir (Bruker, USA) silicon nitride cantilevers with a nominal spring constant of $0.4 \mathrm{~N} \mathrm{~m}^{-1}$ and sharp silicon tips with a nominal tip-end radius of $2 \mathrm{~nm}$ were used to ensure damage-free tip-sample interactions. The value of the individual cantilever spring constant was determined by the thermal tune method ${ }^{[31,32]}$; we obtained values ranging within $0.31-0.39 \mathrm{~N} \mathrm{~m}^{-1}$ depending on the cantilever. In the AFM mode used, sample topography and structure-property relationships are obtained by real-time processing of the force-distance curves. Force-distance curves were captured each time the tip tapped on the specimen surface, i.e. at each pixel; 65,536 force-distance curves were collected $(256 \times 256$ pixels $)$ for each AFM image, which yielded "elasticity maps". The tip followed a $2 \mathrm{kHz}$ sine-wave trajectory when moving from one pixel to another with a peak-force amplitude of $150 \mathrm{~nm}$. Imaging was performed in air, at controlled temperature $\left(21.0 \pm 0.1{ }^{\circ} \mathrm{C}\right)$ and stable values of relative humidity (40\%). Image processing and data evaluation were performed with the NanoScope 8.15 and NanoScope Analysis 1.80 software, respectively. The ScanAsyst panel in the NanoScope 8.15 software was set to be off to minimize the influence of software auto-optimization algorithms on the data collected.

Young's modulus calculations were performed based on the model of Derjaguin, Muller, and Toporov (DMT) ${ }^{[33,34]}$ and the following formalism was employed as- 
suming a rigid AFM tip:

$$
E=\left(F_{L}-F_{a d h}\right) \frac{3\left(1-\nu^{2}\right)}{4} R^{-1 / 2}(z-d)^{-3 / 2}
$$

where $E$ is the sample's Young's modulus, $F_{L}$ is the applied load through the AFM tip against the sample surface, $F_{\text {adh }}$ is the adhesion force between the sample surface and the tip, with $\nu$ sample Poisson's ratio, $R$ radius of curvature of the AFM tip, $z$ the position of the AFM scanner, and $d$ the cantilever deflection. To perform real-time data analysis and reduce the propagation of errors, we applied a simplified formalism of the DMT model to calculate Young's modulus, which is referred to as the "relative method" $[30,35,36]$. Here, the value of the sample Poisson's ratio and radius of curvature of the AFM tip were no longer required, as the values of the Young's moduli were determined using a reference sample with known DMT elastic modulus. As reference, we employed a PDMS gel $150 \mu \mathrm{m}$ film with a Young's modulus of $(3.5 \pm 0.5 \mathrm{MPa})$ (Bruker) ${ }^{[35,37]}$. The adhesion force was calculated as the difference between the baseline and the snap-off point (the lowest point in the force-distance curve).

The distribution of the Young's modulus was plotted as a histogram. The number of bins $k$ was calculated as:

$$
k=\left|\frac{E_{\max }-E_{\min }}{h}\right|
$$

where $E_{\min }$ and $E_{\max }$ are the minimum and maximum Young's modulus, respectively, and $h$ is the bin width that can be calculated by Scott's normal reference rule ${ }^{[38]}$ :

$$
h=\frac{3.5 \sigma}{n^{1 / 3}}
$$

where $\sigma$ is the standard deviation, and $n$ is the sample size.

XPS (X-ray Photoelectron Spectroscopy) measurements were carried out on HCCP-biphenol films. XPS spectra of HCCP-BPH, HCCP-DHPE, and HCCPDHBP films were measured on an Ultra Axis ${ }^{\mathrm{TM}}$ spectrometer (Kratos Analytical, Manchester UK). The films were irradiated with mono energetic $\mathrm{Al} \mathrm{K}_{\alpha 1.2}$ radiation $(1486.6 \mathrm{eV})$ and the spectra were taken at a power of $144 \mathrm{~W}(12 \mathrm{kV} \times 12 \mathrm{~mA})$. The XPS spectrum of the HCCP-BPS film was measured on a Quantera SXM scanning XPS microprobe (Physical Electronics). The films were irradiated with monochromatic $\mathrm{Al} \mathrm{K} \alpha$ radiation $(1486.6 \mathrm{eV}$ ) with a beam size of $200 \mu \mathrm{m}$ at a power of $50 \mathrm{~W}$. Fitting of all spectra was done after shifting the measured spectra with respect to the known reference binding energy of aliphatic carbon C1s at $284.8 \mathrm{eV}$.

Streaming current measurements were performed on a SurPASS analyzer (Anton Paar, Austria) equipped with an adjustable gap cell. HCCP-biphenol films were fastened to the PDMS blocks $\left(2 \times 1 \mathrm{~cm}^{2}\right)$ of the cell with double sided adhesive tape $\left(\right.$ Tesa $\left.{ }^{\circledR} 4965\right)$. The $\mathrm{pH}$ of the electrolyte solution $(5 \mathrm{mM} \mathrm{KCl})$ was automatically 
adjusted using $0.1 \mathrm{M} \mathrm{HCl}$ or $0.1 \mathrm{M} \mathrm{NaOH}$. From the streaming current, the zeta potential could be derived using Equation 4.4:

$$
\zeta=\frac{\mathrm{d} I}{\mathrm{~d} P} \cdot \frac{\eta}{\epsilon \cdot \epsilon_{0}} \cdot \frac{L}{A}
$$

where $\zeta$ is the zeta potential, $\frac{\mathrm{d} I}{\mathrm{~d} P}$ is the slope of the streaming current versus pressure, $\eta$ and $\epsilon$ are the viscosity and dielectric constant of the electrolyte, here taken as that of water, $\epsilon_{0}$ is the permittivity of vacuum, $L$ is the length of the streaming channel, and $A$ is the cross sectional area of the channel.

Combined thermogravimetric analysis (TGA) and mass spectroscopy (MS) measurements were performed on HCCP-biphenol powders using an STA 449 F3 Jupiter TGA with an aluminum sample cup (Netzsch, Germany) and QMS 403 D Aeolos MS (Netzsch, Germany). The methods used for these measurements are described elsewhere ${ }^{[39]}$. Mass loss measurements were performed from 50 to $600{ }^{\circ} \mathrm{C}$ with a heating rate of $10{ }^{\circ} \mathrm{C} \mathrm{min}^{-1}$ under nitrogen atmosphere. Isothermal analysis was performed at $600{ }^{\circ} \mathrm{C}$ with a heating rate of $10{ }^{\circ} \mathrm{C} \mathrm{min}-1$ under nitrogen atmosphere.

Differential scanning calorimetry (DSC) curves were obtained using a PerkinElmer DSC 8000 at a heating and cooling rate of $20{ }^{\circ} \mathrm{C} \mathrm{min}^{-1}$ under a nitrogen atmosphere.

\subsection{Results and discussion}

\subsubsection{Synthesis of hyper-cross-linked polyphosphazenes}

Cyclomatrix hybrid polyphosphazene powders and thin films were prepared by interfacial polymerization of the inorganic monomer HCCP and an aromatic biphenol. The interfacial polymerization of two monomers where one of the monomers has a high functionality $(\geq 3)$ results in an insoluble network at the interface of two immiscible phases. In contrast to the preparation in a single solvent, interfacial polymerization allows for the localized formation of highly cross-linked thin films with a perfectly alternating monomeric structure. To distinguish from conventional cross-linked polymers, we will denote these networks made by interfacial polymerization as hyper-cross-linked.

Scheme 4.1 shows the molecular structure of the biphenols used in this study, where a schematic representation of the reaction with HCCP is also displayed. The hydroxyl groups of the biphenols are deprotonated by $\mathrm{NaOH}$ to form the reactive biphenol dianions, and to make the aromatic biphenols soluble in the aqueous phase. Table 4.1 shows the $\mathrm{pKa}_{1}$ and $\mathrm{pKa}_{2}$ values of the biphenols used in this study, where $\mathrm{pKa}_{1}$ refers to the first deprotonation and $\mathrm{pKa}_{2}$ to the second 
<smiles>Oc1cc[Y](-c2ccc(O)cc2)cc1</smiles>

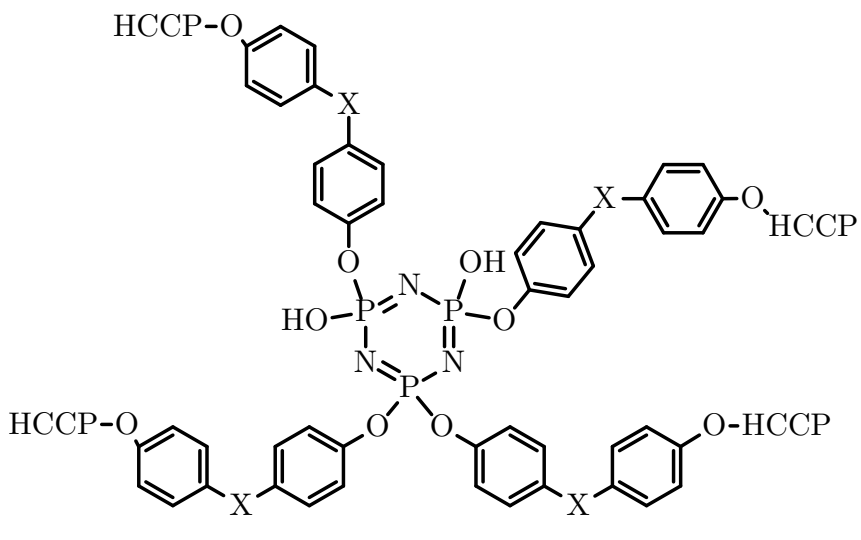

Scheme 4.1: Schematic representation of the reaction at the interface of the aqueous and organic phases. The structures of the aromatic biphenols used are shown in Table 4.1. First, the aromatic biphenol is converted to its more reactive sodium aryloxide by sodium hydroxide, followed by nucleophilic substitution with the HCCP monomer.

deprotonation. The $\mathrm{pH}$ value of the aqueous solution was approximately 13.3, independent of the biphenol used.

Successful network formation relies on the high conversion of the biphenols into dianions, as these species possess a much higher nucleophilicity than the parent biphenols. Complete deprotonation ensures the formation of full dianionic functionality of these reactants. The BPH and DHPE monomers contain electron donating groups that make these aryloxide anions more nucleophilic, and thus more reactive. However, due to the higher $\mathrm{pKa}$ of these biphenols, there is a higher chance of incomplete deprotonation, i.e. of the presence of monoanions among the biphenol dianions. In contrast, the hydroxyl groups of DHBP and BPS are significantly more acidic than those of BPH and DHPE, due to the electron-withdrawing carbonyl and sulfonyl moieties, and are therefore expected to be ionized into dianions more readily by the employed base than BPH and DHPE. It is well known that the degree of dissociation of acids is determined by the difference between the $\mathrm{pH}$ of the employed base solution and the $\mathrm{pKa}$ of the acid ${ }^{[40]}$. We note here, that as we show later, biphenol acidity can be correlated directly with the cross-link density of the formed networks. 
Table 4.1: The chemical structure and pKa values of the aromatic biphenols used in this study.

\begin{tabular}{|c|c|c|c|}
\hline Biphenol & Structure & $\mathrm{pKa}_{1}{ }^{a}$ & $\mathrm{pKa}_{2}{ }^{a}$ \\
\hline $\mathrm{BPH}$ & & 9.64 & 10.32 \\
\hline DHPE & & 9.40 & 10.00 \\
\hline DHBP & & 7.55 & 8.16 \\
\hline BPS & & 7.42 & 8.03 \\
\hline
\end{tabular}

${ }^{a}$ Obtained from Chemicalize.com (ChemAxon) ${ }^{[41]}$.

At the interface of the aqueous phase (biphenol) and the organic phase (HCCP), a sodium aryloxide ion displaces one of the chlorine groups of HCCP to form a $\mathrm{P}-\mathrm{O}-\mathrm{C}$ bond. Due to the high functionality of HCCP, an insoluble hypercross-linked network is formed. In addition to these HCCP-biphenol thin films, HCCP-biphenol powders were prepared by vigorously stirring a mixture of both the aqueous phase and the organic phase. Figure 4.3 shows the FTIR spectra of these HCCP-biphenol powders. All samples show absorbance peaks around $1590 \mathrm{~cm}^{-1}$ and $1490 \mathrm{~cm}^{-1}$ belonging to the $\mathrm{C}=\mathrm{C}$ stretching vibrations of the phenyl rings. The broad band from $1200-1120 \mathrm{~cm}^{-1}$, with a peak at $1150 \mathrm{~cm}^{-1}$, originates from the asymmetric $\mathrm{P}=\mathrm{N}-\mathrm{P}$ stretching, while the peak at $870-880 \mathrm{~cm}^{-1}$ belongs to the symmetric $\mathrm{P}=\mathrm{N}-\mathrm{P}$ stretching ${ }^{[25,26,42]}$. The absorbance peak at $940 \mathrm{~cm}^{-1}$ originates from the $\mathrm{P}-\mathrm{O}-\mathrm{Ph}$ bond, indicating the successful preparation of a crosslinked network for all aromatic monomers used.

The absorption band of the ether group in the DHPE biphenol is not visible in the spectrum of HCCP-DHPE since this band overlaps with the broad band belonging to the $\mathrm{P}=\mathrm{N}-\mathrm{P}$ ring stretching present at $1200-1120 \mathrm{~cm}^{-1}$. The spectrum of HCCPDHBP shows a strong absorption band at $1650 \mathrm{~cm}^{-1}$ due to the carbonyl stretching of the ketone group of the DHBP biphenol. The sulfone group of the BPS monomer gives rise to a strong absorption peak at $1290 \mathrm{~cm}^{-1}$. The second absorption band of the sulfone group overlaps with the $\mathrm{P}=\mathrm{N}-\mathrm{P}$ stretching $\left(1150 \mathrm{~cm}^{-1}\right)$ of the HCCP monomer ${ }^{[25,26]}$. 


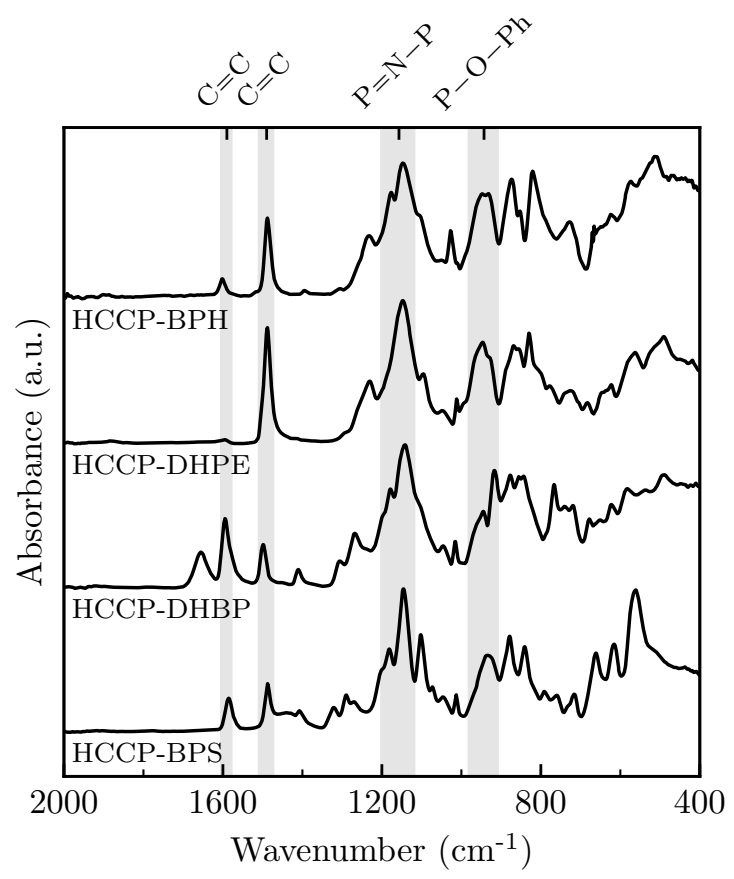

Figure 4.3: ATR-FTIR spectra for HCCP-biphenol powders from $2000-400 \mathrm{~cm}^{-1}$. 
Thin polyphosphazene films were prepared by interfacial polymerization onto the outer surface of the PDMS slabs (Figure 4.2). We note that the use of PDMS as support for interfacial polymerization reduces the mechanical stresses in the films upon drying, thus preventing cracking. Following completion of the reaction, the films can be easily peeled of the PDMS support, to obtain free-standing hypercross-linked polyphosphazene films. Cross-sectional scanning electron micrographs of HCCP-biphenol films prepared onto PDMS are shown in Figure 4.4, and topview scanning electron micrographs are shown in Figure 4.5. The HCCP-BPH and HCCP-DHPE films possess a relatively rough surface on a macroscopic scale (Figure 4.5a-d), while HCCP-DHBP and HCCP-BPS possess a smoother surface (Figure 4.5e-h). Due to contributions of surface roughness, the thickness values of HCCP-BPH vary between 2 and $5 \mu \mathrm{m}$, and the thickness of HCCP-DHPE varies between $3 \mu \mathrm{m}$ and $5 \mu \mathrm{m}$ over the entire cross-section of the films. In contrast, HCCP-DHBP and HCCP-BPS have a very uniform thickness over the entire crosssection of $\sim 3.4 \mu \mathrm{m}$ and $\sim 3.5 \mu \mathrm{m}$, respectively.

The surface morphology of a film derived by interfacial polymerization is strongly dependent on the diffusivity and the solubility of the monomers into the other phase $^{[43,44]}$. The rough surface morphology of HCCP-BPH and HCCP-DHPE films is typically obtained when one of the reactants easily diffuses through the forming film to the reaction site. Zhang et al. ${ }^{[45]}$ found a similar trend when studying the film formation of various amines with trimesoyl chloride. In contrast,
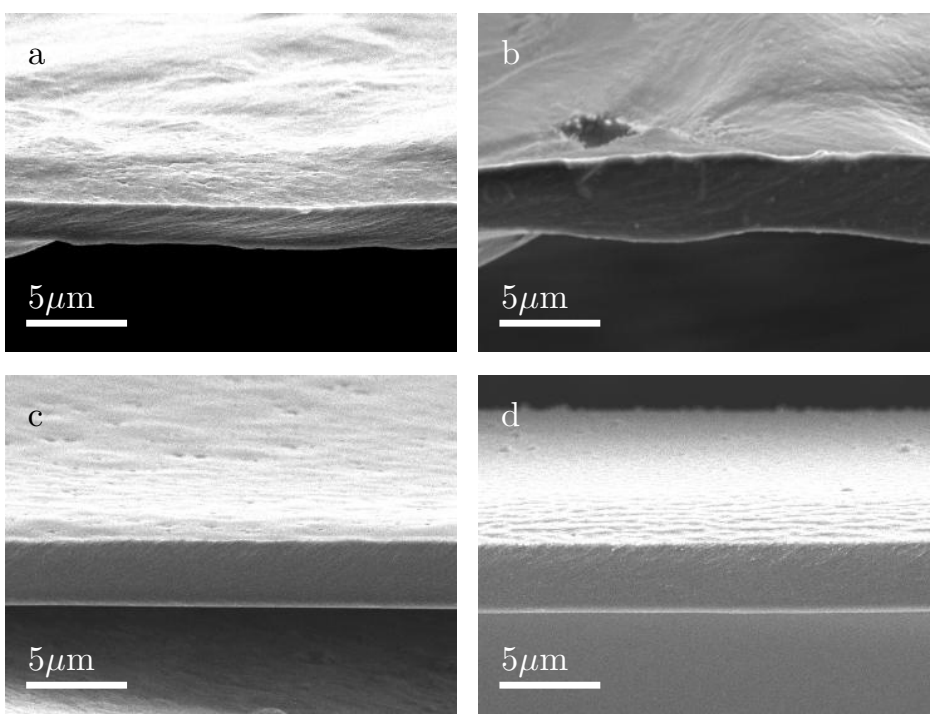

Figure 4.4: Cross-sectional scanning electron micrographs of HCCP-biphenol films. (a) HCCP-BPH, (b) HCCP-DHPE, (c) HCCP-DHBP, and (d) HCCP-BPS. 


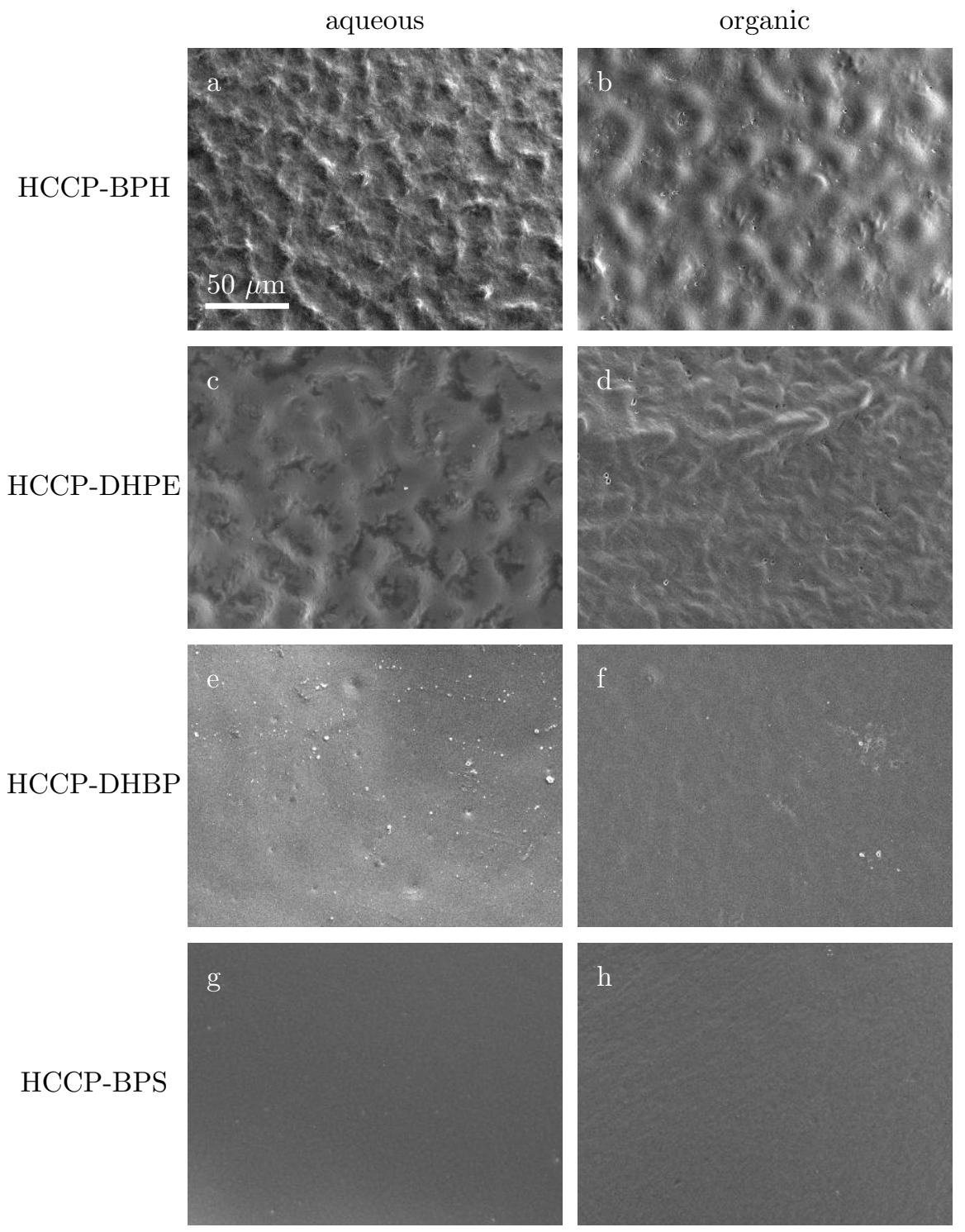

Figure 4.5: Top-view scanning electron micrographs of the HCCP-biphenol films prepared by interfacial polymerization onto PDMS. (a) HCCP-BPH aqueous side, (b) HCCP-BPH organic side, (c) HCCP-DHPE aqueous side, (d) HCCP-DHPE organic side, (e) HCCP-DHBP aqueous side, (f) HCCP-DHBP organic side, (g) HCCP-BPS aqueous side, and (h) HCCPBPS organic side. HCCP-BPH and HCCP-DHPE form a relatively rough film whereas HCCPDHBP and HCCP-BPS have a smooth surface. 
HCCP-DHBP and HCCP-BPS films reveal a smooth surface morphology. This can indicate that the diffusion of monomers through the forming film was more limited resulting in smoother film. Since the sizes of the aromatic biphenols are rather similar, the limited diffusion could be explained by a more tightly crosslinked network in the case of HCCP-DHBP and HCCP-BPS. As can be seen from Figure 4.5, the surface morphology does not strongly differ for the aqueous-phase or organic-phase side for all the films.

The difference in cross-link density, which depends on the employed biphenol, is of influence on the mechanical properties of the final films. As earlier mentioned, we used the PeakForce QNM mode to characterize the morphology and mechanical properties (Young's modulus and adhesion force) of HCCP-biphenol films. Figure 4.6 and Figure 4.7 shows the results of these AFM measurements for all HCCP-biphenol films, for $3 \times 3 \mu \mathrm{m}^{2}$ scan size images. Height (topography) and Young's modulus are presented with corresponding cross-section plots (obtained along the white lines in the images). The cross-section profile in the height images shows no significant differences among the aromatic monomers BPH, DHPE, and DHBP (Figure 4.6a-c); the height varies in the range of $20 \mathrm{~nm}$ for these films. For HCCP-DHBP we observed a grain-like morphology. The grain-like features have a size of approximately $200 \mathrm{~nm}$ in diameter and several $\mathrm{nm}$ in height. The HCCPBPS film (Figure 4.6d) reveals height variations of up to $80 \mathrm{~nm}$. The differences in height profile are also reflected in the surface roughness, i.e. the $\mathrm{R}_{\mathrm{RMS}}$, as shown in Table 4.2.

The Young's modulus maps of the films are shown in Figure 4.7. All films show a rather homogeneous distribution of Young's moduli over the imaged surfaces. This fits well with the notion that the network features a rather homogeneous structure down to the molecular scale.

The average Young's modulus of the HCCP-DHBP $(306 \pm 98 \mathrm{MPa})$ and HCCPBPS $(255 \pm 140 \mathrm{MPa})$ films is significantly different compared to that of the HCCP-BPH $(44 \pm 5 \mathrm{MPa})$ and HCCP-DHPE $(69 \pm 12 \mathrm{MPa})$ films. The modulus distribution also shows variations for the different samples. The higher average

Table 4.2: The surface roughness and Young's modulus of HCCP-biphenol films calculated from the peak force tapping data.

\begin{tabular}{|c|c|c|c|c|}
\hline \multirow[t]{2}{*}{ Sample } & \multirow[t]{2}{*}{$\mathrm{R}_{\mathrm{RMS}^{\mathrm{a}}}(\mathrm{nm})$} & \multicolumn{3}{|c|}{ Young's modulus (MPa) } \\
\hline & & Mean $^{b}$ & Median & Mode \\
\hline HCCP-BPH & 0.9 & $44 \pm 5$ & 43 & 44 \\
\hline HCCP-DHPE & 1.2 & $69 \pm 12$ & 68 & 66 \\
\hline HCCP-DHBP & 2.3 & $306 \pm 98$ & 292 & 321 \\
\hline HCCP-BPS & 8.7 & $255 \pm 140$ & 227 & 182 \\
\hline
\end{tabular}


Young's modulus of HCCP-DHBP and HCCP-BPS can be explained by a higher cross-link density due to the lower pKa values, and thus more complete ionization into dianions, of the biphenols used to obtain the films. The significant standard deviation in the Young's modulus distribution could be caused by variation of tipfilm contact area due to an enhanced surface roughness. The broad distribution could also be caused by local modulus heterogeneities, due to differences in crosslink densities, but this argument remains speculative due to lack of data.
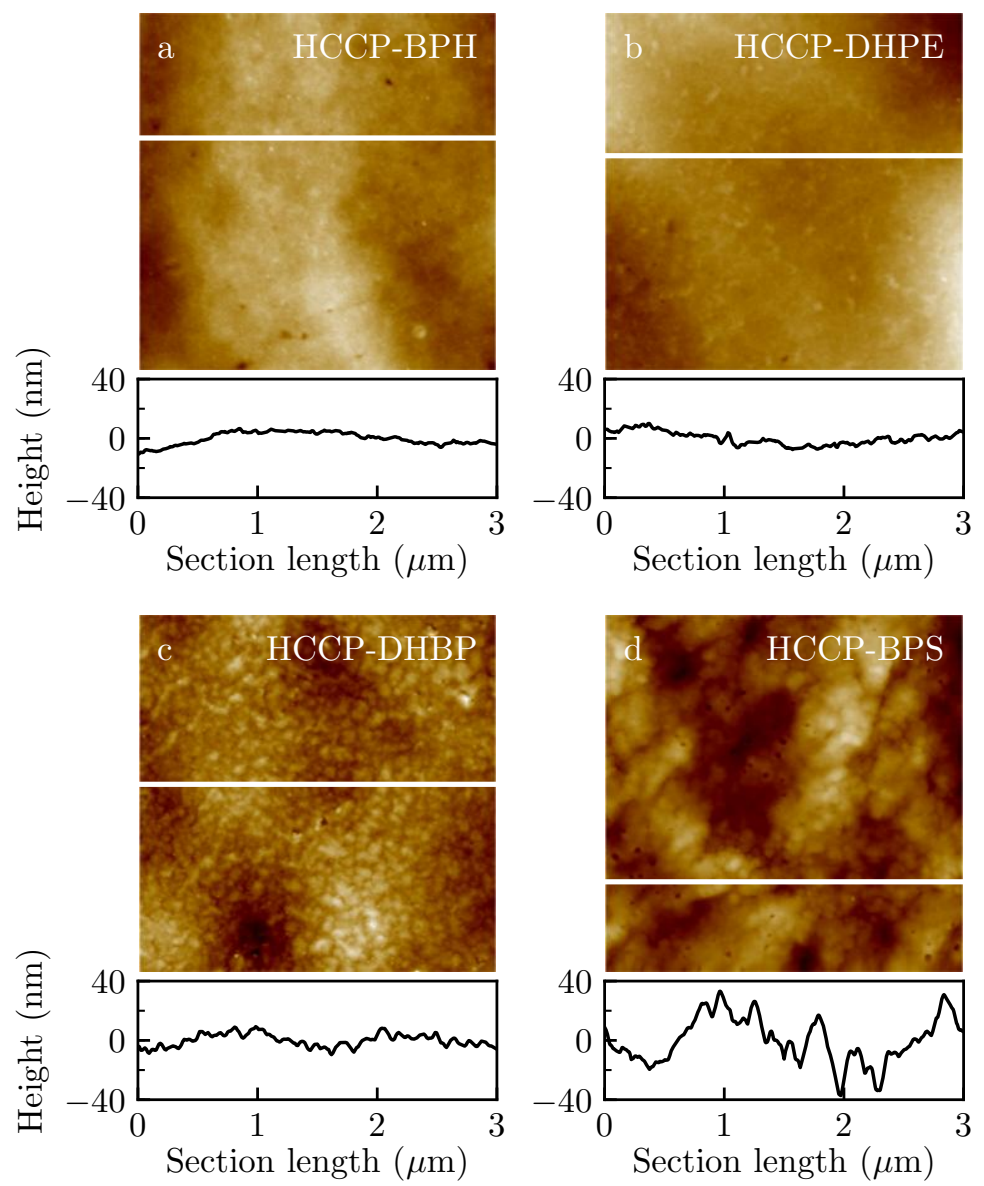

Figure 4.6: $A F M$ quantitative characterization: topographical images $\left(3 \times 3 \mu \mathrm{m}^{2}\right)$ for the organic side of (a) HCCP-BPH, (b) HCCP-DHPE, (c) HCCP-DHBP, and (d) HCCP-BPS films. Height profiles (cross-sections) of the samples were taken along the white lines shown. 

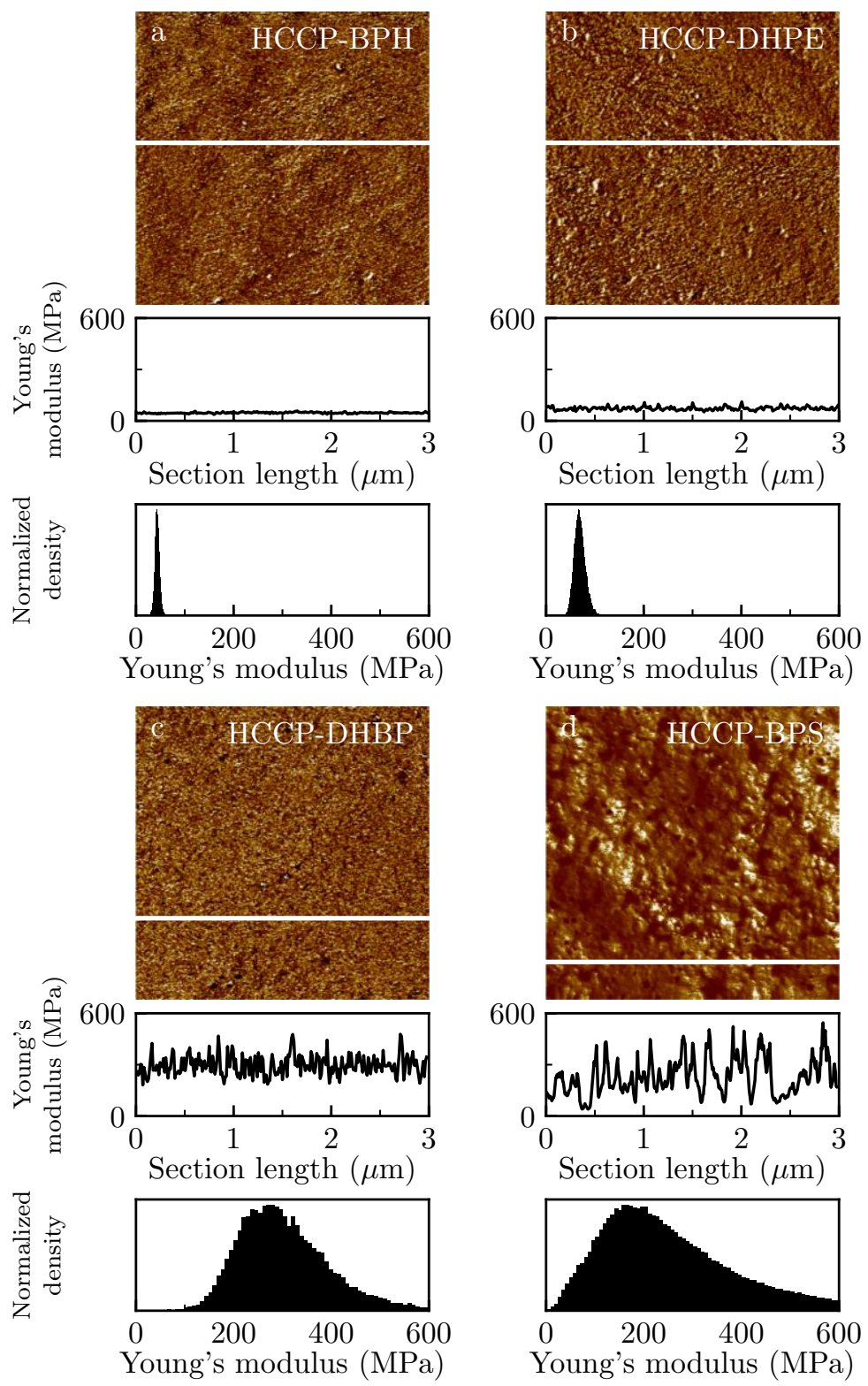

Figure 4.7: AFM quantitative characterization: Young's modulus images $\left(3 \times 3 \mu \mathrm{m}^{2}\right)$ for the organic side of (a) HCCP-BPH, (b) HCCP-DHPE, (c) HCCP-DHBP, and (d) HCCP-BPS films. Young's modulus profiles (cross-sections) of the samples were taken along the white lines shown. The corresponding distributions of Young's moduli are shown as histograms (obtained from all force-distance curves per map). 
The adhesion force maps (not shown) unveiled homogeneous distribution. The adhesion force value distributions are very narrow and exhibit average values within the range of $0.3-4.0 \mathrm{nN}$ for all samples. Taking into account the nominal radius of the AFM tip $(2 \mathrm{~nm})$, this can be converted into a tip-normalized adhesion ranging between 0.15 to $2.0 \mathrm{~N} \mathrm{~m}^{-1}$. The low values of the tip-normalized adhesion for HCCP-BPH, HCCP-DHPE, and HCCP-DHBP confirm that the surfaces of the films are hydrophobic, especially in the case of the rigid HCCP-DHBP films, as the capillary force contributions between the AFM tip and films seem to be greatly reduced ${ }^{[46,47]}$. The HCCP-BPS films show a much higher tip-normalized adhesion, indicating the more hydrophilic character of the film, originating from the sulfonyl-groups.

Table 4.3 shows the atomic composition of the surface of HCCP-biphenol films measured by XPS. Besides the atoms present in HCCP and the aromatic biphenol $(\mathrm{C}, \mathrm{N}, \mathrm{O}, \mathrm{P}, \mathrm{Cl}, \mathrm{S})$ there are some traces of $\mathrm{Si}$ and $\mathrm{Na}$ present at the surface of some of the films. Traces of Si are most likely due to the usage of the PDMS slabs. The traces of $\mathrm{Na}$ can be either from the presence of unreacted sodium aryloxide groups, or from the formation of $\mathrm{NaCl}$ during the condensation reaction. The $\mathrm{Cl}(2 \mathrm{p})$ peak for HCCP-DHPE and HCCP-DHBP can be fitted with two peaks, where one could be fitted with a peak having a maximum at $198.7 \mathrm{eV}$, that corresponds to the binding energy of $\mathrm{NaCl}^{[48]}$.

The number of reacted chlorine groups at the surface of the film can be calculated from various atomic ratio's. Since the atomic percentages of $\mathrm{O}$ and $\mathrm{Cl}$ can be influenced by the hydrolysis of $\mathrm{P}-\mathrm{Cl}$ to $\mathrm{P}-\mathrm{OH}$ in the presence of $\mathrm{H}_{2} \mathrm{O}$, and by the presence of $\mathrm{NaCl}$ entrapped in the network, only the number of reacted chlorine groups based on the ratio's $\mathrm{C} / \mathrm{N}$ and $\mathrm{C} / \mathrm{P}$ is reported. In general, the number of reacted chlorine groups of $\mathrm{HCCP}$ at the surface matches relatively well to the results obtained by AFM; HCCP-DHBP and HCCP-BPS possess a higher modulus, and are therefore more cross-linked. Again, we want to emphasize that this is a surface property, and cannot be correlated with bulk properties. 


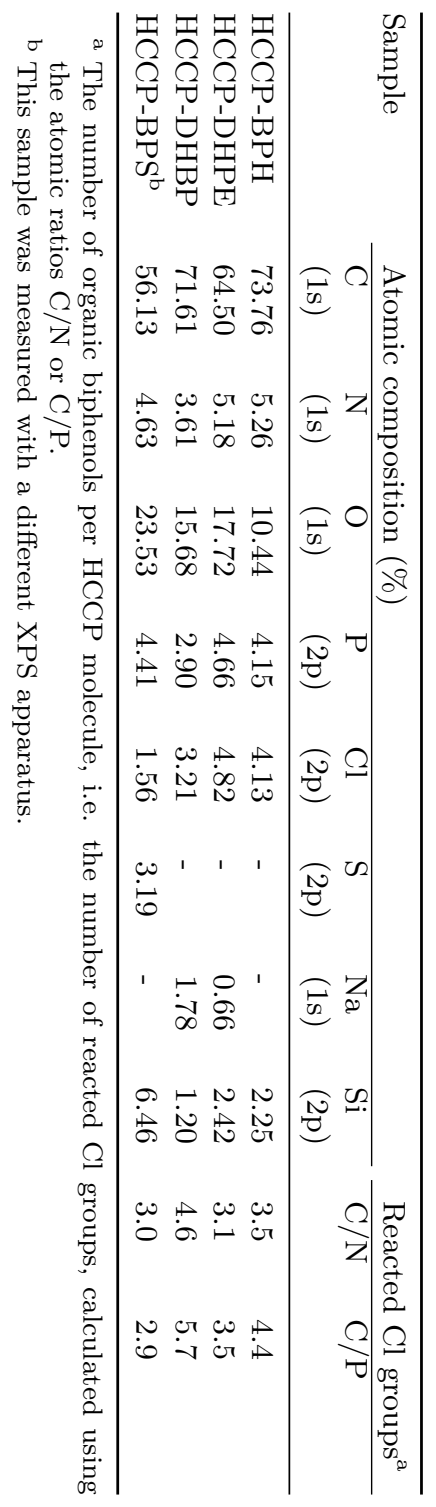

उ 겅

㺃

जे

壁

은

กิ่

종

î

함음

空

ญ ํㅡㄹ

怘

$\sum_{0}$
$\frac{1}{0}$
$\frac{1}{1}$

웅

ำ

ㅇํㄱ

용

마옹

훙 을

ค

는.

号 总

캄

范

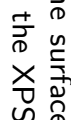

음 욱

站

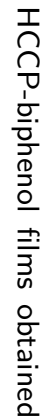

욱

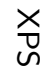


All films show a rather similar surface charge, independent of cross-link density. Figure 4.8 shows the zeta potential of HCCP-biphenol films as a function of $\mathrm{pH}$. The isoelectric point (IEP), i.e. the $\mathrm{pH}$ where the net surface charge is zero, was independent of the biphenol used. The HCCP-BPH film has an IEP of 5.0, HCCPDHPE of 4.6, HCCP-DHBP of 4.5, and HCCP-BPS of 4.8. The films have a highly negatively charged surface at $\mathrm{pH}$ values higher than the IEP. Zhou et al. ${ }^{[14]}$ and Chen et al. ${ }^{[49]}$ reported the zeta potential of HCCP-BPS microspheres in water in the same range as our data. The authors attribute this negative surface charge to the deprotonation of protruding phenolic hydroxy groups. Since the pKa of all biphenols used is much higher than the experimentally found IEP, there must be another functional group contributing to the IEP of the HCCP-biphenol films. As mentioned before, unreacted $\mathrm{P}-\mathrm{Cl}$ bonds can hydrolyze to $\mathrm{P}-\mathrm{OH}$ bonds. Therefore, we attribute the low IEP to the presence of these $\mathrm{P}-\mathrm{OH}$ groups. Calculating the pKa of several substituted (phenoxy)hydroxycyclotriphosphazenes using Chemicalize confirms this assumption ${ }^{[41]}$. At higher $\mathrm{pH}$, the HCCP-DHBP and HCCP-BPS films are more negatively charged compared to the HCCP-BPH and HCCP-DHPE films. This effect can be attributed to the pKa of the phenolic hydroxy groups. DHBP and BPS possess a significantly lower $\mathrm{pKa}_{1}$, and therefore contribute to the surface charge at lower $\mathrm{pH}$, resulting in a lower total surface charge compared to BPH and DHPE at the same $\mathrm{pH}$.

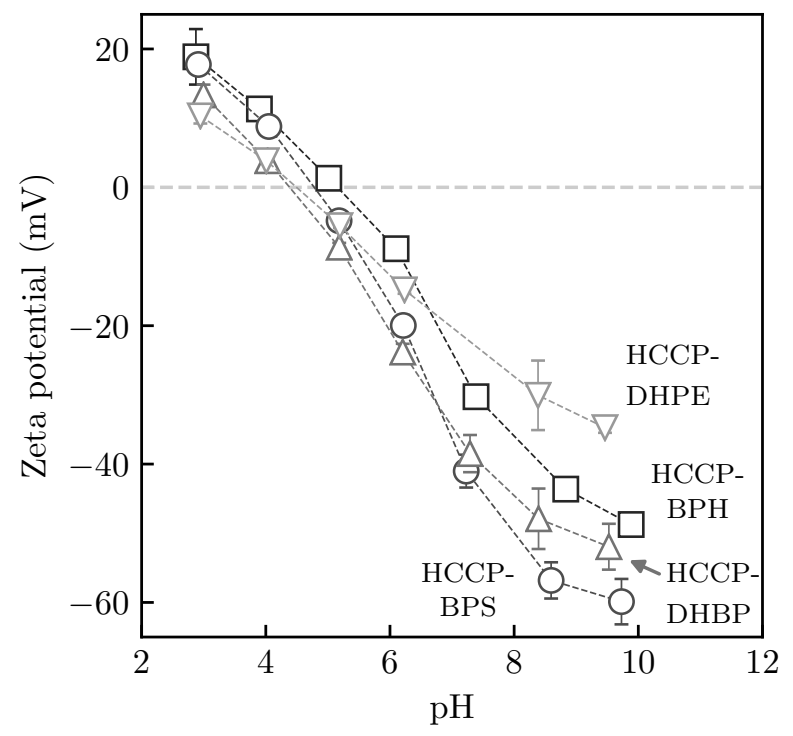

Figure 4.8: Zeta potential as function of $\mathrm{pH}$ for HCCP-BPH (ם), HCCP-DHPE ( $\nabla)$, HCCP$\operatorname{DHBP}(\triangle)$, and HCCP-BPS $(O)$. The error bars represent the $95 \%$ confidence interval, calculated from four data points. 
The thermal properties of HCCP-biphenol powders were characterized with DSC and TGA-MS. None of the powders showed a glass transition temperature in the DSC traces. This confirms the hyper-cross-linked nature of these materials.

Figure $4.9 \mathrm{a}$ shows the mass loss of HCCP-biphenol powders during heating to $600{ }^{\circ} \mathrm{C}$ with a heating rate of $10{ }^{\circ} \mathrm{C} \mathrm{min}-1$. Figure $4.9 \mathrm{~b}$ shows the mass loss during an isothermal phase at $600{ }^{\circ} \mathrm{C}$. Due to the incorporation of an inorganic monomer and the use of fully aromatic organic compounds, the HCCP-phenol networks show excellent thermal stability with mass loses of less than $25 \%$ after a two hour dwell at $600{ }^{\circ} \mathrm{C}$ under nitrogen atmosphere. This has been observed for all networks, except HCCP-BPS that shows a mass loss of $40 \%$ due to the less thermally stable sulfone group.

The gases evolved during heating were analyzed by a mass spectrometer as shown in Figure 4.10. The first fragments were detected starting at temperatures around $100{ }^{\circ} \mathrm{C}$, with a peak around $200{ }^{\circ} \mathrm{C}$ for all powders. Mainly fragments of $\mathrm{C}_{3} \mathrm{H}_{3}$ and $\mathrm{CO}_{2}$ evolved at this stage, although small traces of $\mathrm{H}_{2} \mathrm{O}$ and $\mathrm{HCl}$ were detected as well. The release of these fragments, except $\mathrm{HCl}$, is related to the decomposition of the organic biphenol. These decomposition fragments can originate from unreacted organic monomers entrapped in the network, as well as the thermal conversion of some P-O-C bonds to the more stable P-O-P bonds. The latter results in the release of the organic cross-linker, and would contribute to further cross-linking to ultimately produce a completely inorganic network ${ }^{[50,51]}$. The minor loss of $\mathrm{HCl}$ can originate from further reaction of HCCP with unreacted biphenols.
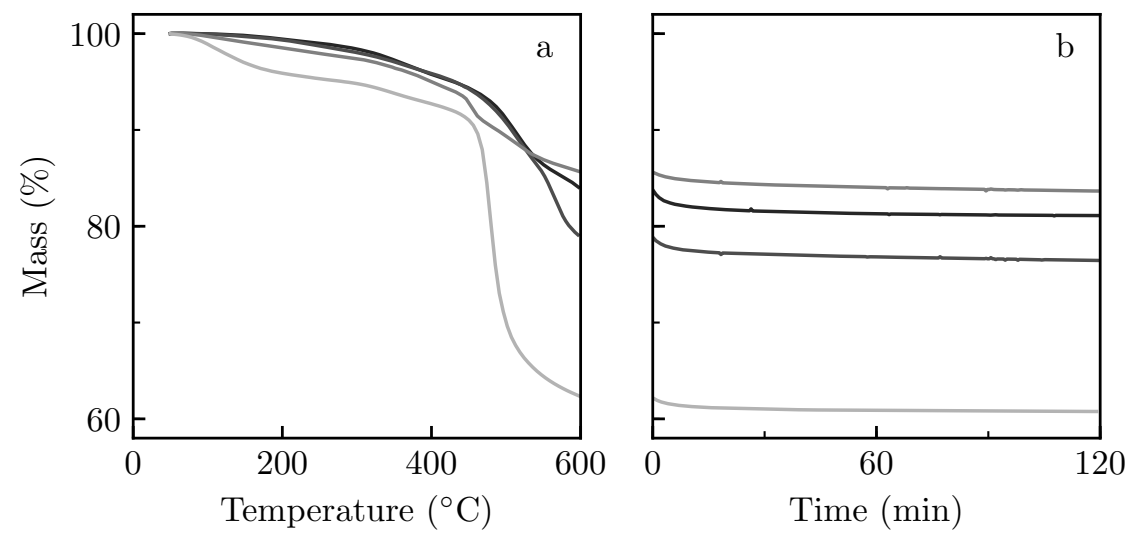

Figure 4.9: (a) Mass loss up to $600{ }^{\circ} \mathrm{C}$ as function of temperature for HCCP-biphenol powders under nitrogen atmosphere, obtained with a heating rate of $10^{\circ} \mathrm{C} \mathrm{min}^{-1}$. (b) Mass loss as a function of time at $600{ }^{\circ} \mathrm{C}$ for 2 hours showing that after an initial mass loss upon heating, the mass is stabilized. 

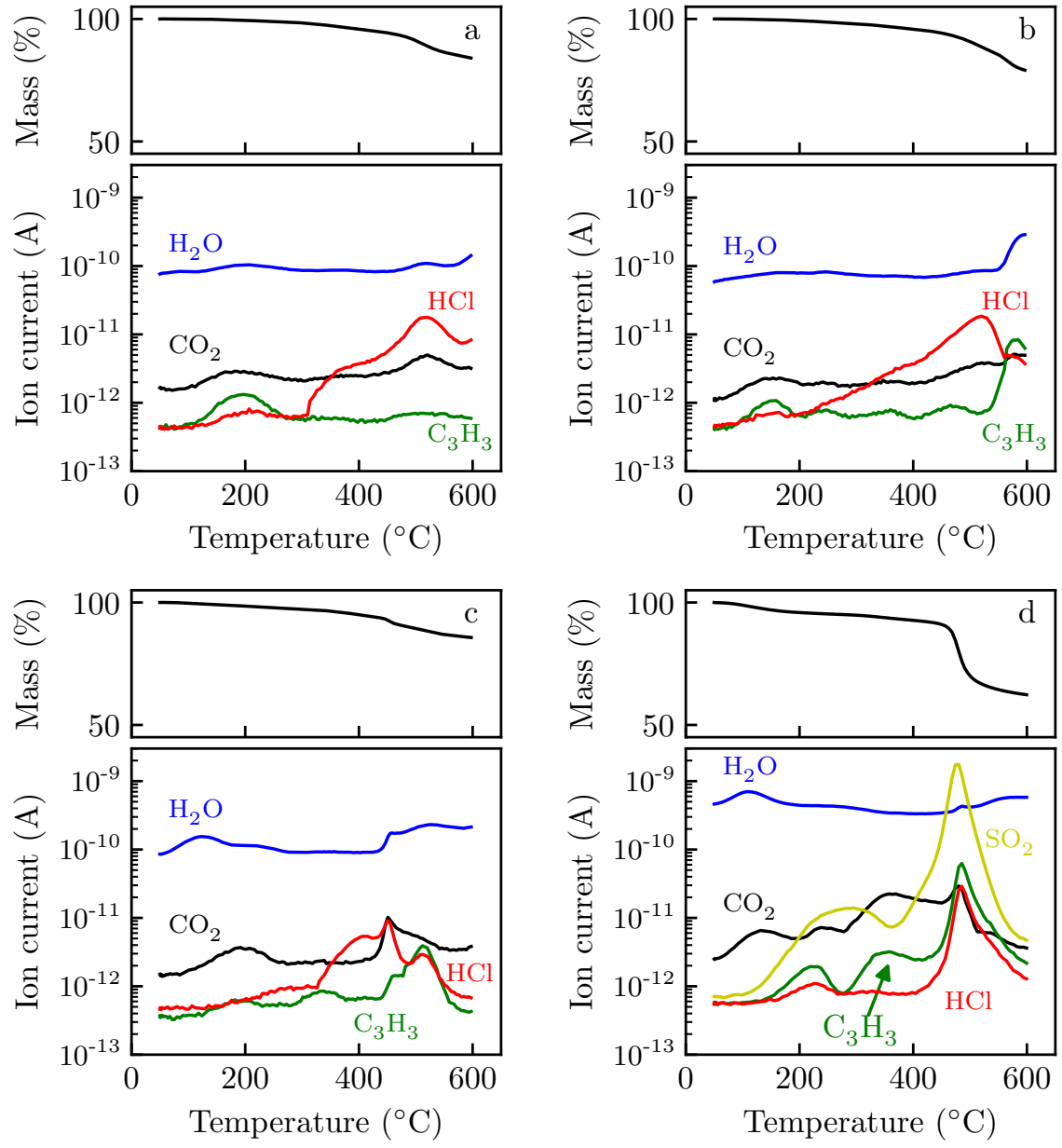

Figure 4.10: The mass loss (top) and mass spectrometer signal (bottom) upon heating for (a) HCCP-BPH, (b), HCCP-DHPE, (c) HCCP-DHBP, and (d) HCCP-BPS. The release of $\mathrm{H}_{2} \mathrm{O}(\mathrm{m} / z=18$, blue, -$), \mathrm{HCl}(m / z=37$, red, -$), \mathrm{C}_{3} \mathrm{H}_{3}(\mathrm{~m} / z=39$, green, - , fragment of aromatic rings), $\mathrm{CO}_{2}(m / z=44$, black, -$)$, and $\mathrm{SO}_{2}(m / z=64$, yellow, -$)$ is shown as function of temperature. 
Above $300{ }^{\circ} \mathrm{C}\left(400{ }^{\circ} \mathrm{C}\right.$ for HCCP-BPS $)$ a significant release of $\mathrm{HCl}$ is detected, followed by the release of $\mathrm{C}_{3} \mathrm{H}_{3}$ at temperatures above $450{ }^{\circ} \mathrm{C}$. The significant release of $\mathrm{HCl}$ can be explained by the decomposition of $\mathrm{P}-\mathrm{Cl}$ bonds. Due to the hyper-cross-linked nature of the material, unreacted $\mathrm{P}-\mathrm{Cl}$ bonds are present. This is caused by highly cross-linked nature of the material; the nucleophile such as a biphenol, or even water, is not able to reach all the reactive sites within the network. The release of $\mathrm{C}_{3} \mathrm{H}_{3}$ above $450{ }^{\circ} \mathrm{C}$ proves that the material is still hybrid in nature at this temperature, despite partial decomposition of the biphenol at lower temperatures.

All networks show the same trends regarding the fragments that are released upon heating and only minor differences are found when considering in more detail. HCCP-BPH shows barely any release of aromatic fragments at temperatures above $450{ }^{\circ} \mathrm{C}$ due to the fully aromatic structure of the biphenol, whereas HCCP-DHPE and HCCP-DHBP have an ether or a ketone linker, respectively; slightly reducing the thermal stability at elevated temperatures. Introducing a sulfone group greatly reduces the stability of the biphenol, and thus the network, as can be concluded from Figure 4.10d.

The release of $\mathrm{HCl}$ and $\mathrm{SO}_{2}$ has the highest contribution to the overall mass loss of the powders when considering the peak area of the MS signal. The release of $\mathrm{HCl}$ can be related to the cross-link density of the material. Of all biphenols, HCCP-DHBP shows the smallest release of $\mathrm{HCl}$ relative to the $\mathrm{CO}_{2}$ signal, which corresponds well to the cross-link density and the highest residual mass. Note that the area of the peaks among the samples is not directly comparable due to the difference in absolute sample mass.

In contrast, HCCP-BPS shows the lowest residual mass. This is mainly caused by the decomposition of the bisphenol $\mathrm{S}$ biphenol, as proven by the release of $\mathrm{SO}_{2}$. The significant mass loss at $500{ }^{\circ} \mathrm{C}$ and the residual mass of $60 \%$ at $600{ }^{\circ} \mathrm{C}$ corresponds well to the findings of Chen-Yang et al. ${ }^{[52]}$ for the chemically similar cyclolinear polymer. The performance of these thin cross-linked polymer films clearly matches that of their linear bulk analogues, thus demonstrating the potential of the interfacial fabrication method.

Additionally, these HCCP-biphenol films possess unreacted chlorine groups at the surface (Table 4.3) that are available for post-functionalization via nucleophilic substitution with a mono-functionalized nucleophile. Chapter 8 will report in more detail on the post-functionalization of these HCCP-biphenol films.

\subsection{Conclusion}

We showed a simple and fast preparation of hybrid cyclomatrix polyphosphazene films made by interfacial polymerization, and provided a detailed characterization of the films obtained. Different aromatic biphenols were used, resulting in films with different cross-link densities and hence different mechanical properties. The 
pKa of the biphenol is found to be an important parameter to tune the film properties. A lower pKa results in a higher cross-link density and yielded films with a smooth surface morphology and high Young's moduli, whereas a high pKa results in rough surface morphology and moderate Young's moduli.

\subsection{Acknowledgements}

This work took place within the framework of the Institute for Sustainable Process Technology (ISPT, project BL-20-02) and by the MESA ${ }^{+}$Institute of Nanotechnology at the University of Twente.

The authors thank Joachim Roes from DWI - Leibniz-Institut für Interaktive Materialien, Aachen Germany for performing the XPS measurements. 


\subsection{References}

[1] Kickelbick, G. Concepts for the incorporation of inorganic building blocks into organic polymers on a nanoscale. Progress in Polymer Science 2003, 28, 83 - 114.

[2] Drisko, G. L.; Sanchez, C. Hybridization in Materials Science - Evolution, Current State, and Future Aspirations. European Journal of Inorganic Chemistry 2012, 2012, 5097-5105.

[3] Allcock, H. R. Inorganic-Organic Polymers. Advanced Materials 1994, 6, 106-115.

[4] Allcock, H. R. Chemistry and Applications of Polyphosphazenes; John Wiley \& Sons, 2002.

[5] Rothemund, S.; Teasdale, I. Preparation of polyphosphazenes: a tutorial review. Chem. Soc. Rev. 2016, 45, 5200-5215.

[6] Manners, I.; Allcock, H. R.; Renner, G.; Nuyken, O. Poly(carbophosphazenes): a new class of inorganic-organic macromolecules. Journal of the American Chemical Society 1989, 111, 5478-5480.

[7] Jaeger, R.; Debowski, M.; Manners, I.; Vancso, G. J. Study of the Molecular Geometry, Electronic Structure, and Thermal Stability of Phosphazene and Heterophosphazene Rings with ab Initio Molecular Orbital Calculations. Inorganic Chemistry 1999, 38, 1153-1159.

[8] Chandrasekhar, V. Inorganic and Organometallic Polymers; Springer Berlin Heidelberg, 2005.

[9] Allcock, H. R. Hybrids of hybrids: nano-scale combinations of polyphosphazenes with other materials. Applied Organometallic Chemistry 2010, 24, 600-607.

[10] Allcock, H. R. Polyphosphazene elastomers, gels, and other soft materials. Soft Matter 2012, 8, 7521-7532.

[11] Köhler, J.; Kühl, S.; Keul, H.; Möller, M.; Pich, A. Synthesis and characterization of polyamine-based cyclophosphazene hybrid microspheres. Journal of Polymer Science Part A: Polymer Chemistry 2014, 52, 527-536.

[12] Kumar, D.; Fohlen, G. M.; Parker, J. A. Fire- and heat-resistant laminating resins based on maleimido-substituted aromatic cyclotriphosphazenes. Macromolecules 1983, 16, 12501257.

[13] Mathew, D.; Nair, C. R.; Ninan, K. Phosphazene-triazine cyclomatrix network polymers: some aspects of synthesis, thermal- and flame-retardant characteristics. Polymer International 2000, 49, 48-56.

[14] Zhou, J.; Meng, L.; Feng, X.; Zhang, X.; Lu, Q. One-Pot Synthesis of Highly Magnetically Sensitive Nanochains Coated with a Highly Cross-Linked and Biocompatible Polymer. Angewandte Chemie International Edition 2010, 49, 8476-8479.

[15] Wei, W.; Huang, X.; Chen, K.; Tao, Y.; Tang, X. Fluorescent organic-inorganic hybrid polyphosphazene microspheres for the trace detection of nitroaromatic explosives. $R S C$ Adv. 2012, 2, 3765-3771.

[16] Kumar, D. Adhesives produced by reaction of hexachlorocyclotriphosphazene with phenols, bisphenols and benzilic acid. International Journal of Adhesion and Adhesives 1998, 18, $109-113$.

[17] Wei, W.; Huang, X.; Zhao, X.; Zhang, P.; Tang, X. A rapid and efficient strategy for preparation of super-hydrophobic surface with cross-linked cyclotriphosphazene/6F-bisphenol A copolymer microspheres. Chem. Commun. 2010, 46, 487-489.

[18] Huang, Z.; Zheng, F.; Chen, S.; Lu, X.; Catharina Elizabeth van Sittert, C. G.; Lu, Q. A strategy for the synthesis of cyclomatrix-polyphosphazene nanoparticles from non-aromatic monomers. RSC Adv. 2016, 6, 75552-75561.

[19] Vandezande, P.; Gevers, L. E. M.; Vankelecom, I. F. J. Solvent resistant nanofiltration: separating on a molecular level. Chem. Soc. Rev. 2008, 37, 365-405.

[20] Lau, W.; Ismail, A.; Misdan, N.; Kassim, M. A recent progress in thin film composite membrane: A review. Desalination 2012, 287, 190 - 199, Special Issue in honour of Professor Takeshi Matsuura on his 75th Birthday. 
[21] Raaijmakers, M. J.; Benes, N. E. Current trends in interfacial polymerization chemistry. Progress in Polymer Science 2016, 63, 86 - 142.

[22] Thompson, T. N.; Ramos-Hunter, S.; Robertson, J.; Arnett, N. Y. Interfacial synthesis of bisphenol A tetrachlorocyclotriphosphazene from bisphenol A and hexachlorocyclotriphosphazene. Tetrahedron Letters 2013, 54, 5311 - 5313.

[23] Chen-Yang, Y. W.; Cheng, S. J.; Tsai, B. D. Preparation of the partially substituted (phenoxy)chlorocyclotriphosphazenes by phase-transfer catalysis. Industrial \& Engineering Chemistry Research 1991, 30, 1314-1319.

[24] Zhu, L.; Xu, Y.; Yuan, W.; Xi, J.; Huang, X.; Tang, X.; Zheng, S. One-Pot Synthesis of Poly(cyclotriphosphazene-co-4,4'-sulfonyldiphenol) Nanotubes via an In-Situ Template Approach. Advanced Materials 2006, 18, 2997-3000.

[25] Zhu, L.; Zhu, Y.; Pan, Y.; Huang, Y.; Huang, X.; Tang, X. Fully Crosslinked Poly[cyclotriphosphazene-co-(4,4'-sulfonyldiphenol)] Microspheres via Precipitation Polymerization and Their Superior Thermal Properties. Macromolecular Reaction Engineering 2007, 1, 45-52.

[26] Zhu, Y.; Huang, X.; Li, W.; Fu, J.; Tang, X. Preparation of novel hybrid inorganic-organic microspheres with active hydroxyl groups using ultrasonic irradiation via one-step precipitation polymerization. Materials Letters 2008, 62, 1389 - 1392.

[27] Fu, J.; Xu, Q.; Chen, J.; Chen, Z.; Huang, X.; Tang, X. Controlled fabrication of uniform hollow core porous shell carbon spheres by the pyrolysis of core/shell polystyrene/crosslinked polyphosphazene composites. Chem. Commun. 2010, 46, 6563-6565.

[28] Wei, W.; Lu, R.; Xie, H.; Zhang, Y.; Bai, X.; Gu, L.; Da, R.; Liu, X. Selective adsorption and separation of dyes from an aqueous solution on organic-inorganic hybrid cyclomatrix polyphosphazene submicro-spheres. J. Mater. Chem. A 2015, 3, 4314-4322.

[29] Schön, P.; Bagdi, K.; Molnár, K.; Markus, P.; Pukánszky, B.; Vancso, G. J. Quantitative mapping of elastic moduli at the nanoscale in phase separated polyurethanes by $\{$ AFM $\}$. European Polymer Journal 2011, 47, 692 - 698, Designer polymers: Controlled synthesis, structure-property relationships and applications (Dedicated to Professor Nikos Hadjichristidis in recognition of his contribution to polymer science).

[30] Gojzewski, H.; Imre, B.; Check, C.; Chartoff, R.; Vancso, J. Mechanical mapping and morphology across the length scales unveil structure-property relationships in polycaprolactone based polyurethanes. Journal of Polymer Science Part B: Polymer Physics 2016, $54,2298-2310$.

[31] Hutter, J. L.; Bechhoefer, J. Calibration of atomic-force microscope tips. Review of Scientific Instruments 1993, 64, 1868-1873.

[32] Sader, J. E.; Larson, I.; Mulvaney, P.; White, L. R. Method for the calibration of atomic force microscope cantilevers. Review of Scientific Instruments 1995, 66, 3789-3798.

[33] Butt, H.-J.; Cappella, B.; Kappl, M. Force measurements with the atomic force microscope: Technique, interpretation and applications. Surface Science Reports 2005, 59, 1 - 152.

[34] Cappella, B.; Dietler, G. Force-distance curves by atomic force microscopy. Surface Science Reports 1999, 34, $1-104$.

[35] Bruker, PeakForce QNM User Guide; 2011.

[36] Gojzewski, H.; Sadej, M.; Andrzejewska, E.; Kokowska, M. Nanoscale Young's modulus and surface morphology in photocurable polyacrylate/nanosilica composites. European Polymer Journal 2017, 88, $205-220$.

[37] Wang, Z.; Volinsky, A. A.; Gallant, N. D. Crosslinking effect on polydimethylsiloxane elastic modulus measured by custom-built compression instrument. Journal of Applied Polymer Science 2014, 131, n/a-n/a.

[38] Scott, D. W. Scott's rule. Wiley Interdisciplinary Reviews: Computational Statistics 2010, 2, 497-502.

[39] Raaijmakers, M. J. T.; Kappert, E. J.; Nijmeijer, A.; Benes, N. E. Thermal Imidization Kinetics of Ultrathin Films of Hybrid Poly(POSS-imide)s. Macromolecules 2015, 48, 30313039 . 
[40] Reijenga, J.; van Hoof, A.; van Loon, A.; Teunissen, B. Development of Methods for the Determination of pK(a) Values. Analytical Chemistry Insights 2013, 8, 53-71.

[41] ChemAxon, Chemicalize. https://chemicalize.com/welcome, 2017.

[42] Sydam, R.; Deepa, M. A new organo-inorganic hybrid of poly(cyclotriphosphazene-4,4'bipyridinium)chloride with a large electrochromic contrast. J. Mater. Chem. C 2013, 1, 7930-7940.

[43] Ghosh, A. K.; Jeong, B.-H.; Huang, X.; Hoek, E. M. Impacts of reaction and curing conditions on polyamide composite reverse osmosis membrane properties. Journal of Membrane Science 2008, 311, $34-45$.

[44] Khorshidi, B.; Thundat, T.; Fleck, B. A.; Sadrzadeh, M. A Novel Approach Toward Fabrication of High Performance Thin Film Composite Polyamide Membranes. Scientific Reports 2016, 6, 22069.

[45] Zhang, Y.; Benes, N. E.; Lammertink, R. G. H. Visualization and characterization of interfacial polymerization layer formation. Lab Chip 2015, 15, 575-580.

[46] Butt, H.-J.; Kappl, M. Normal capillary forces. Advances in Colloid and Interface Science 2009, 146, $48-60$.

[47] Ptak, A.; Gojzewski, H.; Kappl, M.; Butt, H.-J. Influence of humidity on the nanoadhesion between a hydrophobic and a hydrophilic surface. Chemical Physics Letters 2011, 503, 66 -70 .

[48] Moulder, J. F.; Stickle, W. F.; Sobol, P. E.; Bomben, K. D. In Handbook of X-ray Photoelectron Spectroscopy; Chastain, J., Ed.; Perkin-Elmer Corporation, 1992.

[49] Chen, Z.; Fu, J.; Wang, M.; Wang, X.; Zhang, J.; Xu, Q. Adsorption of cationic dye (methylene blue) from aqueous solution using poly(cyclotriphosphazene-co-4,4'-sulfonyldiphenol) nanospheres. Applied Surface Science 2014, 289, 495 - 501.

[50] Maynard, S. J.; Sharp, T. R.; Haw, J. F. Thermal degradation chemistry of poly(diphenoxyphosphazene). Macromolecules 1991, 24, 2794-2799.

[51] Gouri, M. E.; Bachiri, A. E.; Hegazi, S. E.; Rafik, M.; Harfi, A. E. Thermal degradation of a reactive flame retardant based on cyclotriphosphazene and its blend with $\{$ DGEBA epoxy resin. Polymer Degradation and Stability 2009, 94, $2101-2106$.

[52] Chen-Yang, Y. W.; Jiang, J. S.; Ho, Y. W.; Cheng, S. J. Syntheses and thermal properties of (sulfonylbisphenoxy)-containing cyclotriphosphazene polymers. Journal of Inorganic and Organometallic Polymers 1992, 2, 243-254. 


\section{Chapter 5}

\section{The synthesis and pH-stability of poly(aryl ether) films prepared by interfacial polymerization of cyanuric chloride with trialchols}

This chapter is adapted from:

Evelien Maaskant, Wouter Vogel, Theo J. Dingemans, Nieck E. Benes, Synthesis and $\mathrm{pH}$-stability of poly(aryl ether) films prepared by interfacial polymerization of cyanuric chloride with trialchols, Manuscript in preparation 


\begin{abstract}
A series of pH-stable poly(aryl ether)s has been synthesized by the interfacial polymerization of cyanuric chloride (CC) with trifunctional (fully) aromatic alcohols. The use of cyanuric chloride instead of more commonly used acyl chlorides, eliminates the presence of a carbonyl group, strongly enhancing the $\mathrm{pH}$-stability. The pH-stability of the CC-trialcohol films was tested by immersing supported films into water, $0.1 \mathrm{M} \mathrm{NaOH}$, or $0.1 \mathrm{M} \mathrm{HNO}_{3}$, respectively, for periods up to 6 weeks. Top-view scanning electron micrographs did not show a significant change in surface morphology, indicating the potential pH-stability of these CC-trialcohol films. Additionally, it was found that the thickness of the films could be varied from a few micrometer down to the nanometer scale, by altering the size of the monomer and the reaction time.
\end{abstract}




\section{$5.1 \quad$ Introduction}

Polyamides are very important polymers in current engineering technologies. Both aliphatic and aromatic polyamides are commonly used in, e.g., food packaging, membranes, or electronics ${ }^{[1]}$. Unfortunately, polyamides lack stability at extreme $\mathrm{pH}$ conditions. The amide bond can be hydrolyzed to the parent carboxylic acid and amine in the presence of a strong acid or base. In both the acid and base catalyzed hydrolysis, the carbonyl moiety plays an important role. Eliminating this carbonyl group, and thus preparing a polyamine, will significantly enhance the stability of the polymer at extreme $\mathrm{pH}$ conditions.

A versatile monomer to prepare polyamines is cyanuric chloride (CC). CC has a triazine core, with three chlorine side groups available for nucleophilic substitution with, e.g., sulfurs, amines or alcohols in the presence of an acid scavenger ${ }^{[2,3]}$. The reactivity of $\mathrm{CC}$ decreases with the number of substituted chlorine atoms, and therefore the substitution can be controlled in a step-wise manner. The first chlorine group is able to undergo nucleophilic substitution at temperatures around $0{ }^{\circ} \mathrm{C}$, the second chlorine group reacts at room temperature, and the third reacts only under reflux conditions ${ }^{[4,5]}$.

There are many examples of (multi-step) substitution of cyanuric chloride with nucleophiles to obtain symmetrically trisubstituted triazines ${ }^{[6-9]}$ or asymmetric substituted triazines ${ }^{[10,11]}$. Besides functionalized molecules, linear ${ }^{[12-14]}$ or hyperbranched $^{[4,14-16]}$ polymers could be obtained. The stability of these triazine polymers can be further increased by cross-linking, i.e. the formation of a covalent network.

Dallas et al. ${ }^{[17]}$ synthesized covalent networks as ion-exchangers of CC and either benzidine or $p$-phenylenediamine (PPD), although the authors did not analyze their $\mathrm{pH}$ stability. Another example of such a network is the work of Wang et al. ${ }^{[18]}$ where the authors synthesized networks of CC and PPD or melamine for $\mathrm{CO}_{2}$ adsorption, but these networks were not evaluated for their $\mathrm{pH}$ stability either. However, the $\mathrm{pH}$ stability of membranes synthesized from $\mathrm{CC}$ and polyethylenimine (PEI) by interfacial polymerization has been evaluated by Lee et al. ${ }^{[19]}$. These membranes showed excellent stability at extreme $\mathrm{pH}$ conditions $(\mathrm{pH} 1-13)$. In later work, the authors synthesized membranes of $\mathrm{CC}$ and monomeric amines ${ }^{[20]}$. The authors showed that the amine should have at least a functionality of three for successful film formation, which relates perfectly well to the lower reactivity of $\mathrm{CC}$ at room temperature.

In contrast to most of the reported CC networks, Lee et al. ${ }^{[19]}$ used interfacial polymerization (IP) for the formation of the covalent CC-based network. The two (or more) monomers involved in IP are dissolved in two immiscible phases, and only at the interface these monomers react to form a polymer. If one of the reactants has a higher functionality, a cross-linked network is formed. Due to the localized nature of the reaction, a defect-free ultra-thin film can be formed in-situ where needed $^{[21-23]}$. Although IP can be performed at temperatures deviating from room 


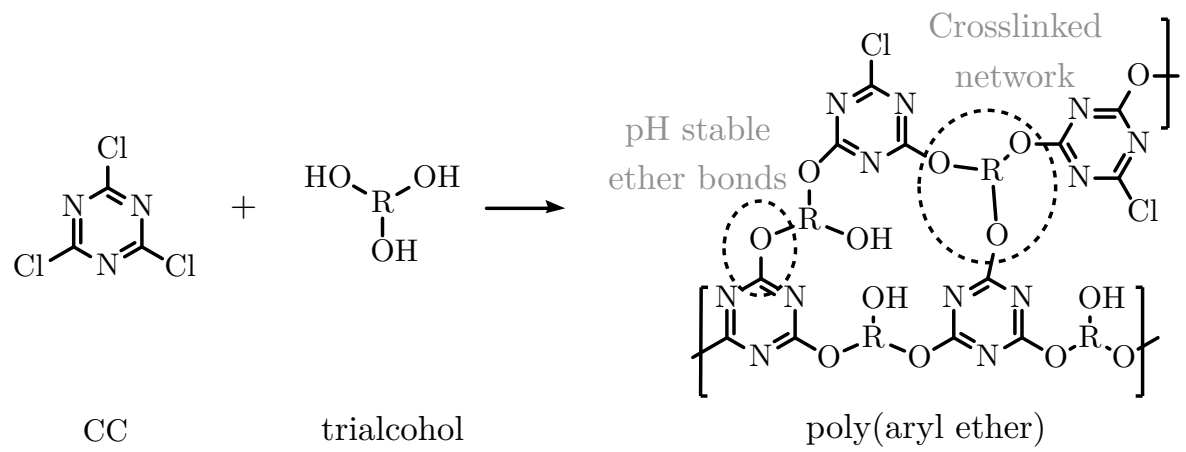

Scheme 5.1: The formation of a cross-linked poly(aryl ether) from the reaction of cyanuric chloride with a trifunctional alcohol. The ether bonds provide more stability in extreme $\mathrm{pH}$ conditions than, for example, amide bonds.

temperature ${ }^{[24-26]}$, it is often performed at room temperature, therefore allowing at most two of the chlorine groups of $\mathrm{CC}$ to react. To allow for the successful formation of CC-based cross-linked networks, the nucleophile should have at least three reactive groups.

In this work, we show, in addition to the work of Lee et al., that pH-stable films could also be obtained from the reaction of $\mathrm{CC}$ with trifunctional (aromatic) alcohols, resulting in a poly(aryl ether) as depicted in Scheme 5.1. Due to the localized nature of interfacial polymerization, very thin yet highly crosslinked films could be prepared. We synthesized two fully aromatic trialcohols, namely benzene-1,3,5-triyltris(4-hydroxyphenyl)methanone (compound 2) and compound 4 ; the azomethine prepared from tris(4-aminophenyl)amine and $p$-hydroxybenzophenone. In this work, we compare the stability of the networks prepared from these newly synthesized monomers to that of the networks prepared from the commercial available (fully) aromatic trialcohols phloroglucinol (PG) and 1,1,1-tris(4-hydroxyphenyl)ethane (TPE).

\section{$5.2 \quad$ Experimental}

\subsubsection{Materials}

Tris(4-nitrophenyl)amine $\quad(>96 \%), \quad$ 1,1,1-tris(4-hydroxyphenyl)ethane (TPE, $>98 \%$ ), and 4-hydroxybenzaldehyde $(>98 \%)$ were obtained from TCI Europe. Methanol was obtained from Merck, and toluene was obtained from Alfa Aesar. Cyanuric chloride (CC, 99\%), sodium hydroxide $(\mathrm{NaOH})$, phloroglucinol (PG, $\geq 99 \%$ ), $p$-toluene sulfonic acid monohydrate ( $p$-TSA), isopropyl alcohol (IPA), chloroform $\left(\mathrm{CHCl}_{3}\right), \mathrm{Pd} / \mathrm{C}(10 \mathrm{wt} \%)$ and dried tetrahydrofuran (THF, Seccosolve) were obtained from Sigma-Aldrich, the Netherlands. All chemicals were used as 
received. Deionized water (18.2 $\mathrm{M} \Omega \mathrm{cm}$, Milli-Q Advantage A10, Millipore) was used in all experiments.

\subsubsection{Synthesis of $\mathrm{pH}$ stable films}

$\mathrm{pH}$-stable films were prepared by the interfacial polymerization of $\mathrm{CC}$ and a (partially) aromatic trialcohol as depicted in Scheme 5.1. The synthesis procedure of monomers 2 and $\mathbf{4}$ can be found in the supporting information. The molecular structure, molecular weight, and concentrations used for each monomer is shown in Table 5.1. The trialcohol was dissolved in the aqueous phase together with 6 molar equivalents $\mathrm{NaOH}$. $\mathrm{CC}$ was dissolved in toluene; the organic phase. Typical procedures for the preparation of supported $\mathrm{pH}$ stable films are given below for various supports.

\section{Films on silicon wafers}

A silicon wafer was fixed to the bottom of a petri dish using adhesive carbon tape. The aqueous phase $(5 \mathrm{~mL})$ was poured into the petri dish. The organic phase $(5 \mathrm{~mL})$ was carefully poured atop of the aqueous phase to prevent any distortions of the water-solvent interface. Both the aqueous and organic phase were discarded when film formation was complete. This results in a wrinkled film at the bottom of the petri dish. The film was carefully rinsed with water while retaining contact with the petri dish at at least one point. The coated silicon wafer was dried using a gentle nitrogen flow to reduce wrinkles in the film.

\section{Films on PESf ultrafiltration membranes}

Hydrophilized polyethersulfone (PESf) ultrafiltration membranes (MicrodynNadir, UH 030, Germany) were clamped in an aluminum frame. The PES support was soaked with the aqueous solution for 5 minutes. The excess aqueous solution was poured off, and the PES support was dried for 10 minutes in a nitrogen chamber $(<5 \%$ relative humidity) to remove water droplets from the surface. After drying, the organic solution was gently poured on top of the PES support. After 30 s reaction time, the organic phase was discarded. The formed film was washed with acetone to remove any unreacted monomer. The PES supported films were stored in water until use.

\section{Films on Anodiscs}

A few droplets of the aqueous phase were soaked into anodized aluminum oxide membrane discs (Anodisc) with a pore size of $0.02 \mu \mathrm{m}$ (Whatman, GE Healthcare). The excess aqueous solution was removed with tissue wipes, and the Anodisc 


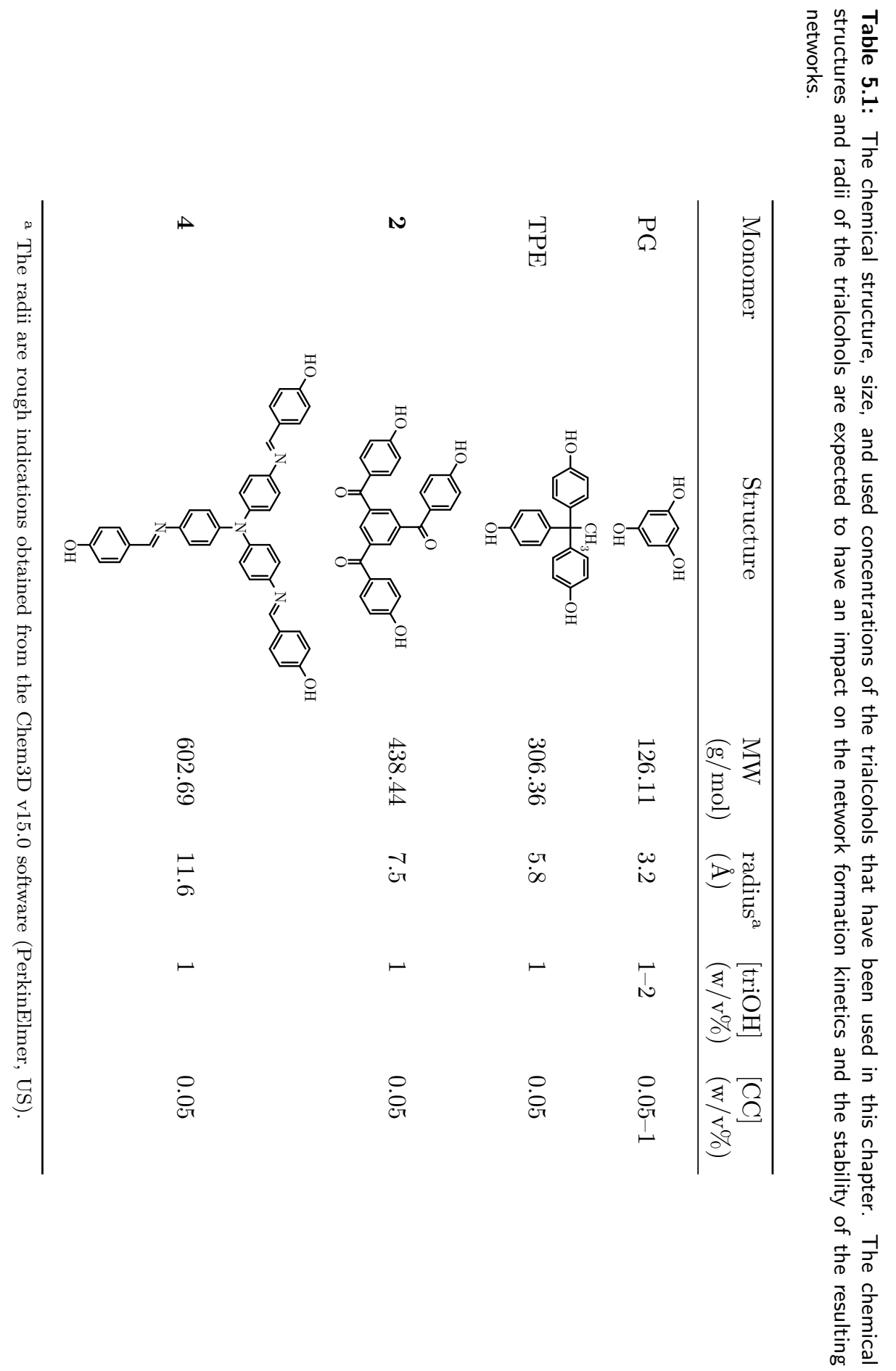


surface was further dried using a gentle flow of nitrogen. A few drops of the organic solution were placed on top of the Anodisc. The reaction was stopped by washing the Anodisc with subsequently acetone and water.

\subsubsection{Characterization}

Fourier-transform infrared spectroscopy (FTIR) spectra of CC-trialcohol films on a silicon wafer were recorded on a Vertex V70 (Bruker, Germany). A background spectrum was taken on a piranha cleaned silicon wafer. All spectra were obtained in transmittance mode. The average of 64 scans with a resolution of $4 \mathrm{~cm}^{-1}$ was taken.

Scanning electron micrographs were taken with a JEOL JSM-7610 field emission scanning electron microscope (FE-SEM). Samples were coated with a $5 \mathrm{~nm}$ chromium layer (Quorum Q150T ES) prior to imaging.

The film thickness of CC-trialcohol films on silicon wafers was measured by spectroscopic ellipsometry. An M2000X spectroscopic ellipsometer (J.A. Woollam Co., US) was equipped with focussing probes. Spectra were recorded at three incident angles: $65^{\circ}, 70^{\circ}$, and $75^{\circ}$. The thickness of the films were obtained by fitting the data to a model using the CompleteEase software package (v4.86, J.A. Woollam Co., US). The film was modeled as a Cauchy layer atop of a silicon wafer bearing a $2 \mathrm{~nm}$ native oxide layer.

Combined thermogravimetric analysis (TGA) and mass spectroscopy (MS) measurements were performed using an STA 449 F3 Jupiter TGA with an alumina sample cup (Netzsch, Germany) and QMS 403 D Aeolos MS (Netzsch, Germany). Powders were heated with a heating rate of $10{ }^{\circ} \mathrm{C} \mathrm{min}-1$ under a nitrogen atmosphere. A more detailed description of the experiments can be found in reference $^{[27]}$.

The stability of the CC-trialcohol films was tested by immersing PES-supported films in acidic and basic environments for up to 6 weeks. Strips of PES supported CC-trialcohol films (approximately $0.5 \times 4 \mathrm{~cm}^{2}$ ) were submerged in $20 \mathrm{~mL}$ of either water, $0.1 \mathrm{M} \mathrm{NaOH}$, or $0.1 \mathrm{M} \mathrm{HNO}_{3}$. The strips were removed from the solutions after 1, 2, 4, and 6 weeks, and thoroughly washed with water. All strips were dried in a vacuum oven overnight prior to FE-SEM analysis. 


\subsection{Results and discussion}

\subsubsection{Synthesis of pH-stable films}

The simplest aromatic trialcohol that could be used in the interfacial polymerization with CC is 1,3,5-trihydroxybenzene, or phloroglucinol. Despite the use of 6 molar equivalent of $\mathrm{NaOH}$, no film formation was observed, even when reaction times as long as 24 hours were applied. This lack of film formation could be caused by the tautomerism of phloroglucinol to 1,3,5-cyclohexanetrione. The dissociation and keto-enol tautomerism of phloroglucinol is strongly dependent on the $\mathrm{pH}$ of the solution. The phloroglucinolate trianion is found to have a pKa of $14^{[28,29]}$. This in combination with the less reactive CC makes phloroglucinol unsuitable for interfacial polymerization.

In contrast, film formation was observed immediately for the other trialcohols TPE, 2, and 4. Figure 5.1 shows FTIR spectra recorded on these CC-trialcohol films supported on silicon wafers with a reaction time of 30 seconds for CC-TPE, and 30 minutes for CC-2 and CC-4 films. The intensity of the spectrum of CC-2 is extremely low, caused by the low film thickness even after 30 minutes, making analysis difficult.

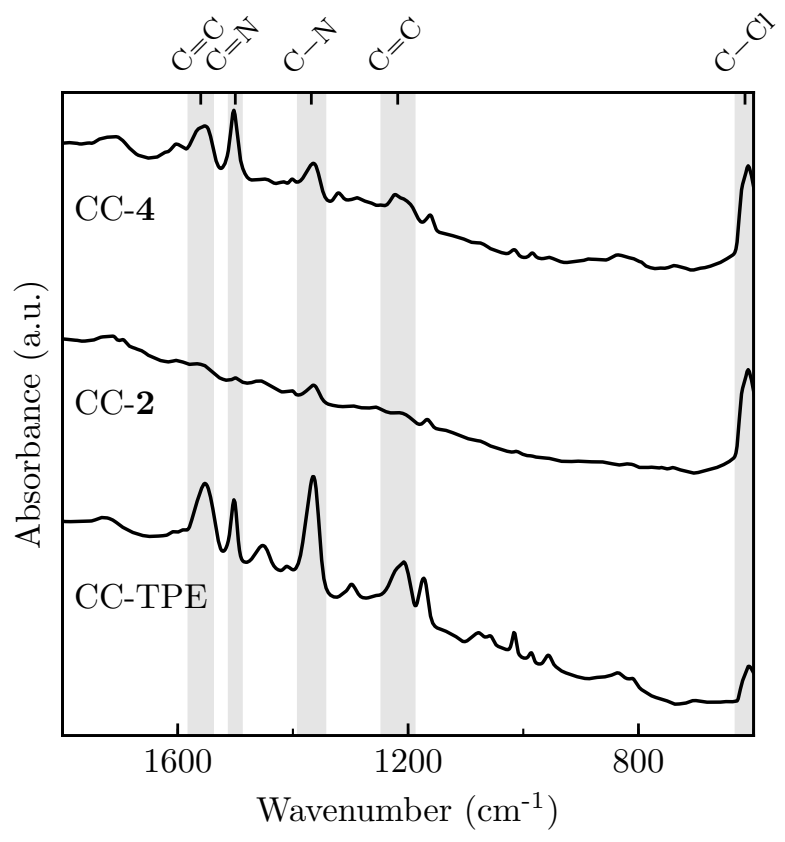

Figure 5.1: FTIR spectra recorded in transmission mode of CC-trialcohol films supported on silicon wafers. 
All samples show strong absorbance peaks at $1360 \mathrm{~cm}^{-1}$ and at $1500 \mathrm{~cm}^{-1}$ belonging to the $\mathrm{C}-\mathrm{N}$ and $\mathrm{C}=\mathrm{N}$ triazine stretching, respectively. In addition, all samples show absorbance peaks at 1550 and $1210 \mathrm{~cm}^{-1}$ belonging to the aromatic $\mathrm{C}=\mathrm{C}$ stretch. Finally, all samples show an absorbance peak at $610 \mathrm{~cm}^{-1}$ originating from unreacted $\mathrm{C}-\mathrm{Cl}$ bonds. The spectrum of CC-TPE shows a small peak at $1450 \mathrm{~cm}^{-1}$ belonging to the $\mathrm{C}-\mathrm{H}$ bending of the $-\mathrm{CH}_{3}$ group.

\subsection{2 pH-stability of CC-trialcohol films}

Compared to the relatively smooth surface morphology of a bare PES support (Figure 5.2a), the CC-trialcohol films show an increase in surface roughness (Figure $5.2 \mathrm{~b}-\mathrm{d}$ ). The size of the morphological features is more or less similar for the CC-TPE and CC-2 films, however the largest monomer of this study (4) results in significantly larger morphological features.
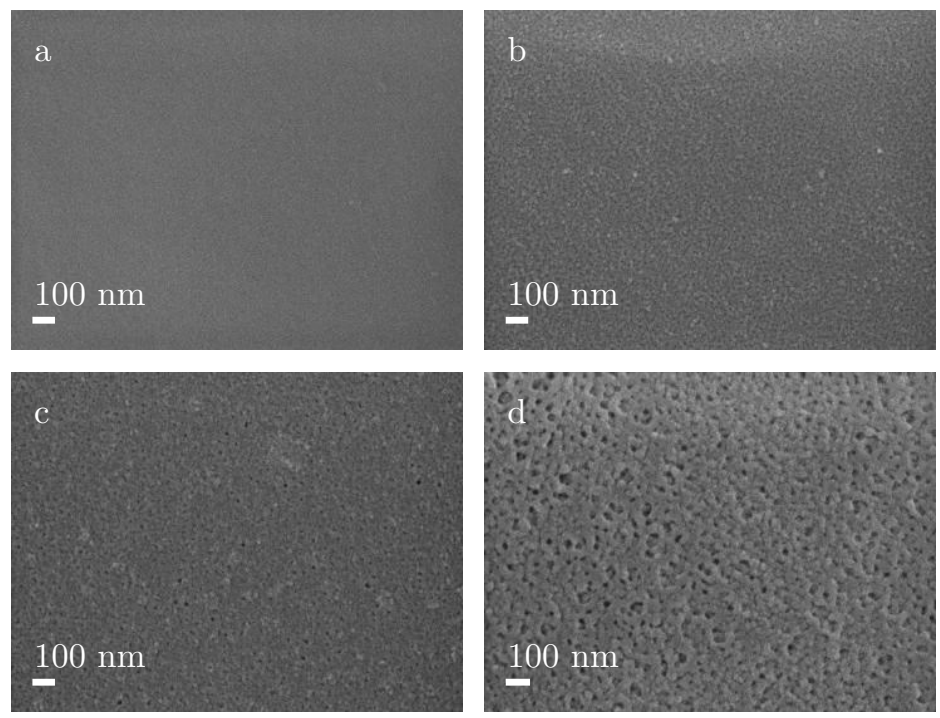

Figure 5.2: Top-view scanning electron micrographs of fresh CC-trialcohol films. (a) Bare PES support, given as reference, (b) CC-TPE, (c) CC-2, and (d) CC-4. 
The CC-trialcohol films were tested for their resistance to extreme $\mathrm{pH}$ conditions. Top-view scanning electron micrographs were taken every 1, 2, 4, and 6 weeks. The results are shown in Figure 5.3 (CC-TPE), Figure 5.4 (CC-2), and Figure 5.5 (CC-4).

Figure 5.3 does not show any change in surface morphology of CC-TPE films upon immersion in water. There are some minor differences in morphology among the samples taken at different immersion periods, but this can be attributed to normal spread in the samples surface morphology. Immersion in $0.1 \mathrm{M} \mathrm{NaOH}$ seems to densify the surface of the CC-TPE film a little after two weeks of immersion, but there are no severe changes in morphology visible even after 6 weeks in $0.1 \mathrm{M} \mathrm{NaOH}$. Immersion in $0.1 \mathrm{M} \mathrm{HNO}_{3}$ results in regions that are partially densified as compared to the fresh film. However, this does not seem to change any more with longer immersion times.

Whereas the surface morphology of CC-TPE films immersed in water stayed unchanged, there is some variation in surface morphology for CC-2 films immersed in water (Figure 5.4). We attribute this to variation in sample surface. In contrast, immersion in $0.1 \mathrm{M} \mathrm{NaOH}$ does result in a significant change in surface morphology visible in week 4 and week 6 . The relatively rough surface has changed to a more flattened surface. However, there is still polymer present when comparing the surface to that of a bare PES support. Again immersion in $0.1 \mathrm{M} \mathrm{HNO}_{3}$ does not seem to have a significant impact on surface morphology.

The trialcohol 4 contains an azomethine, also referred to as imine or Schiff's base, bond. While immersion in water does not alter the surface morphology after 6 weeks immersion (Figure 5.5), the immersion in $0.1 \mathrm{M} \mathrm{NaOH}$ and $0.1 \mathrm{M} \mathrm{HNO}_{3}$ does slightly alter the surface morphology. The most pronounced effect is observed for immersion in $\mathrm{NaOH}$.

Azomethines are formed by the condensation of aldehydes with amines, eliminating water. This reaction is an equilibrium reaction, therefore adding water to the azomethine will invert the azomethine back to its monomers ${ }^{[30]}$. However, extremely stable conjugated thiophene containing azomethines have been reported ${ }^{[31,32]}$. This shows that conjugation helps to stabilize the azomethine bond. Monomer 4 is also a conjugated monomer, making it relatively stable, and therefore only slightly affected when immersed in an extreme $\mathrm{pH}$. 
water

week 1
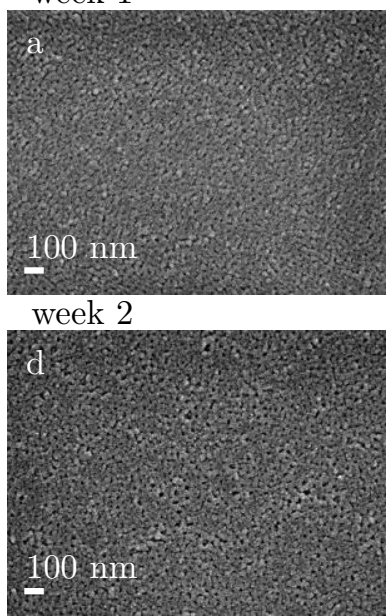

week 4

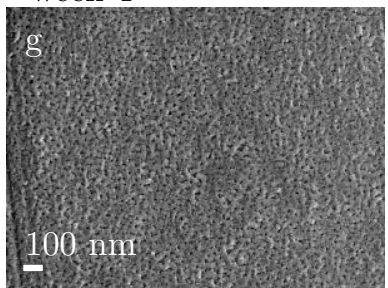

week 6

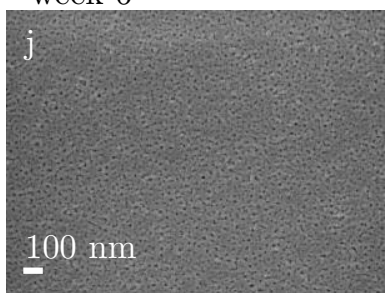

$\mathrm{NaOH}$
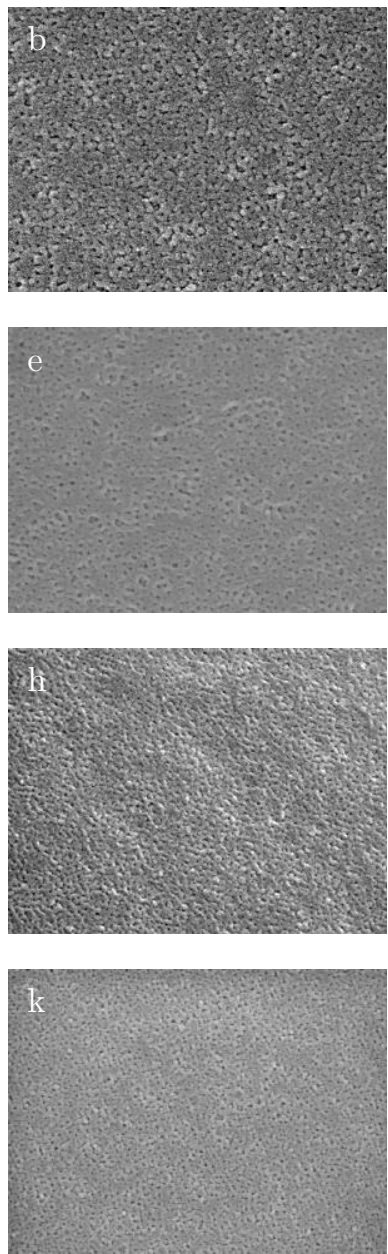

$\mathrm{HNO}_{3}$
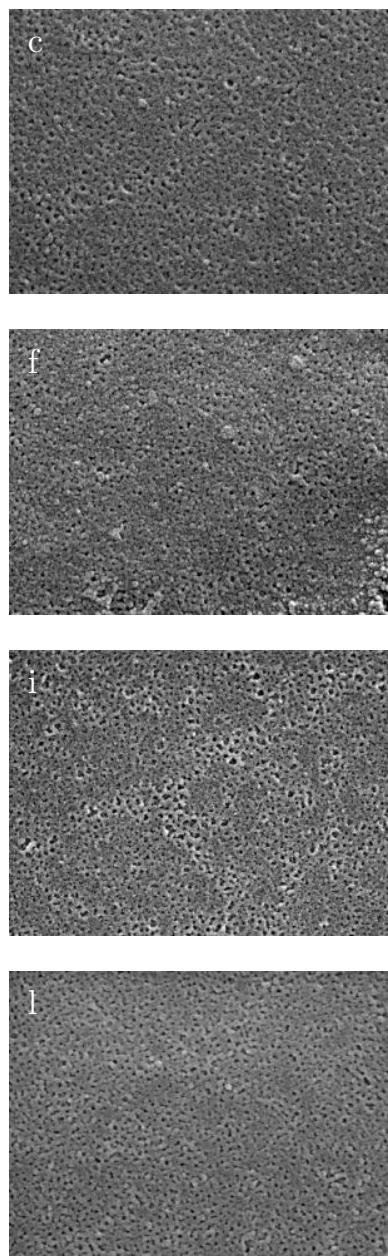

Figure 5.3: Top-view scanning electron micrographs of CC-TPE films submerged in $(a, d, g, j)$ water, $(b, e, h, k) 0.1 \mathrm{M} \mathrm{NaOH}$, and $(\mathrm{c}, \mathrm{f}, \mathrm{i}, \mathrm{I}) 0.1 \mathrm{M} \mathrm{HNO}_{3}$ for up to 6 weeks. 
water

week 1

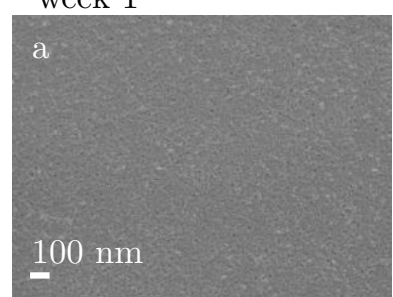

week 2

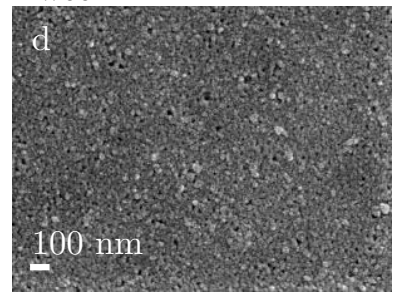

week 4

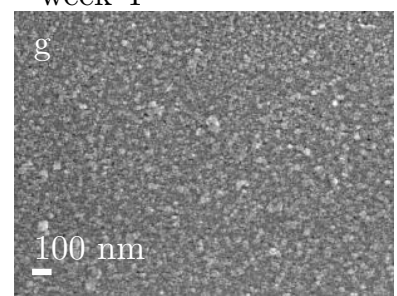

week 6

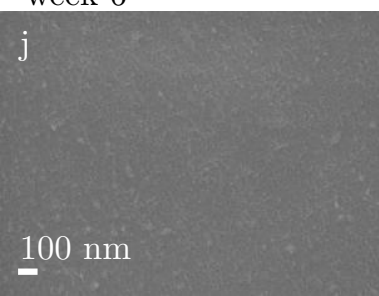

$\mathrm{HNO}_{3}$
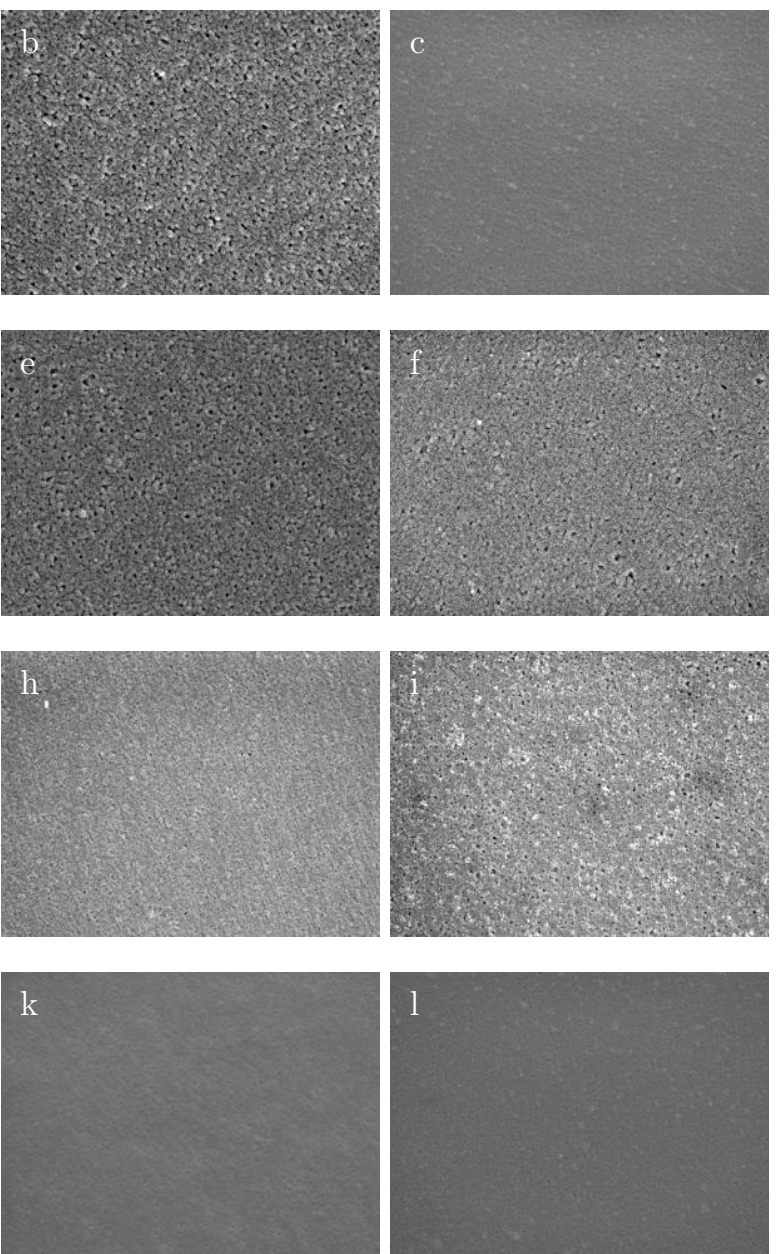

Figure 5.4: Top-view scanning electron micrographs of CC-2 films submerged in $(a, d, g, j)$ water, $(b, e, h, k) 0.1 \mathrm{M} \mathrm{NaOH}$, and $(\mathrm{c}, \mathrm{f}, \mathrm{i}, \mathrm{l}) 0.1 \mathrm{M} \mathrm{HNO}_{3}$ for up to 6 weeks. 
water

week 1

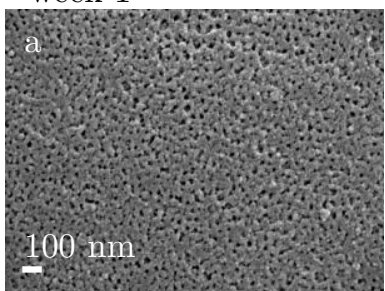

week 2

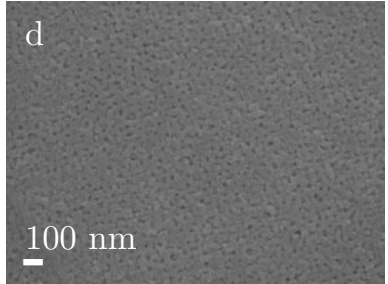

week 4

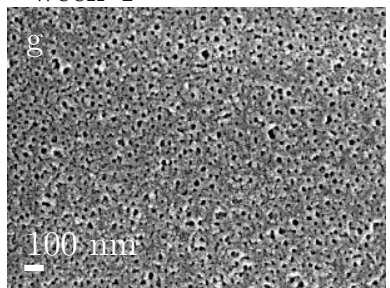

week 6

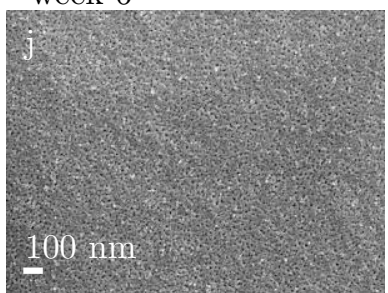

$\mathrm{NaOH}$
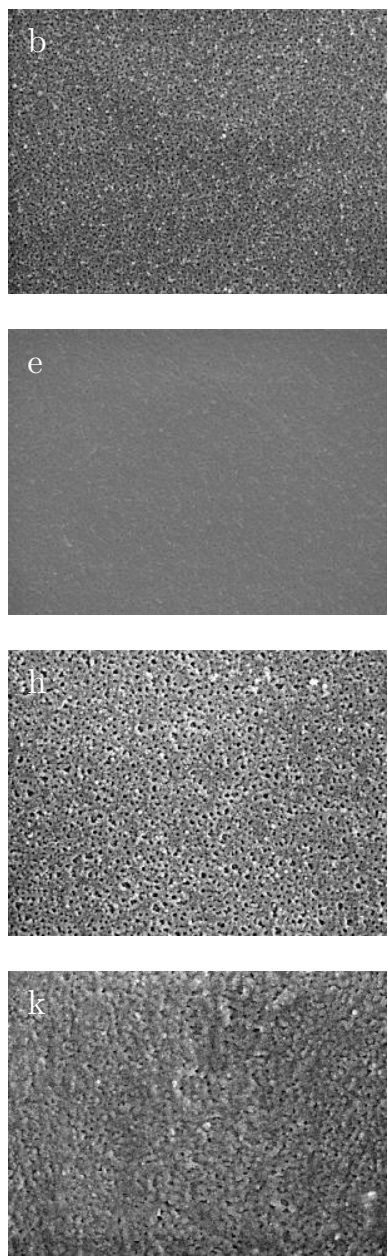

$\mathrm{HNO}_{3}$
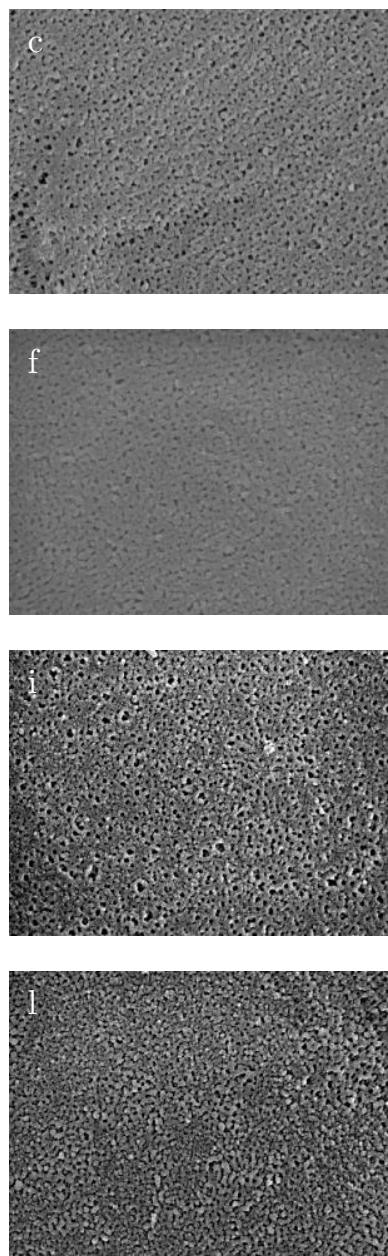

Figure 5.5: Top-view scanning electron micrographs of CC-4 films submerged in $(a, d, g, j)$ water, $(b, e, h, k) 0.1 \mathrm{M} \mathrm{NaOH}$, and $(\mathrm{c}, \mathrm{f}, \mathrm{i}, \mathrm{I}) 0.1 \mathrm{M} \mathrm{HNO}_{3}$ for up to 6 weeks. 


\subsubsection{Film formation kinetics}

The film thickness and morphology of interfacial polymerized layers is dependent on the diffusivity of the monomers through the forming polymeric network ${ }^{[24,26]}$. Since interfacial polymerization reactions commonly take place in the organic phase ${ }^{[33,34]}$, the diffusivity of the trialcohol into the organic phase through the forming film will strongly effect the kinetics of film formation, and thus the film thickness over time.

Figure 5.6 shows the film thickness of CC-TPE, CC-2, and CC-4 films as a function of reaction time. The CC-TPE films are an order of magnitude thicker as compared to both the CC-2 and CC-4 films. The TPE monomer has the lowest molecular weight and radius, making it easier for this monomer to diffuse through the forming network to the reaction side. In addition, the film thickness increases with increasing reaction time, indicating that even after 30 minutes of reaction time the monomer TPE is still able to reach the CC monomers in the organic phase.

The film thickness of CC-2 and CC-4 films seems to level with reaction time, and a more or less constant film thickness is obtained within one minute. This can be attributed to the lack of diffusion of these bigger trialcohols through the forming film. By tuning the size of the trialcohol and the reaction time, poly(aryl ether) films could be obtained in thicknesses ranging from a few micrometer down to a few nanometer; a typical thickness for nanofiltration membranes. 

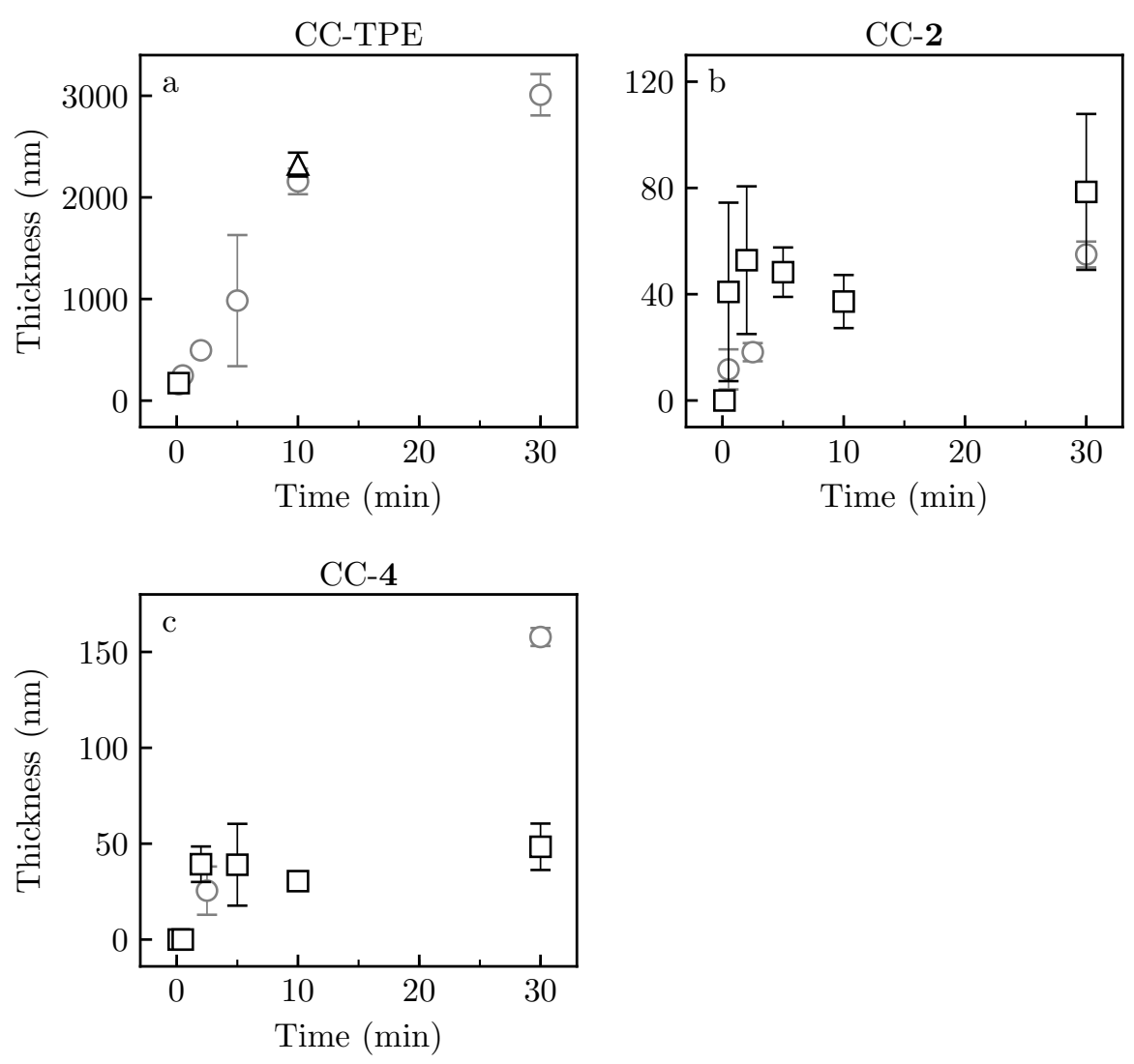

Figure 5.6: The thickness as a function of reaction time for (a) CC-TPE, (b) CC-2, and (c) CC-4 films, respectively. The gray circles $(O)$ are data points obtained by ellipsometry, the black squares ( $\square$ ) are obtained from FE-SEM images on Anodisc supported films, and the black triangle $(\Delta)$ is obtained from FE-SEM images of a freestanding film. Note that the $y$-axes have different scales. 


\subsection{Conclusion}

In this work, we showed the interfacial preparation of CC-trialcohol films. Immersion in water, $0.1 \mathrm{M} \mathrm{NaOH}$, or $0.1 \mathrm{M} \mathrm{HNO}_{3}$ did not seem to alter the surface morphology of the CC-TPE and CC-2 films significantly, as concluded from topview scanning electron micrographs. The presence of the azomethine bond in 4 makes the CC-4 network less stable against extreme $\mathrm{pH}$ conditions.

The film formation kinetics and final film thicknesses seem to depend strongly on the size of the trialcohol. The use of the relatively small TPE monomer results in thick films ( $\sim 3 \mu \mathrm{m}$ after 30 minutes), whereas films prepared from $\mathbf{2}$ or $\mathbf{4}$ are found to have a thickness of only $\sim 50 \mathrm{~nm}$ and $\sim 40 \mathrm{~nm}$, respectively.

\subsection{Acknowledgements}

This work took place within the framework of the Institute for Sustainable Process Technology (ISPT, project BL-20-02) and within The Dutch Polymer Institute under project \#718. The authors thank Bob J. Siemerink (Membrane Science and Technology cluster, University of Twente) for his significant contribution to the FE-SEM imaging, and Clemens J. Padberg (Materials Science and Technology of Polymers, University of Twente) for his contribution to the FTIR imaging. 


\subsection{References}

[1] Herzog, B.; Kohan, M. I.; Mestemacher, S. A.; Pagilagan, R. U.; Redmond, K. Ullmann's Encyclopedia of Industrial Chemistry; Wiley-VCH Verlag GmbH \& Co. KGaA, 2000; Chapter Polyamides.

[2] Afonso, C. A. M.; Lourenco, N. M. T.; Rosatella, A. d. A. Synthesis of 2,4,6-Tri-substituted1,3,5-Triazines. Molecules 2006, 11, 81-102.

[3] Yan, Z.; Xue, W.-L.; Zeng, Z.-X.; Gu, M.-R. Kinetics of Cyanuric Chloride Hydrolysis in Aqueous Solution. Industrial E Engineering Chemistry Research 2008, 47, 5318-5322.

[4] Steffensen, M. B.; Hollink, E.; Kuschel, F.; Bauer, M.; Simanek, E. E. Dendrimers based on [1,3,5]-triazines. Journal of Polymer Science Part A: Polymer Chemistry 2006, 44, 3411-3433.

[5] Mooibroek, T. J.; Gamez, P. The s-triazine ring, a remarkable unit to generate supramolecular interactions. Inorganica Chimica Acta 2007, 360, 381 - 404, Inorganic Chemistry The Next Generation.

[6] Srinivas, K.; Srinivas, U.; Rao, V. J.; Bhanuprakash, K.; Kishore, K. H.; Murty, U. Synthesis and antibacterial activity of 2,4,6-tri substituted s-triazines. Bioorganic \& Medicinal Chemistry Letters 2005, 15, 1121 - 1123.

[7] Suss, H. I.; Neels, A.; Hulliger, J. 2,4,6-Tris(4-cyanophenoxy)-1,3,5-triazine (CNPOT): Trigonal synthons in crystal engineering. CrystEngComm 2005, 7, 370-373.

[8] Qian, L.; Qiu, Y.; Liu, J.; Xin, F.; Chen, Y. The flame retardant group-synergistic-effect of a phosphaphenanthrene and triazine double-group compound in epoxy resin. Journal of Applied Polymer Science 2014, 131, n/a-n/a.

[9] You, G.; Cheng, Z.; Peng, H.; He, H. The synthesis and characterization of a novel phosphorus-nitrogen containing flame retardant and its application in epoxy resins. Journal of Applied Polymer Science 2014, 131, n/a-n/a.

[10] Hayashi, M.; Yamasaki, T.; Kobayashi, Y.; Imai, Y.; Watanabe, Y. Selective Syntheses of Mono- and Diphosphanyltriazines as Novel Ligands for Transition Metal Catalysts. European Journal of Organic Chemistry 2009, 2009, 4956-4962.

[11] Almalioti, F.; MacDougall, J.; Hughes, S.; Hasson, M. M.; Jenkins, R. L.; Ward, B. D.; Tizzard, G. J.; Coles, S. J.; Williams, D. W.; Bamford, S.; Fallis, I. A.; Dervisi, A. Convenient syntheses of cyanuric chloride-derived NHC ligands, their $\mathrm{Ag}(\mathrm{i})$ and $\mathrm{Au}(\mathrm{i})$ complexes and antimicrobial activity. Dalton Trans. 2013, 42, 12370-12380.

[12] Shin, D. C.; Chang, Y.; Kim, J. S.; Noh, I.; Kim, C.; Song, K. Synthesis and Optical Characterization of Polycyanurates with Pendent Second-Order Nonlinear Optical Chromophores. Polym J 1999, 31, 1200-1204.

[13] Tigelaar, D. M.; Meador, M. A. B.; Kinder, J. D.; Bennett, W. R. New APTES CrossLinked Polymers from Poly(ethylene oxide)s and Cyanuric Chloride for Lithium Batteries. Macromolecules 2006, 39, 120-127.

[14] Karak, N.; Roy, B.; Voit, B. s-Triazine-based hyperbranched polyethers: Synthesis, characterization, and properties. Journal of Polymer Science Part A: Polymer Chemistry 2010, 48, 3994-4004.

[15] Borah, J.; Karak, N. Synthesis and characterization of a novel hyperbranched polyether. Polymer International 2004, 53, 2026-2030.

[16] Mahapatra, S. S.; Karak, N. Hyperbranched aromatic polyamines with s-triazine rings. Journal of Applied Polymer Science 2007, 106, 95-102.

[17] Dallas, P.; Bourlinos, A. B.; Petridis, D.; Boukos, N.; Papadokostaki, K.; Niarchos, D.; Guskos, N. Synthesis and characterization of 2-D and 3-D covalent networks derived from triazine central cores and bridging aromatic diamines. Polymer 2008, 49, $1137-1144$.

[18] Wang, W.; Yuan, Y.; Sun, F.-X.; Zhu, G.-S. Targeted synthesis of novel porous aromatic frameworks with selective separation of $\mathrm{CO} 2 / \mathrm{CH} 4$ and $\mathrm{CO} 2 / \mathrm{N} 2$. Chinese Chemical Letters 2014, 25, $1407-1410$. 
[19] Lee, K. P.; Zheng, J.; Bargeman, G.; Kemperman, A. J.; Benes, N. E. pH stable thin film composite polyamine nanofiltration membranes by interfacial polymerisation. Journal of Membrane Science 2015, 478, 75 - 84 .

[20] Lee, K. P.; Bargeman, G.; de Rooij, R.; Kemperman, A. J.; Benes, N. E. Interfacial polymerization of cyanuric chloride and monomeric amines: $\mathrm{pH}$ resistant thin film composite polyamine nanofiltration membranes. Journal of Membrane Science 2017, 523, 487 - 496.

[21] Vandezande, P.; Gevers, L. E. M.; Vankelecom, I. F. J. Solvent resistant nanofiltration: separating on a molecular level. Chem. Soc. Rev. 2008, 37, 365-405.

[22] Lau, W.; Ismail, A.; Misdan, N.; Kassim, M. A recent progress in thin film composite membrane: A review. Desalination 2012, 287, 190 - 199, Special Issue in honour of Professor Takeshi Matsuura on his 75th Birthday.

[23] Raaijmakers, M. J.; Benes, N. E. Current trends in interfacial polymerization chemistry. Progress in Polymer Science 2016, 63, 86 - 142.

[24] Ghosh, A. K.; Jeong, B.-H.; Huang, X.; Hoek, E. M. Impacts of reaction and curing conditions on polyamide composite reverse osmosis membrane properties. Journal of Membrane Science 2008, 311, $34-45$.

[25] Yu, S.; Liu, M.; Liu, X.; Gao, C. Performance enhancement in interfacially synthesized thinfilm composite polyamide-urethane reverse osmosis membrane for seawater desalination. Journal of Membrane Science 2009, 342, 313 - 320.

[26] Khorshidi, B.; Thundat, T.; Fleck, B. A.; Sadrzadeh, M. A Novel Approach Toward Fabrication of High Performance Thin Film Composite Polyamide Membranes. Scientific Reports 2016, 6, 22069.

[27] Raaijmakers, M. J. T.; Kappert, E. J.; Nijmeijer, A.; Benes, N. E. Thermal Imidization Kinetics of Ultrathin Films of Hybrid Poly(POSS-imide)s. Macromolecules 2015, 48, 30313039.

[28] Lohrie, M.; Knoche, W. Dissociation and keto-enol tautomerism of phloroglucinol and its anions in aqueous solution. Journal of the American Chemical Society 1993, 115, 919-924.

[29] Wang, D.; Hildenbrand, K.; Leitich, J.; Schuchmann, H.-P.; von Sonntag, C. pH-Dependent Tautomerism and pKa Values of Phloroglucinol (1,3,5-Trihydroxybenzene), Studied by $13 \mathrm{C}$ NMR and UV Spectroscopy. Zeitschrift für Naturforschung B 1993, 48, 478-482.

[30] Belowich, M. E.; Stoddart, J. F. Dynamic imine chemistry. Chem. Soc. Rev. 2012, 41, 2003-2024.

[31] Dufresne, S.; Bourgeaux, M.; Skene, W. G. Tunable spectroscopic and electrochemical properties of conjugated push-push, push-pull and pull-pull thiopheno azomethines. J. Mater. Chem. 2007, 17, 1166-1177.

[32] Guarin, S. A. P.; Bourgeaux, M.; Dufresne, S.; Skene, W. G. Photophysical, Crystallographic, and Electrochemical Characterization of Symmetric and Unsymmetric SelfAssembled Conjugated Thiopheno Azomethines. The Journal of Organic Chemistry 2007, 72, 2631-2643.

[33] Freger, V. Kinetics of Film Formation by Interfacial Polycondensation. Langmuir 2005, 21, 1884-1894.

[34] Zhang, Y.; Benes, N. E.; Lammertink, R. G. H. Visualization and characterization of interfacial polymerization layer formation. Lab Chip 2015, 15, 575-580. 


\subsection{Supporting information}

\subsubsection{Synthesis of monomers}

\section{Benzene-1,3,5-triyltris((4-fluorophenyl)methanone) (1)}

To a dried $250 \mathrm{~mL}$ 3-neck round bottom flask was added $27.4 \mathrm{~g} \mathrm{AlCl}_{3}$ and $75 \mathrm{~mL}$ 1,2-dichloroethane (DCE). Fluorobenzene (18 g) was added slowly to this mixture. Trimesoyl chloride $(20 \mathrm{~g})$ was dissolved in $60 \mathrm{~mL}$ DCE and added drop-wise. This was stirred for $4 \mathrm{~h}$ before water was added slowly to quench the reaction. After stirring overnight, the mixture was extracted with DCM. The DCM was evaporated using a rotary evaporator and a white product was obtained. Recrystallization from acetone yielded a bright white solid, $14.19 \mathrm{~g}(42 \%)$. MP: $182{ }^{\circ} \mathrm{C}$. MS (EI), $m / z: 444(\mathrm{M}) .{ }^{1} \mathrm{H}-\mathrm{NMR}$ (DMSO, $\left.\delta, \mathrm{ppm}\right): 8.24(\mathrm{~s}, 3 \mathrm{H}), 7.95-7.79(\mathrm{~m}$, 6H), 7.48-7.43 (t, 6H). ${ }^{13} \mathrm{C}-\mathrm{NMR}$ (DMSO, $\left.\delta, \mathrm{ppm}\right): 193,167,164,138,133,116$.

\section{Benzene-1,3,5-triyltris((4-hydroxyphenyl)methanone) (2)}

To a $250 \mathrm{~mL}$ flask was added $90 \mathrm{ml} \mathrm{DMSO}$ and $6 \mathrm{~g}$ of $\mathbf{1}$ (Scheme 5.2). This was dissolved at $50{ }^{\circ} \mathrm{C}$ before $6 \mathrm{~g}$ of $\mathrm{NaOH}$ in $12 \mathrm{~mL}$ of water was added. The dark red solution was stirred overnight at $120^{\circ} \mathrm{C}$. After stirring for $24 \mathrm{~h}, 1 \mathrm{M} \mathrm{HCl}$ was added to reduce the $\mathrm{pH}$ to 1 . The mixture was extracted with $200 \mathrm{~mL}$ EtOAc and washed with $2 \times 150 \mathrm{~mL}$ brine. The EtOAc was removed under reduced pressure to give a yellow solid. The solid was dissolved in $2 \mathrm{M} \mathrm{NaOH}$, washed with EtOAc and acidified to give a yellow solid (53\%). MP: $272{ }^{\circ} \mathrm{C}$. ATR-FTIR $\left(\nu, \mathrm{cm}^{-1}\right)$ : 35003000, 1594, 1509, 1442, 1249, 1163. ${ }^{1} \mathrm{H}-\mathrm{NMR}$ (DMSO, $\left.\delta, \mathrm{ppm}\right): 10.52$ (s, 3H), $8.08(\mathrm{~s}, 3 \mathrm{H}), 7.76-7.73(\mathrm{~d}, 6 \mathrm{H}), 6.92-6.89(\mathrm{~d}, 6 \mathrm{H}) .{ }^{13} \mathrm{C}-\mathrm{NMR}$ (DMSO, $\left.\delta, \mathrm{ppm}\right)$ : $193,163,139,133,128,116$.

\section{Tris(4-aminophenyl)amine (3)}

Tris(4-nitrophenyl)amine (10.10 g, $0.03 \mathrm{~mol})$ was partially dissolved in $250 \mathrm{~mL}$ dry THF and $\mathrm{Pd} / \mathrm{C}$ was added (10wt\% loading, $1.52 \mathrm{~g}$ ). The mixture was degassed with argon for 30 minutes, and shaken overnight under an initial 3.4 bar hydrogen atmosphere. The reaction mixture was filtered over celite, and the solvent was removed using a rotary evaporator, resulting in a yellow powder $(7.42 \mathrm{~g}, 96 \%)$. ${ }^{1} \mathrm{H}-\mathrm{NMR}$ (DMSO, $\delta$, ppm): $6.58(\mathrm{~d}, 6 \mathrm{H}), 6.42(\mathrm{~d}, 6 \mathrm{H}), 4.67$ (s, 6H). ${ }^{13} \mathrm{C}-\mathrm{NMR}$ (DMSO, $\delta, \mathrm{ppm}):$ 144, 139, 125, 115. 

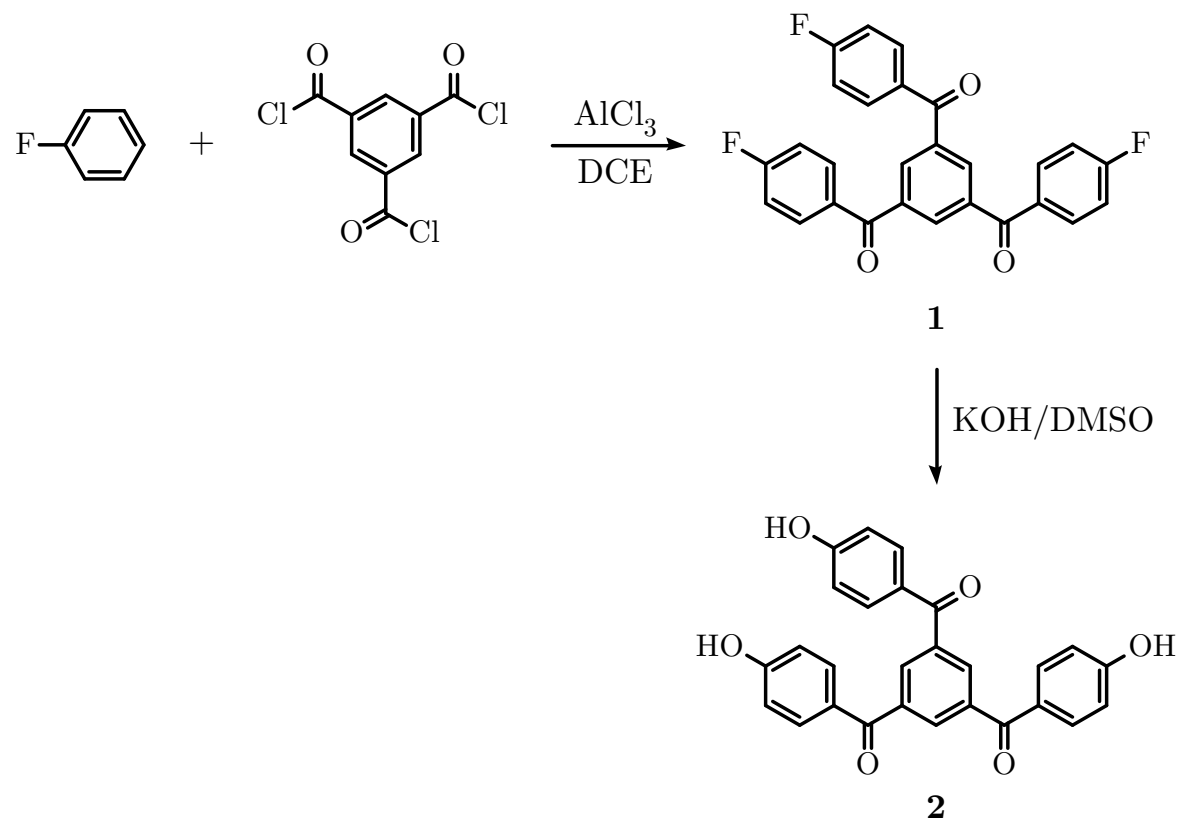

Scheme 5.2: The synthesis of benzene-1,3,5-triyltris((4-hydroxyphenyl)methanone) 2 . 


\section{Triazomethine (4)}

Tris(4-aminophenyl)amine $(\mathbf{3}, 1.14 \mathrm{~g}, 3.9 \mathrm{mmol})$ and $p$-hydroxybenzaldehyde (1.47 $\mathrm{g}, 12 \mathrm{mmol})$ were dissolved in a mixture of dry isopropyl alcohol $(40 \mathrm{~mL})$ and dry $\mathrm{CHCl}_{3}(80 \mathrm{~mL}) . p$-TSA $(0.01 \mathrm{~g}, 0.05 \mathrm{mmol})$ was added and the reaction mixture was heated to $60{ }^{\circ} \mathrm{C}$ for three days. Subsequently, the mixture was cooled to room temperature and the solvent was removed using a rotary evaporator (Scheme 5.3). The resulting solids were washed two times with cold $\mathrm{MeOH}$, and once with MeOH:TEA (98:2) to obtain a brown powder $(0.62 \mathrm{~g}, 26 \%)$. ${ }^{1} \mathrm{H}-\mathrm{NMR}$ (DMSO, $\delta, \mathrm{ppm}): 10.10(\mathrm{~s}, 3 \mathrm{H}), 8.50(\mathrm{~s}, 3 \mathrm{H}), 7.76(\mathrm{~d}, 6 \mathrm{H}, \mathrm{J}=8.7 \mathrm{~Hz}), 7.22(\mathrm{~d}$, $6 \mathrm{H}, \mathrm{J}=8.7 \mathrm{~Hz}), 7.05(\mathrm{~d}, 6 \mathrm{H}, \mathrm{J}=8.7 \mathrm{~Hz}), 6.88(\mathrm{~d}, 6 \mathrm{H}, \mathrm{J}=8.7 \mathrm{~Hz}) .{ }^{13} \mathrm{C}-\mathrm{NMR}$ (DMSO, $\delta, \mathrm{ppm}): 160,158,147,145,130,128,124,122,116$.<smiles>O=[N+]([O-])c1ccc(N(c2ccc([N+](=O)[O-])cc2)c2ccc([N+](=O)[O-])cc2)cc1</smiles>

$\underset{\mathrm{THF}}{\stackrel{\mathrm{Pd} / \mathrm{C}}{\longrightarrow}}$<smiles>Nc1ccc(N(c2ccc(N)cc2)c2ccc(N)cc2)cc1</smiles>

3<smiles>O=Cc1ccc(O)cc1</smiles><smiles>Oc1ccc(/C=N/c2ccc(N(c3ccc(/N=C/c4ccc(O)cc4)cc3)c3ccc(/N=C/c4ccc(O)cc4)cc3)cc2)cc1</smiles>

4

Scheme 5.3: The synthesis of the triazomethine 4 from tris(4-nitrophenyl)amine. 


\subsection{2 pH-stability of TMC-TPE films}

In addition to CC-trialcohol films, a TMC-TPE film supported on a PES substrate was prepared. The reaction of TMC with a trialcohol results in an aromatic polyester which is more susceptible to hydrolysis at extreme $\mathrm{pH}$ conditions as compared to its aromatic polyether analogue. Figure 5.7a shows the surface morphology of a freshly prepared TMC-TPE film. Immersion in $0.1 \mathrm{M} \mathrm{NaOH}$ (Figure 5.7b) or $0.1 \mathrm{M} \mathrm{HNO}_{3}$ (Figure 5.7c) for 4 weeks results in a more open surface morphology. This change in surface morphology can be attributed to basic or acidic hydrolysis of the polyester bonds.
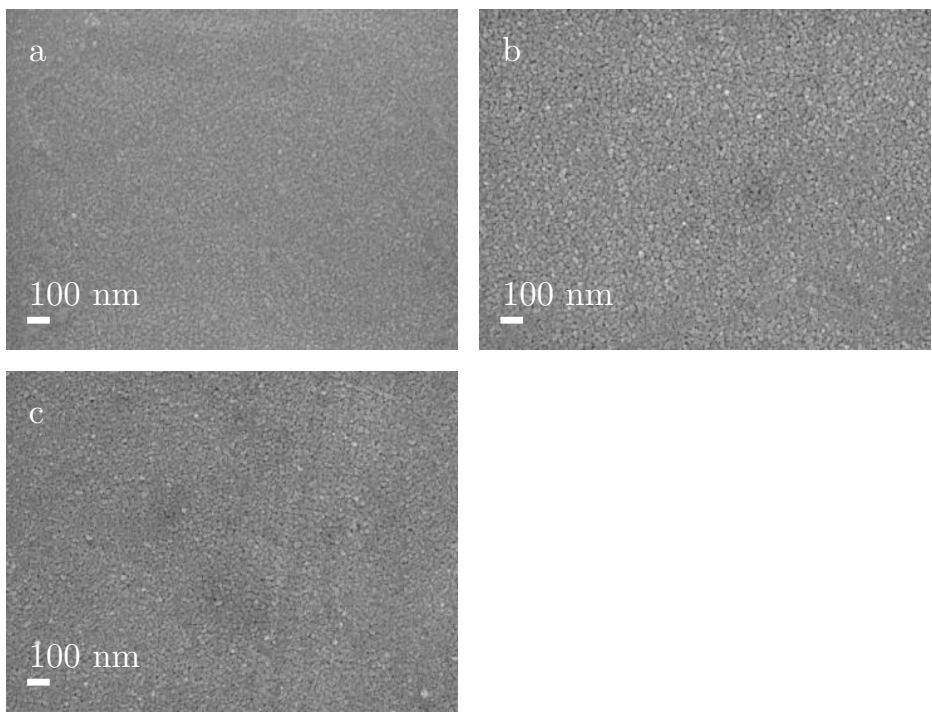

Figure 5.7: Top-view scanning electron micrographs of TMC-TPE films. (a) As prepared, (b) after 4 weeks immersion in $0.1 \mathrm{M} \mathrm{NaOH}$, and (c) after 4 weeks immersion in $0.1 \mathrm{M}$ $\mathrm{HNO}_{3}$. 


\subsubsection{Thermogravimetric analysis}

Both TMC-TPE and CC-TPE powders show a similar thermal degradation upon heating as shown in Figure 5.8. Both powders show an initial weight loss of $5 \%$ at a temperature of $100{ }^{\circ} \mathrm{C}$, whereas the main weight loss occurs above $300{ }^{\circ} \mathrm{C}$. TMC-TPE has a residual weight of $37 \%$ at $600{ }^{\circ} \mathrm{C}$, and $\mathrm{CC}-\mathrm{TPE}$ has a residual weight of $47 \%$ at this temperature.
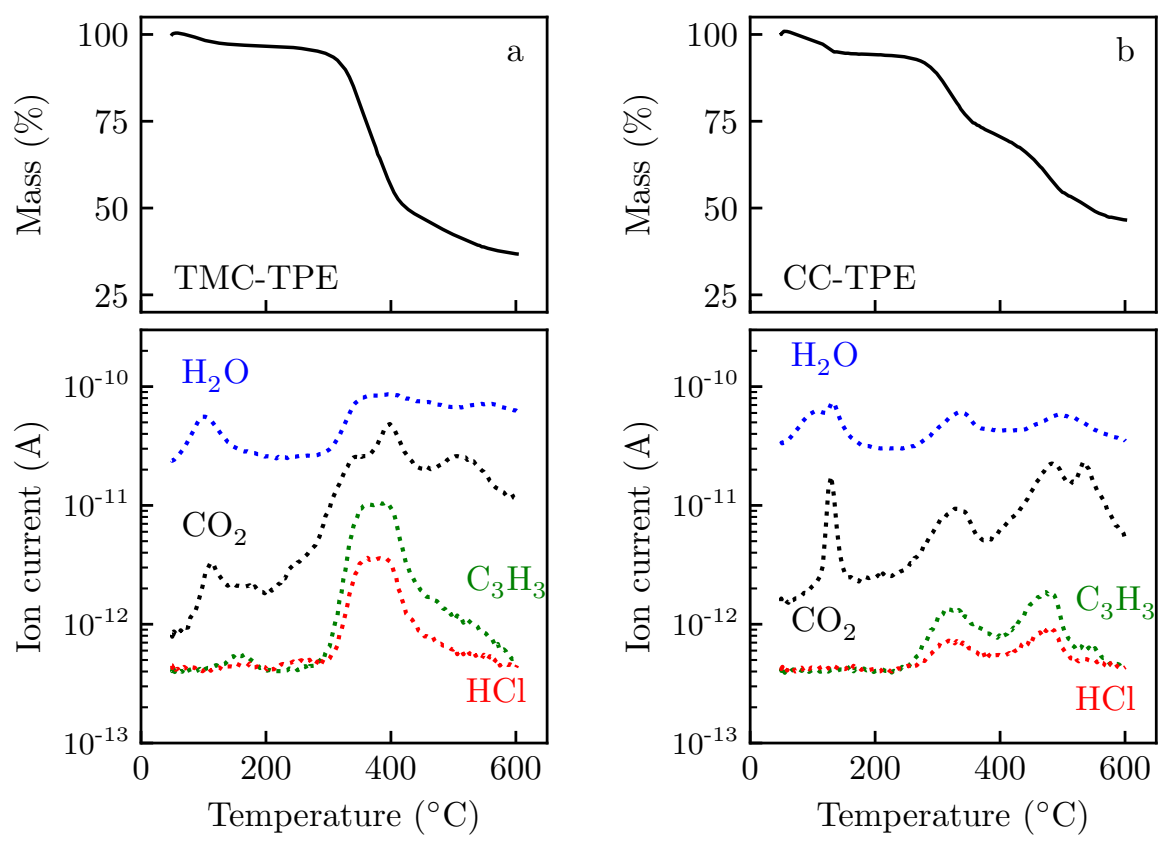

Figure 5.8: TGA-MS graphs of (a) TMC-TPE and (b) CC-TPE powders. All data is obtained under a nitrogen atmosphere with a heating rate of $10{ }^{\circ} \mathrm{C} / \mathrm{min}$. The top graphs show the mass loss as function of temperature. The bottom graphs show the evolved gases. The tracked $m / z$ values are $\mathrm{H}_{2} \mathrm{O}(m / z=18$, blue, -$), \mathrm{HCl}(m / z=38$, red, -$), \mathrm{C}_{3} \mathrm{H}_{3}(m / z=39$, fragment originating from aromatic ring, green, - ) , and $\mathrm{CO}_{2}(m / z=44$, black, - ). 



\section{Chapter 6}

\section{All-aromatic cross-linked hyperbranched poly(aryl ether ketone)s for gas separation at elevated temperatures}

This chapter is adapted from:

Wouter Vogel, Evelien Maaskant, Kristianne Tempelman, Nieck E. Benes, Theo J. Dingemans, All-aromatic cross-linked hyperbranched poly(aryl ether ketone)s for gas separation at elevated temperatures, Manuscript in preparation 


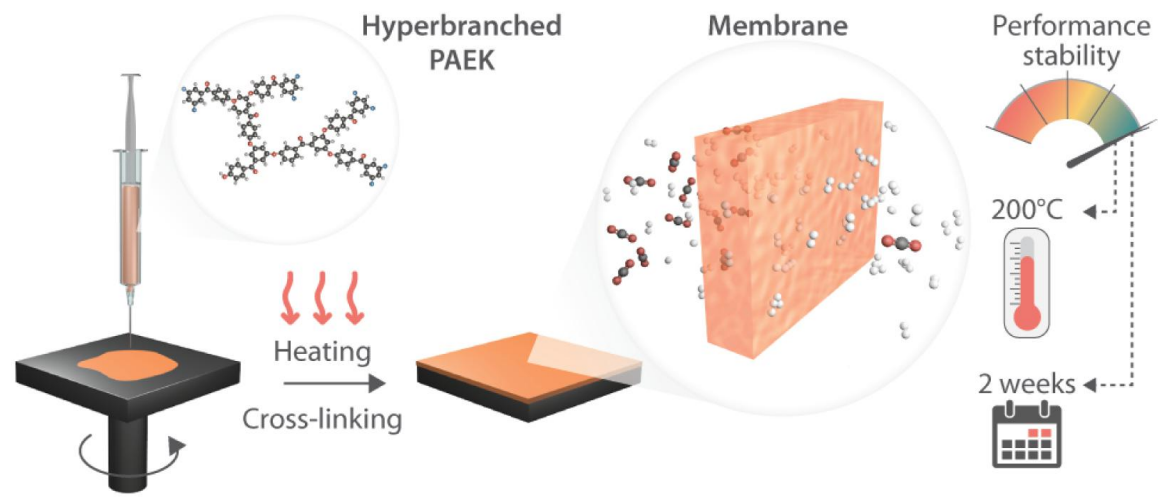

\section{Abstract}

A series of thermally stable hyperbranched poly(aryl ether ketone)s (HBPAEKs) has been synthesized and characterized. These HBPAEKs bear fluorine end-groups that can partially be replaced by 4 -(phenylethynyl)phenol (PEP) end-groups to allow for additional chemical cross-linking. The effect of these end-groups on the glass transition temperature $\left(\mathrm{T}_{\mathrm{g}}\right)$ and the excess free fractional volume (EFFV) was studied for both uncured and cured HBPAEKs by in-situ spectroscopic ellipsometry. A significant increase in both $\mathrm{T}_{\mathrm{g}}$ (up to $250{ }^{\circ} \mathrm{C}$ ) and $\mathrm{EFFV}(>9 \%)$ was found for cured HBPAEKs containing PEP as compared to their neat analogues. In addition, these PEP containing HBPAEKs showed to retain selectivity at elevated temperatures (up to $200{ }^{\circ} \mathrm{C}$ ), even for prolonged periods of time (up to 14 days). 


\subsection{Introduction}

Polymeric membranes can be used in the separation of valuable gases. Of particular interest is the separation of $\mathrm{CO}_{2}$ from high-pressure gas mixtures containing, e.g., methane to make natural gas and biogas suitable for use as fuels ${ }^{[1,2]}$. To enhance the membrane performance, people often (1) increase the excess free fractional volume (EFFV) in the polymer, or (2) improve the affinity of the polymer towards the permeating compound ${ }^{[3,4]}$. Well-known polymers for the separation of $\mathrm{CO}_{2}$ are the thermally and chemically stable 4,4'-(hexafluoroisopropylidene)diphthalic anhydride (6FDA)-based polyimides. The $\mathrm{CF}_{3}$ groups within the polymer restrict torsional motion of the phenyl rings, leading to less ordered chains and increased volume within the polymer ${ }^{[5]}$. Polyimides that are functionalized with $\mathrm{CF}_{3}$ groups are known to exhibit both a higher permeability and permselectivity as compared to conventional polyimides due to additional bulkyness ${ }^{[6,7]}$. However, there is still a debate on the role of the fluorine atoms and their affinity for specific gases ${ }^{[8,9]}$.

In addition to polyimides, poly(aryl ether ketone)s (PAEKs) like poly(ether ketone)s (PEK) and poly(ether ether ketone)s (PEEK) are interesting candidates for use as high performance polymer membranes due to their chemically stability and ability to operate at high temperatures ${ }^{[10,11]}$. However, processing these polymers is hard and requires high temperatures or harsh solvents. They are also semi-crystalline, which is a disadvantage for gas separation membranes as the crystal domains hinder gas transport. For these reasons, PEEK and PEK have not been explored as materials for membranes applied in gas separation. Here, we report the preparation of amorphous hyperbranched poly(aryl ether ketone)s (HBPAEKs) membranes, which have high solubility, excellent processability and higher chemical functionality compared to their linear analogues ${ }^{[10,11]}$. While polymers like linear PEK or PEEK are often insoluble, HBPAEKs are soluble at room temperature in common solvents like THF, $\mathrm{CHCl}_{3}$ and $\mathrm{NMP}^{[12]}$, which offer significant advantages in material processing (e.g., spin-coating and film casting) and characterization (NMR). We have synthesized HBPAEKs using a multifunctional monomer $\left(\mathrm{AB}_{2}\right)$ approach which facilitates well defined end-groups (fluorine in this case), that can be modified to alter the properties of the polymer and add new functionalities to the polymer. The number of end-groups is determined by the degree of polymerization (number of fluorine end-groups $=\mathrm{DP}+1$ ). The large number of fluorine end-groups gives a distinct advantage over its linear PAEK analogues that do not have functional groups for functionalization readily available. The architecture of these HBPAEKs is described by the degree of branching (DB) and can adopt a value between 0 (linear polymer) and 1 (dendritic polymer) ${ }^{[13]}$. The value of $\mathrm{DB}$ is also related to the number of end-groups with a higher DB having more end-groups per polymer. Furthermore, a high DB reduces the tendency of the polymer to crystallize, and increases the excess free volume of the polymer network ${ }^{[14]}$. 
To improve the mechanical properties of the HBPAEK and to increase the excess free volume (EFFV) and $\mathrm{T}_{\mathrm{g}}$, we cured the polymers by the existing end-groups ${ }^{[15]}$, and by adding reactive end-groups in the form of alkynes ${ }^{[16]}$. If part of the fluorine end-groups are replaced by 4-(phenylethynyl)phenol (PEP), a thermal treatment can chemically cross-link the triple bond; connecting the HBPs and forming a network, as shown in Figure 6.1.

In summary, the excellent chemical and thermal stability, flexible chemistry, and potential functionalization of HBPAEKs makes them interesting candidates as alternative membrane materials for the separation of gases. In this chapter, we report on the synthesis and characterization of neat HBPAEKs with varying amounts of alkyne end-groups to explore the potential of of these fully aromatic hyperbranched poly(aryl ether ketone)s as gas separation membranes at elevated temperatures.

\subsection{Experimental}

\subsubsection{Materials and equipment}

3,5-difluorobenzoyl chloride was purchased from Alfa Aesar. Anisole and $\mathrm{HBr}$ were purchased from Sigma Aldrich. All were used as received. Dry NMP and dry toluene were obtained from Acros Organics and used as received. Phenyl acetylene was purchased from Sigma Aldrich and vacuum distilled before use.

Differential Scanning Calorimetry (DSC) curves were measured on a TA instruments 2500 series at $10{ }^{\circ} \mathrm{C} \mathrm{min}{ }^{-1}$ (heating and cooling) under nitrogen atmosphere in crimped aluminum sample pans. The $\mathrm{T}_{\mathrm{g}}$ was determined as the inflection point, i.e., the global minimum of the first derivative. The thermal gravimetric analysis (TGA) measurements were done with a TA instruments 5500 TGA at $10{ }^{\circ} \mathrm{C} \mathrm{min}-1$ under nitrogen purge in aluminum pans.

${ }^{1} \mathrm{H}-\mathrm{NMR}(400 \mathrm{MHz})$ and ${ }^{13} \mathrm{C}-\mathrm{NMR}(100 \mathrm{~Hz})$ spectra were recorded on a Varian AS-400 spectrometer and chemical shifts are given in $\mathrm{ppm}(\delta)$ relative to tetramethylsilane (TMS) as an internal standard. The ${ }^{1} \mathrm{H}-\mathrm{NMR}$ splitting patterns are designated as follows: $\mathrm{s}$ (singlet), d (doublet), dd (double doublet), t (triplet), $\mathrm{q}$ (quartet), m (multiplet) and b (broad signal). The coupling constants, if given, are in Hertz.

SEC measurements were performed using a Shimadzu GPU DHU-20A3 equipped with a refractive index detector; polystyrene standards were used for calibration of the instrument. All samples were dissolved at a $1 \mathrm{mg} \mathrm{mL}^{-1}$ concentration in THF and filtered over a $0.45 \mu \mathrm{m}$ PTFE filter prior to use. Samples for mass spectrometry were analyzed on a Shimadzu GC/MS-QP2010S in electron-impact ionization (EI) mode, equipped with an Optic-3 injector and SGE capillary column (PBX5, 30m, 0.25mm). Data were acquired and processed using GCMS solution software. 


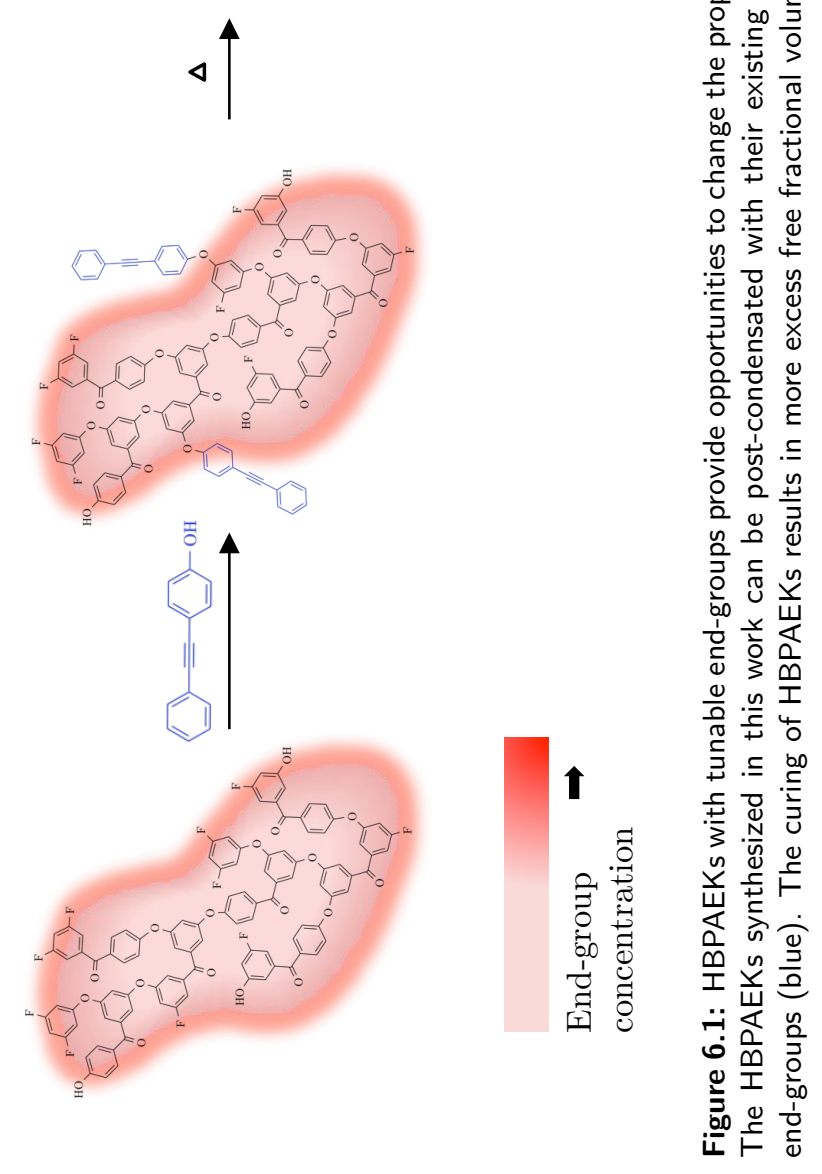

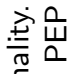

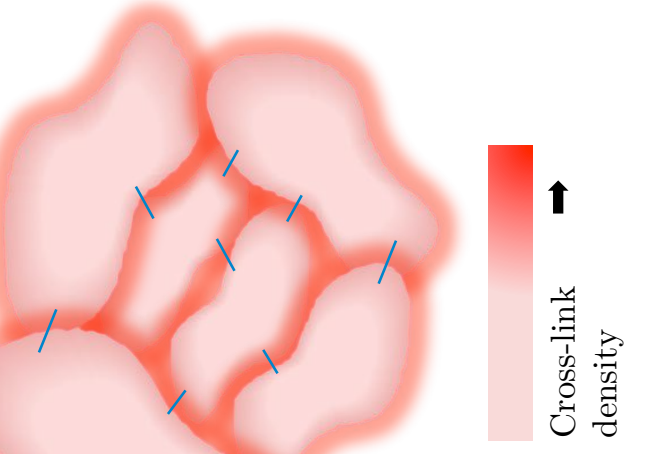

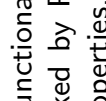

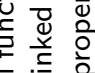

ปั

要

$\geq \frac{5}{4}$

즘 $\stackrel{\sigma}{\xi} \stackrel{\Phi}{\xi}$

兄站

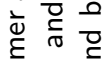

긍

을

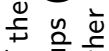

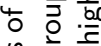

पू

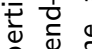

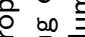

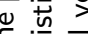

ช

ธัฮ บ

암당

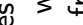

品

응

Оิ ह

는

음

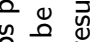

동

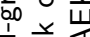

के

$\frac{\infty}{2}$

. $\subseteq$ bo

通

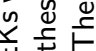

的。

또늘

话合

오응

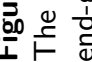


FT-IR spectra were recorded from powdered samples on a Perkin Elmer Spectrum 100 FT-IR Spectrometer, measuring from $600-4000 \mathrm{~cm}^{-1}$.

The density of HBPAEKs was measured using an AccuPyc II 1340 gas displacement density analyzer (Micrometrics, USA), using helium as gas source. For each sample, 150 individual density measurements were performed, where only the last 50 measurements were used to obtain the average density.

\subsubsection{Syntheses}

\section{(3,5-Difluorophenyl)(4-hydroxyphenyl)methanone, $\mathrm{AB}_{2}$}

A $1 \mathrm{~L}$ round bottom flask was charged with $50 \mathrm{~g}$ (0.2 mol) (3,5-difluorophenyl)(4-methoxyphenyl) methanone, which was synthesized according to procedures described in literature ${ }^{[17]}$. To the flask was added $450 \mathrm{~mL}$ of acetic acid and the mixture was stirred and heated to $50{ }^{\circ} \mathrm{C}$ until a transparent solution was obtained. Then $300 \mathrm{~mL} \mathrm{HBr} \mathrm{(48 \% )} \mathrm{was} \mathrm{added} \mathrm{and} \mathrm{a} \mathrm{white} \mathrm{precipitate} \mathrm{was} \mathrm{formed.} \mathrm{The}$ mixture was heated to $130{ }^{\circ} \mathrm{C}$ for a steady reflux (the mixture became transparent at $100{ }^{\circ} \mathrm{C}$ ). The reaction was stirred overnight and TLC (DCM as eluent) confirmed the completion of the reaction $(\mathrm{Rf}=0.2)$. The reaction was cooled and the mixture was evaporated to dryness. The white/pinkish solid was added to $1.5 \mathrm{~L}$ water and extracted with $3 \times 300 \mathrm{~mL}$ of ether. The product was recrystallized from $100 \%$ $\mathrm{EtOH}$ and dried overnight in vacuum at $60{ }^{\circ} \mathrm{C}$ resulting in $43.1 \mathrm{~g}$ the target compound as a white solid (91\%). MP: $150-151{ }^{\circ} \mathrm{C}$. FT-IR $\left(\mathrm{cm}^{-1}\right)$ : 3400-3000, 1640, 1582, 1438, 1329. MS (EI), $m / z: 234(\mathrm{M}), 121 .{ }^{1} \mathrm{H}-\mathrm{NMR}$ (DMSO-d6), $\delta=$ $10.58(\mathrm{~s}, 1 \mathrm{H}), 7.9(\mathrm{~d}, \mathrm{~J}=8.7,2 \mathrm{H}), 7.51-7.47(\mathrm{tt}, \mathrm{J}=2.4 \mathrm{~Hz}, 1 \mathrm{H}), 7.31-7.29(\mathrm{~m}, 2 \mathrm{H})$, $6.90(\mathrm{~d}, \mathrm{~J}=8.7,2 \mathrm{H}) .{ }^{13} \mathrm{C}-\mathrm{NMR}$ (DMSO-d6), $\delta=191.98,163.67,163.06,161.20$, 142.01, 133.12, 127.20, 115.89, 112.54, 107.34. Anal. Calcd for $\mathrm{C}_{13} \mathrm{H}_{8} \mathrm{~F}_{2} \mathrm{O}_{2}$ : C, 66.67; H, 3.44; F, 16.22. Found C, 66.58; H, 3.37; F, 16.06 .

\section{Fluoro-terminated HBPAEK}

To a $250 \mathrm{~mL}$ round bottom flask equipped with Dean-Stark trap was added $15 \mathrm{~g}$ of $\mathbf{A B}_{2}, 100 \mathrm{~mL}$ dry NMP, $75 \mathrm{ml}$ dry toluene and $15 \mathrm{~g} \mathrm{~K}_{2} \mathrm{CO}_{3}$. This was stirred for $3 \mathrm{~h}$ at $165{ }^{\circ} \mathrm{C}$ while de toluene/water azeotrope was collected. The temperature was subsequently raised in 30 minutes to $200{ }^{\circ} \mathrm{C}$ and the stirring was continued for $3 \mathrm{~h}$. The mixture was cooled to room temperature and precipitated in $3 \mathrm{~L}$ water. The collected solid was dissolved in THF, precipitated in $\mathrm{MeOH}$ and the collected solid was boiled in $\mathrm{MeOH}$, filtered hot, boiled in EtOH and filtered hot and dried in vacuum at $60{ }^{\circ} \mathrm{C}$ and $150{ }^{\circ} \mathrm{C}$ to obtain the target compound as an off-white very fine powder, $11.2 \mathrm{~g}(82 \%)$. FT-IR $\left(\mathrm{cm}^{-1}\right)$ : 1663, 1581, 1501, 1435, 1321, 1233. ${ }^{1} \mathrm{H}-\mathrm{NMR}\left(400 \mathrm{MHz}, \mathrm{CDCl}_{3}\right), \delta=7.90-7.50(\mathrm{~m}, 2 \mathrm{H}), 7.30-6.50(\mathrm{~m}, 5 \mathrm{H})$. 


\section{4-(Phenylethynyl)phenol (PEP)}

We used the synthesis method of Yuan et al. ${ }^{[18]}$ with a slightly modified work-up. To a $1 \mathrm{~L}$ 1-neck round-bottom flask was added $\mathrm{Pd}\left(\mathrm{PPh}_{3}\right) \mathrm{Cl}_{2}(0.8 \mathrm{~g}, 1 \mathrm{mmol}), \mathrm{CuI}$ $(0.43 \mathrm{~g}, 2 \mathrm{mmol})$ and $\mathrm{PPh}_{3}(0.30 \mathrm{~g}, 1 \mathrm{mmol})$. The flask was place under vacuum and subsequently filled with Argon. 4-Iodophenol $(25 \mathrm{~g}, 0.11 \mathrm{mmol})$ in $650 \mathrm{ml}$ $\mathrm{Et}_{3} \mathrm{~N}$ and phenyl acetylene $(16.35 \mathrm{ml}, 0.15 \mathrm{~mol})$ in $150 \mathrm{ml} \mathrm{Et}{ }_{3} \mathrm{~N}$ were added. This was stirred for $24 \mathrm{~h}$ before the yellow suspension was filtered, washed with $\mathrm{Et}_{3} \mathrm{~N}$ and concentrated. The resulting dark oil was purified via column chromatography over silica in DCM $(\mathrm{Rf}=0.2)$ to give the desired product, $19 \mathrm{~g}(87 \%)$. The product can be recrystallized from DCM after the silica column purification to afford colorless plate-like crystals. MS (EI), $\mathrm{m} / z: 194$ (M). FT-IR $\left(\mathrm{cm}^{-1}\right): 3400-$ 3000, 2225, 1608, 1590, 1509, 1440, 1371. MP: $125{ }^{\circ} \mathrm{C} .{ }^{1} \mathrm{H}-\mathrm{NMR}\left(\mathrm{CDCl}_{3}\right), \delta=$ 7.53-7.51 (d, 2H), 7.44-7.42 (d, 2H), 7.34-7.33 (d, 3H), 6.82-6.80 (d, 2H), 5.2-4.6 (b, $1 \mathrm{H}) .{ }^{13} \mathrm{C}-\mathrm{NMR}\left(\mathrm{CDCl}_{3}\right), \delta=155.57,133.27,131.44,128.31,127.99,123.48$, $115.67,115.50,89.20,88.09$.

\section{PEP end-capped HBPAEK}

To a $100 \mathrm{ml}$ flask was added $2 \mathrm{~g}$ of fluoro-terminated HBPAEK and this was dissolved in $30 \mathrm{ml} \mathrm{NMP} . \mathrm{K}_{2} \mathrm{CO}_{3}$ (2 eq.) and PEP were added and the solution stirred at $140{ }^{\circ} \mathrm{C}$ for $4 \mathrm{~h}$. The dark solution was precipitated in ice-cold water or methanol and the solid was collected, washed in a Soxhlet apparatus for $24 \mathrm{~h}$ with $\mathrm{MeOH}$ and dried in vacuum at $60{ }^{\circ} \mathrm{C}$ (quantitative yield). ${ }^{1} \mathrm{H}-\mathrm{NMR}(400 \mathrm{MHz}$, $\left.\mathrm{CDCl}_{3}\right), \delta=7.90-7.50(\mathrm{~m}, 2 \mathrm{H}), 7.30-6.50(\mathrm{~m}, 5 \mathrm{H}) .{ }^{13} \mathrm{C}-\mathrm{NMR}\left(\mathrm{CDCl}_{3}\right), \delta=192.88$, $162.89,160.30,140.72,132.61,118.88,116.48,112.78,107.70,94.47$ (alkyne), 89.03 (alkyne).

\subsubsection{In-situ spectroscopic ellipsometry}

\section{Film preparation}

Thin HBPAEKs films ( 150 nm) were dynamically spin-coated (Laurell WS-400B6NPP-Lite) on a silicon wafer (100, front side polished, CZ test grade, Silchem). Depending on the wafer size, $40-120 \mu \mathrm{L}$ of HBPAEK (1.5 $\mathrm{wt} \%$ in $\mathrm{CHCl}_{3}$ or $3 \mathrm{wt} \%$ in cyclopentanone) was deposited with a spin-coating speed of $4000 \mathrm{rpm}$ for $30 \mathrm{sec}-$ onds. Films were annealed for 30 minutes at $200{ }^{\circ} \mathrm{C}$ under nitrogen atmosphere.

\section{Heat-stage measurements}

The thickness and refractive index of HBPAEKs films on silicon wafers were measured as function of time and temperature by in-situ spectroscopic ellipsometry (SE). Measurements were performed on a M2000-XI ellipsometer (J.A. Woolam 
Co., USA) equipped with a heat stage (THMSEL600, Linkam, UK), calibrated as described by Kappert et al. ${ }^{[19]}$. Measurements were conducted at a fixed incident angle of $70^{\circ}$, in the full wavelength range of $210-1000 \mathrm{~nm}$ under a $100 \mathrm{~mL} \mathrm{~min}{ }^{-1}$ dried nitrogen flow.

The initial $\mathrm{T}_{\mathrm{g}}$ before thermal treatment was measured by heating the samples to $200{ }^{\circ} \mathrm{C}$ with $5{ }^{\circ} \mathrm{C} \mathrm{min}^{-1}$, where the samples were held for $15 \mathrm{~min}$ and sequentially cooled down again with $5{ }^{\circ} \mathrm{C} \mathrm{min}^{-1}$. The $\mathrm{T}_{\mathrm{g}}$ was determined as the intercept between the extrapolated curves above the bend and below the bend of the cooling down temperature-thickness curve as explained in more detail in literature ${ }^{[20]}$. The two different temperature programs that were used to cure the HBPAEKs are shown in Figure 6.2. Program " $280{ }^{\circ} \mathrm{C}$ " has a heating and cooling rate of $5{ }^{\circ} \mathrm{C}$ $\mathrm{min}^{-1}$, and a $1 \mathrm{~h}$ dwell temperature of $280{ }^{\circ} \mathrm{C}$. Program " $280-350{ }^{\circ} \mathrm{C}$ " has a heating and cooling rate of $5{ }^{\circ} \mathrm{C} \mathrm{min}{ }^{-1}$ and a dwell of $1 \mathrm{~h}$ at 280 and $1 \mathrm{~h}$ at $350{ }^{\circ} \mathrm{C}$. At least two different samples were measured for each temperature program.

The obtained spectra were modeled using CompleteEASE (v4.86, J.A. Woollam Co., USA). The HBPAEK film was modeled as an isotropic Cauchy layer fitted in the wavelength range from 500-1000 nm (fit parameters: thickness, $A, B$, and $k$, the Urbach absorption tail), on top of a Silicon wafer with a $2 \mathrm{~nm}$ native oxide layer. The temperature dependent optical parameters of the silicon wafer are taken from the literature ${ }^{[21]}$.

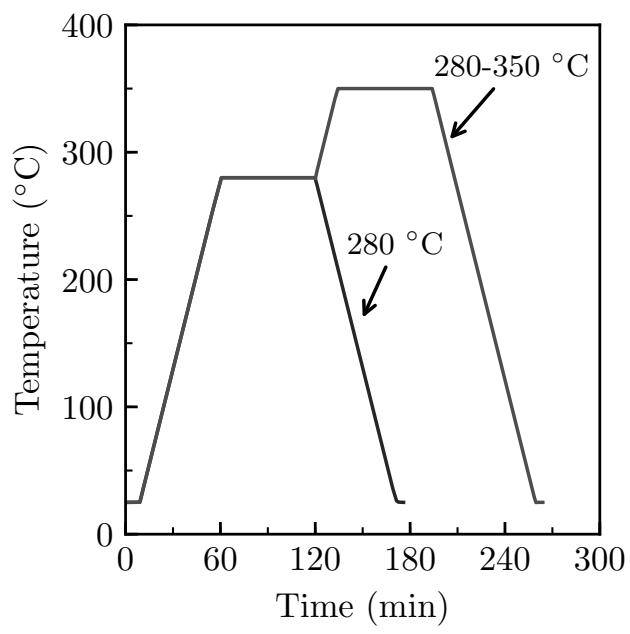

Figure 6.2: The temperature profiles as function of time for the curing programs used in this study. All curing programs have a heating and cooling rate of $5^{\circ} \mathrm{C} \min ^{-1}$, and a 1 hour isothermal hold. 


\section{$\mathrm{CO}_{2}$ sorption}

$\mathrm{CO}_{2}$ sorption experiments were conducted at elevated gas pressures with an AlphaSE ellipsometer (J.A. Woollam Co. Inc.). All measurements were performed at a fixed incident angle of $70^{\circ}$ and a wavelength range of $370-900 \mathrm{~nm}$. A custom-built stainless steel cell $\left(P_{\max }=200\right.$ bar, $\left.T_{\max }=200{ }^{\circ} \mathrm{C}\right)$ equipped with a temperature and pressure control system was used. The pressure was controlled and stabilized using a syringe pump (Teledyne ISCO, 500D) from vacuum to 60 bar, and the temperature of the pump was kept constant using a water bath at $35^{\circ} \mathrm{C}$. The $\Psi$ and $\Delta$ spectra were recorded approximately every $2 \mathrm{~min}$ for each pressure step until a stable film thickness and refractive index were obtained (this took approximately 20-30 minutes per pressure step). A correction for pressure-induced birefringence of the cell windows was performed using a high pressure (vacuum-60 bar) $\mathrm{CO}_{2}$ calibration measurement on a $500 \mathrm{~nm} \mathrm{SiO}_{2} / \mathrm{Si}$ wafer.

The obtained spectra were modeled using CompleteEASE (v4.86, J.A. Woollam Co., USA). The HBPAEK film was modeled as an isotropic Cauchy layer fitted in the wavelength range from 500-900 $\mathrm{nm}$ (fit parameters: thickness, $A, B$, and $k$, the Urbach absorption tail). The ambient was fitted as a Cauchy dispersion with the pressure dependent refractive index of $\mathrm{CO}_{2}{ }^{[22]}$.

The swelling degree (SD) of the film upon swelling in $\mathrm{CO}_{2}$ was calculated using Equation 6.1.

$$
\mathrm{SD}=\left(\frac{d_{t}}{d_{0}}-1\right) \cdot 100 \%
$$

Where $d_{t}$ and $d_{t}$ are the thicknesses of the film at the starting time $(t=0)$ or at a certain point in time $(t=t)$, respectively. The change in refractive index $(\Delta \eta)$ was obtained similarly from the refractive index at the starting time $\left(\eta_{0}\right)$ and at a certain point of time $\left(\eta_{t}\right)$. Because of the low changes in refractive index upon $\mathrm{CO}_{2}$ sorption, $\Delta \eta$ is expressed in permille (\%).

From the film thickness and the refractive index, the concentration of sorbed $\mathrm{CO}_{2}$ can be calculated using the Clausius-Mosotti equation, which is described in more detail in references ${ }^{[23,24]}$.

\subsubsection{Membrane preparation and characterization}

\section{Membrane preparation}

HBPAEK membranes were prepared by dynamically spin-coating the polymer on an $\alpha$-alumina porous support with a $3 \mu \mathrm{m}$ thick $\gamma$-alumina top-layer (Pervatech, the Netherlands). HBPAEKs were dissolved in cyclopentanone (3 wt\%) overnight. $0.15 \mathrm{~mL}$ of polymer solution was spun for 10 seconds at $500 \mathrm{rpm}$, followed by 5 minutes at $1000 \mathrm{rpm}$. The membranes were annealed directly after their synthesis to remove anisotropy induced by spin-coating. All membranes were heated to 
$200{ }^{\circ} \mathrm{C}$ with a heating rate of $10^{\circ} \mathrm{C} \mathrm{min}^{-1}$ for 30 minutes in a chamber furnace under a nitrogen atmosphere (Carbolite HTMA 5/28500 ${ }^{\circ} \mathrm{C}$ ). Annealed membranes were additionally cured by program " $280-350{ }^{\circ} \mathrm{C}$ ". The membrane thickness, used to calculate permeability, was assumed to be constant for all membranes, due to the identical spin-coating conditions.

\section{Single gas permeance}

Single gas $\left(\mathrm{He}, \mathrm{H}_{2}, \mathrm{CO}_{2}, \mathrm{~N}_{2}\right.$, and $\mathrm{CH}_{4}$ ) permeance measurements were performed using a custom-built setup (Convergence, the Netherlands). All experiments were performed in dead-end mode at a transmembrane pressure of 2 bar. The membrane module was heated to temperatures between 50 and $200{ }^{\circ} \mathrm{C}$. At least 2 uncured and 2 cured membranes were measured for both PEP containing polymers.

\section{Prolonged stability test}

The prolonged stability of a cured $10 \%$ PEP containing membrane was tested by measuring alternately the hydrogen and nitrogen permeance at a transmembrane pressure of 2 bar and a temperature of $200{ }^{\circ} \mathrm{C}$ for two weeks. The nitrogen permeance was measured for 5.5 hours, after which the feed gas was switched to hydrogen for 30 minutes. We report the average permeance during the last 5 minutes of every step.

\subsection{Results and discussion}

\subsubsection{Synthesis of HBPAEKs}

HBPAEKs were first synthesized by Hawker and $\mathrm{Chu}^{[17]}$, who modified a reaction developed by McGrath. As shown in Scheme 6.1, the $\mathrm{AB}_{2}$ monomer (3,5-difluorophenyl)(4-hydroxyphenyl)methanone was synthesized from the reaction of 3,5-difluorobenzoyl chloride and anisole, followed by a demethylation step to obtain an alcohol. The resulting $\mathrm{AB}_{2}$ monomer was polymerized to obtain a HBPAEK.

The resulting HBPAEK polymer can be cross-linked by existing fluorine and hydroxyl end-groups via a post-condensation process, as well via alkyne end-groups. In this work, we synthesized HBPAEKs containing 4-(phenylethynyl)phenol (PEP) end-groups which further increase the $\mathrm{T}_{\mathrm{g}}$ and $\mathrm{EFFV}$, and improve the mechanical properties after cross-linking. PEP is synthesized by the Sonogashira coupling of 4-iodophenol and phenyl acetylene ${ }^{[25]}$. The fluorine end-groups of the HBPAEK polymer were partially replaced by PEP via nucleophilic aromatic substitution. The PEP contains a carbon-carbon triple bond that can be thermally cured without any volatile evolution to produce extremely stable products ${ }^{[26]}$. 


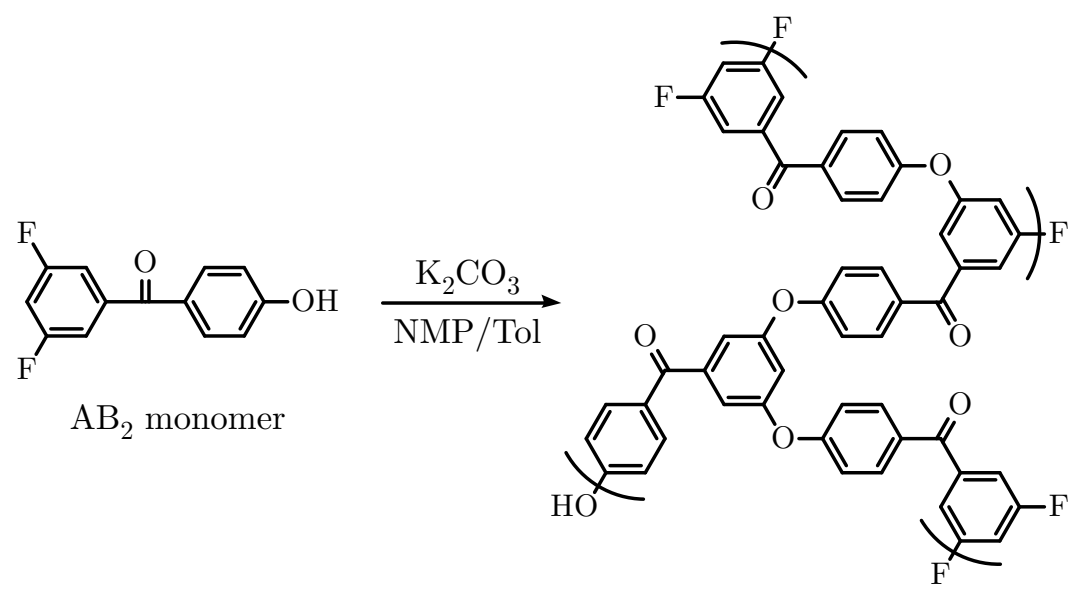

HBPAEK polymer

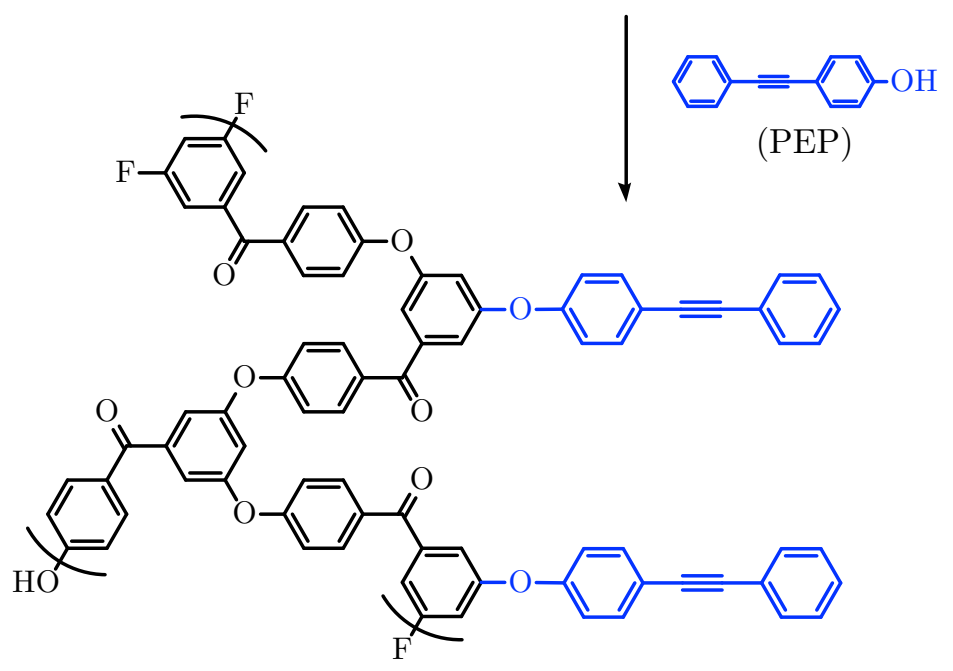

Partially PEP terminated HBPAEK polymer

Curing, $\triangle$

Cross-linked network

Scheme 6.1: Synthesis of the $A B_{2}$ monomer and subsequent polymerization to a HBPAEK. The PEP reactive end-groups can be used to thermally cure the polymers. 


\subsubsection{Characterization of HBPAEKs}

\section{Size exclusion chromatography}

The molecular weight (MW) of the synthesized HBPAEKs could be tuned by varying the reaction time. A molecular weight HBPAEK of $33 \mathrm{~K}$ was obtained after 3 hours stirring at $200{ }^{\circ} \mathrm{C}$. In addition, a similar range of HBPAEK with two different concentrations (based on stoichiometry) of PEP were synthesized.The molecular weight of all HBPAEKS in this study was kept similar to exclude possible effects of molecular weight on the polymers properties. Figure 6.3 shows the SEC curves for the HBPAEKs with and without PEP end-groups. It can be seen that all molecular weights are broadly distributed, and that the distribution is at least bimodal.

The obtained $\mathrm{M}_{\mathrm{n}}, \mathrm{M}_{\mathrm{w}}$ and polydispersity (PDI) from the SEC curves are displayed in Table 6.1. The PDI values of all polymers are relatively high, which is characteristic for randomly branched hyperbranched polymers. The degree of branching for all HBPAEKs was around the theoretical value of 0.5 , as determined by the literature procedure using ${ }^{19} \mathrm{~F}-\mathrm{NMR}{ }^{[17]}$.

Density measurements were performed with helium pycnometry on uncured HBPAEKs. The HBPAEKs have a higher density than that of the chemically similar linear polyether ketone (PEK) and polyether ether ketone (PEEK) (both

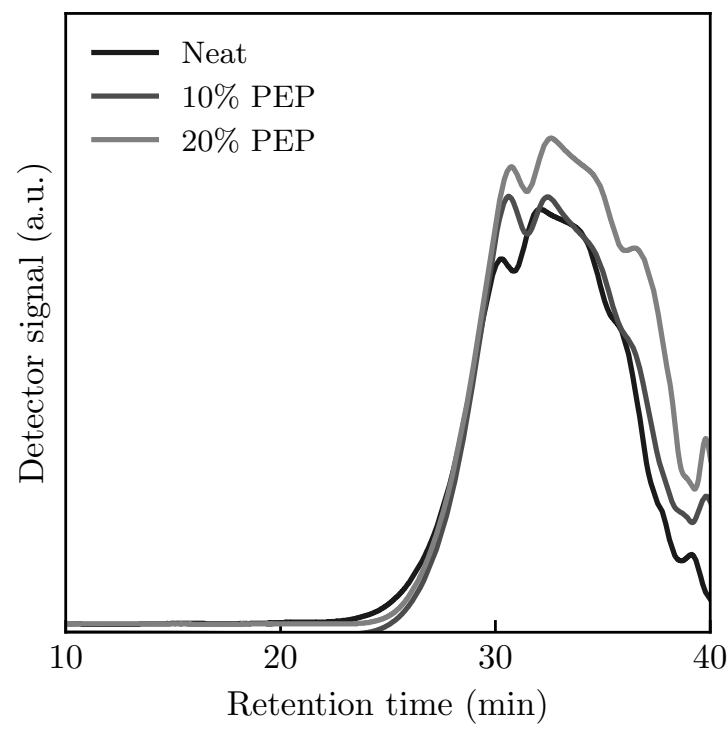

Figure 6.3: Size exclusion chromatograms of a neat HBPAEK, and HBPAEKs containing $10 \%$ and $20 \%$ PEP. 
around $\left.1.3 \mathrm{~g} \mathrm{~cm}^{-3}\right)^{[27,28]}$. The replacement of fluorine groups by alkyne end-group reduces the density of the polymer from 1.50 to $1.44 \mathrm{~g} \mathrm{~cm}^{-3}$.

Contact angles were measured according to the procedure described in the supporting information, and the results showed a hydrophobic character for all HBPAEKs (see supporting information Figure 6.23).

\section{Thermal stability}

HBPAEKs are, like their linear analogue, thermally very stable. Figure 6.4 compares the mass loss during the thermal degradation of the cured and uncured HBPAEKs up to $600{ }^{\circ} \mathrm{C}$. The introduction of PEP end-groups reduces the thermal stability slightly due to the presence of the alkyne group. All HBPAEKs show an initial mass loss starting around $270{ }^{\circ} \mathrm{C}$, which corresponds to the postcondensation process ${ }^{[15]}$, where fluorine and hydroxyl groups react and release HF. The polymer backbone starts to degrade at temperatures above $400{ }^{\circ} \mathrm{C}$, shown by the steep decrease in mass. The degradation of small $\mathrm{MW}$ fractions is proposed to cause the difference amongst the three compounds, supported by the SEC curves shown in Figure 6.3.

An increase in thermal stability is observed for the HBPAEKs containing $10 \%$ and $20 \%$ PEP (Figure 6.4b-c) when these materials are cured at $280-350{ }^{\circ} \mathrm{C}$, whereas the neat HBPAEK did not show an improvement in thermal stability upon curing (Figure 6.4a).
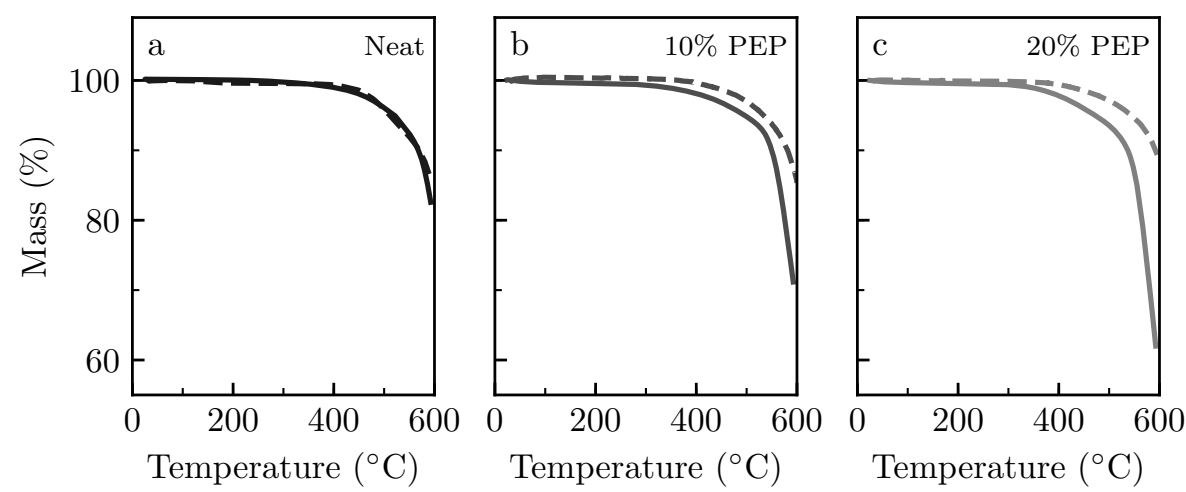

Figure 6.4: The mass loss as function of temperature for (a) neat HBPAEKs, (b) HBPAEKs containing $10 \%$ PEP, and (c) HBPAEKs containing 20\% PEP. The solid lines represent the uncured polymers, and the dashed lines the cured polymers. The thermal stability is enhanced for the cured polymers containing PEP end-groups due to cross-linking of the polymer upon curing. 


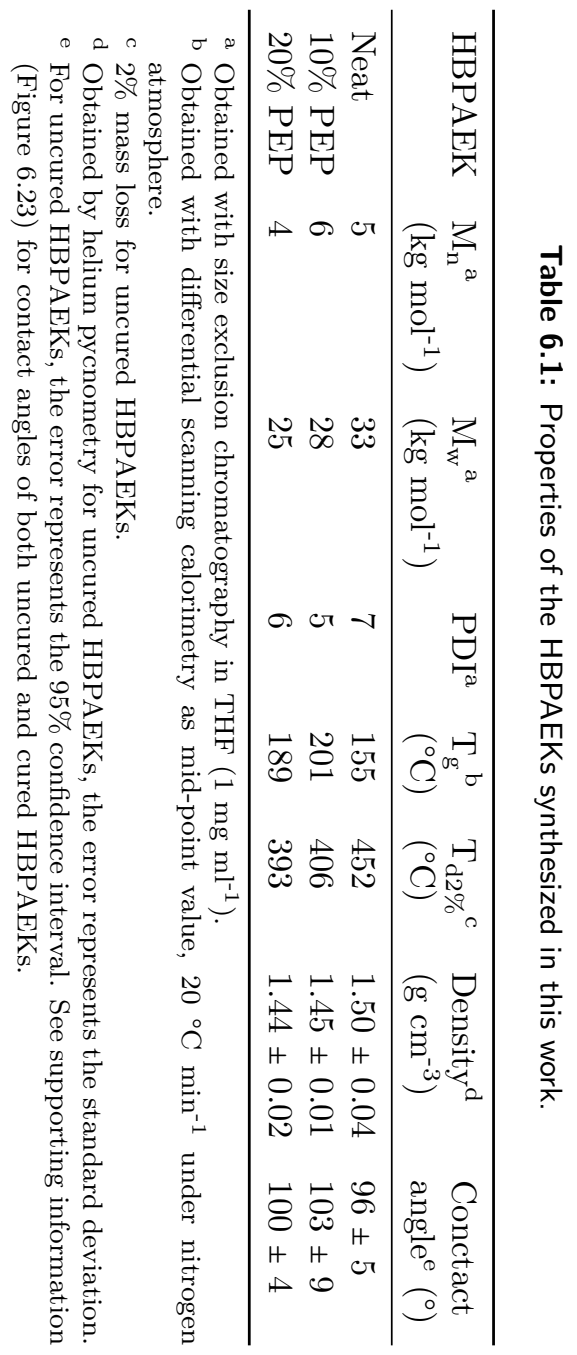




\section{Glass transition temperature}

The glass transition temperature, $\mathrm{T}_{\mathrm{g}}$, of uncured HBPAEKs was measured by DSC, and the results are shown in Figure 6.5. The $T_{g}$ for the neat HBPAEK is $155^{\circ} \mathrm{C}$. Introducing PEP end-groups results in a significant increase (up to $46{ }^{\circ} \mathrm{C}$ ) in $\mathrm{T}_{\mathrm{g}}$. It is quite common for hyperbranched polymers that the $\mathrm{T}_{\mathrm{g}}$ is affected when the end-groups are replaced. Examples of shifting glass transition temperatures can be found in literature for hyperbranched poly(ether ketones) ${ }^{[17]}$ and hyperbranched polyphenylenes ${ }^{[29,30]}$.

\subsubsection{In-situ spectroscopic ellipsometry}

\section{Thermal properties}

To study the effect of post-condensation and curing of PEP on the $\mathrm{T}_{\mathrm{g}}$ and EFFV, the change in film thickness and refractive index of HBPAEK films were measured by in-situ spectroscopic ellipsometry (SE) equipped with a heat stage. The polymers were heated by two different temperature programs, to study the influence of curing temperature on the thermal and optical properties. The films were either heated to $280^{\circ} \mathrm{C}$ with a 1 hour dwell, or heated to subsequently $280{ }^{\circ} \mathrm{C}$ and

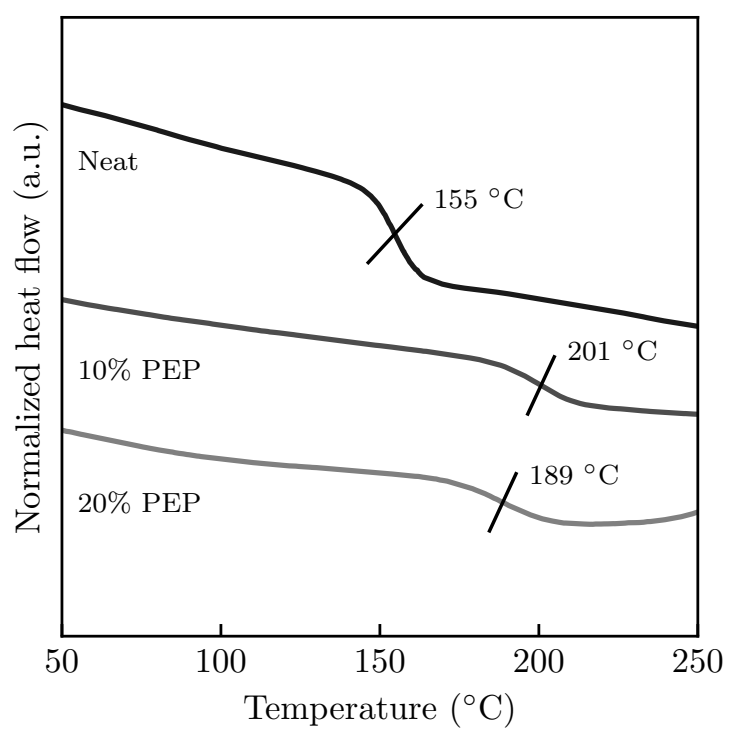

Figure 6.5: Glass transition temperatures of uncured HBPAEKs. The $T_{\mathrm{g}}$ was determined as the global minimum in the first derivative of the curves obtained by differential scanning calorimetry. The introduction of PEP end-groups results in an increase in $T_{g}$. 
$350{ }^{\circ} \mathrm{C}$ with a 1 hour dwell at both isothermal stages. The temperature profiles are plotted as a function of time in the experimental section (Figure 6.2). Additionally, the coefficients of thermal expansion were derived with SE, using the thickness versus temperature slope (see supporting information, Table 6.3). The glass transition temperature $\left(\mathrm{T}_{\mathrm{g}}\right)$ and excess free fractional volume (EFFV) of the polymers can be derived from this SE data ${ }^{[20]}$. Figure 6.6 shows the dependence of the $T_{g}$ for all HBPAEKs upon curing. The values shown are the average of at least two individual measurements, where the absolute difference in $\mathrm{T}_{\mathrm{g}}$ between the measurements was always less than $3{ }^{\circ} \mathrm{C}$.

The $\mathrm{T}_{\mathrm{g}}$ of all polymers increases with curing due to the reduced chain mobility and is clearly related to the amount of PEP cross-linker. Introducing these PEP end-groups increases the initial $\mathrm{T}_{\mathrm{g}}$ to $172{ }^{\circ} \mathrm{C}$ and the $\mathrm{T}_{\mathrm{g}}$ can reach values up to $250{ }^{\circ} \mathrm{C}$ after curing. The values of the $\mathrm{T}_{\mathrm{g}}$ for the uncured HBPAEKs obtained by ellipsometry are lower compared to those obtained by DSC, although the trends found are similar. The value of the measured $\mathrm{T}_{\mathrm{g}}$ depends strongly on the measurement method, thus explaining the differences in value obtained by DSC and ellipsometry.

When the polymers are heated to $280{ }^{\circ} \mathrm{C}$, a post-condensation process starts, resulting in a relatively small increase of the $\mathrm{T}_{\mathrm{g}}$ for all polymers. This curing starts around $270{ }^{\circ} \mathrm{C}$, based on rheology data presented in earlier work ${ }^{[15]}$, and will continue with increasing the temperature. At temperatures above $300{ }^{\circ} \mathrm{C}$, the alkyne groups of the PEP end-groups starts to cross-link. The temperature program

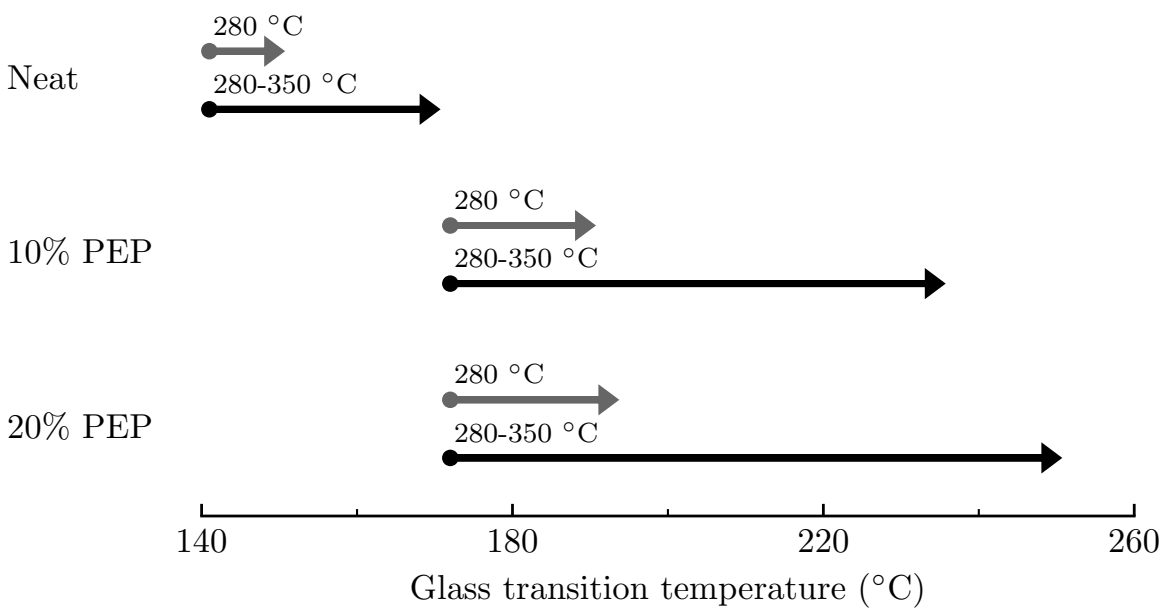

Figure 6.6: The change in $T_{\mathrm{g}}$ as a function of the curing temperature for the different HBPAEKs. The arrows indicate the change in $T_{\mathrm{g}}$ before and after curing. The temperature program is mentioned above the corresponding arrow and refers to an isothermal hold at that temperature. More details on the curing conditions can be found in the experimental section. 
"280-350 ${ }^{\circ} \mathrm{C}$ " results in a more pronounced effect on the $\mathrm{T}_{g}$. The $\mathrm{T}_{\mathrm{g}}$ increases at least $35 \%$ compared to the uncured polymer. The effect on the HBPAEKs without the PEP end-groups stays limited. The $\mathrm{T}_{\mathrm{g}}$ will only increase marginally due to the post-condensation, as no alkyne groups are present. When comparing polymers with and without PEP, we conclude that alkyne cross-linking has the largest contribution to the increase in $\mathrm{T}_{\mathrm{g}}$.

Similar to the $\mathrm{T}_{\mathrm{g}}$, the EFFV of the polymers could be derived from the SE temperature dependent data using Equation 6.2:

$$
\mathrm{EFFV}=\frac{h_{\mathrm{DG}}-h_{\mathrm{DL}}^{*}}{h_{\mathrm{DG}}}
$$

where $h_{\mathrm{DG}}$ is the glassy thickness and $h_{\mathrm{DL}}^{*}$ the extrapolated liquid thickness (for more information, see reference ${ }^{[20]}$ ). Figure 6.7 shows the EFFV for all polymers before and after thermal treatment. The same trend is observed for the EFFV as for the $\mathrm{T}_{\mathrm{g}}$ : curing, and thus cross-linking, the HBPAEK results in an increase in EFFV.

A more significant increase in EFFV is observed when HBPAEKs with PEP endgroups are cured. When the $\mathrm{T}_{\mathrm{g}}$ is increased due to cross-linking, the polymer will be in the glassy state at a higher temperature, thus at an earlier point in time when cooling down. Therefore the EFFV will be higher when cooled down to room temperature. Interestingly, PEP containing HBPAEKs that are cured at

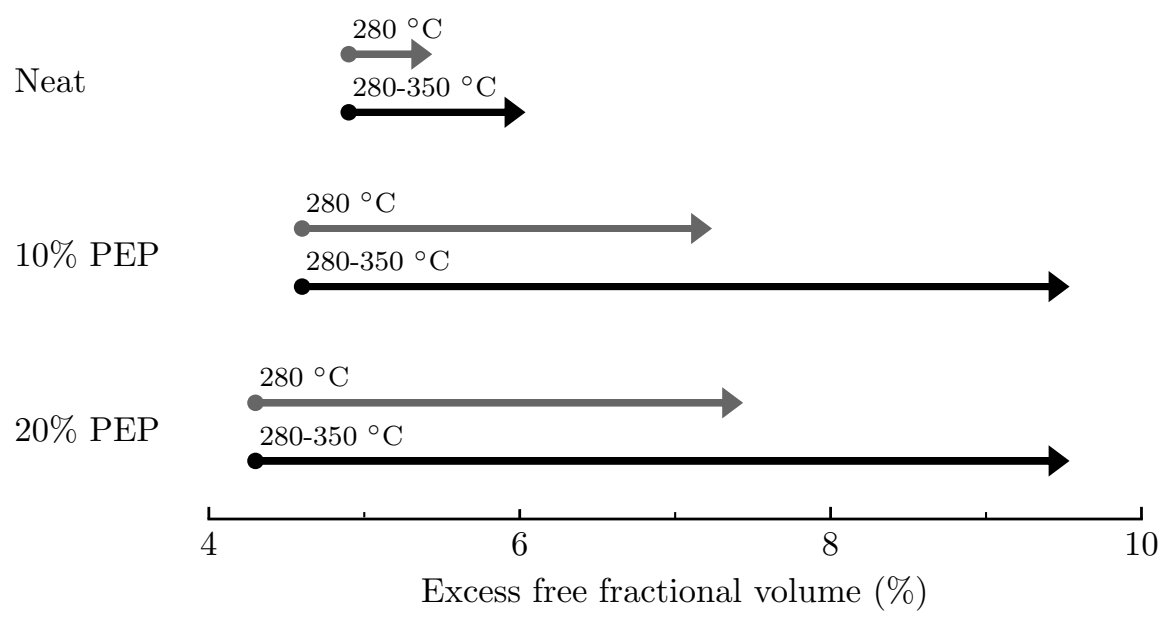

Figure 6.7: The change in EFFV as a function of the curing temperature for the different HBPAEKs. The arrows indicate the change in EFFV before and after curing. The temperature program is mentioned above the corresponding arrow and refers to an isothermal hold at that temperature. More details on the curing conditions can be found in the experimental section. 
$280{ }^{\circ} \mathrm{C}$ are found to have a higher EFFV as compared to cured neat HBPAEKs, despite the fact that this curing temperature is too low for alkyne cross-linking. This stresses the effect of introducing different end-groups on the properties of a hyperbranched polymer.

HBPAEKs bearing PEP end-groups can have an EFFV of up to $9.5 \%$ after curing at $280-350{ }^{\circ} \mathrm{C}$. This is relatively high compared to other glassy polymers such as poly(ether imide) $(7 \%)$, and polysulfone $(6.6 \%)$, but lower than Matrimid ${ }^{\circledR}$ (12\%) (data from unpublished work). Due to their high $\mathrm{T}_{\mathrm{g}}$ and EFFV, the PEP containing HBPAEKs were further analyzed for their $\mathrm{CO}_{2}$ sorption behavior and gas separation performance.

\section{$\mathrm{CO}_{2}$ sorption}

High-pressure $\mathrm{CO}_{2}$ sorption measurements were conducted on the PEP containing HBPAEK films. Figure 6.8 shows (a) the swelling degree, (b) the change in refractive index, and (c) adsorbed concentration of $\mathrm{CO}_{2}$ as a function of the $\mathrm{CO}_{2}$ pressure for a HBPAEK film containing $10 \%$ PEP that was cured at $280-350{ }^{\circ} \mathrm{C}$ prior to the sorption measurements. The HBPAEKs that were uncured, or containing $20 \% \mathrm{PEP}$ showed the same trends upon $\mathrm{CO}_{2}$ sorption. All results can be found in the supporting information, Figure 6.17-Figure 6.21.

The obtained $\mathrm{CO}_{2}$ induced swelling isotherm (Figure 6.8a) has a typical shape for a glassy polymer ${ }^{[31]}$ with swelling degrees in the same order as linear sulfonated poly(ether ether ketone) (SPEEK) (4\% at 50 bar) and Matrimid ${ }^{\circledR}(6.5 \%$ at 50 bar) ${ }^{[23]}$. The refractive index of the HBPAEK film (Figure 6.8b) initially increases with increasing $\mathrm{CO}_{2}$ pressures up to approximately 6 bar, followed by a decrease in index with further increasing $\mathrm{CO}_{2}$ pressures up to 60 bar. The initial increase in refractive index can be attributed to the filling of the EFFV by $\mathrm{CO}_{2}$ molecules, while at higher pressures the dilation of the polymer matrix results in a decrease of the index ${ }^{[32,33]}$. To what extent the index initially increases seems to be dependent on the EFFV. For example, a 10\% PEP containing HBPAEK that is uncured has a lower EFFV, and therefore a lower initial increase in index. We note that the absolute changes in refractive index are extremely low, and in combination with a low sensitivity towards the refractive index, the data must be interpreted with care.

From the thickness and refractive index, the concentration of $\mathrm{CO}_{2}$ in the polymer matrix could be derived, as shown in Figure 6.8c. There is an initial steep increase in the $\mathrm{CO}_{2}$ concentration due to filling of the EFFV, while at higher $\mathrm{CO}_{2}$ pressures the sorption is limited by the dilation of the polymer network, and therefore the slope decreases. The HBPAEK shows a strong hysteresis between sorption and desorption for both the swelling and refractive index data. This originates from polymer chain reorganizations at the time scale of the measurements despite the curing of the polymer. The change in refractive index drops below 0 at vacuum after desorption, indicating that the polymer structure is changed due to dilation. 

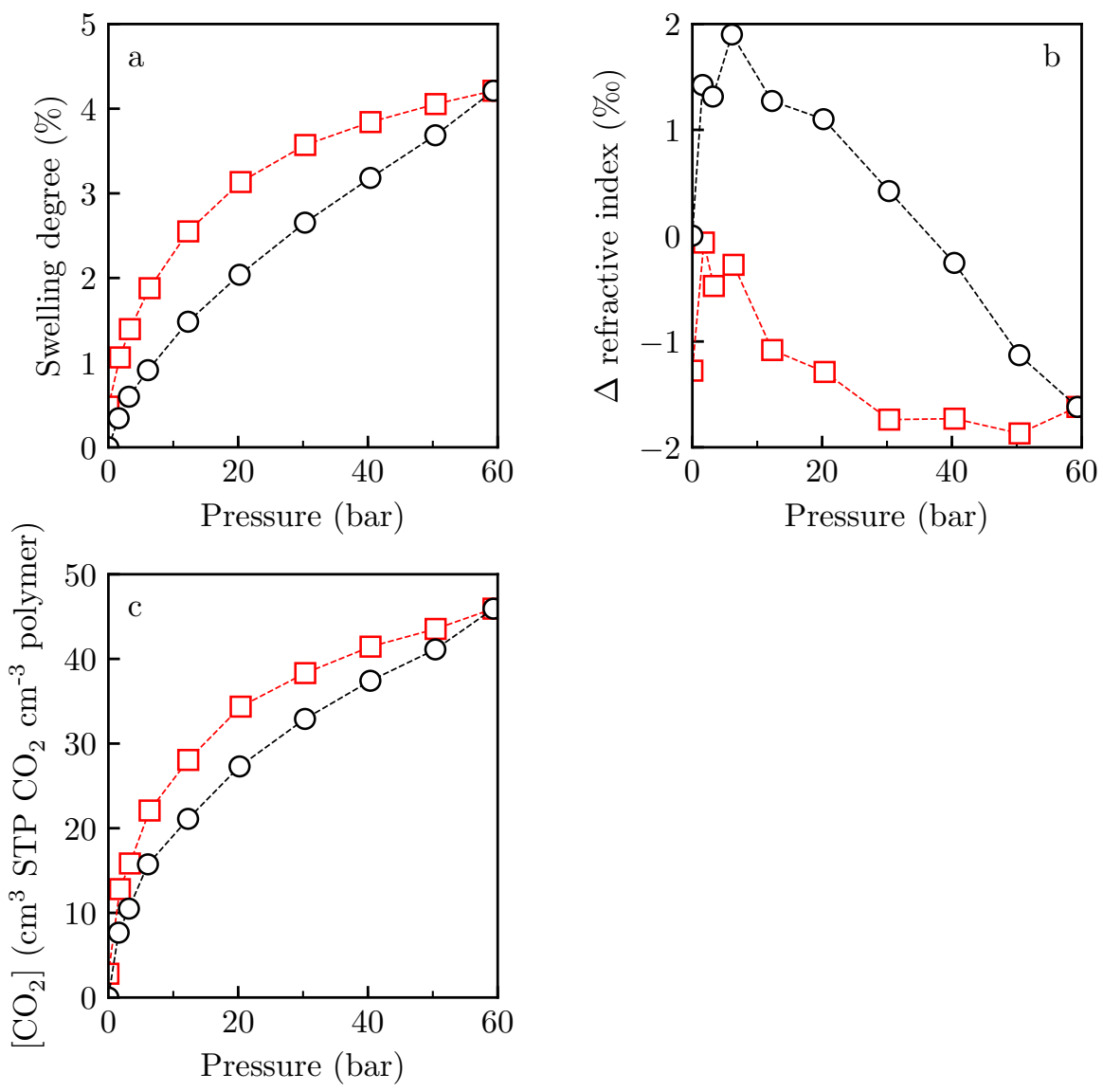

Figure 6.8: $\mathrm{CO}_{2}$ sorption (O) and desorption ( $\square$ ) for a HBPAEK containing $10 \%$ PEP cured at $280-350{ }^{\circ} \mathrm{C}$. (a) The swelling degree, (b) the change in refractive index, and (c) the concentration of $\mathrm{CO}_{2}$ as function of pressure. 
The same behavior is found for, for example, Matrimid ${ }^{\circledR 32]}$ or other poly(ether imide)s ${ }^{[33]}$. From the sorption isotherm the onset of plasticization could be determined as the point where the isotherm shows a steep linear increase with $\mathrm{CO}_{2}$ pressure. In addition to this steep linear increase, no hysteresis between sorption and desorption is observed in the case of plasticization. The sorption isotherms for the HBPAEKs show no increase in slope up to pressures of 50 bar $\mathrm{CO}_{2}$, and thus we can conclude that no plasticization occurs at $\mathrm{CO}_{2}$ pressures up to at least 50 bar. After this point the slope of the sorption isotherm seems to increase, however the signal noise and therefore errors at these extreme pressures are relatively large. This lack of plasticization is in great contrast to linear polymers that are commonly used for gas separation ${ }^{[34]}$.

\subsubsection{Gas separation performance}

Thin HBPAEK films supported by a porous alumina support were tested for their membrane performance (for additional information on the behavior of this support, see supporting information Figure 6.24 and Table 6.4). Figure 6.9 shows a scanning electron micrograph of the cross-section of such a cured HBPAEK film containing $10 \%$ PEP. Three layers can be clearly distinguished: the bottom layer is a $>2 \mathrm{~mm}$ thick $\alpha$-alumina layer (pore size $\sim 100 \mathrm{~nm}$, porosity $\sim 30 \%$ ), the middle layer is an approximately $3 \mu \mathrm{m}$ thick $\gamma$-alumina layer (pore size $\sim 3 \mathrm{~nm}$, porosity $\sim 40 \%$ ), and the top layer is a $700 \mathrm{~nm}$ thick HBPAEK film.

The gas separation performance for $10 \%$ and $20 \%$ PEP containing HBPAEKS is shown in Figure 6.10 and Figure 6.11, respectively. The single gas permeance as function of gas kinetic diameter for the uncured HBPAEKs is given in Figure 6.10a and Figure 6.11a, and for the HBPAEKs cured at $280-350{ }^{\circ} \mathrm{C}$ in Figure $6.10 \mathrm{~b}$ and Figure $6.11 \mathrm{~b}$. Due to the lower $\mathrm{T}_{\mathrm{g}}$ of the uncured HBPAEKS (see Figure 6.6), the maximum temperature was set to $150{ }^{\circ} \mathrm{C}$ instead of $200{ }^{\circ} \mathrm{C}$. For both $10 \%$ and $20 \%$ HBPAEKs it was found that the single gas permeance decreases with increasing gas

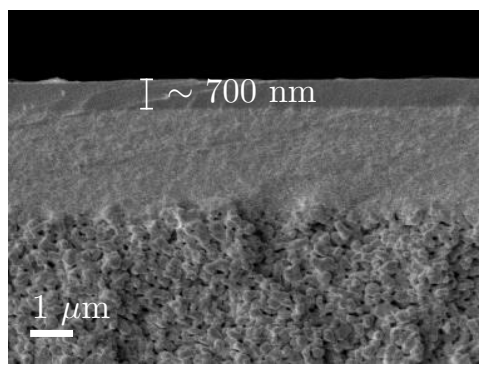

Figure 6.9: Cross-section scanning electron micrograph of a cured 10\% PEP HBPAEK film atop of a ceramic support. The support is made of an $\alpha$-alumina support with a $3 \mu \mathrm{m}$ thick $\gamma$-alumina layer. Atop of this $\gamma$-alumina layer sits the $\sim 700 \mathrm{~nm}$ thick HBPAEK film. 
kinetic diameter. This is a typical trend observed for glassy polymers, indicating a sieving mechanism. With increasing temperature, the permeance increased due to the increased mobility of a gas at higher temperatures.

The Arrhenius plot of the $\ln$ (permeance) as a function of $\mathrm{T}^{-1}$ is shown in Figure 6.10c,d and Figure 6.11c,d. The activation energy of the gas transport could be derived from the slope of this plot for every measured gas. Table 6.2 shows the values of the activating energy for all HBPAEKs and gases. The constant slopes of the activating energy suggest that the HBPAEK films do not suffer from temperature induced changes in chain mobility.

In general, the activation energy is similar for all gases and membranes. Typically used fluorine rich polymers, e.g., polyimides containing trifluoromethyl $\left(\mathrm{CF}_{3}\right)$ groups, show a low activation energy for $\mathrm{CO}_{2}$ transport due to the high solubility of $\mathrm{CO}_{2}$ in the membrane matrix at lower temperatures. At higher temperatures the $\mathrm{CO}_{2}$ solubility decreases, while the diffusivity increases. The permeability is the product of solubility and diffusivity, and therefore these effects cancel out at elevated temperatures. Studies on 6FDA-based polyimides show that the $\mathrm{CO}_{2}$ permeability was constant or even decreases with increasing temperature while for other gases the permeability increases with temperature ${ }^{[35,36]}$. Polyimides without these $\mathrm{CF}_{3}$ groups show also an increase in permeability with temperature for $\mathrm{CO}_{2}{ }^{[37]}$. The activating energy for $\mathrm{CO}_{2}$ transport does not differ from the other gases for the HBPAEK films measured in this study. The fluorine groups of the HBPAEKs show no increased affinity for $\mathrm{CO}_{2}$ in the gas separation measurements, hinting that fluorine atoms only display an effect when employed as bulky groups (e.g. in $-\mathrm{CF}_{3}$ groups). However, there is still a lot of debate on the nature of the $\mathrm{CO}_{2}$-F interaction ${ }^{[9,38]}$.

Table 6.2: Activating energies $\left(\mathrm{kJ} \mathrm{mol}^{-1}\right)$ for gas transport through the HBPAEK films.

\begin{tabular}{llllll}
\hline Gas & \multicolumn{2}{l}{$10 \% \mathrm{PEP}^{\mathrm{a}}$} & & \multicolumn{2}{l}{$20 \% \mathrm{PEP}^{\mathrm{a}}$} \\
\cline { 2 - 3 } \cline { 5 - 6 } & uncured & cured & & uncured & cured \\
\hline Helium & $16 \pm 0.4$ & $16 \pm 0.3$ & & $16 \pm 0.0$ & $15 \pm 0.1$ \\
Hydrogen & $16 \pm 0.5$ & $16 \pm 0.5$ & & $15 \pm 0.0$ & $15 \pm 0.3$ \\
Carbon dioxide & $22 \pm 8.3$ & $21 \pm 1.3$ & & $21 \pm 1.9$ & $14 \pm 1.7$ \\
Nitrogen & $21 \pm 3.9$ & $15 \pm 1.5$ & & $18 \pm 5.0$ & $17 \pm 2.2$ \\
Methane & $27 \pm 0.8$ & $23 \pm 1.7$ & & $16 \pm 2.8$ & $20 \pm 1.7$ \\
\hline
\end{tabular}

a The errors represent the standard error, since the limited amount of data points ( $n=3$ or 4 ) does not allow for the calculation of a meaningful $95 \%$ confidence interval. 

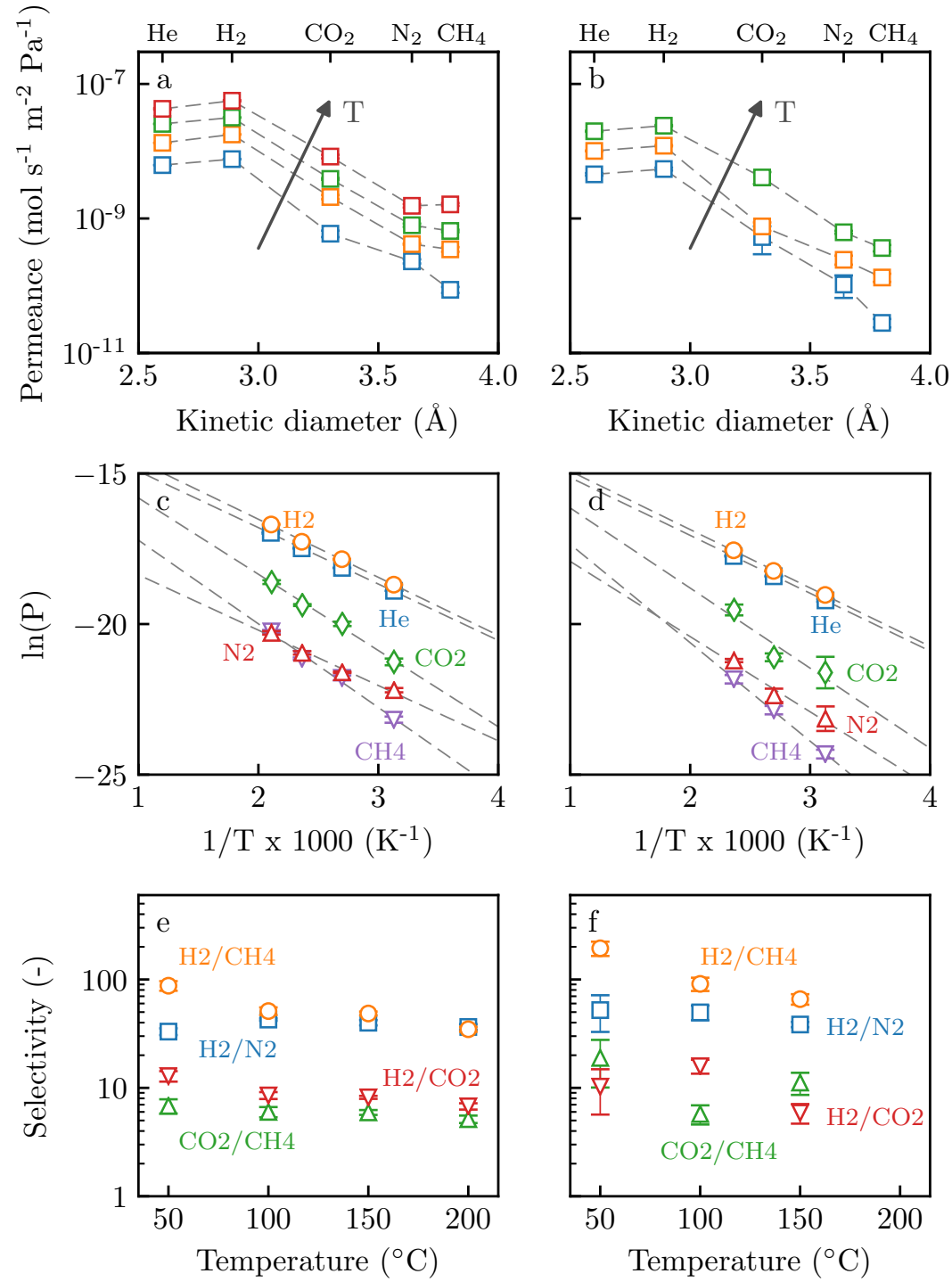

Figure 6.10: Gas permeation for uncured $(a, c, e)$ and cured at $280-350{ }^{\circ} \mathrm{C}(b, d, f)$ HBPAEKs containing $10 \%$ PEP. (a,b) Permeance as function of the gas kinetic diameter. (c,d) Arrhenius plot of single gas permeances. (e,f) Ideal selectivity of $\mathrm{H}_{2} / \mathrm{CH}_{4}, \mathrm{H}_{2} / \mathrm{N}_{2}, \mathrm{H}_{2} / \mathrm{CO}_{2}$, and $\mathrm{CO}_{2} / \mathrm{CH}_{4}$ as function of temperature. All error bars represent the standard error. 


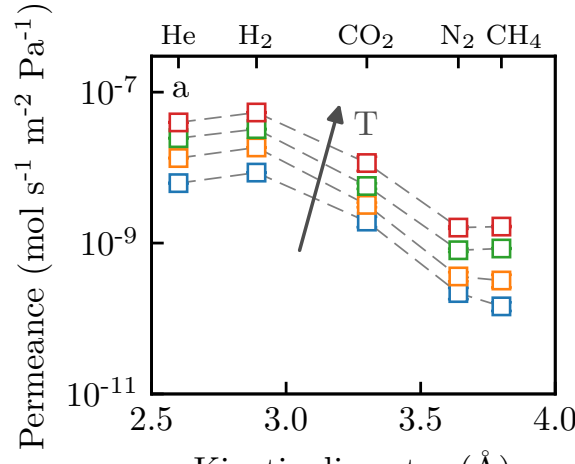

Kinetic diameter $(\AA)$
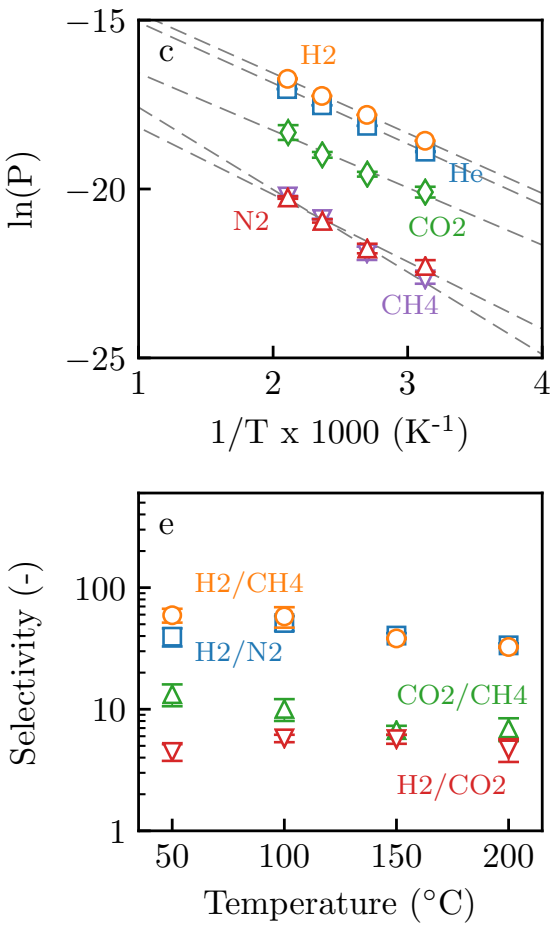
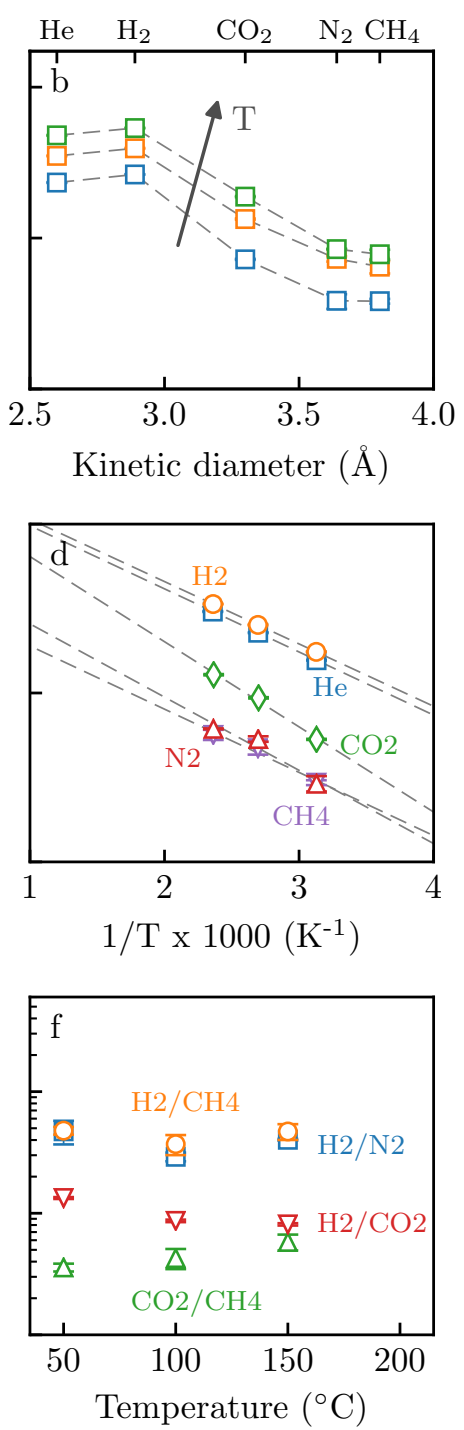

Figure 6.11: Gas permeation for uncured $(a, c, e)$ and cured at $280-350{ }^{\circ} \mathrm{C}(b, d, f)$ HBPAEKs containing $20 \%$ PEP. (a,b) Permeance as function of the gas kinetic diameter. (c,d) Arrhenius plot of single gas permeances. (e,f) Ideal selectivity of $\mathrm{H}_{2} / \mathrm{CH}_{4}, \mathrm{H}_{2} / \mathrm{N}_{2}, \mathrm{H}_{2} / \mathrm{CO}_{2}$, and $\mathrm{CO}_{2} / \mathrm{CH}_{4}$ as function of temperature. All error bars represent the standard error. 
The ideal selectivity $\left(P_{\alpha} / P_{\beta}\right)$ of $\mathrm{H}_{2} / \mathrm{CH}_{4}, \mathrm{H}_{2} / \mathrm{N}_{2}, \mathrm{H}_{2} / \mathrm{CO}_{2}$, and $\mathrm{CO}_{2} / \mathrm{CH}_{4}$ gas pairs as function of temperature is shown in Figure 6.10e,f and Figure 6.11e,f. It can be concluded that all membranes are still selective at higher temperatures up to $200{ }^{\circ} \mathrm{C}$. Independent of temperature, the selectivity of $\mathrm{H}_{2} / \mathrm{CH}_{4}$ and $\mathrm{H}_{2} / \mathrm{N}_{2}$ is higher compared to that of $\mathrm{H}_{2} / \mathrm{CO}_{2}$ and $\mathrm{CO}_{2} / \mathrm{CH}_{4}$ which is in agreement with the molecular sieving mechanism.

If the performance of the HBPAEKs measured at $50{ }^{\circ} \mathrm{C}$ is compared with currently used high-performance linear polymers in gas separation, e.g. the linear polyimide Matrimid ${ }^{\circledR}$, measured at $35{ }^{\circ} \mathrm{C}$, there are some interesting differences. While the selectivity of $\mathrm{H}_{2} / \mathrm{CH}_{4}$ and $\mathrm{H}_{2} / \mathrm{N}_{2}$ of our HBPAEKS are comparable to those found for Matrimid ${ }^{\circledR}$ (64 and 56, respectively), the $\mathrm{CO}_{2} / \mathrm{CH}_{4}$ selectivity of our HBPAEKs is lower as compared to Matrimid ${ }^{\circledR}(36)$. Additionally, the selectivity of $\mathrm{H}_{2} / \mathrm{CO}_{2}$ is higher as compared to Matrimid ${ }^{\circledR}(1.8)^{[3]}$.

Fang et al. ${ }^{[39]}$ reported on the synthesis and membrane performance of hyperbranched polyimide membranes. The authors show that besides the end-groups, the cross-linking mechanism of a hyperbranched polymer has a great influence on the membrane performance. In general, their measured $\mathrm{CO}_{2}$ permeability is comparable (1-4 Barrer) up to significantly higher (65 Barrer) as compared to our HBPAEKs (1-4 Barrer). The relatively low $\mathrm{CO}_{2}$ permeability found for our HBPAEKs fits very well with the low swelling degrees measured by in-situ SE (Figure 6.8). In addition, their $\mathrm{CO}_{2} / \mathrm{CH}_{4}$ selectivity is much higher (41-61) compared to our HBPAEKs (4-19). The work of Suzuki et al. ${ }^{[40]}$ showed the $\mathrm{CO}_{2}$ permeability of another hyperbranched polyimide. They report either comparable or up to 3 times higher $\mathrm{CO}_{2}$ permeability compared to our best HBPAEK. To compare the performance of the HBPAEKs membranes to other membranes available, their performance was plotted in the Robeson plot, shown in the supporting information (Figure 6.25).

Most state-of-the-art polymeric membranes show a decline in membrane performance at elevated temperatures caused by an increase in macromolecular dynam$\operatorname{ics}^{[41]}$. However, the development of a membrane stable at elevated temperatures would be of great interest in industry. Because of their excellent thermal stability, HBPAEK membranes showed to be still selective at temperatures up to $200{ }^{\circ} \mathrm{C}$ (the limit of the experimental setup). To further study their excellent thermal stability, the gas separation performance of a cured 10\% PEP containing polymer was studied for 2 weeks. As can be concluded from Figure 6.12, the HBPAEK did not show any sign of degradation by the loss of performance, indicating the great potential of these materials for gas separation at elevated temperatures. 

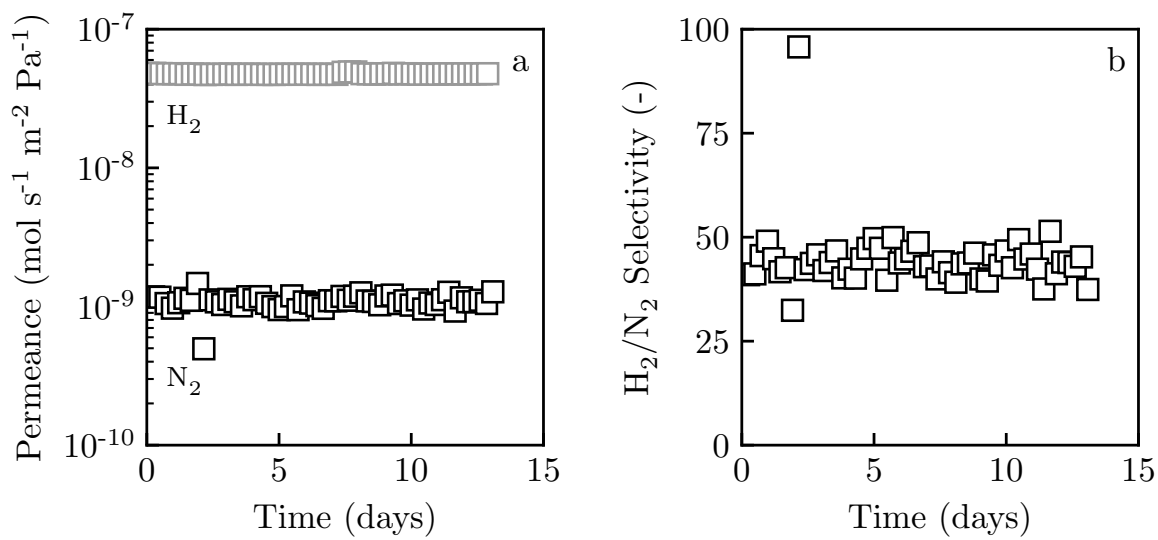

Figure 6.12: Prolonged stability of a cured HBPAEK containing $10 \%$ PEP. (a) The permeance of $\mathrm{H}_{2}$ and $\mathrm{N}_{2}$ as a function of time, and (b) the $\mathrm{H}_{2} / \mathrm{N}_{2}$ selectivity as function of time. It can be concluded that there is no decrease in selectivity, and thus no degradation of the polymer, after at least 14 days

\subsection{Conclusion}

In this work, we showed the synthesis and characterization of a series of HBPAEKs that are highly soluble in common organic solvents, that can be solution processed, and can be cured via a post-condensation process. The fluorine end-groups of the HBPAEK polymers were partially replaced by thermally cross-linkable PEP end-groups to be able to further increase the polymer properties. Thermally crosslinking the alkyne end-groups significantly increased the $\mathrm{T}_{\mathrm{g}}$ (up to $250{ }^{\circ} \mathrm{C}$ ) and the EFFV (up to 9.5\%), as compared to both the HBPAEK without PEP or uncured PEP terminated HBPAEKs. The large number of residual fluorine atoms in the HBPAEK provides additional possibilities for further functionalization. The first membrane performance results of HBPAEKs show a robust hyperbranched backbone that has excellent stability at elevated temperatures $\left(200{ }^{\circ} \mathrm{C}\right.$ for up to 2 weeks).

\subsection{Acknowledgements}

Parts of this project were funded by The Dutch Polymer Institute under project \#718. Parts of this work took place within the framework of the Institute for Sustainable Process Technology (ISPT, Project BL-20-02). 


\subsection{References}

[1] Baker, R. W.; Lokhandwala, K. Natural Gas Processing with Membranes: An Overview. Industrial \& Engineering Chemistry Research 2008, 47, 2109-2121.

[2] Scholz, M.; Melin, T.; Wessling, M. Transforming biogas into biomethane using membrane technology. Renewable and Sustainable Energy Reviews 2013, 17, 199 - 212.

[3] Sanders, D. F.; Smith, Z. P.; Guo, R.; Robeson, L. M.; Mcgrath, J. E.; Paul, D. R.; Freeman, B. D. Energy-efficient polymeric gas separation membranes for a sustainable future: A review. Polymer 2013, 54, 4729-4761.

[4] Bernardo, P.; Drioli, E.; Golemme, G. Membrane Gas Separation : A Review / State of the Art. Ind. Eng. Chem. Res. 2009, 4638-4663.

[5] Tanaka, K.; Okano, M.; Toshino, H.; Kita, H.; Okamoto, K.-I. Effect of methyl substituents on permeability and permselectivity of gases in polyimides prepared from methylsubstituted phenylenediamines. Journal of Polymer Science Part B: Polymer Physics 1992, 30, 907-914.

[6] Matsumoto, K.; Xu, P. Gas permeation of aromatic polyimides . II . Influence of chemical structure. Journal of Membrane Science 1993, 81, 23-30.

[7] Hirayama, Y.; Yoshinaga, T.; Kusuki, Y.; Ninomiya, K.; Sakakibara, T.; Tamari, T. Relation of gas permeability with structure of aromatic polyimides I. Journal of Membrane Science 1996, 111, 169-182.

[8] Yampolskii, Y. Polymeric Gas Separation Membranes. Macromolecules 2012, 45, 32983311.

[9] Raveendran, P.; Wallen, S. L. Exploring CO2-Philicity: Effects of Stepwise Fluorination. The Journal of Physical Chemistry B 2003, 107, 1473-1477.

[10] Zheng, Y.; Li, S.; Weng, Z.; Gao, C. Hyperbranched polymers: advances from synthesis to applications. Chem. Soc. Rev. 2015, 44, 4091-4130.

[11] Jikei, M.; Kakimoto, M.-a. Hyperbranched polymers: a promising new class of materials. Progress in Polymer Science 2001, 26, 1233-1285.

[12] Morikawa, A. Comparison of Properties among Dendritic and Hyperbranched Poly(ether ether ketone)s and Linear Poly(ether ketone)s. Molecules (Basel, Switzerland) 2016, 21.

[13] Hölter, D.; Burgath, A.; Frey, H. Degree of branching in hyperbranched polymers. Acta Polymerica 1997, 48, 30-35.

[14] Lederer, A.; Burchard, W. Hyperbranched polymers; The Royal Society of Chemistry, 2015.

[15] Vogel, W.; Dingemans, T. J. Cure Behaviour of Neat All-aromatic Hyperbranched Poly(aryl ether ketone)s. 2018, Unpublished manuscript.

[16] Mu, J.; Zhang, C.; Wu, W.; Chen, J.; Jiang, Z. Synthesis, Characterization, and Functionalization of Hyperbranched Poly(ether ether ketone)s with Phenoxypheyl Side Group. Journal of Macromolecular Science, Part A 2008, 45, 748-753.

[17] Hawker, C. J.; Chu, F. Hyperbranched Poly(ether ketones): Manipulation of Structure and Physical Properties. Macromolecules 1996, 29, 4370-4380.

[18] Yuan, W. Z.; Qin, A.; Lam, J. W. Y.; Sun, J. Z.; Dong, Y.; Häussler, M.; Liu, J.; Xu, H. P.; Zheng, Q.; Tang, B. Z. Disubstituted Polyacetylenes Containing Photopolymerizable Vinyl Groups and Polar Ester Functionality: Polymer Synthesis, Aggregation-Enhanced Emission, and Fluorescent Pattern Formation. Macromolecules 2007, 40, 3159-3166.

[19] Kappert, E. J.; Raaijmakers, M. J.; Ogieglo, W.; Nijmeijer, A.; Huiskes, C.; Benes, N. E. Temperature calibration procedure for thin film substrates for thermo-ellipsometric analysis using melting point standards. Thermochimica Acta 2015, 601, 29 - 32.

[20] Ogieglo, W.; Wormeester, H.; Wessling, M.; Benes, N. E. Effective medium approximations for penetrant sorption in glassy polymers accounting for excess free volume. Polymer $\mathbf{2 0 1 4}$ $55,1737-1744$.

[21] Herzinger, C. M.; Johs, B.; McGahan, W. A.; Woollam, J. A.; Paulson, W. Ellipsometric determination of optical constants for silicon and thermally grown silicon dioxide via 
a multi-sample, multi-wavelength, multi-angle investigation. Journal of Applied Physics 1998, 83, 3323-3336.

[22] Obriot, J.; Ge, J.; Bose, T.; St-Arnaud, J.-M. Determination of the density from simultaneous measurements of the refractive index and the dielectric constant of gaseous $\mathrm{CH} 4$, SF6, and CO2. Fluid Phase Equilibria 1993, 86, $314-350$.

[23] Simons, K.; Nijmeijer, K.; Sala, J. G.; van der Werf, H.; Benes, N. E.; Dingemans, T. J.; Wessling, M. CO2 sorption and transport behavior of ODPA-based polyetherimide polymer films. Polymer 2010, 51, 3907 - 3917.

[24] Horn, N. R.; Paul, D. R. Carbon Dioxide Sorption and Plasticization of Thin Glassy Polymer Films Tracked by Optical Methods. Macromolecules 2012, 45, 2820-2834.

[25] Yuan, W. Z.; Qin, A.; Lam, J. W. Y.; Sun, J. Z.; Dong, Y.; Häussler, M.; Liu, J.; Xu, H. P.; Zheng, Q.; Tang, B. Z. Disubstituted Polyacetylenes Containing Photopolymerizable Vinyl Groups and Polar Ester Functionality: Polymer Synthesis, Aggregation-Enhanced Emission, and Fluorescent Pattern Formation. Macromolecules 2007, 40, 3159-3166.

[26] Knijnenberg, A.; Weiser, E. S.; StClair, T. L.; Mendes, E.; Dingemans, T. J. Synthesis and Characterization of Aryl Ethynyl Terminated Liquid Crystalline Oligomers and Their Cured Polymers. Macromolecules 2006, 39, 6936-6943.

[27] Stuart, B. Polymer Analysis; John Wiley \& Sons, Ltd., 2002.

[28] Arjula, S.; Harsha, A. Study of erosion efficiency of polymers and polymer composites. Polymer Testing 2006, 25, 188 - 196.

[29] Kim, Y. H.; Webster, O. W. Hyperbranched Polyphenylenes. Macromolecules 1992, 25, 5561-5572.

[30] Kim, Y. H.; Beckerbauer, R. Role of End Groups on the Glass Transition of Hyperbranched Polyphenylene and Triphenylbenzene Derivatives. Macromolecules 1994, 27, 1968-1971.

[31] Visser, T.; Koops, G.; Wessling, M. On the subtle balance between competitive sorption and plasticization effects in asymmetric hollow fiber gas separation membranes. Journal of Membrane Science 2005, 252, 265 - 277.

[32] Raaijmakers, M. J.; Ogieglo, W.; Wiese, M.; Wessling, M.; Nijmeijer, A.; Benes, N. E. Sorption Behavior of Compressed CO2 and CH4 on Ultrathin Hybrid Poly(POSS-imide) Layers. ACS Applied Materials \& Interfaces 2015, 7, 26977-26988.

[33] Ogieglo, W.; Madzarevic, Z. P.; Raaijmakers, M. J. T.; Dingemans, T. J.; Benes, N. E. Highpressure sorption of carbon dioxide and methane in all-aromatic poly(etherimide)-based membranes. Journal of Polymer Science Part B: Polymer Physics 2016, 54, 986-993.

[34] Bos, A.; Punt, I.; Wessling, M.; Strathmann, H. CO2-induced plasticization phenomena in glassy polymers. Journal of Membrane Science 1999, 155, $67-78$.

[35] Lin, W.-H.; Chung, T.-S. Gas permeability, diffusivity, solubility, and aging characteristics of 6FDA-durene polyimide membranes. Journal of Membrane Science 2001, 186, 183 193.

[36] Duthie, X.; Kentish, S.; Powell, C.; Nagai, K.; Qiao, G.; Stevens, G. Operating temperature effects on the plasticization of polyimide gas separation membranes. Journal of Membrane Science 2007, 294, $40-49$.

[37] Villaluenga, J.; Seoane, B.; Hradil, J.; Sysel, P. Gas permeation characteristics of heterogeneous ODPA-BIS P polyimide membranes at different temperatures. Journal of Membrane Science 2007, 305, 160 - 168.

[38] Singley, E. J.; Liu, W.; Beckman, E. J. Phase behavior and emulsion formation of novel fluoroether amphiphiles in carbon dioxide. Fluid Phase Equilibria 1997, 128, 199 - 219.

[39] Fang, J.; Kita, H.; ichi Okamoto, K. Gas permeation properties of hyperbranched polyimide membranes. Journal of Membrane Science 2001, 182, 245 - 256.

[40] Suzuki, T.; Yamada, Y.; Tsujita, Y. Gas transport properties of 6FDA-TAPOB hyperbranched polyimide membrane. Polymer 2004, 45, 7167 - 7171.

[41] Koros, W.; Woods, D. Elevated temperature application of polymer hollow-fiber membranes. Journal of Membrane Science 2001, 181, 157 - 166. 
[42] Buck, A. L. New Equations for Computing Vapor Pressure and Enhancement Factor. Journal of Applied Meteorology 1981, 20, 1527-1532.

[43] Mueller, A.; Kowalewski, T.; Wooley, K. L. Synthesis, Characterization, and Derivatization of Hyperbranched Polyfluorinated Polymers. Macromolecules 1998, 31, 776-786.

[44] Uhlhorn, R.; Keizer, K.; Burggraaf, A. Gas and surface diffusion in modified $\gamma$-alumina systems. Journal of Membrane Science 1989, 46, 225 - 241.

[45] Baker, R. W. Membrane Technology and Applications, 3rd ed.; John Wiley \& Sons, Ltd, 2012.

[46] Robeson, L. M. The upper bound revisited. Journal of Membrane Science 2008, 320, 390 -400 . 


\subsection{Supporting information}

\subsubsection{Experimental}

\section{Time effect on the glass transition temperature}

The effect of curing time on the glass transition temperature and the excess free fractional volume was measured by in-situ $\mathrm{SE}$ in a similar way as described in the experimental section of the main chapter. The polymer films supported onto a silicon wafer were heated with $20{ }^{\circ} \mathrm{C} \mathrm{min}-1$ to either $250{ }^{\circ} \mathrm{C}$, or $400{ }^{\circ} \mathrm{C}$ for 30 or 120 minutes, and cooled to room temperature with a heating rate of $10^{\circ} \mathrm{C} \mathrm{min}^{-1}$.

\section{$\mathrm{H}_{2} \mathrm{O}$ sorption by in-situ spectroscopic ellipsometry}

Humidity dependent in-situ SE measurements were performed on a M2000-X (J.A. Woollam Co., USA) ellipsometer equipped with a heated liquid cell (J.A. Woollam Co., USA) at a fixed incident angle of $75^{\circ}$. The temperature of the liquid cell was set to $35^{\circ} \mathrm{C}$. Nitrogen gas was bubbled through two bubblers in series filled with water, and mixed with dry nitrogen. The sum of the two flows was kept constant at $300 \mathrm{~mL} \mathrm{~min}{ }^{-1}$. A humidity sensor (Sensirion digital humidity sensor, SHTW2) was placed at the outlet of the cell, and the humidity in the cell was calculated from the humidity and temperature measured at the outlet of the cell using the Buck equation ${ }^{[42]}$.

\section{Contact angle measurements}

Static contact angle measurements on spin-coated HBPAEK films on silicon wafers were performed by the sessile drop method ( $2 \mu \mathrm{L}$, Milli-Q water) with an OCA 15 (Dataphysics, Germany). The contact angle was determined 3s after applying the water droplet to the surface.

Figure 6.13 shows an example of the method used to calculate the contact angle. All images were analyzed with Python (v3.5) using the scipy.ndimage package (v0.18.1). The contact angle was defined as the angle between the baseline and the lines tangent to the circle describing the droplet. The image was first thresholded to obtain a binary image. The height of the baseline was determined on both sides of the droplet by scanning the pixels downward. The y-position of the last row being completely black was averaged for these two sides, resulting in the y-position of the baseline.

To define the circle describing the droplet, the top of the droplet was located together with the two points to the left and to the right of the center line at $40 \%$ of the droplet height. These three points define the center location and the radius of the circle that defines the circumference of the droplet. The contact angle was 

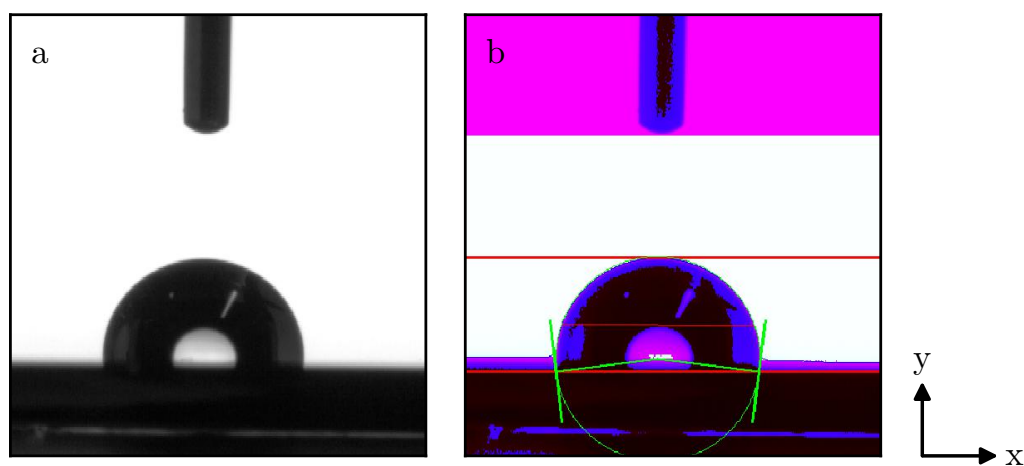

Figure 6.13: An example of the determination of the contact angle. (a) The image as captured by the camera. (b) The image showing the position of the calculated baseline, the top of the droplet, and $40 \%$ of the droplet height (red), and the corresponding drop contour and tangent to the drop at the baseline (green).

calculated from the line tangent to the circle at the intersection of the baseline and the circle.

\subsubsection{Results and discussion}

\section{In-situ spectroscopic ellipsometry: heat stage measurements}

The glass transition temperature and the excess fractional free volume of HBPAEK films after thermal curing was obtained by in-situ spectroscopic ellipsometry. Figure 6.14 shows the results of such a measurement for a $10 \%$ PEP film, cured at $280-350{ }^{\circ} \mathrm{C}$. Figure 6.14 a shows the relative thickness as function of time, and Figure $6.14 \mathrm{~b}$ shows the relative refractive index as function of time. Both are obtained by dividing the values obtained at $t=t$ by the value obtained at $t=0$.

The thickness of the polymer film increases during heating due to thermal expansion. The temperature at which the slope changes is defined as the $\mathrm{T}_{\mathrm{g}}$. While the temperature is constant at $280{ }^{\circ} \mathrm{C}$, the polymer shows a little overshoot in the thickness due to the thermal expansion. This is directly followed by a decrease in thickness because of densification of the polymer during curing. The same effect is visible for the second heating step to $350{ }^{\circ} \mathrm{C}$, but it is more pronounced due to the higher temperature. Upon cooling, the material shrinks, and shows a $\mathrm{T}_{\mathrm{g}}$ at a much higher temperature due to the cross-linking of the material. The final film thickness has slightly decreased after curing due to compaction of the polymer matrix.

In contrast to the thickness, the refractive index of the HBPAEK film decreases upon heating due to thermal expansion. While the refractive index is more or 

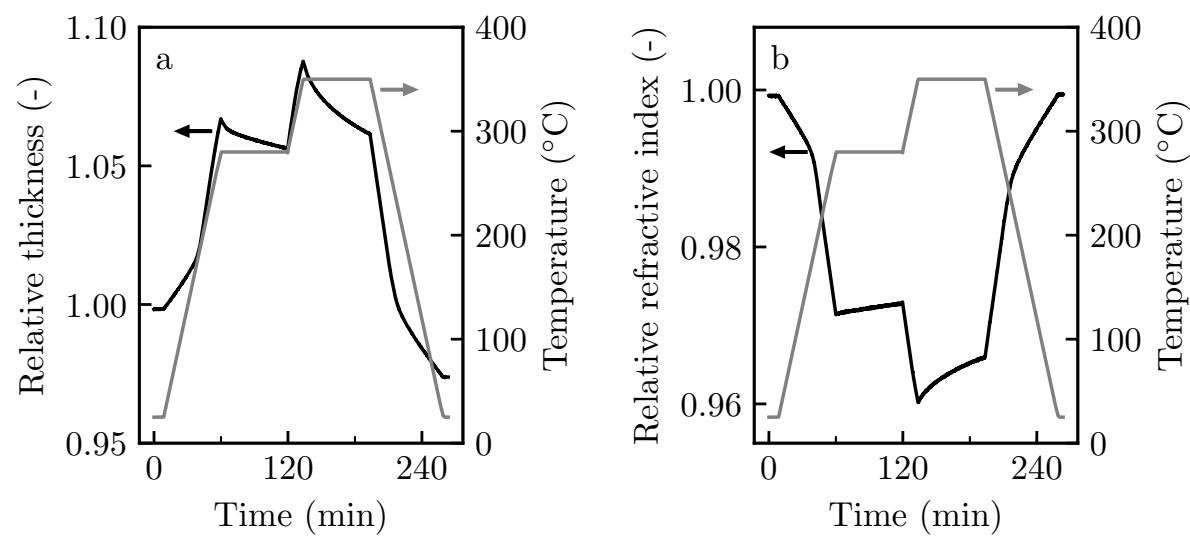

Figure 6.14: A typical output obtained by in-situ spectroscopic ellipsometry when studying the curing of a HBPAEK containing $10 \%$ PEP. (a) Relative thickness as function of time, and (b) relative refractive index as function of time. The second $y$-axis represents the temperature for both graphs.

less constant during the first isothermal step $\left(280^{\circ} \mathrm{C}\right)$, it increases significantly at $350{ }^{\circ} \mathrm{C}$ due to the cross-linking of the polymer chains. The final refractive index is unchanged compared to the index of the uncured polymer. The changes in the thickness are relatively small, and the refractive index data is less accurate than the thickness, therefore small structural changes are not shown in the refractive index data.

The linear coefficient of thermal expansion (CTE) of the HBPAEK films can be calculated by:

$$
\alpha_{\mathrm{L}}=\frac{1}{d} \cdot \frac{\mathrm{d} d}{\mathrm{~d} T}
$$

Where $\alpha_{\mathrm{L}}$ is the linear coefficient of thermal expansion $\left({ }^{\circ} \mathrm{C}^{-1}\right), d$ the initial film thickness $(\mathrm{m}), \mathrm{d} d$ the change in thickness $(\mathrm{m})$, and $\mathrm{d} T$ the change in temperature $\left({ }^{\circ} \mathrm{C}\right)$. The CTE can be extracted from the temperature and thickness data above the $T_{\mathrm{g}}$. The thermal expansion coefficient was obtained for both the heating and cooling phase. The initial temperature was defined as $T_{\max }-80$, and the final temperature as $T_{\max }-5$. The corresponding thicknesses were taken as the initial and final thickness. Figure 6.15 shows an example of the determination of the thickness and temperature. All red points represent the data for the CTE at heating, and the blue points the data points for cooling. The squares correspond to the thickness data, and the circles to the temperature data.

Although there is a relative large spread in the CTE between the three HBPAEKs studied, the CTE is always significantly larger upon cooling as compared to heating (Table 6.3). This indicates that during the heating phase, there is compaction of 


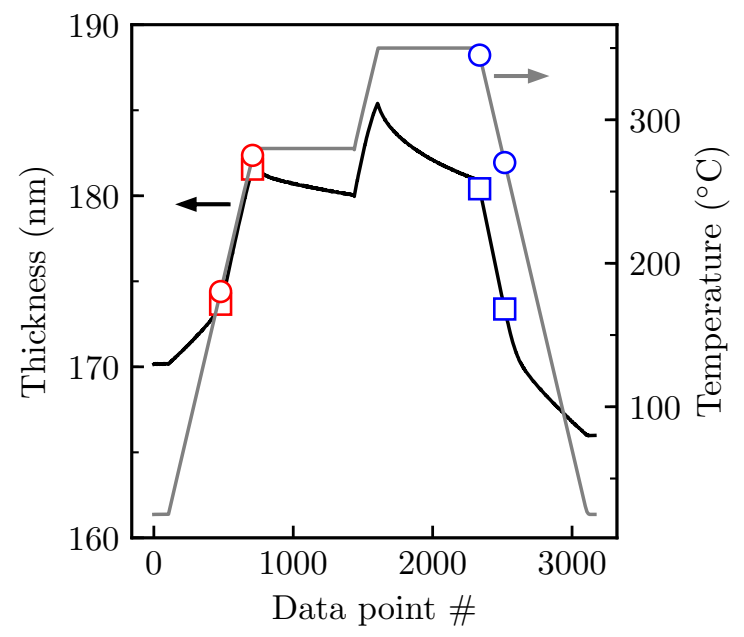

Figure 6.15: An example of the determination of the data points used to calculate the linear coefficient of thermal expansion. The initial temperature was defined 80 degrees below the maximum temperature, and the final temperature 5 degrees below the maximum temperature.

Table 6.3: Linear coefficient of thermal expansion $\left(10^{-6}{ }^{\circ} \mathrm{C}^{-1}\right)$ of the HBPAEKs measured by $\mathrm{SE}$. The average of two samples is taken.

\begin{tabular}{|c|c|c|c|c|c|c|}
\hline \multirow[t]{2}{*}{ Curing program } & \multicolumn{2}{|l|}{ Neat } & \multicolumn{2}{|c|}{$10 \%$ PEP } & \multicolumn{2}{|c|}{$20 \%$ PEP } \\
\hline & heating & cooling & heating & cooling & heating & cooling \\
\hline $280^{\circ} \mathrm{C}$ & 461 & 540 & 486 & 537 & 475 & 528 \\
\hline $280-350{ }^{\circ} \mathrm{C}$ & 456 & 504 & 476 & 551 & 478 & 521 \\
\hline
\end{tabular}

the material because of curing, and thus we can conclude that cross-linking of the polymer chains is already occurring during the heating of the polymer.

Figure 6.16 shows the effect of curing time and temperature on the $T_{g}$ and EFFV of neat HBPAEKs. When the HBPAEKs are heated below the post-condensation temperature, there is independent of the time, little or no change in the $T_{\mathrm{g}}$ and EFFV. Heating above the post-condensation temperature, however, results in an increase in $\mathrm{T}_{\mathrm{g}}$ and EFFV, of which the magnitude is dependent on the heating time.

\section{In-situ spectroscopic ellipsometry: $\mathrm{CO}_{2}$ sorption measurements}

Figure 6.17-Figure 6.21 show the $\mathrm{CO}_{2}$ sorption characteristics of the HBPAEK films except for the HBPAEK with $10 \%$ PEP that is cured at $280-350{ }^{\circ} \mathrm{C}$, that is shown in the main chapter. 
a

$30 \min$

$$
250{ }^{\circ} \mathrm{C}
$$

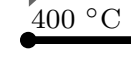

$120 \mathrm{~min}$

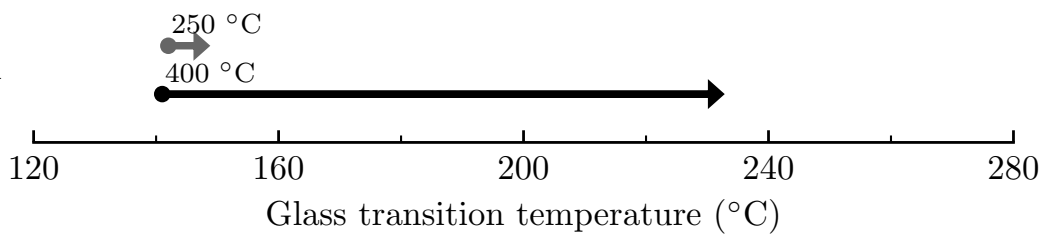

$\mathrm{b}$

$30 \min$

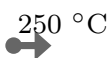

30 min

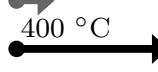

$120 \mathrm{~min}$

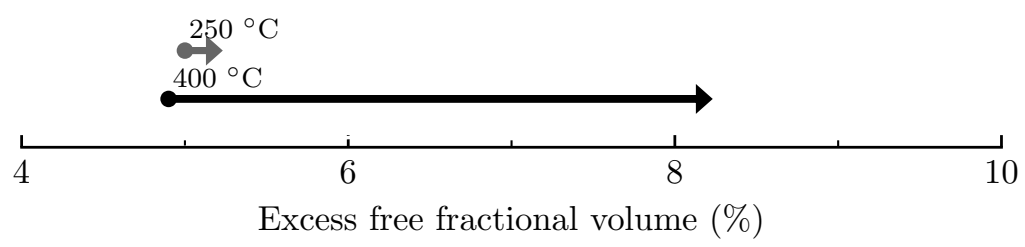

Figure 6.16: The change in $T_{g}(a)$ and EFFV (b) for the neat 33K HBPAEK as function of curing time and temperature.
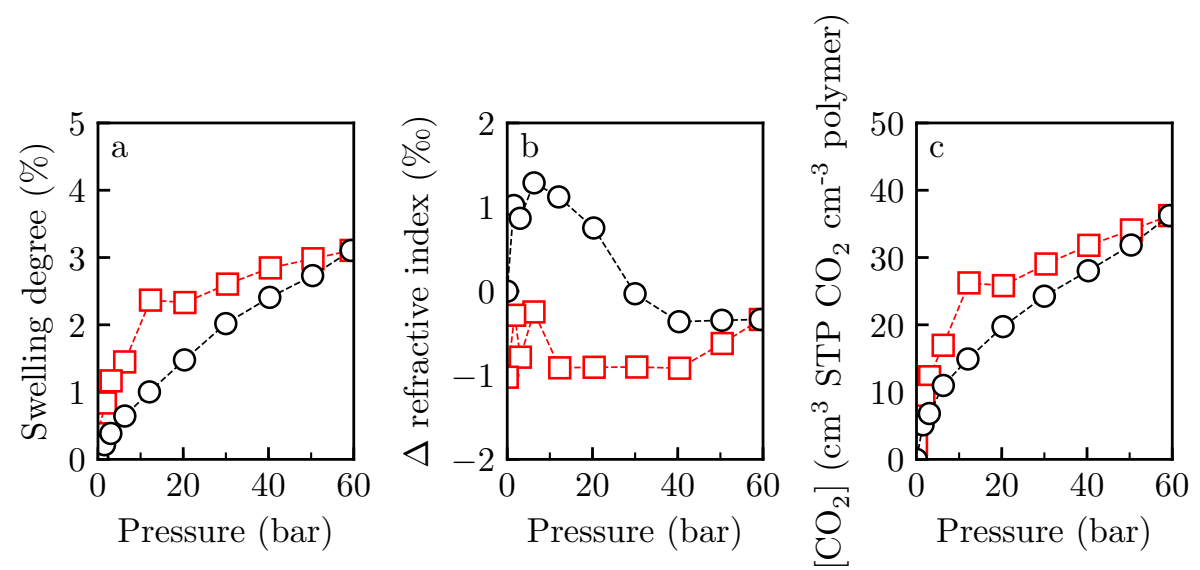

Figure 6.17: $\mathrm{CO}_{2}$ sorption (O) and desorption ( $\square$ ) for an uncured HBPAEK containing 10\% PEP. (a) The swelling degree, (b) the change in refractive index, and (c) the concentration of $\mathrm{CO}_{2}$ as function of pressure. 

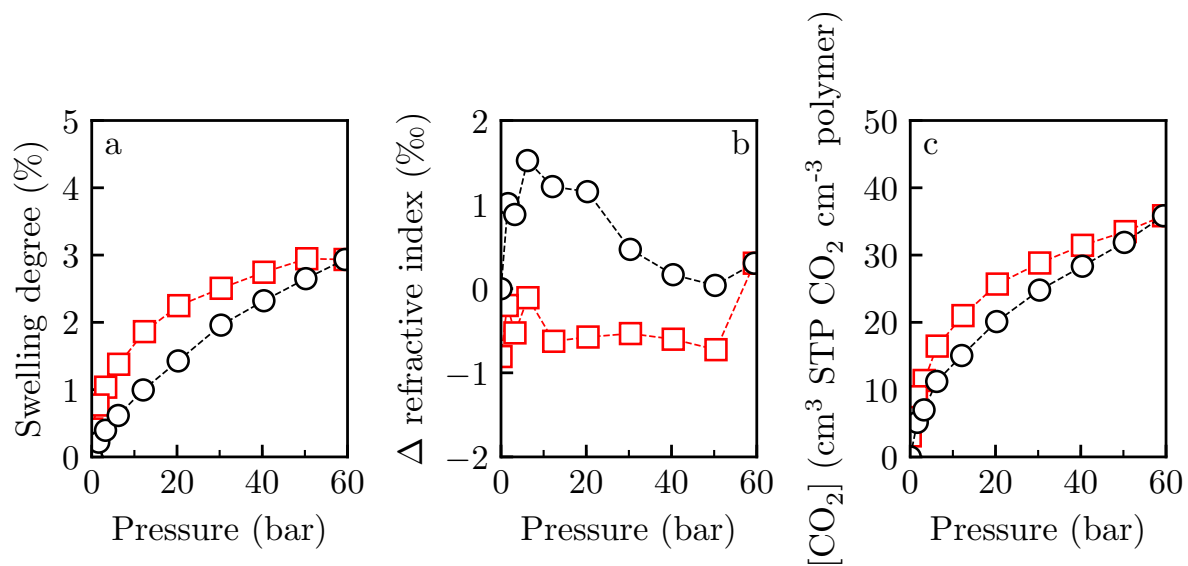

Figure 6.18: $\mathrm{CO}_{2}$ sorption (O) and desorption ( $\square$ ) for a HBPAEK containing 10\% PEP cured at $280{ }^{\circ} \mathrm{C}$. (a) The swelling degree, (b) the change in refractive index, and (c) the concentration of $\mathrm{CO}_{2}$ as function of pressure.
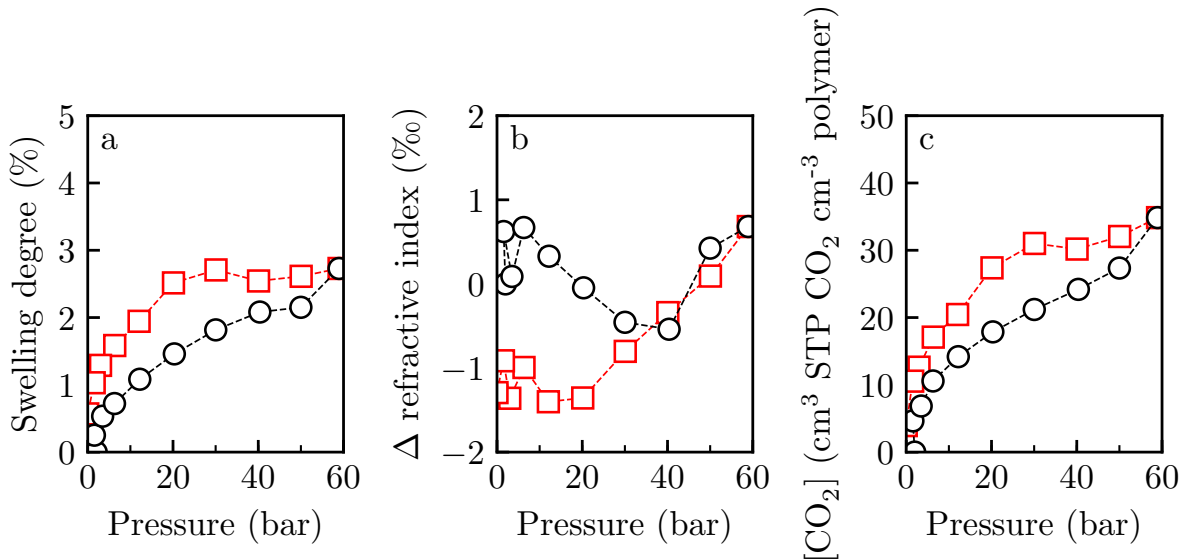

Figure 6.19: $\mathrm{CO}_{2}$ sorption (O) and desorption ( $\square$ ) for an uncured HBPAEK containing $20 \%$ PEP. (a) The swelling degree, (b) the change in refractive index, and (c) the concentration of $\mathrm{CO}_{2}$ as function of pressure. 

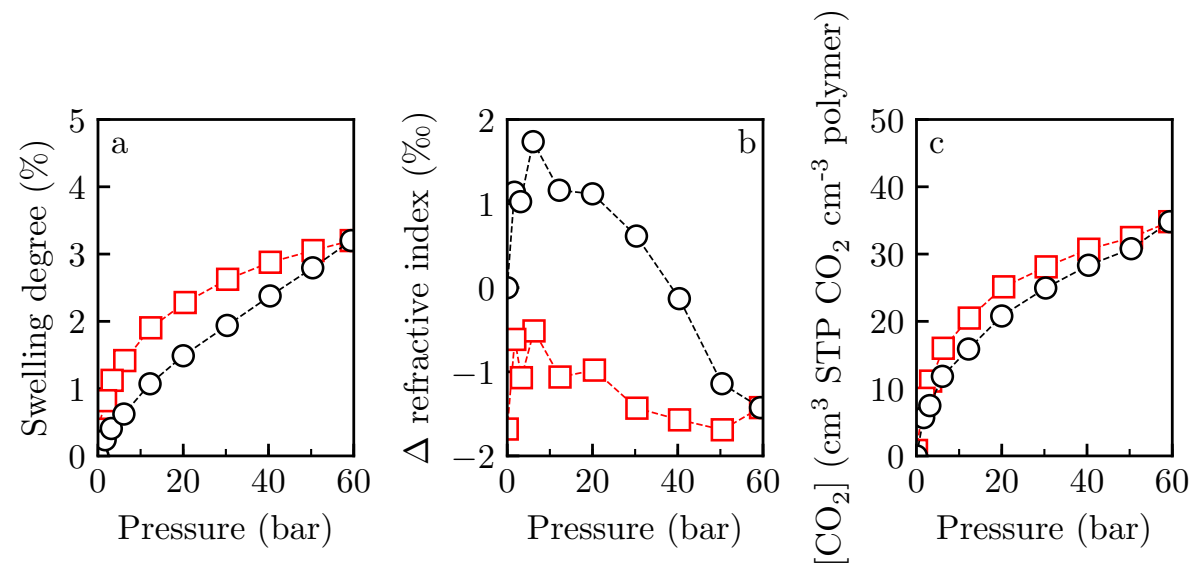

Figure 6.20: $\mathrm{CO}_{2}$ sorption (O) and desorption ( $\square$ ) for a HBPAEK containing 20\% PEP cured at $280{ }^{\circ} \mathrm{C}$. (a) The swelling degree, (b) the change in refractive index, and (c) the concentration of $\mathrm{CO}_{2}$ as function of pressure.
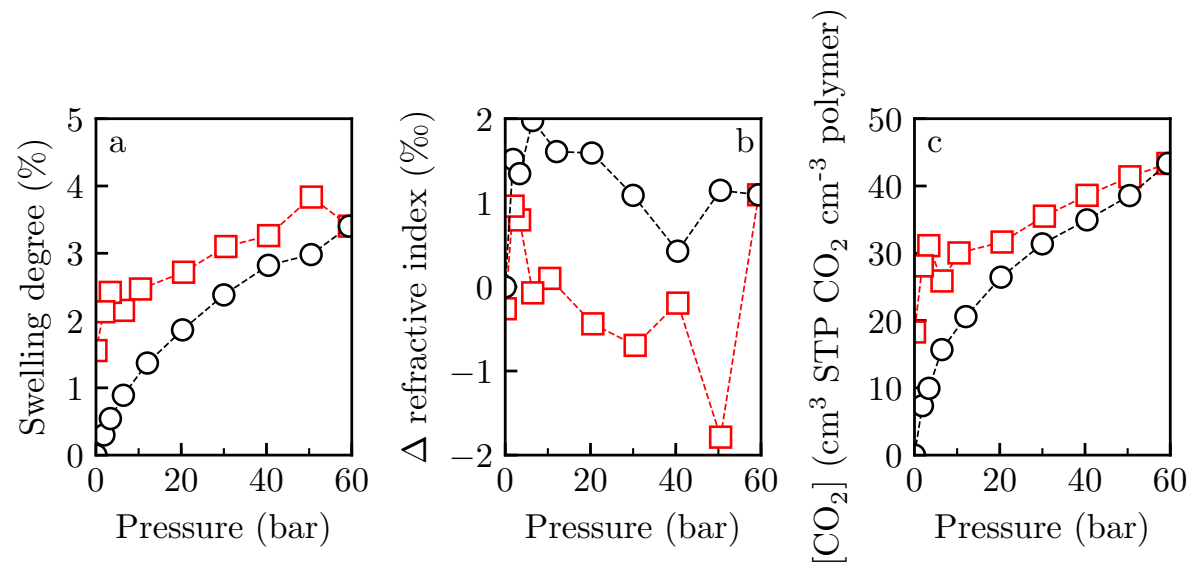

Figure 6.21: $\mathrm{CO}_{2}$ sorption (O) and desorption ( $\square$ ) for a HBPAEK containing 20\% PEP cured at $280-350{ }^{\circ} \mathrm{C}$. (a) The swelling degree, (b) the change in refractive index, and (c) the concentration of $\mathrm{CO}_{2}$ as function of pressure. 

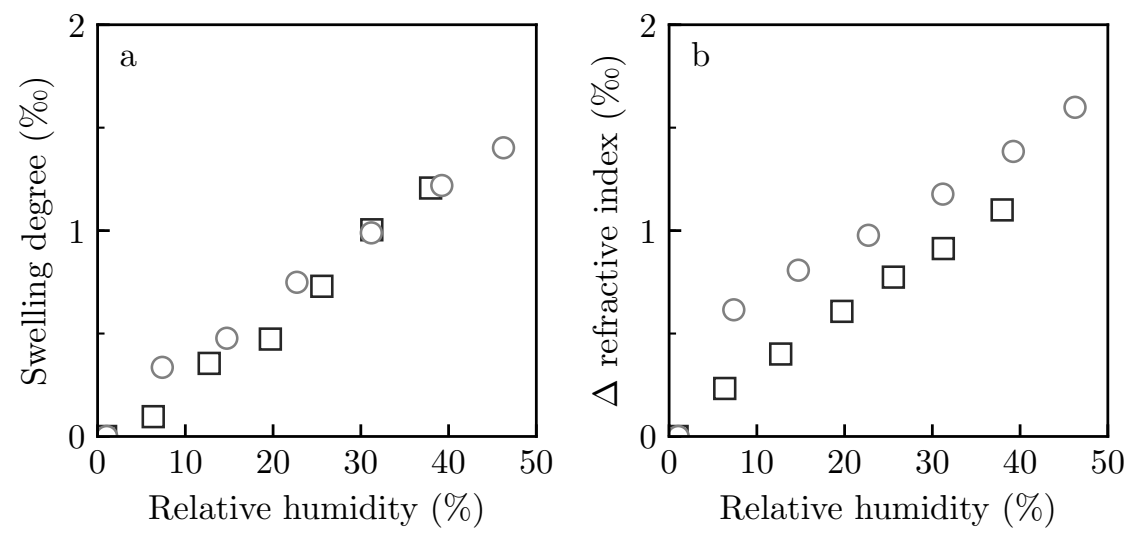

Figure 6.22: (a) The swelling degree and (b) the change in refractive index as function of relative humidity for HBPAEKs containing 10\% PEP (口) and $20 \%$ PEP (O) cured at $280-350^{\circ} \mathrm{C}$. Note that both the swelling degree and change in refractive index are expressed in promille $(\% 0)$.

\section{In-situ spectroscopic ellipsometry: $\mathrm{H}_{2} \mathrm{O}$ sorption measurements}

Figure 6.22 shows (a) the swelling degree, and (b) the change in refractive index for HBPAEKs containing $10 \% \mathrm{PEP}(\square)$ and $20 \% \mathrm{PEP}(\mathrm{O})$ cured at $280-350{ }^{\circ} \mathrm{C}$ as a function of relative humidity, measured by in-situ SE. The HBPAEKs show almost no swelling in water vapor, indicating that water is not penetrating into the polymer network. The minor swelling is accompanied with a minor increase in refractive index due to the replacement of void $(n=1.00)$ with water $(n=1.33)$. The low water sorption could indicate that these HBPAEKs are insusceptible to degradation by the presence of water vapor in the feed stream.

\section{Contact angle measurements}

Figure 6.23 shows the contact angle of HBPAEK films for uncured and cured $\left(280-350{ }^{\circ} \mathrm{C}\right)$ films. All contact angles were measured with the sessile drop method using Milli-Q water. From this data it can not be concluded whether there is a difference in contact angle between the different HBPAEKs and the uncured or cured state. The average contact angle varies between $95^{\circ}$ and $103^{\circ}$, indicating the hydrophobic character of the HBPAEKs. The values are similar to those for HBPAEK films reported in literature ${ }^{[43]}$. 


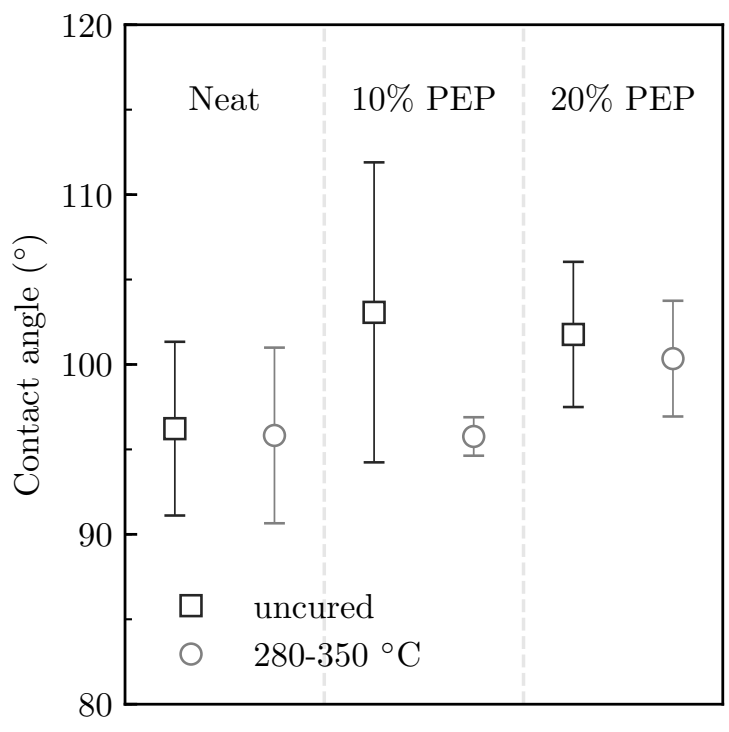

Figure 6.23: The contact angle of uncured ( $\square$ ) and cured $(\bigcirc)$ (temperature program 280-350 ${ }^{\circ} \mathrm{C}$ ) HBPAEK films on silicon wafers. The error bars represent the $95 \%$ confidence interval determined over 5 measurements

\section{Single gas permeation characteristics of an alumina support}

Figure 6.24 shows the single gas permeation characteristics of a bare alumina support. The pore size of the $\gamma$-alumina allows for separation by Knudsen diffusion ${ }^{[44]}$. The selectivity in the case of Knudsen diffusion can be calculated by:

$$
\alpha_{\mathrm{a} / \mathrm{b}}=\sqrt{\frac{M_{\mathrm{b}}}{M_{\mathrm{a}}}}
$$

where $\alpha_{\mathrm{a} / \mathrm{b}}$ is the selectivity (-) of the membrane and $M_{i}$ is the molar mass of the gas molecule $i\left(\mathrm{~g} \mathrm{~mol}^{-1}\right)$. All experimentally obtained values are in good agreement with the theoretical Knudsen selectivity (Table 6.4) except for that of $\mathrm{H}_{2} / \mathrm{CO}_{2}$. This could be caused by the condensability of $\mathrm{CO}_{2}$. The $\mathrm{CO}_{2}$ molecules adsorbed onto the pore wall can move by surface diffusion, resulting in an increased $\mathrm{CO}_{2}$ permeability and therefore reduced selectivity ${ }^{[45]}$. 

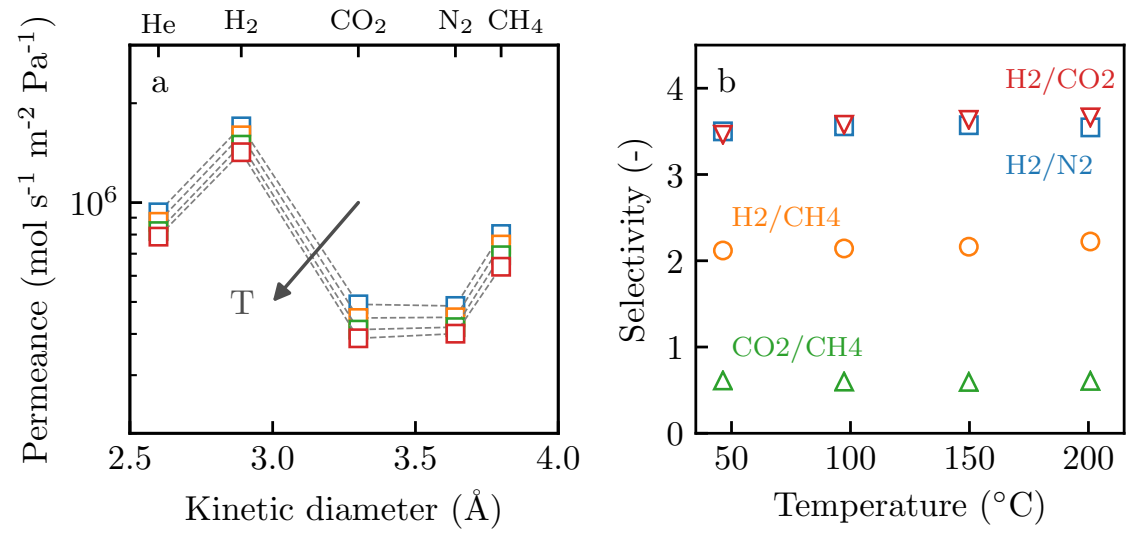

Figure 6.24: Single gas permeation characteristics for the bare alumina membrane support. (a) Permeance as function of gas kinetic diameter. (b) Ideal selectivity of $\mathrm{H}_{2} / \mathrm{CH}_{4}, \mathrm{H}_{2} / \mathrm{N}_{2}$, $\mathrm{H}_{2} / \mathrm{CO}_{2}$, and $\mathrm{CO}_{2} / \mathrm{CH}_{4}$ as function of temperature.

Table 6.4: Theoretical Knudsen selectivity and measured selectivity for various gas pairs.

\begin{tabular}{lll}
\hline Gas pair & Knudsen selectivity & Measured selectivity \\
\hline $\mathrm{H}_{2} / \mathrm{CO}_{2}$ & 4.7 & 3.6 \\
$\mathrm{H}_{2} / \mathrm{N}_{2}$ & 3.7 & 3.6 \\
$\mathrm{H}_{2} / \mathrm{CH}_{4}$ & 2.8 & 2.1 \\
$\mathrm{CO}_{2} / \mathrm{CH}_{4}$ & 0.6 & 0.6 \\
\hline
\end{tabular}

${ }^{a}$ Measured at $50{ }^{\circ} \mathrm{C}$.

\section{Robeson plots}

Figure 6.25 shows the Robeson plots for all membranes studied. The permeability was calculated from the permeance measured at $50{ }^{\circ} \mathrm{C}$ and a fixed membrane thickness of $700 \mathrm{~nm}$. Robeson found an empirical upper bound relationship between the permeability (permeability $=$ permeance $\cdot$ thickness) and selectivity of a gas $^{[46]}$. From Figure 6.25 , it can be concluded that our HBPAEKs are far off the present upper limit for $\mathrm{CO}_{2} / \mathrm{CH}_{4}, \mathrm{H}_{2} / \mathrm{N}_{2}$, and $\mathrm{H}_{2} / \mathrm{CH}_{4}$ gas pairs. However, the cured $\left(280-350{ }^{\circ} \mathrm{C}\right) \mathrm{HBPAEK}$ films containing $10 \%$ or $20 \% \mathrm{PEP}$ are found to be at the 2008 upper limit for the $\mathrm{H}_{2} / \mathrm{CO}_{2}$ gas pair. 

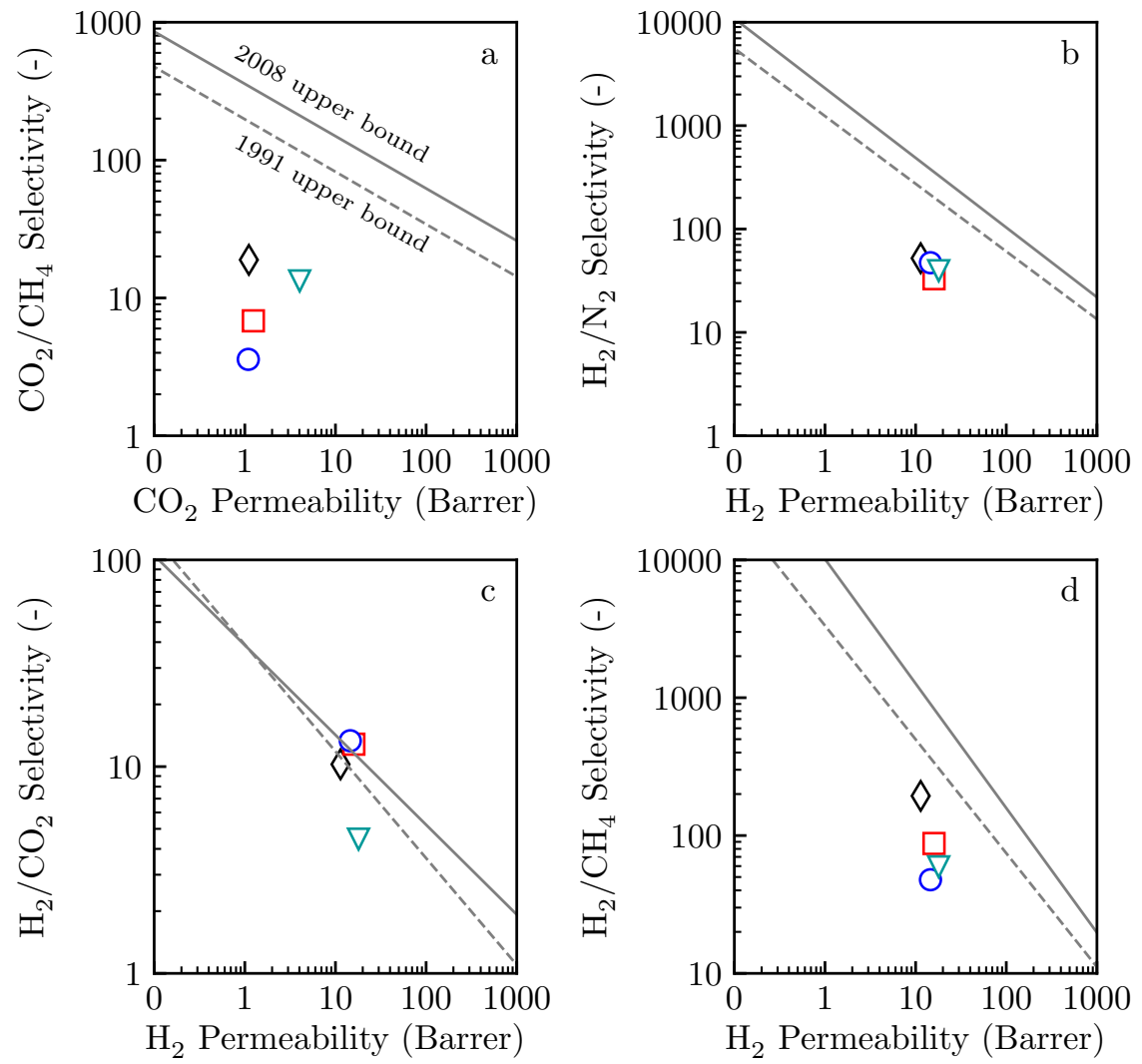

Figure 6.25: Robeson plots for (a) $\mathrm{CO}_{2} / \mathrm{CH}_{4}$, (b) $\mathrm{H}_{2} / \mathrm{N}_{2}$, (c) $\mathrm{H}_{2} / \mathrm{CO}_{2}$, and (d) $\mathrm{H}_{2} / \mathrm{CH}_{4}$ gas pairs. The permeabilities were obtained from the permeances measured at $50{ }^{\circ} \mathrm{C}$. The thickness of the separating layer was assumed to be $700 \mathrm{~nm}$ for all membranes. The theoretical upper bound as in 1991 (dashed line) and 2008 (solid line) were plotted as reference. The symbols represent: $10 \%$ PEP uncured $(\diamond), 10 \%$ PEP cured at $280-350{ }^{\circ} \mathrm{C}(\square), 20 \%$ PEP uncured $(\nabla)$, and $20 \%$ PEP cured at $280-350{ }^{\circ} \mathrm{C}(\mathrm{O})$. 



\section{Chapter 7}

\section{Direct interfacial polymerization onto thin ceramic hollow fibers}

This chapter is adapted from:

Evelien Maaskant, Patrick de Wit, Nieck E. Benes, Direct interfacial polymerization onto thin ceramic hollow fibers, Journal of Membrane Science 2018, 550, 296-301, DOI: 10.1016/j.memsci.2018.01.009 


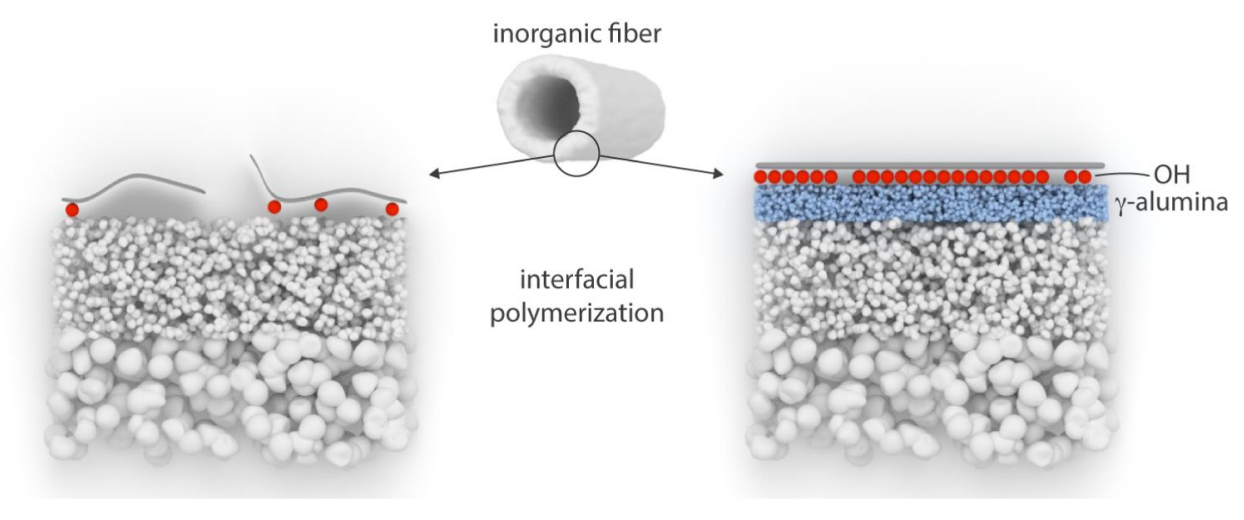

\section{Abstract}

Membrane separation under harsh conditions, such as high- $p, T$ or in the presence of aggressive chemicals, requires a robust membrane support. In academia, ceramic disks are commonly used for this purpose, but these disks posses a too low surface-area-to-volume ratio for practical applications. Ceramic hollow fibers potentially provide a much larger specific surface area, but applying a defect free thin selective layer on such structures is more intricate. Here we show the successful preparation of a thin polyamide layer onto a thin porous hollow $\alpha$-alumina fiber by interfacial polymerization of piperazine with trimesoyl chloride. Two aspects of the fabrication method are identified as particularly crucial for obtaining a high quality selective layer: i) the ceramic surface should have a sufficient amount of hydroxyl groups for covalent attachment in order to avoid delamination, and ii) controlled drying steps are necessary to avoid local surplus or lack of liquid on the outer surface of the ceramic. To increase the hydroxyl group concentration, and to ensure the presence of sufficient reactants in a large volume of small pores, the fibers have been coated with a layer of $\gamma$-alumina. Sufficiently long drying steps (20 min) have been employed to avoid uneven drying over the length of the fiber. The obtained fibers show clean water fluxes in the range of $2-5 \mathrm{~L} \mathrm{~m}^{-2} \mathrm{~h}^{-1} \mathrm{bar}^{-1}$ combined with a retention of rose bengal above $99 \%$. 


\subsection{Introduction}

Interfacial polymerization (IP) is a well-known technique to fabricate extremely thin separation layers on porous supporting structures and has been studied extensively over the past decades ${ }^{[1,2]}$. Research has been done on preparing thin selective films on porous polymeric supports, such as polyethersulfone or polyetherimide $^{[3-7]}$. The use of such membranes in harsh conditions can be limited by the stability of the thin selective layer as well as by the stability of the porous support. In applications involving high- $p, T$, or in the presence of aggressive chemicals, polymer supports can suffer from plasticization, swelling, or thermal degradation. The thermo-mechanical-chemical stability of an inorganic porous support avoids such problems. Ceramics have been successfully used as support for thin IP films for applications where the mechanical and thermal stability of the ceramic is required, in for example pervaporation ${ }^{[8]}$ or sieving of hot gases by hybrid inorganic-imide polymer networks ${ }^{[9]}$. In addition, the superior thermal stability of a ceramic support allows for the fabrication of thin IP films that require a thermal treatment, such as the imidization step in the fabrication of the hybrid poly(imide) networks ${ }^{[10]}$. This opens up new possibilities for IP chemistries for membranes.

Commonly, in academia inorganic supports have the geometry of a flat disk, with a far too low surface-area-to-volume ratio to be viable for industrial application. Hollow fibers provide a much larger surface-area-to-volume ratio ${ }^{[7,11,12]}$ allowing for industrial application ${ }^{[13]}$. Inorganic porous hollow fibers can be prepared from various materials, for example alumina $\left(\mathrm{Al}_{2} \mathrm{O}_{3}\right)^{[14]}$, titanium dioxide $\left(\mathrm{TiO}_{2}\right)^{[15]}$, or silicon carbide $(\mathrm{SiC})^{[16]}$. The diameters of such fibers can be as small as $\sim 200 \mu \mathrm{m}^{[17]}$. Limited research is reported on thin film composite (TFC) membranes, made of interfacial polymerized layers prepared directly atop of porous inorganic hollow fibers. Nearly all IP films on inorganic porous hollow fibers involve the use of a polymeric intermediate layer. For example, a polyethersulfone (PES) repair layer was coated onto a commercially available ceramic tube prior to the IP fabrication of a poly(vinyl alcohol)-piperazine-trimesoyl chloride (PVA-Pip-TMC) layer ${ }^{[18]}$. A polymeric coating of polydopamine (PDA) or polyethyleneimine (PEI) was applied onto an alumina fiber with a relatively large outer diameter of $3.7 \mathrm{~mm}$, in order to facilitate the IP fabrication of an $m$-phenylenediamine-trimesoyl chloride (MPD-TMC) layer ${ }^{[8]}$. The use of a polymeric repair layer inherently reduces the overall thermo-chemical stability of the final membrane. Peters et al. ${ }^{[19]}$ coated ceramic fibers with an inorganic ( $\gamma$-alumina) intermediate layer, prior to applying a microporous silica layer ${ }^{[19]}$ or a poly(vinyl alcohol) layer ${ }^{[20]}$ via dip-coating. Cao et al. ${ }^{[21]}$ introduced a process based on IP assisted dip-coating of nanocrystals on alumina hollow fibers without an intermediate layer. In this elegant concept the polymer produced by IP serves to arrest seed crystals on the support surface in the form of a thin dense layer. This layer does not function as selective membrane but supplies abundant nucleation sites for the secondary growth of a zeolite. ${ }^{21]}$

To our knowledge, fabrication of a thin defect-free selective film by IP on an entirely inorganic thin porous hollow fiber support has never been reported. We show 
that it is possible to fabricate a defect-free IP polyamide layer onto an alumina hollow fiber with an outer diameter of $1.5 \mathrm{~mm}$ that is coated with meso-porous inorganic intermediate layers. We have chosen to use a well-known model system for interfacial polymerization, piperazine and trimesoyl chloride, to eliminate the influence of any unknown chemistry. Without optimizing the performance of these fibers, the measured permeances are similar to those of some commercial nanofiltration membranes and IP membranes on polymer hollow fibers supports reported in literature. This demonstrates that an extremely stable fully inorganic porous hollow fiber can be used as a support for a high quality thin film composite membrane. This extends the application range of interfacial polymerized membranes in harsh conditions, and allows to further develop high performance membranes based on novel advanced chemistries. These advanced IP chemistries are presently sporadically investigated due to the limited thermo-chemical stability of porous polymer supports.

\section{$7.2 \quad$ Experimental}

\subsubsection{Chemicals}

AKP-30 $\alpha$-alumina powder $\left(99.9 \% \mathrm{Al}_{2} \mathrm{O}_{3}\right.$, particle size of $0.3 \mu \mathrm{m}$, Sumitomo Chemicals Co. LTD. Japan), polyethersulfone (PES, Ultrason ${ }^{\circledR}$ E6020 P, BASF), and de-ionized water ( $>18.2 \mathrm{M} \Omega \mathrm{cm})$, Milli-Q Advantage A10, Millipore) were used for fiber preparation. Prior to use, PES was dried overnight at $80{ }^{\circ} \mathrm{C}$. Piperazine (Pip, 99\%), $n$-hexane (anhydrous, 95\%), trimesoyl chloride (TMC, 98\%), rose bengal (95\%), poly(vinyl alcohol) (PVA, Mowiol 8-88, $\mathrm{M}_{\mathrm{w}} 67,000 \mathrm{~g} \mathrm{~mol}^{-1}$ ), poly(vinyl pyrrolidone) (PVP, $\mathrm{M}_{\mathrm{w}} \sim 1,300,000 \mathrm{~g} \mathrm{~mol}^{-1}$ ), and $N$-methyl-2-pyrrolidone (NMP, $<99.5 \%$ ) were obtained from Sigma-Aldrich (the Netherlands) and used as received. Nitric acid (1 M) was obtained from Merck and diluted to $0.05 \mathrm{M}$ or $0.02 \mathrm{M}$ for further use.

\subsubsection{Fiber fabrication}

Alumina hollow fiber membranes were prepared by dry-wet spinning based on non-solvent induced phase separation (NIPS) using a well-established method ${ }^{[17]}$. Briefly, a mixture of AKP-30 $\alpha$-alumina powder, PES, NMP and PVP was spun into a coagulation bath with de-ionized water functioning as non-solvent. The mixture composition and spinning parameters are listed in Table 7.1. After thermal treatment $\left(300{ }^{\circ} \mathrm{C}\right.$ for $1 \mathrm{~h}, 1400{ }^{\circ} \mathrm{C}$ for $2 \mathrm{~h}$, heating rate of $\left.5{ }^{\circ} \mathrm{C} \mathrm{min}{ }^{-1}\right)$ the fibers were coated with an AKP-30 alumina layer in order to lower the surface roughness. A $50 \mathrm{wt} \%$ suspension of AKP-30 in $0.05 \mathrm{wt} \% \mathrm{PVA}$ in $0.02 \mathrm{M} \mathrm{HNO}_{3}$ solution is treated ultra-sonically to disperse the AKP-30 particles. Prior to coating, one end of the fiber was sealed with hot melt adhesive (Dremel) and the fibers 
Table 7.1: Spinning conditions

\begin{tabular}{ll}
\hline Condition & Value \\
\hline PES & $9.40 \mathrm{wt} \%$ \\
NMP & $40.0 \mathrm{wt} \%$ \\
AKP-30 & $48.9 \mathrm{wt} \%$ \\
PVP K95 & $0.70 \mathrm{wt} \%$ \\
Water & $1.00 \mathrm{wt} \%$ \\
Bore Liquid & $\mathrm{H}_{2} \mathrm{O}$ \\
Coagulation bath & $\mathrm{H}_{2} \mathrm{O}$ \\
Extrusion pressure & $2 \mathrm{bar}$ \\
Air gap & $3 \mathrm{~cm}$ \\
Bore liquid flow rate & $7 \mathrm{~mL} \mathrm{~min}-1$ \\
Outer diameter spinneret & $2.0 \mathrm{~mm}$ \\
Inner diameter spinneret & $0.8 \mathrm{~mm}$ \\
Drying after spinning & $>24 \mathrm{~h}$ \\
\hline
\end{tabular}

were dip coated vertically with a rate of $0.6 \mathrm{~m} \mathrm{~min}^{-1}$ and a holding time of $30 \mathrm{~s}$. After drying $\left(1 \mathrm{~h}, 25^{\circ} \mathrm{C}\right.$, relative humidity $\left.50-80 \%\right)$ the fibers are sintered for $1 \mathrm{~h}$ at $1000{ }^{\circ} \mathrm{C}$ with a heating rate of $5{ }^{\circ} \mathrm{C} \mathrm{min}^{-1}$.

Two layers of $\gamma$-alumina were applied on top of the $\alpha$-alumina fiber to provide enough hydroxyl-groups for covalent attachment of the polyamide layer to the support, and to provide a large volume of small pores for the aqueous phase in the IP process. For each layer of $\gamma$-alumina, $20 \mathrm{~mL}$ of PVA solution $(2.25 \mathrm{~g}$ PVA in $75 \mathrm{~mL} 0.05 \mathrm{M} \mathrm{HNO}_{3}$ ) and $30 \mathrm{~mL}$ of boehmite sol were mixed. The details of the boehmite synthesis and coating procedure are described elsewhere ${ }^{[22]}$. The lower end of the fiber was sealed with hot melt adhesive and the fibers were vertically dip coated with a rate of $2.4 \mathrm{~m} \mathrm{~min}^{-1}$, and a holding time of $1 \mathrm{~s}$. After drying $\left(2 \mathrm{~h}, 25{ }^{\circ} \mathrm{C}\right.$, relative humidity $\left.50-80 \%\right)$ and removal of the hot melt adhesive, the $\gamma$-alumina layer is sintered for $1 \mathrm{~h}$ at $600{ }^{\circ} \mathrm{C}$ with a heating rate of $5{ }^{\circ} \mathrm{C} \mathrm{min}-1$.

\subsubsection{Interfacial polymerization}

Prior to dip-coating, the fibers were sealed at the lower end with a $1.5 \mathrm{~cm}$ long glass tube filled with Araldite 2014-1 (Huntsman) and cured for $24 \mathrm{~h}$ at ambient conditions. There was no further pretreatment applied to the fibers. The fibers were inserted in the aqueous phase containing $2 \mathrm{wt} \%$ piperazine for 1 minute, and withdrawn with a vertical dipcoater $\left(9 \mathrm{~m} \mathrm{~min}^{-1}\right)$. The fibers were dried at ambient conditions for 20 minutes, and inserted for 10 seconds in the organic phase (0.15 wt\% TMC in $n$-hexane). The fibers were then withdrawn with a speed of $9 \mathrm{~m} \mathrm{~min}^{-1}$, rinsed with acetone to remove any unreacted monomers, and stored under ambient conditions until further use. 


\subsubsection{Module fabrication}

The final fiber was glued (Araldite 2014, Huntsman) in a 1/4" piece of metal tubing that acts as the membrane outlet, whereas the other side of the fiber was already glued using an Araldite filled glass cap. The fiber is enclosed with a metal tube and connected to a T-piece for permeate/retentate streams. Figure 7.1 shows a schematic overview of the potted fiber and how the module assembly is connected to the setup for permeation experiments.

\subsubsection{Characterization methods}

Scanning electron micrographs of the cross-section and top view morphology of green, sintered, and TFC fibers were obtained with a Zeiss Merlin FE-SEM or JEOL-JSM6010 scanning electron microscope. Samples were coated with a $10 \mathrm{~nm}$ chromium layer (Quorum Q150T ES) prior to imaging.

The outer diameter of the fibers was measured using a Nikon V-12 profile projector with a 50x objective lens (Nippon Kogaku, Japan). 18 samples originating from 3 different fibers were analyzed and the average diameter was taken for flux calculations.

Clean water fluxes were measured in a custom-built setup (Convergence, the Netherlands) in dead-end operation with pressures ranging from 8 to 18 bar applied to an outside-in-geometry. The permeate volume was measured over time volumetrically. Rose bengal retention (35 $\mu \mathrm{M}$ in water) was measured at a custombuilt dead-end filtration setup. The feed was pressurized with nitrogen to 18 bar applied to an outside-in geometry. Solute concentrations of the feed and permeate streams were measured with an UV-VIS spectrophotometer at $549 \mathrm{~nm}$ (Varian Cary 300 scan).
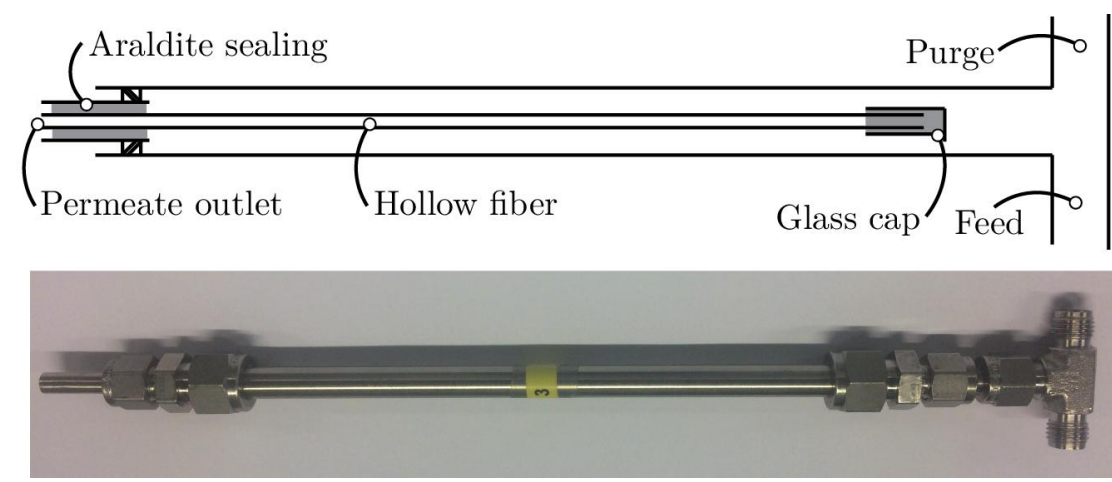

Figure 7.1: Schematic overview of membrane potting and assembly of the module. 
The retention $(R)$ is defined as:

$$
R=\frac{c_{f}-c_{p}}{c_{f}} \cdot 100 \%
$$

where $c_{f}$ is the concentration of the solute in the feed stream, and $c_{p}$ the concentrate in the permeate stream.

\subsection{Results and discussion}

\subsubsection{Fiber fabrication and coating}

The $\alpha$-alumina fibers prepared by dry-wet spinning based on NIPS have pores in the range of $350 \mathrm{~nm}$ (not shown here, see ${ }^{[23]}$ ). The fibers were coated with an AKP-30 smoothing layer by vertical dip-coating to reduce the pore size to approximately $100 \mathrm{~nm}$, and to eliminate the presence of macrovoids close to or reaching the surface. Zhang et al. ${ }^{[24]}$ showed the possibility of film formation beyond the length scale of the AKP-30 pores, when the liquid-liquid interface is well defined.

Figure 7.2a and b show top-view scanning electron micrographs of a layer prepared directly on the AKP-30 smoothing layer. A polyamide film is present covering most parts of the surface, while clear patches of the ceramic support are still visible. It is hypothesized that this delamination is for a large part due the insufficient drying of the fiber after being in contact with the aqueous phase. An excess of aqueous solution may shield of the fiber surface from the reactant in the organic phase, causing film formation to occur at a slight distance from the fiber surface and prohibiting the surface hydroxyl groups to partake in the polymerization reaction. A sufficiently long drying time is required to avoid that excess aqueous solution
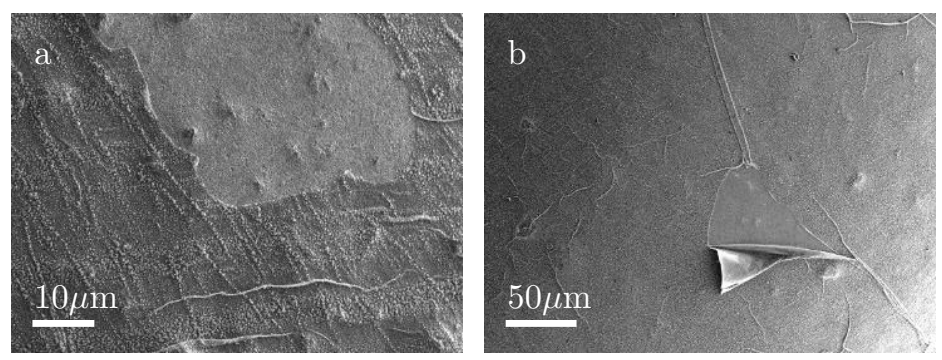

Figure 7.2: (a) and (b) Scanning electron micrographs (top view) of a TMC-Pip film on an AKP-30 smoothed fiber. A polyamide film is present covering parts of the surface, but also clear patches of the ceramic support are visible. 
is present on the outer surface of the fiber, but the drying is complicated by the relative large pores $(100 \mathrm{~nm})$ and low porosity (30\%) of the AKP-30 intermediate layer. The capillary forces inside the large pores can be too small to counter the gravitational force, hence it affects the ability to contain the aqueous phase inside the porous structure. In addition, the surface roughness of the fiber could play a role. Ogieglo et al. ${ }^{[25]}$ showed that the surface roughness of a flat polished AKP-30 surface is already of the order of a standard polyamide film thickness. This surface roughness could prevent the formation of a stable well-defined interface. Finally, even if a well defined film could be formed, sufficient hydroxyl groups are required to prevent delamination.

To increase the amount of hydroxyl groups ${ }^{[26]}$, and to allow for a larger reactant reservoir in $\sim 5 \mathrm{~nm}$ small pores, the fibers were coated with $\gamma$-alumina atop of the AKP-30 smoothing layer. The use of $\gamma$-alumina intermediate layers has been studied elaborately for, for instance, the fabrication of high performance inorganic gas separation membranes ${ }^{[27]}$. Initial tests have been done in this study to find the appropriate dip-coating velocity and hold-down time, and the minimum required number of $\gamma$-alumina layers. After applying the initial $\gamma$-alumina layer there are still some uncovered AKP-30 spots present on the surface (data not shown) that prevent a proper layer attachment due to their relatively large size. Applying a second $\gamma$-alumina layer results in a coating that completely covers of the $\alpha$-alumina layer. The remaining small sized minor defects do not prevent the formation of an attached polyamide film.

Figure 7.3a-d show the successful coating of an $\gamma$-alumina coated NIPS hollow fiber. Figure 7.3a shows the outside of the NIPS fiber wall on which the AKP-30 smoothing layer is coated. Since the AKP-30 layer is not coated by a NIPS process, there are no macrovoids present, resulting in a smooth fiber wall. Figure 7.3b shows a detail image of two $\gamma$-alumina layers on the AKP-30 smoothing layer. It can be seen that the thickness of the two $\gamma$-alumina layers is in the order of a few hundred nanometer. Figure $7.3 \mathrm{c}$ and $\mathrm{d}$ show a high resolution image of the $\gamma$-alumina layer, without (Figure 7.3c) and with (Figure 7.3d) the TMC-Pip layer present. The TMC-Pip membrane is a relatively thin film $(\sim 100 \mathrm{~nm})$, as is expected for these polyamide films. 

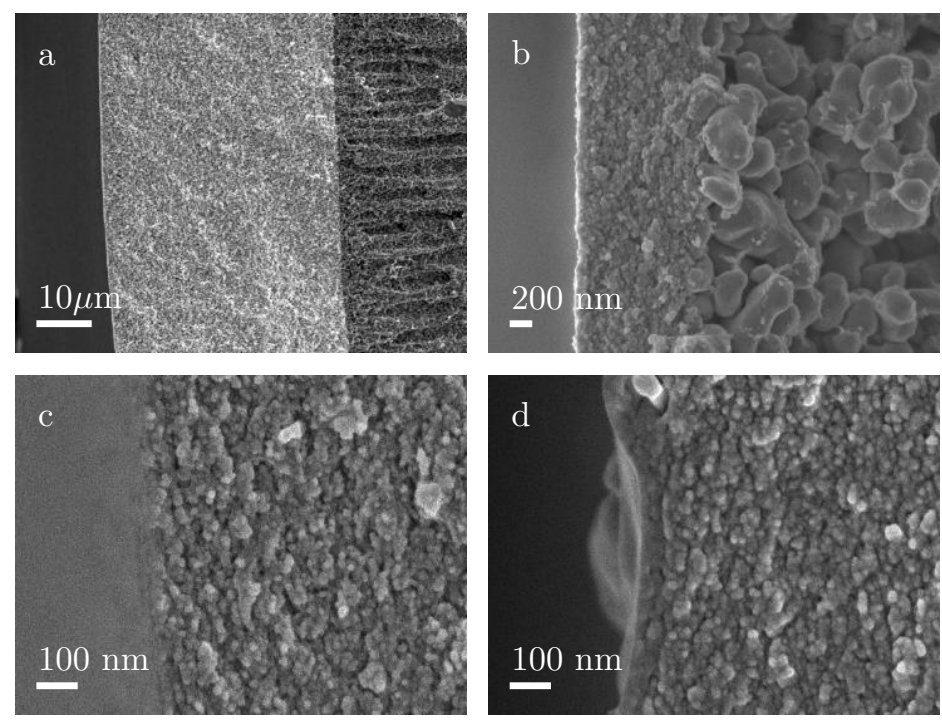

Figure 7.3: Cross-section scanning electron micrographs of the wall of an $\alpha$-alumina fiber. (a) The AKP-30 smoothing layer atop of a NIPS alumina fiber. (b) The $\gamma$-alumina layer atop of the AKP-30 smoothing layer. The thickness of the two $\gamma$-alumina layers is in the order of a few hundred nanometer. (c,d) High resolution images of the $\gamma$-alumina layers (c) without and (d) with the TMC-Pip film. The TMC-Pip film has a thickness of around $100 \mathrm{~nm}$. 
The $\gamma$-alumina coated fibers were submerged in the aqueous phase to fill the porous structure with piperazine monomer. The drying procedure after this step appears to be an important factor for successful preparation of well attached polyamide films. Figure 7.4 shows the influence of the drying time at ambient conditions on the adhesion of the TMC-Pip layer to the gamma-coated alumina support. Top view scanning electron micrographs were taken at the top and the bottom of the fiber after 10 and 20 minutes drying. Since the fibers were dried vertically, the amount of residual water is expected to be higher at the bottom of the fiber. There is a significant difference in film morphology at the top and bottom of the fiber after 10 minutes of drying (Figure $7.4 \mathrm{a}$ and c). The polyamide film at the bottom of the fiber showed to be a freestanding film with huge defects due to the presence of a film of excess water on the outer surface of the fiber. The top of the fiber does not show the ceramic structure, although there is no smooth continuous film visible. However, 20 minutes of drying does result in a well-attached continuous film on both the top and bottom side of the fiber. There are still some minor differences in film morphology at the top and bottom of the fiber, probably due to small differences in local reaction conditions, but these are not expected to excessively affect the membrane performance.
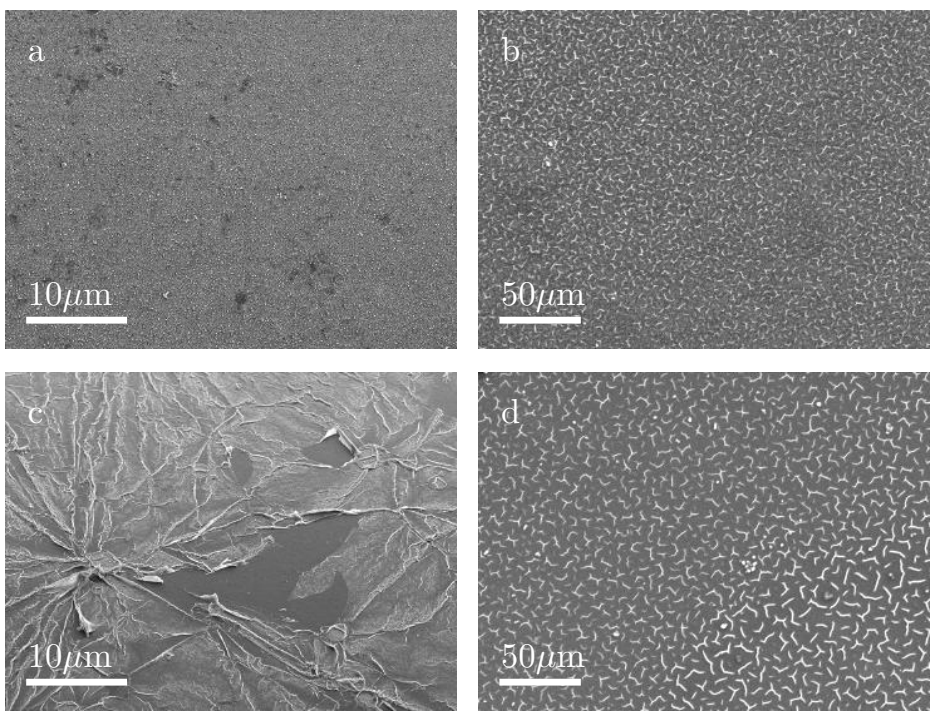

Figure 7.4: Top-view scanning electron micrographs of the TMC-Pip polyamide films. Micrographs were taken on $(a, b)$ the top and $(c, d)$ the bottom of the hollow fiber. The fiber shown in (a) and (c) was dried for 10 minutes, the fiber shown in (b) and (d) dried for 20 minutes. An unattached, freestanding film has formed at the bottom of the fiber after 10 minutes of drying, while after 20 minutes of drying the film is well-attached to the fiber surface. 


\subsubsection{Permeation and retention}

In total 13 fibers with a length over $12 \mathrm{~cm}$ have been fabricated and used for performance testing. Table 7.2 shows the results of these measurements. One of the 13 fibers broke during potting. The remaining 12 fibers have been tested for their clean water permeance and rose bengal retention. Three fibers showed a poor retention and high permeance and have been omitted from further analysis. This indicates that even due to careful surface pre-treatment, still minor defects can be present. These defects might not necessarily be in the TMC-Pip layer itself, but can also arise from fiber handling during the coating steps, or from handling during potting of the fiber. The remaining nine fibers show acceptable permeances and good rose bengal retention. The clean water permeance is in the order of $2-5 \mathrm{~L} \mathrm{~m}^{-2} \mathrm{~h}^{-1}$ bar $^{-1}$ with an average $3.8 \mathrm{~L} \mathrm{~m}^{-2} \mathrm{~h}^{-1} \mathrm{bar}^{-1}$. The clean water permeances are slightly lower as values reported in literature for TMC-Pip membranes on polymeric supports (Table 7.3). This can be explained by the small rigid pores present in the $\gamma$-alumina layer. The nanoconfinement of a polyamide network in these small rigid pores could lead to lower chain dynamics ${ }^{[28]}$, and hence lower water fluxes.

The prepared fibers showed excellent retention (>99\%) for rose bengal in water, as compared to a retention of $61.6 \%$ for a fiber with only two $\gamma$-alumina layers. Even without optimizing the IP process with respect to performance, the permeance of the fibers approaches that of some commercial membranes and of some polymer supported IP membranes presented in literature. The significant increment of rose bengal retention demonstrates the feasibility of fabricating defect free ceramic supported thin film composite membranes, which opens many possibilities for developing IP membranes for harsh conditions or IP membranes based on new chemistries involving thermal or otherwise demanding steps. 
Table 7.2: The performance of 13 TMC-Pip fibers prepared using 20 minutes drying time at ambient conditions, on hollow fiber supports coated with two $\gamma$-layers. The clean water permeance (CWP) was measured for six pressures varying from 8 to 18 bar. The CWP given is based on a linear fit of the permeance versus pressure. For comparison also the results of an $\gamma$-alumina fiber (indicated with $\#=\gamma$ ) are shown.

\begin{tabular}{llll}
\hline $\begin{array}{l}\text { Fiber } \\
\#\end{array}$ & $\begin{array}{l}\text { Length } \\
(\mathrm{cm})\end{array}$ & $\begin{array}{l}\text { Retention } \\
(\%)\end{array}$ & $\begin{array}{l}\mathrm{CWP}^{\mathrm{b}} \\
\left(\mathrm{L} \mathrm{m}^{-2} \mathrm{~h}^{-1} \mathrm{bar}^{-1}\right)\end{array}$ \\
\hline$\gamma$ & 10.2 & $61.6 \pm 1$ & $17.4 \pm 0.8$ \\
1 & 14.1 & $\mathrm{n} / \mathrm{m}^{\mathrm{c}}$ & $\mathrm{n} / \mathrm{m}^{\mathrm{c}}$ \\
2 & 13.7 & $99.8 \pm 1$ & $3.9 \pm 0.1$ \\
3 & 13.6 & $97.9 \pm 1$ & $3.8 \pm 0.3$ \\
4 & 13.9 & $\mathrm{n} / \mathrm{m}^{\mathrm{c}}$ & $\mathrm{n} / \mathrm{m}^{\mathrm{c}}$ \\
5 & broken $^{\mathrm{d}}$ & & \\
6 & 13.7 & $99.8 \pm 1$ & $3.2 \pm 0.3$ \\
7 & 13.1 & $99.7 \pm 1$ & $2.3 \pm 0.2$ \\
8 & 13.2 & $99.9 \pm 1$ & $5.0 \pm 0.3$ \\
9 & 14.7 & $99.8 \pm 1$ & $4.1 \pm 0.5$ \\
10 & 13.0 & $\mathrm{n} / \mathrm{m}^{c}$ & $\mathrm{n} / \mathrm{m}^{c}$ \\
11 & 12.8 & $99.9 \pm 1$ & $3.3 \pm 0.3$ \\
12 & 14.7 & $100.0 \pm 1$ & $4.7 \pm 0.7$ \\
13 & 12.9 & $99.6 \pm 1$ & $4.0 \pm 0.2$ \\
\hline
\end{tabular}

a The given uncertainty is an estimate of the measurement error.

b Clean water permeance with the $95 \%$ confidence interval, based on linear regression of the measured permeance and pressure.

c The flux was in the order of an unmodified fiber, and is therefore omitted from further analysis.

$\mathrm{d}$ This fiber broke during potting. 


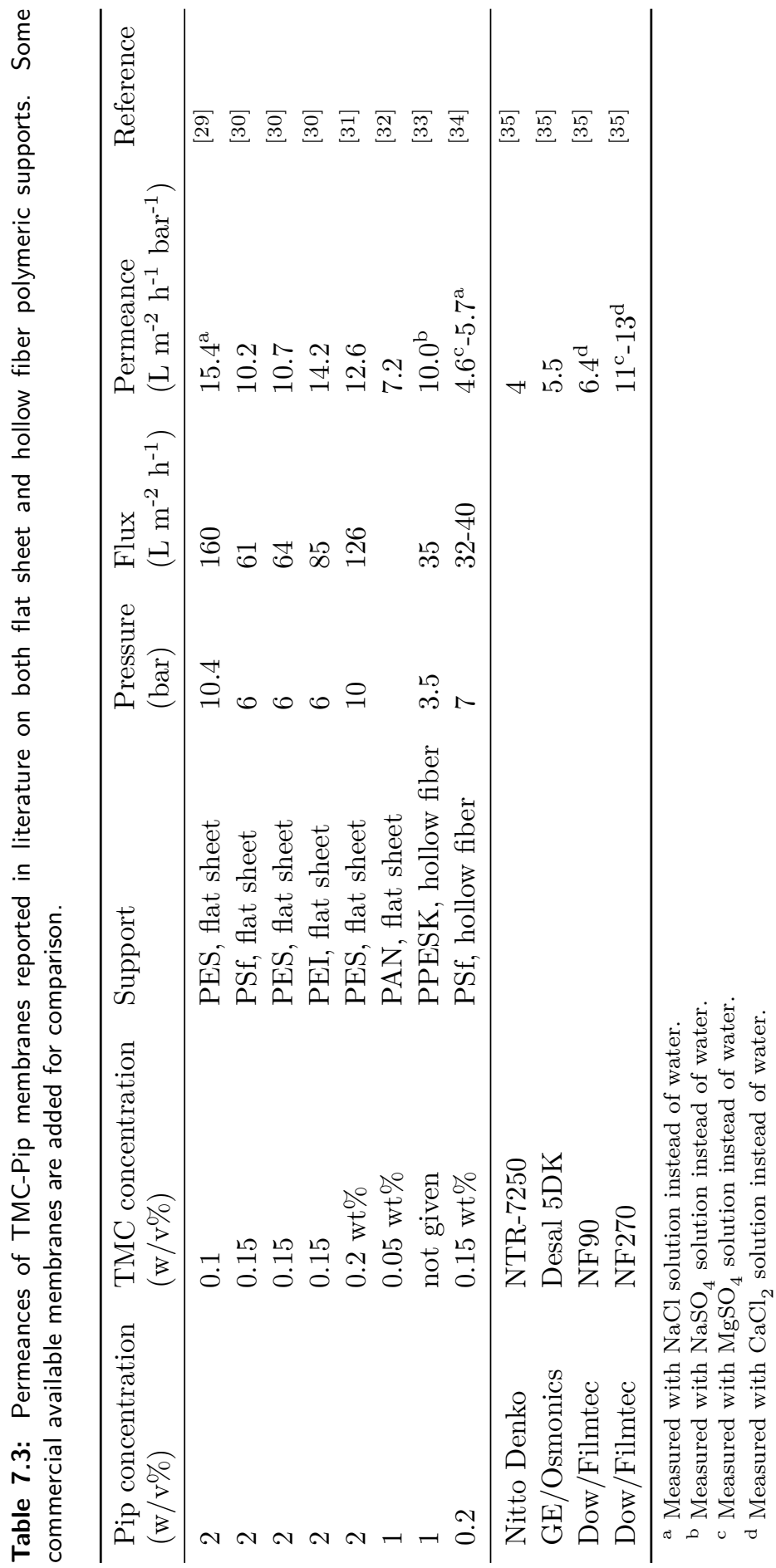




\subsection{Conclusion}

In this chapter we demonstrated a method to make a TFC membrane on a completely inorganic hollow fiber support. By modification of an alumina fiber, prepared by dry-wet spinning, with an AKP-30 smoothing layer using dip coating, a sufficiently smooth surface is obtained to allow the formation of TMC-pip thin films. In order to improve the chemical bonding to the support, sufficient hydroxylgroups are required, which can be obtained by coating two layers of $\gamma$-alumina onto the fiber. This, combined with appropriate drying of the fiber after it has been soaked with the aqueous phase, allows for defect free thin films to be obtained. The TFC fibers show promising water permeance values (average $3.8 \mathrm{~L} \mathrm{~m}^{-2} \mathrm{~h}^{-1} \mathrm{bar}^{-1}$ ) with good retention of rose bengal $\left(1017 \mathrm{~g} \mathrm{~mol}^{-1}\right)$.

Out of 12 tested fibers, with a length over $12 \mathrm{~cm}$, nine fibers are completely defect free. The other three fibers showed a lower retention or high flux. Despite careful surface pre-treatment, minor defects can still be present. These defects may not necessarily be located in the TMC-Pip layer itself, but can also arise from fiber handling or fiber potting and sealing. To conclude, this study shows that thin inorganic porous hollow fibers can indeed be a suitable support for layers prepared by interfacial polymerization and that the pre-treatment of the fiber is of key importance in order to allow proper adhesion of the layer. The results obtained in this study can aid fabrication of thin films on inorganic porous hollow fibers with more advanced chemistry, which can promote industrial application of these layers on an industrial scale under harsh conditions.

\subsection{Acknowledgements}

This research is supported by the Dutch Technology Foundation STW (Project no 12543), which is part of the Netherlands Organization for Scientific Research (NWO), and which is partly funded by the Ministry of Economic Affairs. Parts of this work have been carried out within the framework of the Institute for Sustainable Process Technology (ISPT, project BL-20-02) 


\subsection{References}

[1] Raaijmakers, M. J. T.; Benes, N. E. Current trends in interfacial polymerization chemistry. Prog. Polym. Sci. 2015, 63, 86-142.

[2] Lau, W.; Ismail, A.; Misdan, N.; Kassim, M. A recent progress in thin film composite membrane: A review. Desalination 2012, 287, 190 - 199.

[3] Fang, W.; Shi, L.; Wang, R. Mixed polyamide-based composite nanofiltration hollow fiber membranes with improved low-pressure water softening capability. Journal of Membrane Science 2014, 468, 52-61.

[4] Zhang, R.-X.; Liu, T.; Braeken, L.; Liu, Z.; Wang, X.-L.; Van der Bruggen, B. A design of composite hollow fiber membranes with tunable performance and reinforced mechanical strength. Journal of Applied Polymer Science 2015, 132, n/a-n/a.

[5] Wei, X.; Wang, S.; Shi, Y.; Xiang, H.; Chen, J.; Zhu, B. Characterization of a positively charged composite nanofiltration hollow fiber membrane prepared by a simplified process. Desalination 2014, 350, $44-52$.

[6] Hua, D.; Ong, Y. K.; Wang, P.; Chung, T.-S. Thin-film composite tri-bore hollow fiber (TFC TbHF) membranes for isopropanol dehydration by pervaporation. Journal of Membrane Science 2014, 471, 155 - 167.

[7] Veríssimo, S.; Peinemann, K.-V.; Bordado, J. New composite hollow fiber membrane for nanofiltration. Desalination 2005, 184, 1 - 11, Desalination and the EnvironmentDesalination and the Environment.

[8] Shi, G. M.; Chung, T.-S. Thin film composite membranes on ceramic for pervaporation dehydration of isopropanol. Journal of Membrane Science 2013, 448, 34 - 43.

[9] Raaijmakers, M. J. T.; Hempenius, M. A.; Schön, P. M.; Vancso, G. J.; Nijmeijer, A.; Wessling, M.; Benes, N. E. Sieving of hot gases by hyper-cross-linked nanoscale-hybrid membranes. J. Am. Chem. Soc. 2014, 136, 330-5.

[10] Raaijmakers, M. J. T.; Kappert, E. J.; Nijmeijer, A.; Benes, N. E. Thermal Imidization Kinetics of Ultrathin Films of Hybrid Poly(POSS-imide)s. Macromolecules 2015, 48, 30313039.

[11] Kosaraju, P.; Sirkar, K. Interfacially polymerized thin film composite membranes on microporous polypropylene supports for solvent-resistant nanofiltration. Journal of Membrane Science 2008, 321, 155 - 161.

[12] Dutczak, S.; Tanardi, C.; Kopeć, K.; Wessling, M.; Stamatialis, D. "Chemistry in a spinneret" to fabricate hollow fibers for organic solvent filtration. Sep. Purif. Technol. 2012, $86,183-189$.

[13] Moch, I. Kirk-Othmer Encycl. Chem. Technol.; John Wiley \& Sons, Inc., 2000.

[14] Kingsbury, B.; Li, K. A morphological study of ceramic hollow fibre membranes. J. Memb. Sci. 2009, 328, 134-140.

[15] Zhao, T.; Liu, Z.; Nakata, K.; Nishimoto, S.; Murakami, T.; Zhao, Y.; Jiang, L.; Fujishima, A. Multichannel $\mathrm{TiO} 2$ hollow fibers with enhanced photocatalytic activity. $J$. Mater. Chem. 2010, 20, 5095.

[16] de Wit, P.; Kappert, E. J.; Lohaus, T.; Wessling, M.; Nijmeijer, A.; Benes, N. E. Highly permeable and mechanically robust silicon carbide hollow fiber membranes. J. Memb. Sci. 2015, 475, 480-487.

[17] Luiten-olieman, M. W. J.; Raaijmakers, M. J. T.; Winnubst, L.; Bor, T. C.; Wessling, M.; Nijmeijer, A.; Benes, N. E. Towards a generic method for inorganic porous hollow fibers preparation with shrinkage-controlled small radial dimensions, applied to $\mathrm{Al} 2 \mathrm{O} 3, \mathrm{Ni}, \mathrm{SiC}$, stainless steel, and YSZ. J. Memb. Sci. 2012, 407-408, 155-163.

[18] Chu, L.-Y.; Wang, S.; Chen, W.-M. Surface Modification of Ceramic-Supported Polyethersulfone Membranes by Interfacial Polymerization for Reduced Membrane Fouling. Macromolecular Chemistry and Physics 2005, 206, 1934-1940.

[19] Peters, T. A.; Fontalvo, J.; Vorstman, M. A. G.; Benes, N. E.; Van Dam, R. A.; Vroon, Z. A. E. P.; Van Soest-Vercammen, E. L. J.; Keurentjes, J. T. F. Hollow fibre microporous silica 
membranes for gas separation and pervaporation: Synthesis, performance and stability. $J$. Memb. Sci. 2005, 248, 73-80.

[20] Peters, T.; Benes, N.; Buijs, H.; Vercauteren, F.; Keurentjes, J. Thin high flux ceramicsupported PVA membranes. Desalination 2006, 200, 37-39.

[21] Cao, Y.; Wang, M.; Xu, Z.-l.; Ma, X.-h.; Xue, S.-m. A Novel Seeding Method of Interfacial Polymerization-Assisted Dip Coating for the Preparation of Zeolite NaA Membranes on Ceramic Hollow Fiber Supports. ACS Applied Materials \& Interfaces 2016, 8, 2538625395, PMID: 27603411.

[22] Uhlhorn, R.; Huis in't Veld, M.; Keizer, K.; Burggraaf, A. Synthesis of ceramic membranes. J. Mater. Sci. Lett. 1992, 27, 527-537.

[23] de Wit, P.; Daalen, F. S.; Benes, N. E. The mechanical strength of inorganic porous hollow fibers. J. Memb. Sci. 2017, 524, 721-728.

[24] Zhang, Y.; Benes, N. E.; Lammertink, R. G. H. Visualization and characterization of interfacial polymerization layer formation. Lab Chip 2015, 15, 575-580.

[25] Ogieglo, W.; Wormeester, H.; Wessling, M.; Benes, N. Spectroscopic ellipsometry analysis of a thin film composite membrane consisting of polysulfone on a porous $\alpha$-alumina support. ACS Applied Materials and Interfaces 2012, 4, 935-943.

[26] Cochrane, H.; Rudham, R. Heats of immersion of alpha and gamma alumina. Trans. Faraday Soc. 1965, 61, 2246-2254.

[27] de Vos RM,; Verweij, H. High-selectivity, high-flux silica membranes for gas separation. Science 1998, 279, 1710-1711.

[28] Napolitano, S.; Pilleri, A.; Rolla, P.; Wübbenhorst, M. Unusual Deviations from Bulk Behavior in Ultrathin Films of Poly(tert-butylstyrene): Can Dead Layers Induce a Reduction of Tg? ACS Nano 2010, 4, 841-848.

[29] Saha, N.; Joshi, S. Performance evaluation of thin film composite polyamide nanofiltration membrane with variation in monomer type. Journal of Membrane Science 2009, 342, 60 -69 .

[30] Misdan, N.; Lau, W.; Ismail, A.; Matsuura, T.; Rana, D. Study on the thin film composite poly(piperazine-amide) nanofiltration membrane: Impacts of physicochemical properties of substrate on interfacial polymerization formation. Desalination 2014, 344, 198 - 205.

[31] Jahanshahi, M.; Rahimpour, A.; Peyravi, M. Developing thin film composite poly(piperazine-amide) and poly(vinyl-alcohol) nanofiltration membranes. Desalination 2010, 257, 129 - 136.

[32] Dalwani, M.; Benes, N. E.; Bargeman, G.; Stamatialis, D.; Wessling, M. Effect of pH on the performance of polyamide/polyacrylonitrile based thin film composite membranes. Journal of Membrane Science 2011, 372, 228 - 238.

[33] Yang, F.; Zhang, S.; Yang, D.; Jian, X. Preparation and characterization of polypiperazine amide/PPESK hollow fiber composite nanofiltration membrane. Journal of Membrane Science 2007, 301, 85 - 92 .

[34] Li, H.; Wang, W.; Zhang, Y. Preparation and characterization of high-selectivity hollow fiber composite nanofiltration membrane by two-way coating technique. Journal of Applied Polymer Science 2014, 131, n/a-n/a.

[35] Bargeman, G.; Westerink, J.; Manuhutu, C.; ten Kate, A. The effect of membrane characteristics on nanofiltration membrane performance during processing of practically saturated salt solutions. Journal of Membrane Science 2015, 485, $112-122$. 


\section{Chapter 8}

Reflections and perspectives 

The objective of the work described in this thesis was to use new monomers to design and synthesize networks by interfacial polymerization with enhanced film properties. Interfacial polymerization provides a broad platform for the design and synthesis of novel hyper-cross-linked materials. A network prepared by interfacial polymerization is in this thesis considered to consist of four key elements: the network former, the bridge in between the network formers, functional side groups of the bridge molecule, and the anchor connecting the network former and the bridge. All these elements can be individually tuned to enhance the performance of the formed network.

This thesis describes several combinations of monomers that are incorporated in interfacial polymerization, and it reports on the properties of the resulting films. In addition, it describes the opportunities of a hyperbranched poly(aryl ether ketone) as membrane material for gas separation. Finally, it describes a method to apply membranes prepared by interfacial polymerization in demanding conditions using ceramic hollow fiber supports.

The first sections of this chapter reflect on the materials reported in this thesis, and give possible directions for further research on these specific materials. This is followed by a section that describes some other monomers that could be of interest in interfacial polymerization, and a section that reflects on general requirements for the application of new monomers in interfacial polymerization. Finally, a general conclusion is given in the last section of this chapter.

\subsection{Traditional polyamide thin film composite membranes}

Many research papers have been published on the influence of monomer architecture on the performance of polyamide TFC membranes. Most studies make minor structural variations to either or both the acyl chloride and the amine, and report on the membrane performance. However, most papers lack the connection of membrane performance to monomer architecture. Therefore, it is necessary to study in a systematic manner the influence of monomer architecture on the membrane performance, and eventually develop design criteria for TFC polyamide membranes.

In this thesis, a new star-shaped trifunctional acyl chloride monomer was synthesized bearing flexible ether linkages. The effect of these ether linkages on the membrane performance was studied. A systematic study on the influence of monomer architecture could eventually help to develop design criteria for polyamide membranes. We prepared polyamide TFC membranes from this star-shaped acyl chloride and either $m$-phenylenediamine or $p$-phenylenediamine. In contrast to TMC, the use of the star-shaped acyl chloride resulted in significant differences in membrane performance depending on the structural isomerism of the aromatic diamine. We hypothesized that MPD has a lower reactivity compared to PPD, and thus a lower membrane performance. This difference in reactivity is not pronounced 
in TMC-based membranes due to the high reactivity of TMC. However, the starshaped acyl chloride prepared by us, has a lower reactivity than TMC due to the electron donating ether linkages. Therefore, the difference in reactivity between MPD and PPD is more pronounced when a less reactive acyl chloride is used.

Independent on the aromatic diamine used, we found that the membranes prepared with the star-shaped acyl chloride have a lower salt retention compared to TMC-MPD membranes. This could be caused by the relatively large size of this acyl chloride. Therefore, the salt retention could be increased by decreasing the size of the acyl chloride while maintaining the electron donating ether linkage. The structures of possible tri- or tetrafunctional diphenyl ether acyl chlorides are shown in Figure 8.1a-b. The synthesis of the carboxylic acid derivatives of these compounds have been reported on in literature ${ }^{[1,2]}$. The corresponding acyl chlorides can be obtained by treatment with thionyl chloride $\left(\mathrm{SOCl}_{2}\right)$.

The size of the diphenyl ether acyl chlorides in Figure 8.1a-b is similar to that of biphenyl acyl chlorides commonly reported on in literature. Membranes prepared with these biphenyl acyl chlorides are found to have excellent salt rejection, indicating that the size of these biphenyl monomers is sufficiently small to allow for a dense top-layer. Therefore, the diphenyl ether acyl chlorides as depicted in Figure 8.1a-b can be used to study the effect of the electron donating ether group on the membrane performance. Additionally, it could be interesting to study the effect of an electron withdrawing group, such as a diphenyl bearing a ketone linker.

A flexible method to alter the size of the monomer in a systematic way is to use an alkyl linker between the aromatic rings bearing the acyl chloride functionalities. For example, the synthesis of 5,5'-(butane-1,4-diyl)-bis(oxy)-diisophthalic acid, bearing a butane linker, has been reported on in literature ${ }^{[3]}$. This carboxylic acid is prepared from the reaction of 5-hydroxy-isophthalic acid diethyl ester and 1,4-dichlorobutane. By varying the length of the dichloroalkane linker, the size of the carboxylic acid can easily be altered. Again, the carboxylic acid can

a<smiles>O=C(Cl)c1ccc(Oc2cc(C(=O)Cl)cc(C(=O)Cl)c2)cc1</smiles>

$\mathrm{b}$<smiles>O=C(Cl)c1cc(Oc2cc(C(=O)Cl)cc(C(=O)Cl)c2)cc(C(=O)Cl)c1</smiles>

$\mathrm{c}$<smiles>O=C(Cl)c1cc(OCCCCOc2cc(C(=O)Cl)cc(C(=O)Cl)c2)cc(C(=O)Cl)c1</smiles>

Figure 8.1: Structures of acyl chlorides that could be an alternative to TMC. 


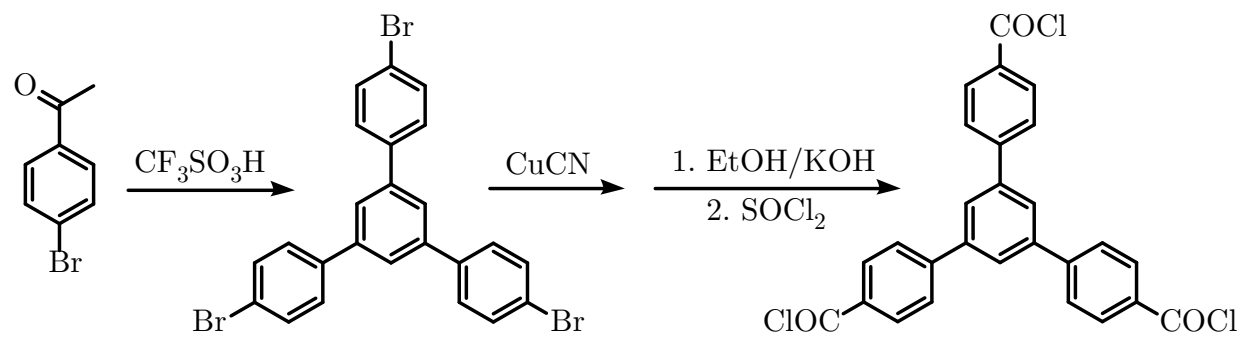

Scheme 8.1: The synthesis of the fully aromatic and planar 1,3,5-tris(4-chlorocarbonylphenyl)benzene from 4'-bromoacetophenone.

be converted into its corresponding acyl chloride by the treatment with thionyl chloride. Figure 8.1c shows this acyl chloride bearing a butane linker.

In addition to the star-shaped trifunctional acyl chloride reported on in this thesis, we intended to study the effect of a completely aromatic and planar acyl chloride on the resulting TFC membrane performance. The synthesis route of this acyl chloride, 1,3,5-tris(4-chlorocarbonylphenyl)benzene, is shown in Scheme 8.1. 1,3,5-Tris(4-carboxyphenyl)benzene could be synthesized from 4'-bromoacetophenone $\left({ }^{1} \mathrm{H}-\mathrm{NMR}\right.$ (DMSO, $\left.\delta, \mathrm{ppm}\right): 8.03(\mathrm{~m}),{ }^{13} \mathrm{C}-\mathrm{NMR}$ (DMSO, $\delta, \mathrm{ppm}): 168,144,141,130,130,128,126)$ and was obtained in good yield. However, this compound shows to be insoluble in thionyl chloride even after refluxing overnight. The low solubility is probably caused by a combination of stacking of the molecules and the presence of the carboxylic acid groups. The chemical structure of the resulting compound could not be verified because of the low solubility in any organic solvent. In addition, this low solubility makes this compound unusable for any interfacial polymerization reaction. The solubility of this planar fully aromatic molecule could be enhanced by introducing side groups, for example methyl groups, that disrupts the highly ordered packing of 1,3,5-tris(4-carboxyphenyl)benzene.

\subsection{Hybrid materials bearing POSS as network former}

Hybrid materials are an interesting class of materials that bear both organic and inorganic moieties. Due to their hybrid nature, these materials often show enhanced properties compared to their individual counterparts. A inorganic network former with high potential is the class of POSS monomers. POSS could readily be polymerized with small organic molecules in an interfacial fashion ${ }^{[4-6]}$ resulting in glassy materials.

In this thesis it is shown that the class of these POSS-based systems is not limited to these glassy materials, but that rubbery bridges can be incorporated as well. 
"Rubbery" poly(PDMS-POSSimides) were prepared from the interfacial polymerization of octa-ammoniumPOSS and succinic anhydride terminated PDMS. The resulting poly(PDMS-POSSimides) show completely distinct swelling in organic solvents compared to conventional PDMS. The swelling in the non-polar solvent $n$ hexane, and the polar aprotic solvent ethyl acetate is greatly reduced because of the restrictions of chain movement due to cross-linking. In contrast, the poly(PDMSPOSSimide) show to have a higher swelling in the polar protic solvent ethanol. This higher affinity for ethanol has been explained by the presence of positively charged ammonium groups in the material.

The succinic anhydride terminated PDMS was chosen because of its high reactivity towards the amine groups present on the POSS, and because it is commercially available. However, the molecular weight of this PDMS was around $900 \mathrm{~g} \mathrm{~mol}^{-1}$, and therefore one could better speak of a PDMS oligomer. Of course, this small molecular weight restricts swelling more compared to a higher molecular weight PDMS with the same cross-link density. In addition, the permeance of ethanol through the poly(PDMS-POSSimide) film was almost zero because of these short PDMS chains.

Succinic anhydride terminated PDMS can be synthesized from the hydrosilylation of hydride terminated PDMS with allylsuccinic anhydride in the presence of Karstedt's catalyst $\left(\mathrm{Pt}_{2}\left[\left(\mathrm{Me}_{2} \mathrm{SiCH}=\mathrm{CH}_{2}\right)_{2} \mathrm{O}\right]_{3}\right)$ as depicted in Scheme 8.2. Hydride terminated PDMS is commercially available in a wide range of molecular weights. Using this approach, a range of poly(PDMS-POSSimides) could be synthesized with varying PDMS chain length. It would be interesting to study the effect of the PDMS chain length on the swelling in organic solvents. In addition, the use of a longer PDMS chain could result in an enhanced solvent permeance, making these materials of great interest for organic solvent nanofiltration.

As an alternative to anhydride terminated PDMS, octaAnhydride POSS could be synthesized from the hydrosilylation of octaSilane POSS with allylsuccinic anhydride $^{[7]}$. This octaAnhydride POSS could react with hydroxy terminated PDMS,
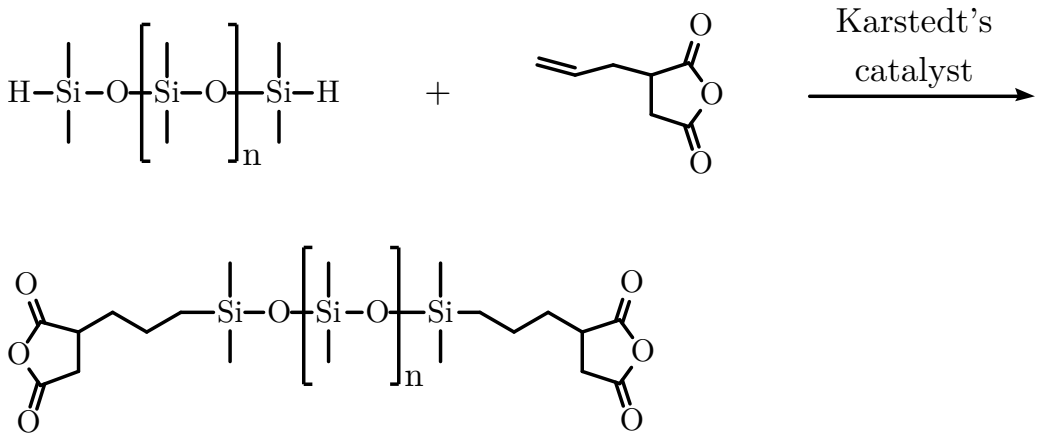

Scheme 8.2: The synthesis of succinic anhydride terminated PDMS from the hydrosilylation of hydride terminated PDMS with allylsuccinic anhydride. 
resulting in the same poly(PDMS-POSSimide) structure as obtained before. However, both monomers are not water-soluble in this approach, making this a less attractive synthesis route for the preparation of poly(PDMS-POSSimides) by interfacial polymerization.

\section{Chemical imidization}

The reaction of octaAmmonium POSS with succinic anhydride terminated PDMS yielded a poly(PDMS-POSSamic acid) film. In this thesis, the poly(PDMS-POSSamic acid) film was thermally imidized to the stable poly(PDMS-POSSimide). Due to this thermal treatment, a ceramic support has to be used which limits the application of these films in organic solvent nanofiltration. An alternative to the thermal imidization is chemical imidization. The cyclization of the amic acid to the imide ring can be achieved by treating the polymer with a dehydrating agent in combination with a base catalyst under mild conditions. Chemical imidization is often performed on linear poly(amic acid) polymers, however, very limited literature is available on the chemical imidization of supported thin poly(amic acid)s.

Figure 8.2 shows the FTIR spectra of a poly(PDMS-POSSamic acid) film before and after treatment with a mixture of pyridine and acetic anhydride. The spec-

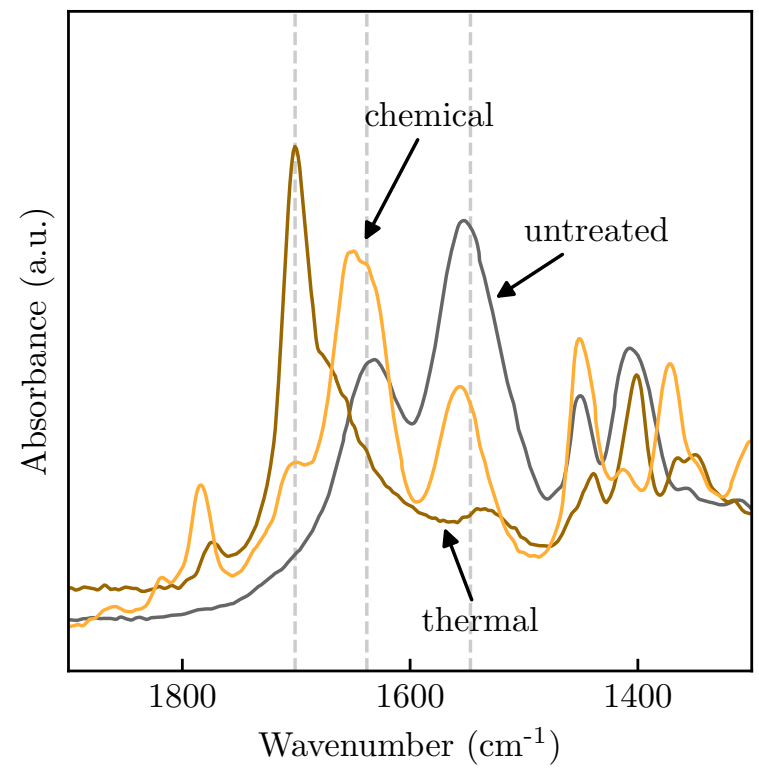

Figure 8.2: ATR-FTIR spectra of an untreated poly(PDMS-POSSamic acid) film on PAN $(-)$, and a poly(PDMS-POSSamic acid) film on PAN treated with a mixture of pyridine and acetic anhydride for 2 days (-). The ATR-FTIR spectrum of a thermally imidized poly(PDMS-POSSimide) powder $(-)$ is added as reference. 
<smiles>[R1]N=C1OC(=O)CC1[R]</smiles>

isoimide<smiles>[R]NC(=O)C([R])CC(=O)O</smiles>

amic acid

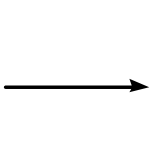

imide

Scheme 8.3: The chemical structure of an isoimide, amic acid, and imide bond.

trum of thermally imidized poly(PDMS-POSSimide) powder is added as reference. Thermally imidized poly(PDMS-POSSimide) powder shows a clear absorbance peak at $1700 \mathrm{~cm}^{-1}$ belonging to the $\mathrm{C}=\mathrm{O}$ stretching of the imide ring, while the characteristic amide absorption peaks have vanished. However, these amide peaks are still present in the spectrum of the chemically treated poly(PDMS-POSSamic acid) film supported on PAN. Additionally, a small peak belonging to the imide is present at $1700 \mathrm{~cm}^{-1}$, and an additional isoimide (Scheme 8.3) absorption peak is present at $1780 \mathrm{~cm}^{-1}$. Both indicate an incomplete imidization, since an isoimide ring is only found to isomerize into the stable imide ring when all amic acid groups have been consumed ${ }^{[8]}$.

The use of different dehydrating mixtures resulted in similar chemical composition of the films, as shown in Figure 8.13 in the supporting information of this chapter. The low conversion of amic acid into imide groups could be caused by the tightly cross-linked network, and thus the inability of the dehydrating agents to penetrate into the network.

\section{Poly(PDMS-POSSimide) films as dense barriers in microfluidics}

The poly(PDMS-POSSimide) films prepared in this thesis, show little to no ethanol permeance due to the short PDMS linker used. However, the preparation of a highly cross-linked PDMS layer, of which the surface properties could relatively easily be tuned by the selection of the monomers, could be of interest in microfluidic devices that are often prepared from PDMS. By interfacial polymerization, a thin layer of the impermeable poly(PDMS-POSSimide) could be coated locally inside a microfluidic device. To study the feasibility of this concept, PDMS slabs were coated with a poly(PDMS-POSSimide) film by interfacial polymerization. The PDMS slab was swollen in the organic phase containing the succinic anhydride terminated PDMS, and was subsequently immersed in the aqueous phase containing deprotonated octaAmmonium POSS. Figure 8.3 shows top-view scanning electron micrographs of this coated PDMS slab. A poly(PDMS-POSSamic acid) film could be clearly distinguished on the surface of the PDMS slab. The roughness of the film varies over the surface of the film (see insets b and c). The local high surface roughness could be caused by the presence of a thin toluene 


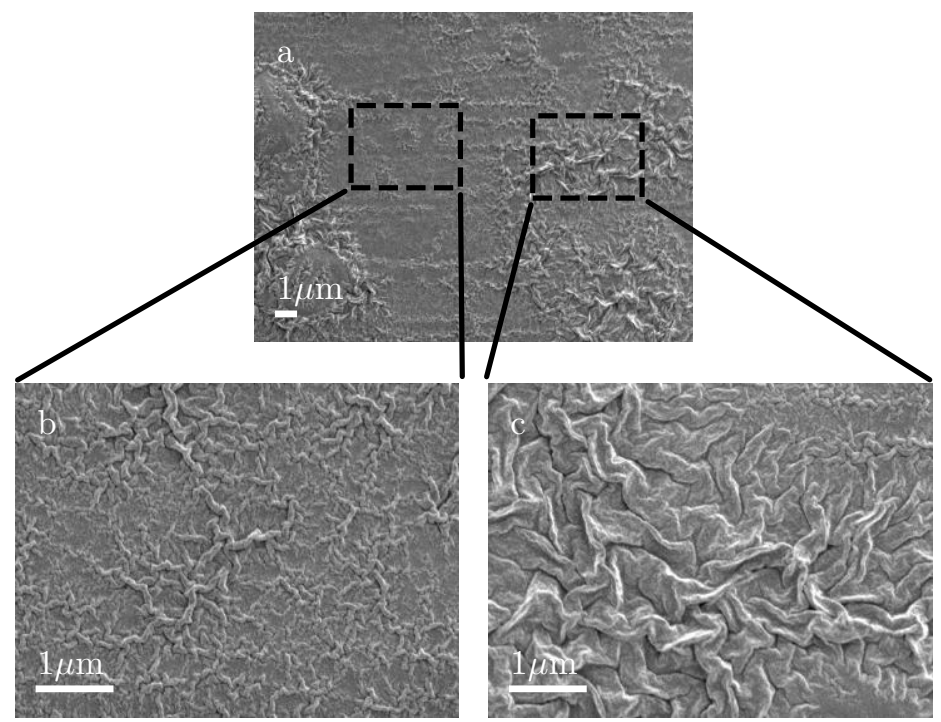

Figure 8.3: Top-view scanning electron micrographs of an poly(PDMS-POSSamic acid) film on top of a PDMS slab. (a) 5,000x magnification, (b,c) 20,000x magnification.

film on top of the PDMS slab surface. Since organic solvents are more volatile compared to water, the drying time gets more critical. Although some optimization is needed, Figure 8.3 shows that PDMS could be coated with a thin layer of poly(PDMS-POSSamic acid).

The poly(PDMS-POSSamic acid) is susceptible to hydrolytic attack. To enhance the stability, the film can be imidized to form a poly(PDMS-POSSimide). Figure 8.4 shows top-view scanning electron micrographs of such a poly(PDMSPOSSimide) film on top of a PDMS slab prepared by thermal imidization. Figure 8.4a shows that the typical surface morphology of interfacial polymerized films is still present. However, thermal imidization results in crack formation within this poly(PDMS-POSSimide) film, as shown in Figure 8.4b. This crack formation could be caused by the difference in thermal expansion coefficient between the poly(PDMS-POSSimide) film and the PDMS slab.

Thus, it can be concluded that the surface of a PDMS slab could be coated with a thin layer of a poly(PDMS-POSS). However, the use of an imide linker, and thus the need for thermal imidization, hampers the defect-free film formation. Therefore, alternative chemistry that avoids a thermal treatment must be used. 

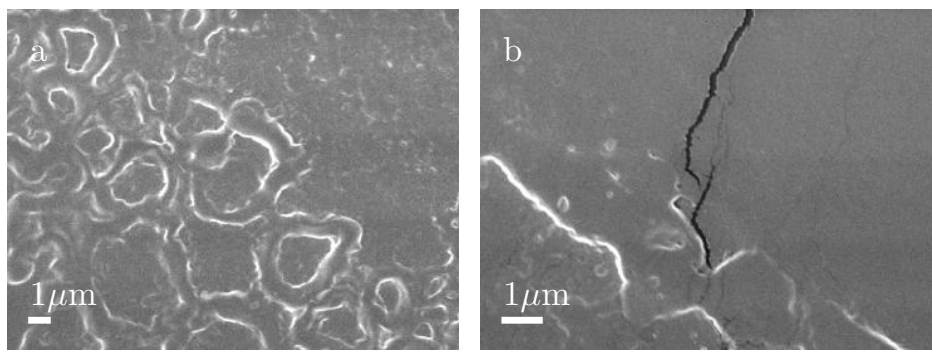

Figure 8.4: (a) and (b) Top-view scanning electron micrographs of a poly(PDMSPOSSimide) film on top of a PDMS slab.

\section{Hydrolysis of POSS cages in basic solutions}

The hybrid hyper-cross-linked networks using a POSS molecule as network former, use octaAmmonium POSS because of its high solubility and its eight possible reactive groups. OctaAmmonium POSS is very stable at neutral and acidic conditions, but the $\mathrm{Si} / \mathrm{O}$ framework is prone to cleavage at basic conditions ${ }^{[9,10]}$. The ammonium groups of octaAmmonium POSS need to be neutralized to their free amine analogues to be able to react with electrophiles in an interfacial polymerization. This neutralization is achieved at basic conditions ${ }^{[4]}$, thereby compromising the $\mathrm{Si} / \mathrm{O}$ framework. The formed free amine groups can attack the silicon atoms, followed by the cleavage of a $\mathrm{Si}-\mathrm{O}$ bond and the formation of a $\mathrm{Si}-\mathrm{OH}$ bond ${ }^{[9]}$. It is reported on in literature that the formed structure is the disilanol depicted in Scheme 8.4.

Figure 8.5 shows ${ }^{1} \mathrm{H}-\mathrm{NMR}$ spectra of octaAmmonium POSS in heavy water $\left(\mathrm{D}_{2} \mathrm{O}\right)$. It can be concluded from Figure 8.5b that this compound is stable for up to two days in $\mathrm{D}_{2} \mathrm{O}$. After two days, a small upfield shift in the peak belonging to the $\mathrm{CH}_{2}-\mathrm{CH}_{2}-\mathrm{NH}_{3}{ }^{+}$triplet is observed, while the other peaks stayed unchanged. This upfield shift can be caused by the conversion of ammonium groups into free<smiles>[R][Si]12O[Si]3([R])O[Si]4([R])O[Si]([R])(O1)O[Si]1([R])O[Si]([R])(O2)O[Si]([R])(O3)O[Si]([R])(O4)O1</smiles>

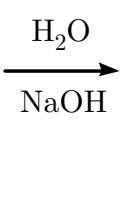<smiles>[R][Si]1(O)O[Si]2([R])O[Si]3([R])O[Si]([R])(O)O[Si]4([R])O[Si]([R])(O2)O[Si]([R])(O[Si]([R])(O1)O3)O4</smiles>

Scheme 8.4: The hydrolysis of an octaAmmonium POSS cage upon contact with a base, such as $\mathrm{NaOH}$. 

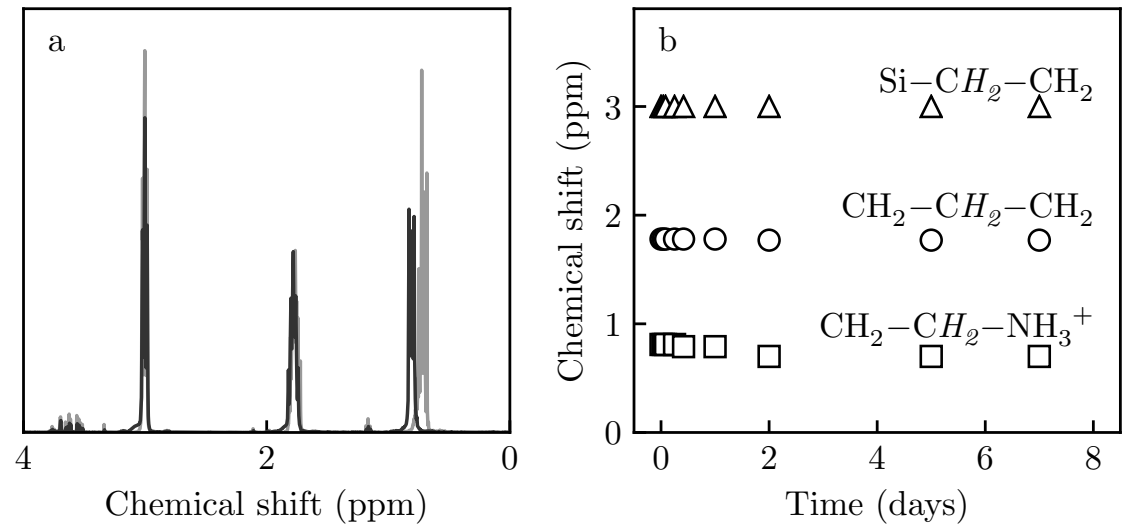

Figure 8.5: (a) ${ }^{1} \mathrm{H}$-NMR spectra of octaAmmonium POSS in heavy water $\left(\mathrm{D}_{2} \mathrm{O}\right)$ at $t=0$ days $(-)$ and after seven days $(-)$ (b) The chemical shift as function of time for the three peaks belonging to the ammoniumpropyl end-group.

amine groups. However, there is no sign of severe cage cleavage. It must be noted that heavy water is a weaker acid than normal water, and thus heavy water is less dissociated compared to water ${ }^{[11]}$. This means that there are less $\mathrm{OD}^{-}$ions present that can cause cage cleavage.

If a base, such as $\mathrm{NaOD}$, is added to an octaAmmonium POSS solution, all peaks shift upfield (Figure 8.6) due to the formation of free amine groups and simultaneous cage cleavage. The position of all peaks stabilizes 15 minutes after NaOD addition, indicating that an equilibrium is reached within this period. The shift of all signals is dependent on the concentration of $\mathrm{NaOD}$, with the largest shifts for the highest $\mathrm{NaOD}$ concentration. Examining the multiplicity of the peaks reveals that the $\mathrm{Si}-\mathrm{CH}_{2}-\mathrm{CH}_{2}$ and $\mathrm{CH}_{2}-\mathrm{CH}_{2}-\mathrm{NH}_{3}{ }^{+}$peaks start as perfect triplets, but transform into multiplets caused by a complex chemical environment. Unfortunately, the exact structure of the POSS could not be derived from only ${ }^{1} \mathrm{H}-\mathrm{NMR}$ data. However, it could be concluded that a solution of octaAmmonium POSS was stable for at least 19 hours.

A method to neutralize octaAmmonium POSS without the use of a base, is by eluting a methanol or 14:1 ethanol-water solution of octaAmmonium POSS across a column containing the basic Amberlite IRA-400 resin ${ }^{[9,12]}$. However, the formed amine is marginally stable in solution at relatively low concentrations $(<3 \mathrm{w} / \mathrm{v} \%)$, and therefore should be prepared directly before the interfacial polymerization. A methanolic solution of the neutralized octaAmmonium POSS could be used in the interfacial polymerization with common electrophiles dissolved in, for example, cyclohexane, $n$-hexane, $n$-pentane, or $n$-heptane. 


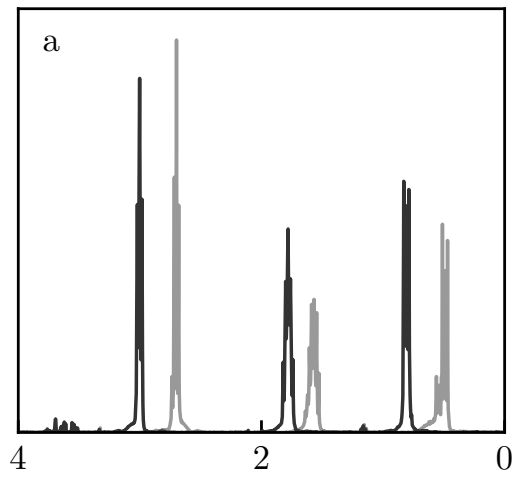

Chemical shift (ppm)

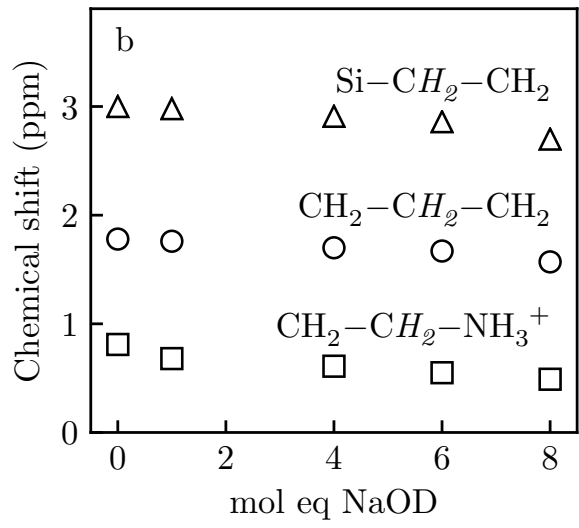

Figure 8.6: (a) ${ }^{1} \mathrm{H}$-NMR spectra of octaAmmonium POSS without the addition of $\mathrm{NaOD}$ $(-)$ and with the addition of $8 \mathrm{~mol}$ equivalent $\mathrm{NaOD}(-)$ (b) The chemical shift as function of the amount of $\mathrm{NaOD}$ added for the three peaks belonging to the ammoniumpropyl endgroup. The chemical shift was measured 15 minutes after the addition of $\mathrm{NaOD}$. No changes in chemical shift were observed for up to 19 hours.

\section{Alternative chemistries with POSS}

Networks prepared by interfacial polymerization bearing POSS as network former are usually prepared from a basic solution of octaAmmonium POSS. Inherent to this approach is the cleavage of the POSS cage to a mixture of cage and ladder structures. The effect of this cage cleavage on the membrane performance is not known. To study this effect, octaAmmonium POSS could be neutralized by passing across an Amberlite IRA-400 resin. However, this method is very time consuming, and chain cleavage catalyzed by free amine groups is still a risk.

Many alternative POSS frameworks have been reported on that could be of interest in the preparation of thin films by interfacial polymerization. For example, poly $(\text { POSSazomethines })^{i}$ have been synthesized ${ }^{[13-15]}$. These poly(POSSazomethines) are prepared in a two step reaction: the octaAmmonium POSS is deprotonated by triethylamine in methanol, followed by the addition of a methanolic solution of an aromatic aldehyde, as summarized in Scheme 8.5. This method could be transferred to an interfacial method, by dissolving the aromatic aldehyde in an immiscible solvent with methanol. To avoid the neutralization step, and thus cage cleavage, a methanolic solution of octaAminophenyl POSS could be of interest.

Despite its cage cleavage, octaAmmonium POSS has some unique properties that make it so much of interest for interfacial polymerization. Primarily, octaAmmo-

\footnotetext{
${ }^{\mathrm{i}}$ azomethines are also referred to as imines or Schiffs bases
} 


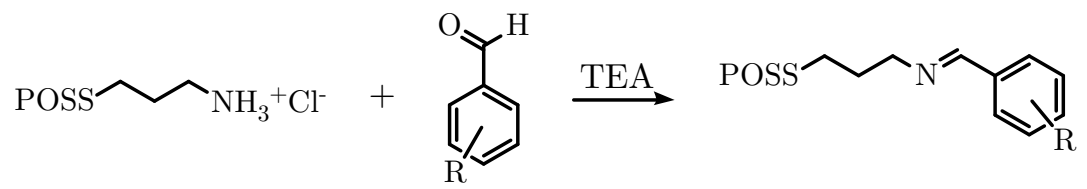

Scheme 8.5: The formation of a poly(POSSazomethine) from octaAmmonium POSS and an aromatic aldehyde.

nium POSS is highly soluble in water, and thereby allowing for simple interfacial polymerization with a wide variety of electrophiles dissolved in a wide range of organic solvents. Additionally, films prepared with octaAmmonium POSS showed to be very thin and smooth ${ }^{[16]}$. This is attributed to a combination of the large molecular weight, and the highly positively charged nature of the monomer; both limit the diffusion into the organic phase.

Other water-soluble, permanently positively charged POSS structures could be synthesized from the Menschutkin reaction of a tertiary amine with an aryl or alkyl halide. Two main approaches for the synthesis of tertiary amine functionalized POSS have been reported on in literature so far (Scheme 8.6). The first approach is based on the hydrosilylation of octaSilane POSS with allyldimethylamine ${ }^{[17]}$. The second is based on the thiol-ene click chemistry of 3-(dimethylamino)1-propanethiol to octaVinyl POSS ${ }^{[18]}$. A wide variety of aryl or alkyl halides could be selected. Examples are alkyne, alkene, vinyl, or azide functionalized molecules.

Alternatively, chemistry without the involvement of amines could be of interest. For example, isocyanates are very reactive precursors to polyurethanes or

i)<smiles>[3H]S(=O)(=[Rh])O[SiH](C)C</smiles><smiles>C=CCN(C)C</smiles>

ii)<smiles>C=CS(=O)O</smiles><smiles>CN(C)CCCS</smiles>

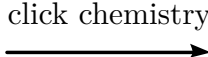

thiol-ene
Karstedt's

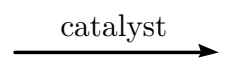<smiles>CN(C)CCC[Si](C)(C)OS(=O)(=O)O</smiles>

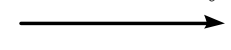<smiles>CN(C)CCCSCCSS(=O)(=O)c1ccccc1</smiles>

Menschutkin

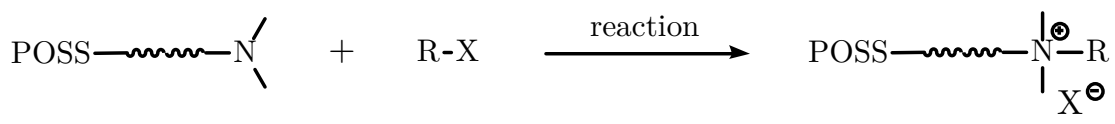

Scheme 8.6: The synthesis of a permanent positively charged POSS monomer via sequential hydrosilylation (i) or thiol-ene click chemistry (ii) and a Menschutkin reaction. 

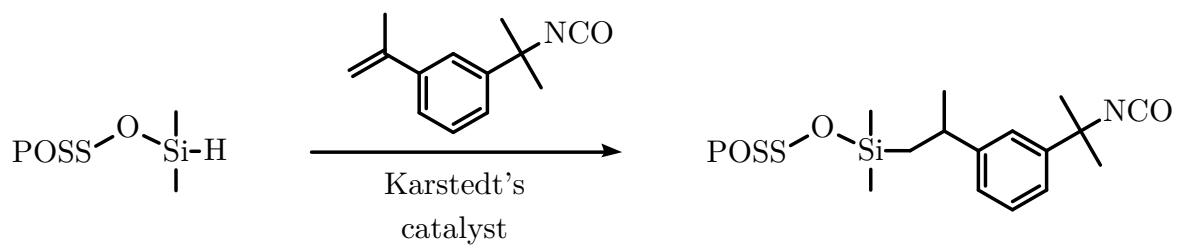

Scheme 8.7: The synthesis of an octalsocyanate POSS from the hydrosilylation of octaSilane POSS with $m$-isopropenyl- $\alpha, \alpha^{\prime}$-dimethylbenzyl isocyanate.

polyureas. The synthesis of an octaIsocyanate POSS could be of interest for poly(PDMS-POSS) films. The synthesis of this POSS is described by Neumann et al. ${ }^{[19]}$. In short, octaSilane POSS and $m$-isopropenyl- $\alpha, \alpha^{\prime}$-dimethylbenzyl isocyanate $(m$-TMI) react in the presence of Karstedt's catalyst to form an octaIsocyanate POSS (Scheme 8.7). The $m$-TMI is specifically chosen, because it exclusively forms the $\beta$ addition product without any competition of the functional isocyanate group.

Indeed, octaIsocyanate POSS can be synthesized via the method described by Neumann et al.. Unfortunately, we could not remove the excess $m$-TMI from the product due to the lack of a sufficiently high vacuum during vacuum distillation. If the pure octaIsocyanate POSS could be obtained, it would provide a very attractive method to prepare poly(PDMS-POSS) films without the need of a thermal treatment. Poly(PDMS-POSSurethane) or poly(PDMS-POSSurea) films could be prepared from the reaction of octaIsocyanate POSS with hydroxy- or amino-terminated PDMS. Because of the low solubility of PDMS and the reaction of octaIsocyanate POSS with water, this reaction can not be carried out as conventional interfacial polymerization. However, both monomers could be dissolved in tetrahydrofuran (THF), followed by the addition of catalyst (e.g., dibutyltin dilaurate or stannous octoate). This mixture could be cast or spin-coated into a thin film, followed by a curing step ${ }^{[20]}$.

Hydroxy- and amine-terminated PDMS are readily available in a wide range of molecular weights. This makes it a perfect system to study the influence of the molecular weight of PDMS on the swelling and solvent permeation of poly(PDMSPOSS) films. A wide range of rubbery, yet highly cross-linked, materials could be developed with the solvent permeation and MWCO dependent on the length of the PDMS chain used.

\section{Incompletely condensed POSS as monomer}

The formation of incompletely condensed POSS cages via the controlled cleavage of fully condensed POSS cages could be of interest for the preparation of many polymeric materials ${ }^{[21]}$. Hillson et al. ${ }^{[22]}$ showed that these incompletely condensed, thus open, cage structures are still rigid. These incompletely condensed 
POSS cages provide a reactive site that could be used for the cross-linking of a monomer or even polymer.

Shi et al. ${ }^{[23]}$ showed a method to prepare a PDMS-POSS composite using incompletely condensed POSS cages (Scheme 8.8). The Si-OH groups of the incompletely condensed POSS and hydroxy terminated PDMS could be condensed in the presence of dibutyltin dilaurate, to form a PDMS functionalized POSS. The network was cross-linked using the co-cross-linker methyltris(methylethylketoxime)silane. However, one could expect the formation of a cross-linked network without the use of a co-cross-linking, because of the difunctional PDMS. The curing of these networks can be performed at ambient conditions, making this chemistry interesting for the application onto polymeric porous supports.

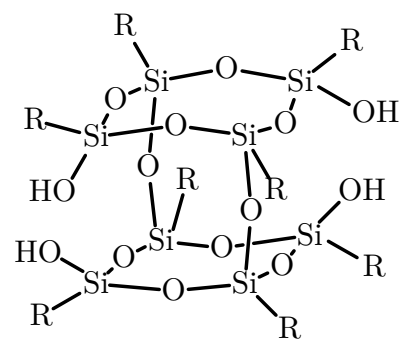
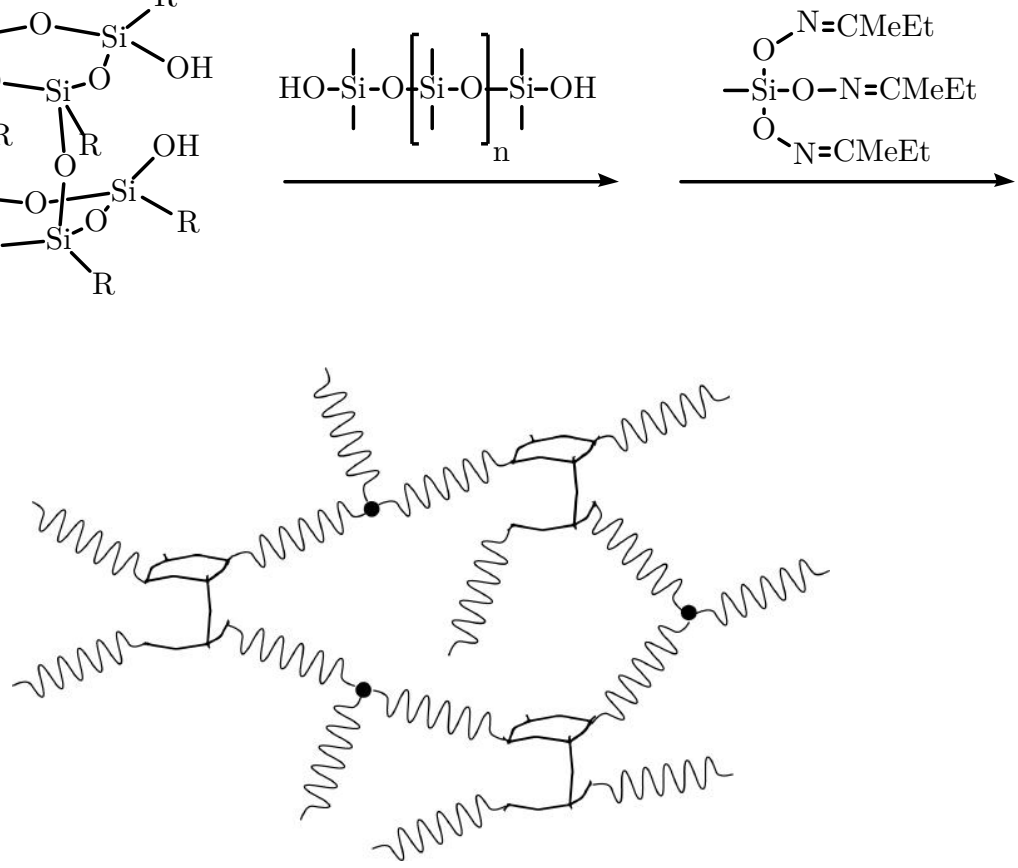

Scheme 8.8: The synthesis of a cross-linked silicon rubber by incompletely condensed POSS cages. 


\subsection{Cyclomatrix polyphosphazenes}

In addition to POSS, hybrid networks could alternatively be formed using the inorganic HCCP monomer. HCCP is able to react with a bifunctional nucleophile to yield an insoluble cross-linked material. Such a material is referred to as a cyclomatrix polyphosphazene. Cyclomatrix polyphosphazene materials are widely reported on in literature. However, their synthesis in a single solvent yield mostly microspheres. In this thesis, we describe for the first time the formation of thin cyclomatrix polyphosphazene films made by interfacial polymerization. We found that the reactivity of the used aromatic biphenol has a strong influence on the properties of the films formed. A relatively low pKa of the biphenol resulted in more cross-linked films, as could be deduced from the relatively high Young's modulus. In contrast, a relatively high pKa resulted in films with a moderate Young's modulus, and hence lower cross-link density. The properties of the cyclomatrix polyphosphazenes could thus be tuned by varying the acidity of the biphenol.

\section{Post-functionalization}

The cyclomatrix polyphosphazene films as described in this thesis contain a high amount of unreacted chlorine groups. From the XPS data it can be concluded that these chlorine groups are present on the surface of the films, which opens up the possibility of post-functionalization of these films. Post-functionalization could be performed with any monofunctional nucleophile that is able to undergo nucleophilic substitution with HCCP.

The possibility of post-functionalization is tested with HCCP-BPH films. HCCP$\mathrm{BPH}$ films were prepared by the method described in this thesis. Immediately after their synthesis, the PDMS slabs were submerged for 5 minutes in a solution containing 2,2,2-trifluoroethanol (TFE) and $\mathrm{NaOH}$. After 5 minutes the films were washed with water, and dried at ambient conditions overnight. The TFE forms in contact with sodium hydroxide the reactive monomer sodium 2,2,2-trifluoroethanolate. This monomer can undergo nucleophilic substitution with the remaining chlorine groups on the surface of the film. Figure 8.7 shows scanning electron micrographs of the aqueous side of both an unfunctionalized HCCP-BPH film and a TFE functionalized HCCP-BPH film. From Figure 8.7, it can be concluded that the post-functionalization does not significantly alter the surface morphology of the HCCP-BPH film. 


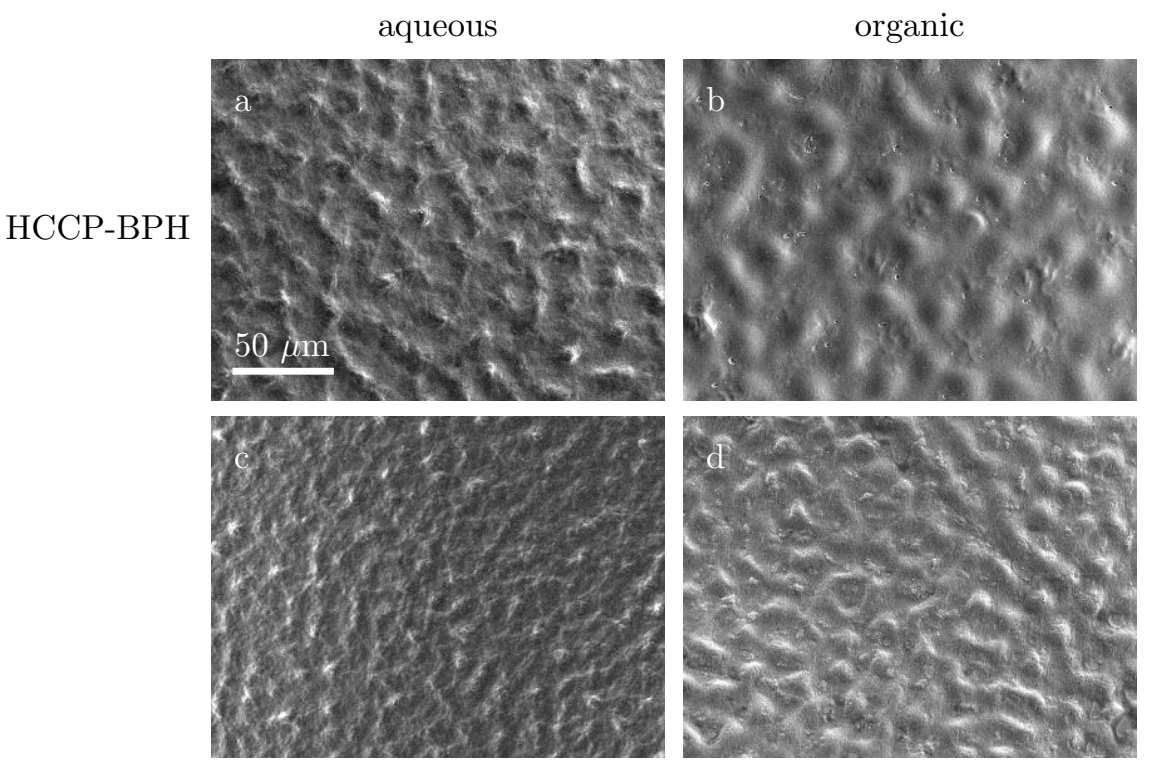

Figure 8.7: Top-view scanning electron micrographs of the aqueous and organic side of $(a, b)$ a HCCP-BPH film, and (c,d) a HCCP-BPH film functionalized with trifluoroethanol.

The presence of TFE on the surface of the films can be proven by, for example, energy dispersive X-ray spectroscopy (EDX). Figure 8.8a shows such an EDX spectrum of the aqueous side of a TFE functionalized HCCP-BPH film. A clear peak belonging to fluorine atoms, that are part of TFE, is present at $0.7 \mathrm{keV}$. Figure 8.8b-e shows a back-scatter scanning electron micrograph and EDX maps of the elements $\mathrm{C}, \mathrm{P}$, and F, respectively. These EDX maps show that the elements are equally distributed over the sample.

From the EDX maps it can be concluded that fluorine is indeed present at the interface (with a thickness of the EDX penetration depth) of a post-functionalized HCCP-BPH film. Although it is likely that this fluorine originates from the TFE covalently attached to the film surface, this can not be proven by just EDX measurements. More detailed experiments on the chemical binding energy of the oxygen belonging to TFE is necessary to indeed prove the covalent attachment of TFE to the HCCP-BPH film, and thus the successful post-functionalization of these films. 


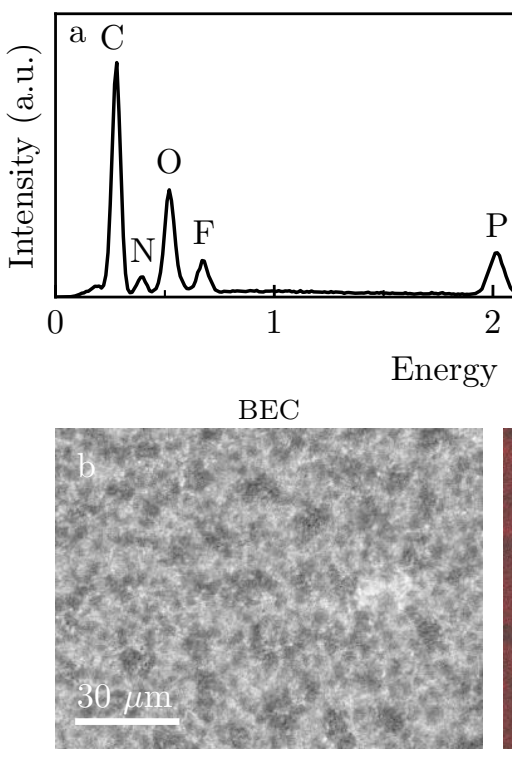

P

F
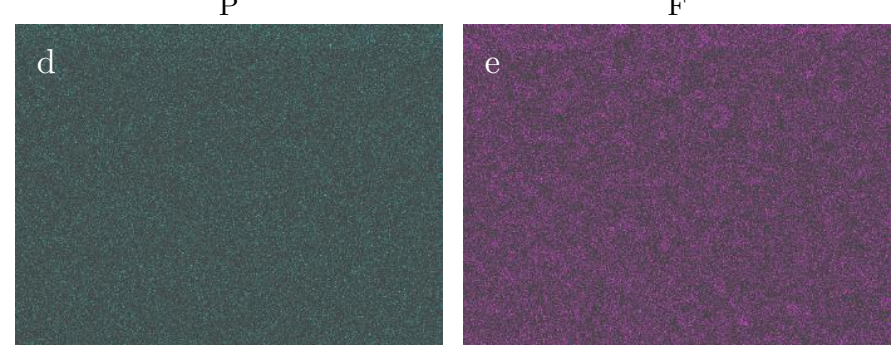

Figure 8.8: (a) EDX spectrum, (b) back-scatter scanning electron micrograph, (c-e) EDX maps of the elements $C, P$, and $F$ taken on the aqueous side of a HCCP-film functionalized with trifluoroethanol. 


\section{Hydrolytic stability}

The hydrolytic stability of polyphosphazenes is strongly dependent on the organic side-groups ${ }^{[24]}$. The linear polydichlorophosphazene is very sensitive to hydrolytic cleavage due to the chlorine side groups. The mechanism of this cleavage is given in Scheme 8.9. Depending on the organic side-groups, the hydrolysis rate can increase in acidic media ${ }^{[25,26]}$.

The HCCP-biphenol films prepared in this thesis contain a relatively high amount of residual chlorine groups. Despite the highly cross-linked nature of these films, these residual chlorine side-groups could be a risk for the hydrolytic stability. Figure 8.9 shows the mass loss of cyclomatrix polyphosphazene films stored for three weeks in Milli-Q water. Relatively large standard deviations are found due to differences in size and mass of the fresh films, and thus differences in the exposed area. It can be speculated that the highly cross-linked HCCP-DHBP and HCCPBPS films show a lower mass loss, and are therefore more resistant to hydrolysis. This can be caused by the higher cross-link density of these films, and hence a lower amount of residual chlorine side-groups. However, more accurate experiments are needed to prove this hypothesis.

The exact hydrolysis mechanism for these cyclomatrix polyphosphazene films has not been studied. However, the knowledge of the hydrolysis mechanism could be crucial to develop more hydrolytically stable films. A possible mechanism could be based on an outside-in film cleavage (Figure 8.10a). This mechanism will be present when the network is too tightly cross-linked for the water molecule to penetrate into the network. Only the chlorine groups at the outer surface of the film will be exposed to water, and therefore only the outer surface of the film is hydrolyzed. Due to this hydrolysis, chlorine groups slightly more towards the center are exposed to water, and the hydrolysis moves progressively towards the center of the film. Eliminating all the chloride groups on the outer surface of the film could protect the film from this type of hydrolysis.
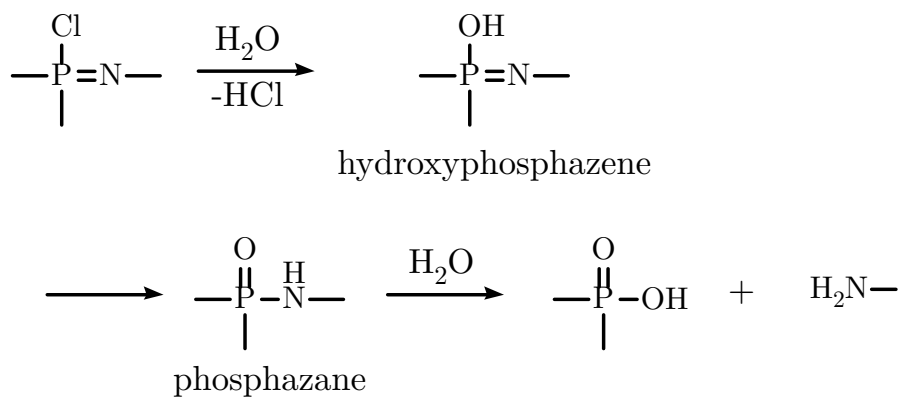

Scheme 8.9: The hydrolysis of a polydichlorophosphazene repeating unit in the presence of water. 


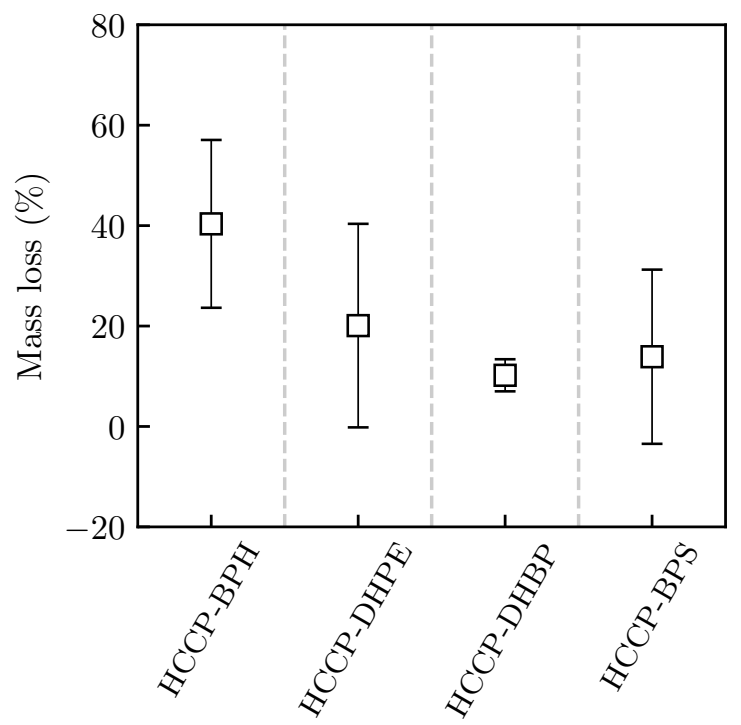

Figure 8.9: Mass loss of HCCP-biphenol films as a result of hydrolysis upon storage in Milli-Q water for three weeks. Error bars represent the standard deviation.
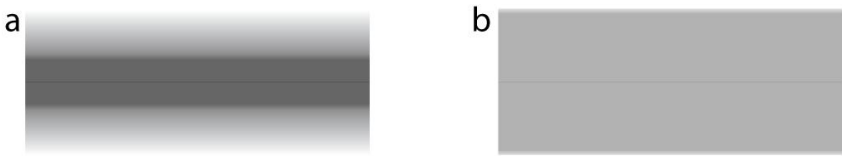

Figure 8.10: Two possible mechanisms of the hydrolysis of HCCP-biphenol films. (a) Only the outer-surface of the film will be hydrolyzed, and thereby slowly moving the hydrolysis front through the film. (b) The hydrolysis rate is homogeneous throughout the whole film.

In the case the water molecule is able to penetrate through the network, the hydrolysis rate will be equal throughout the entire film and post-functionalization will not prevent hydrolysis (Figure $8.10 \mathrm{~b}$ ). The hydrolytic stability could only be enhanced by reducing the chlorine groups in the material. Since the molecules that can be used for post-functionalization are significantly larger in size compared to the water molecule, post-functionalization could not be applied to remove chlorine groups in the bulk of the film due to steric hindrance. Instead, the amount of chlorine groups has to be reduced prior to the formation of the network.

Scheme 8.10 shows a possible method to reduce the amount of chloride groups present on the HCCP monomer prior to network formation. This can be done by partially end-capping the chloride groups of HCCP with a monofunctional 


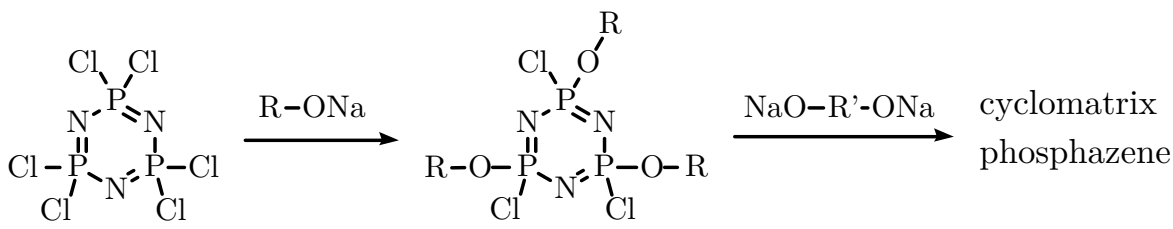

Scheme 8.10: The synthesis of a cyclomatrix polyphosphazene with a reduced amount of chlorine groups. The HCCP monomer is partially end-capped with a monofunctional nucleophile.

nucleophile. Of course, the amount of end-capped groups should be carefully tuned: too many end-caps will prevent network formation; too few will not improve the hydrolytic stability.

\section{Polyphosphazene films as membranes}

The cyclomatrix polyphosphazene films could find their application in membranes. In addition to the required enhanced hydrolytic stability, the film thickness should preferably be reduced. Currently, the films have a thickness varying between 2-5 $\mu \mathrm{m}$, however reducing the film thickness to a few hundred nanometer will enhance the flux through the film.

The thickness of a film prepared by interfacial polymerization depends strongly on the reaction time, monomer concentration, and on the use of a phase transfer catalyst. The use of a phase transfer catalyst was crucial when using the solvent pair water/dichloromethane, however, it was not needed when using the solvent pair DMSO/cyclohexane. However, DMSO is a good solvent for many polymers, and inherently porous polymeric supports can dissolve in DMSO. While ceramic supports are not at risk of dissolving in DMSO, it was found that DMSO did not enter the small pores of a $\gamma$-alumina layer. For the practical reasons described above, the use of DMSO to prepare supported TFC membranes should be avoided, and one should stick to the water/dichloromethane solvent pair.

A simple improvement could be the reduction of the reaction time. Currently, a reaction time of 5 minutes is applied. However, a simple experiment in a beaker revealed immediate film formation upon addition of the aqueous phase. Therefore, the reaction time could be reduced to decrease the film thickness. In addition, the concentrations of both HCCP and the biphenol used are extremely high compared to conventionally used concentrations in interfacial polymerization. Typically used concentrations would be in the order of 1-2 w/v\% for the biphenol and $0.1-0.5 \mathrm{w} / \mathrm{v} \%$ for HCCP. Applying these concentrations did not result in film formation, but the currently used concentrations of $\sim 10 \mathrm{w} / \mathrm{v} \%$ of biphenol and $3.5 \mathrm{w} / \mathrm{v} \%$ HCCP could probably be reduced to some extent.

The preparation of cyclomatrix polyphosphazene films by interfacial polymerization using the water/dichloromethane solvent pair requires a PDMS surface to 
avoid film cracking. Salih et al. ${ }^{[27]}$ showed that a PDMS interlayer on a polysulfone support could be used in the successful preparation of TMC-poly(etheramine) membranes. The same approach could be used to fabricate polyphosphazene membranes.

\section{4 pH-stable poly (aryl ether) films}

Polyamide materials suffer from hydrolysis upon extreme $\mathrm{pH}$ conditions, due to the presence of the carbonyl group. Lee et al. ${ }^{[28]}$ showed the successful preparation of polyamine films from $\mathrm{CC}$ with monomeric or polymeric diamines. In this thesis, we show that besides amines, alcohols could be used in the preparation of pH-stable films. Three different films were prepared onto a porous PES support, each with a different (fully) aromatic trialcohol. One of the trialcohols was prepared from the condensation of an amine and an aldehyde, and thus contained an azomethine linkage. Suematsu et al. ${ }^{[29]}$ reported on the rapid decomposition of polyazomethine films prepared from terephthalaldehyde and hexamethylenediamine in acidic environments (such as $5 \% \mathrm{H}_{2} \mathrm{SO}_{4}$ and $5 \% \mathrm{HCl}$ ). In contrast, the azomethine prepared in this thesis showed little signs of hydrolysis. This could be explained by the use of a conjugated azomethine, whereas Suematsu et al. used an aliphatic diamine, and thus prepared a non-conjugated polymer. This shows that the use of a conjugated system is of importance in the preparation of $\mathrm{pH}$-stable azomethines.

The pH-stability of the films prepared in this thesis, was tested by immersing the films into $0.1 \mathrm{M} \mathrm{NaOH}$ or $0.1 \mathrm{M} \mathrm{HNO}_{3}$ for up to 6 weeks. Scanning electron micrographs were taken to study the surface morphology of the films. We assumed that the films were stable due to the unchanged surface morphology. However, this method can not prove exclusively the pH-stability of these films. Due to the highly cross-linked nature of these materials, the amount of possible characterization methods is limited. One method that could help to prove the $\mathrm{pH}$-stability is to measure the clean water flux as function of transmembrane pressure. Figure 8.11 shows the results of this measurement for CC-TPE films stored for 4 weeks in water, $0.1 \mathrm{M} \mathrm{NaOH}$, or $0.1 \mathrm{M} \mathrm{HNO}_{3}$, respectively. The clean water permeances and $\mathrm{NaCl}$ retentions are given in Table 8.1.

The measured clean water permeance increases slightly when the CC-TPE membrane is immersed in $0.1 \mathrm{M} \mathrm{NaOH}$. However, the $\mathrm{NaCl}$ retention does not change. Since the clean water permeance is based on one membrane coupon, it is more likely that this difference in clean water permeance is caused by a spread within the samples. In contrast, the clean water permeance increases significantly, while the $\mathrm{NaCl}$ retention decreases upon immersion in $0.1 \mathrm{M} \mathrm{HNO}_{3}$. Both can be attributed to the degradation of the poly(aryl ether) network, which is surprisingly based on the chemistry. To exclude the effect of fabrication errors and normal sample spread, it is highly recommended to study more membrane coupons to evaluate the pH-stability of these materials. 


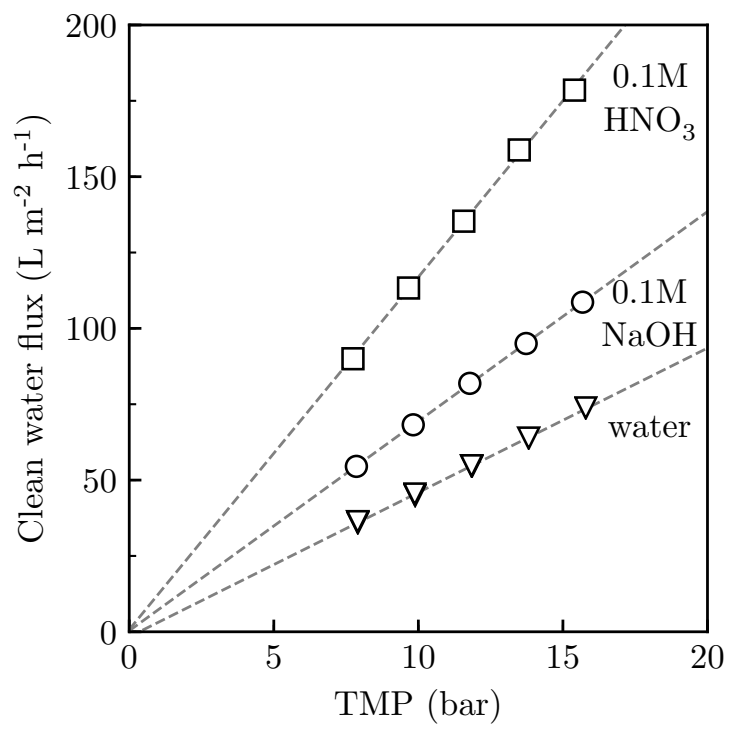

Figure 8.11: The clean water flux as function of transmembrane pressure for CC-TPE membranes stored 4 weeks in water $(\nabla), 0.1 \mathrm{M} \mathrm{NaOH}(\mathrm{O})$, and $0.1 \mathrm{M} \mathrm{HNO}_{3}(\square)$.

Table 8.1: The clean water permeance of CC-TPE films after 4 weeks immersion in either water, $0.1 \mathrm{M} \mathrm{NaOH}$, or $0.1 \mathrm{M} \mathrm{HNO}_{3}$.

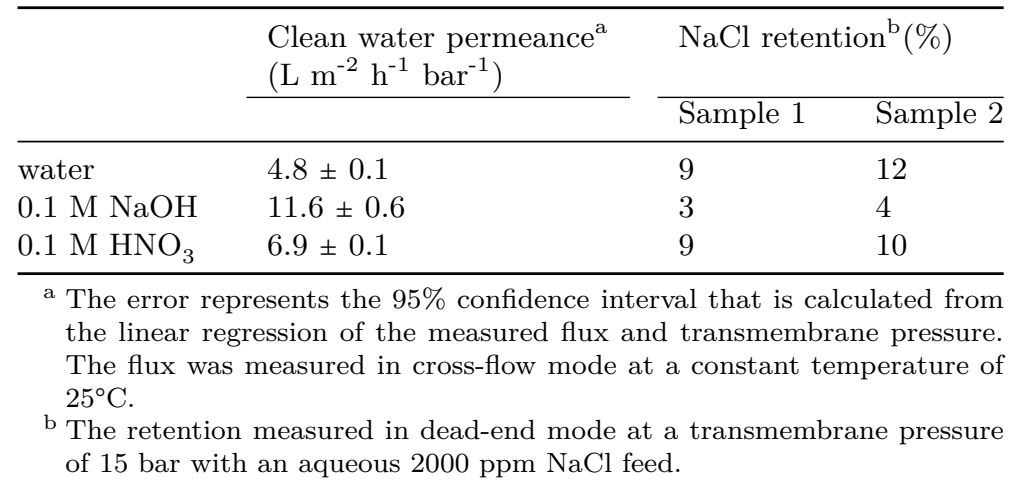




\subsection{Hyperbranched poly(aryl ether ketone)s}

In addition to films prepared by interfacial polymerization, we described the synthesis and characterization of a hyperbranched poly(aryl ether ketone) (HBPAEK) in this thesis. Hyperbranched poly(aryl ether ketone)s have a high solubility, processability and chemical functionality in contrast to its linear analogues, poly(ether ketone) (PEK) and poly(ether ether ketone) (PEEK). The prepared HBPAEKs possess fluorine end-groups that could be modified to change the properties of the HBPAEK or to introduce cross-linkable groups. In this thesis, HBPAEKs have been functionalized with 4-(phenylethynyl)phenol (PEP) end-groups. The alkyne moieties of the PEP end-groups form chemical cross-links upon heating.

In this thesis, the effect of post-condensation and alkyne end-group curing has been studied. We found that thermally treated HBPAEKs, bearing these PEP end-groups, showed a significant increase of the glass transition temperature and the excess free volume. Both are interesting when this polymer is applied as a dense polymeric membrane in gas separation. Membranes prepared from this HBPAEK retained their selectivity at elevated temperature (up to $200{ }^{\circ} \mathrm{C}$ ), even when exposed for 2 weeks.

The HBPAEKs contain fluorine side-groups after synthesis, that allow for further modification. For example, the glass transition temperature could be tuned by the introduction of different side-groups. Or the cross-link density could be altered by changing the concentration of cross-linkable end-groups. To conclude, the HBPAEK chemistry provides an interesting platform for the design of new, extremely stable, yet processable, high performance materials.

\subsection{Interfacial polymerization on ceramic hollow fibers}

Industrial separation processes often require a large membrane surface area. A very attractive geometry to meet this high surface area, with a relatively small volume, is the hollow fiber geometry. Interfacial polymerization is readily applied onto polymeric hollow fibers ${ }^{[30,31]}$. However, ceramics are considered to be superior to polymers in demanding conditions. Here, we showed the preparation of a polyamide top layer onto an alumina hollow fiber. We found that a $\gamma$-alumina intermediate layer is required for proper attachment of the polyamide film onto the surface. The $\gamma$-alumina layer reduces the surface roughness, is hydrophilic, is highly porous, and provides hydroxyl groups that can covalently participate in the interfacial polymerization.

With this $\gamma$-alumina intermediate layer, defect-free polyamide top layers could be obtained. However, the use of a highly stable support is more of interest 
in the preparation of chemically robust top-layers, or top-layers that require a thermal treatment. For example, Raaijmakers et al. ${ }^{[5]}$ showed the preparation of thermally stable poly(POSSimide)s. These films showed excellent gas separation performance at temperatures up to $300{ }^{\circ} \mathrm{C}$, but the ceramic disks supporting these top layers provide a very low surface-to-volume ratio. Therefore, the preparation of these films onto ceramic hollow fibers is of great interest.

Some preliminary experiments showed that the position of the fibers during thermal imidization is a very important parameter in the production of defect-free layers. The fibers were heated in a horizontal position, with both ends of the fiber supported by a ceramic block. These blocks on itself were supported by a large ceramic plate. It turned out that the use of such a ceramic plate results in inhomogeneous heating of the fiber. The side of the fiber facing the ceramic plate turned into a darker brown color as result of the imidization, compared to the side of the fiber facing the furnace chamber. The optimal position of the fiber during thermal treatment needs more study. A good starting point could be the vertical clamping of the fiber, and thereby avoiding the presence of a radiating body nearby the fiber surface.

\title{
8.7 Some other monomers that could be of inter- est for interfacial polymerization
}

\begin{abstract}
Abd-El-Aziz et al. ${ }^{[32]}$ reported on the synthesis of a star-shaped metal containing monomer by the reaction of a cyclopentadienyliron-chloroarene complex with phloroglucinol (Scheme 8.11). The coordination of the metal complex activates the chloro-groups of the chloroarene towards nucleophilic substitution ${ }^{[33]}$, and therefore this reaction could be carried out at mild conditions (room temperature, $\mathrm{DMF}, \mathrm{K}_{2} \mathrm{CO}_{3}$ ). The terminal chloro-groups of the formed monomer could react again with aromatic alcohols, potentially in an interfacial manner forming a fully aromatic polyether. The metal complex could be eventually removed by simple irradiation with UV-light ${ }^{[34]}$.
\end{abstract}

However, a metal containing film could be of interest in membrane applications. The metal provides a positive charge and could thereby enhance the affinity for polar solvents yielding higher fluxes, and might even reduce membrane fouling.

An interesting class of inorganic monomers that has not been discussed in this thesis, is the class of borazines. Borazines are characterized by a six-membered ring containing alternating boron and nitrogen atoms. Borazines are often referred to as "inorganic benzenes" because it is isoelectric and isostrucutral to benzene. The borazine $(\mathrm{NHBH})_{3}$ is often used as a precursor in the formation of boron nitride ceramics ${ }^{[35]}$. 


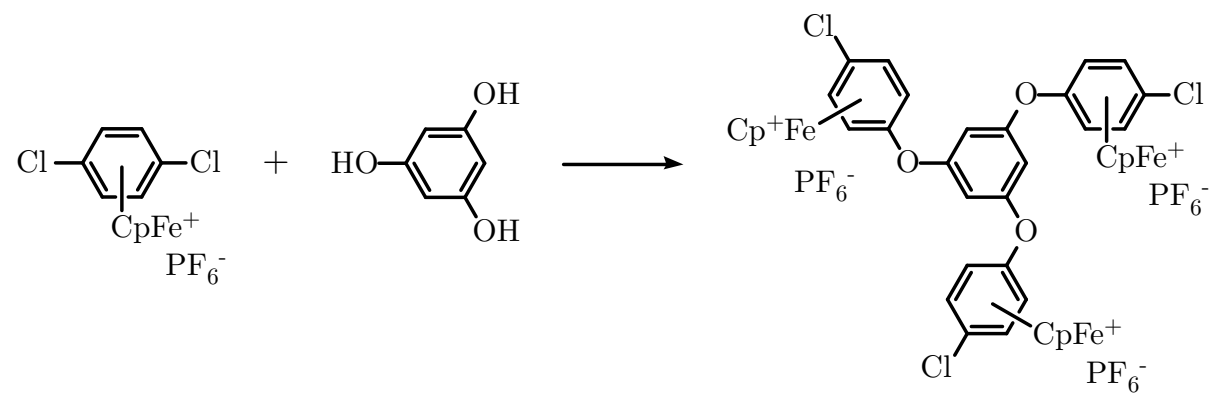

Scheme 8.11: The synthesis of a star-shaped metal containing polymer precursor.<smiles>[R]N1B(Cl)N([R])B(Cl)N([R])B1Cl</smiles><smiles>[R17]NB1N([R])B(N[R17])N([R])B(N[R17])N1[R]</smiles>

Scheme 8.12: The synthesis of borazine derivatives.

Borazine derivatives can be synthesized from the reaction of boron trichloride $\left(\mathrm{BCl}_{3}\right)$ with an monofunctionalized amine (Scheme 8.12) ${ }^{[36]}$. Porous polymer networks can be formed when using a di-, tri-, or tetrafunctional amine in the reaction with $\mathrm{BCl}_{3}{ }^{[37-39]}$. In addition to the formation of porous polymer networks, $B$-trichloroborazine can undergo nucleophilic substitution reactions at the boron atoms (Scheme 8.12). Examples are reactions with Grignard reagents or primary and secondary amines ${ }^{[40]}$.

Riensch et al. ${ }^{[41]}$ showed the preparation of borazine based cyclomatrix microspheres. In one of their reported synthesis methods, $B, B^{\prime}, B^{\prime \prime}$-trichloro- $N, N^{\prime}, N^{\prime \prime}$-trimethylborazine was mixed with aromatic diamines and triethylamine in acetonitrile. The authors report on the immediate formation of a precipitate, proving the fast reaction and the possibility for the use in an interfacial manner. 


\subsection{Requirements for the application of new monomers in interfacial polymerization}

So far, the limitations and possible solutions for the monomers and polymers that are described in this theses have been discussed in this chapter. Additionally, some general recommendations for the application of new monomers in interfacial polymerization will be made in the next section.

\section{Non-aqueous interfacial polymerization}

Nowadays, interfacial polymerization is mostly carried out with an aqueous phase and an organic phase. However, the amount of monomers that dissolve, and are stable in aqueous solutions is limited. A possible method to increase the possible monomer combinations, is to make use of an immiscible organic-organic interface.

Despite the many available immiscible solvent pairs ${ }^{[42,43]}$, organic-organic interfacial polymerization has hardly been described in literature. Ogata et al. ${ }^{[44]}$ reported on the preparation of polyesters in adiponitrile $\left(\mathrm{NC}\left(\mathrm{CH}_{2}\right)_{4} \mathrm{CN}\right) /$ carbon tetrachloride, adiponitrile/dibutyl ether, ethylene glycol/carbon tetrachloride, and ethylene glycol/benzene. However, adiponitrile and carbon tetrachloride are extremely toxic, and their use should be avoided.

Other solvent pairs that could be of interest are DMF/xylene or methanol/cyclohexane, DMSO/cyclohexane, DMF/cyclohexane, or acetonitrile/cyclohexane. For example, HCCP-BPH films could be prepared by dissolving $\mathrm{KOH}$ and $\mathrm{BPH}$ in hot DMSO, and dissolving HCCP in cyclohexane, followed by interfacial polymerization. This reaction proceeded without the use of a phase transfer catalyst, and by this method freestanding films could be obtained. Unfortunately, some polymeric supports, such as PAN ${ }^{[4]}$, dissolve in DMSO, and thus DMSO could often not be used for the preparation of most polymeric supported membranes. In addition, DMSO did not penetrate sufficiently into the pores of $\gamma$-alumina, thus preventing film formation on a $\gamma$-alumna support.

In aqueous-organic interfacial polymerization the miscibility of the solvents is an important parameter. Applying organic-organic interfacial polymerization can reduce the miscibility gap between the solvents, thereby reducing the quality of the film formed. The use of alcoholic solvents can result in competition between the monomer and solvent, just as is the case for water.

\section{Supports for interfacial polymerization}

Of course, the porous support of a TFC membrane should be stable at the operating conditions. Just as important is the stability of the support during the synthesis of the TFC membrane. For example, polymeric supports can not withstand the high temperatures needed to convert a poly(amic acid) top layer into a 
polyimide top layer. However, inorganic supports, such as alumina, suffer from a low or even zero permeance for non-polar solvents.

Pulido et al. ${ }^{[46]}$ reported on the synthesis of a ultrafiltration support made from the polymer poly(oxindolebiphenylylene), that was found to be stable at temperatures up to $500{ }^{\circ} \mathrm{C}$. This could be an interesting alternative to ceramic supports for the preparation of polyimide top layers, although the authors did not report on the porosity after heat treatment.

The porous support must also be resistant to the solvent/monomer mixtures used in interfacial polymerization. For example, the $-\mathrm{CN}$ groups or PAN are known to hydrolyze into $-\mathrm{CONH}_{2}$ and $-\mathrm{COOH}$ groups upon contact with a base such as $\mathrm{NaOH}^{[47,48]}$. This hydrolysis results in an increased negative surface charge and hydrophilicity ${ }^{[49]}$. However, an increased surface hydrophilicity can result in a lower salt rejection and a higher water permeance ${ }^{[50]}$. Depending on the pKa of, e.g., alcoholic monomers, a high $\mathrm{pH}$ of the aqueous solution can be required. The contact time of a support with the aqueous phase is generally in the order of minutes, thereby reducing the risk of severe hydrolysis. Despite these short contact times, care must be taken with highly alkaline aqueous phases.

\section{Characterization methods}

The synthesis of a membrane, the characterization, and performance are closely related as depicted in Figure 8.12. Information retrieved by performance measurements (e.g., permeance and rejection) and by in-situ or in-operando characterization techniques can be very valuable input parameters for the synthesis of new membrane materials.

A very powerful technique to study in-situ the behavior of thin films upon exposure to heat or solvent penetration is ellipsometry. Freestanding films prepared by interfacial polymerization can be transferred onto a silicon wafer as described in this thesis and by Park et al. ${ }^{[49]}$. However, the ability of revealing the thickness and refractive index of these films depends strongly on the surface roughness of the films ${ }^{[51]}$. The polyamide films in Chapter 2 suffered from a high surface roughness, and thus low intensity and accuracy. The poly(PDMS-POSSimide) (Chapter 3) and poly(aryl ether) films (Chapter 5) possessed a sufficient reflectivity to model the film thickness and refractive index. Unfortunately, the binding strength between the silicon wafer and the film was found to be insufficient upon immersion in a solvent for some of these films, resulting in delamination from the wafer. In addition, a silicon wafer dissolves in $0.1 \mathrm{M} \mathrm{NaOH}$, thereby making it an inadequate substrate for pH-stability tests by ellipsometry.

The preparation of free standing films results in different film properties compared to supported films. Therefore, it would be more valuable to study the properties of the films as prepared by supported interfacial polymerization. An optical model for films prepared on $\gamma$-alumina has been developed ${ }^{[52,53]}$, however, we found this 


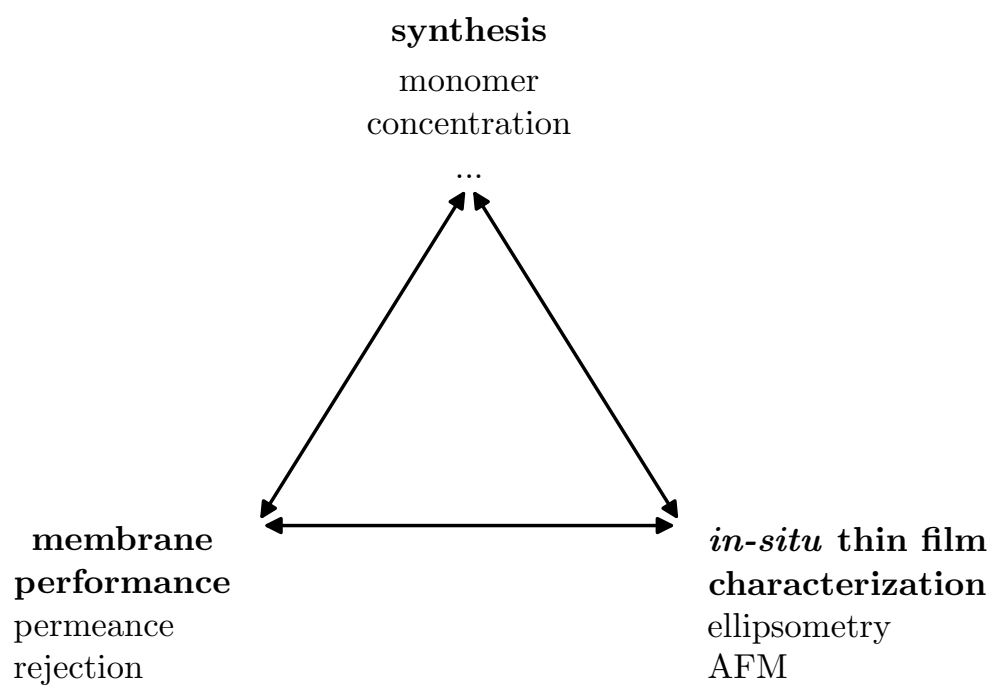

Figure 8.12: The synthesis, in-situ characterization, and membrane performance are closely related.

model to be inapplicable to solvent sorption measurements. There is a need for more robust optical models that describe porous polymeric or ceramic supports with a thin film on top, and still can describe these TFC membranes with liquid filled pores. When more robust models have been developed, it would be of great interest to study film properties in-operando.

Perry and Coronell ${ }^{[54]}$ described a very elegant method to transfer the top layer of a TFC membrane onto a silicon wafer. First, the non-woven backing was peeled off by hand. Then, the TFC membrane was transferred onto a silicon wafer with the top layer facing the wafer. The TFC membrane was then fixed to the wafer by clamping the wafer-membrane assembly in a stainless steel frame. The porous polymeric support layer was subsequently dissolved in an appropriate solvent, leaving the cross-linked top layer on the silicon wafer.

We found that this method worked well for PAN supported membranes. The PAN layer could be carefully dissolved in DMF or DMSO. Unfortunately, this method did not work for PES membranes, because the non-woven backing could not be removed without damaging the membrane.

Atomic force microscopy (AFM) is widely used to study, e.g., surface morphology or mechanical properties of TFC membranes ${ }^{[55-57]}$. in-situ AFM is mainly applied to films in aqueous solutions at ambient conditions, however it would be interesting to be able to study the surface morphology or mechanical properties at typical operating conditions. A high-pressure AFM has been reported in literature that could measure in-situ with applied pressures up to $100 \mathrm{~atm}$ and temperatures up 
to $75{ }^{\circ} \mathrm{C}^{[58]}$. In addition, a high-temperature AFM has been reported, enabling imaging at temperatures up to $750{ }^{\circ} \mathrm{C}$ in air or vacuum ${ }^{[59]}$. Developing a highpressure solvent resistant AFM would be of great interest for the development of organic solvent nanofiltration membranes.

The cross-linking, and thus insolubility, of the TFC top layer improves stability at operation conditions. Unfortunately, this insolubility reduces the possible characterization methods for the top layer polymer. Solid state NMR could be an interesting characterization technique for these films ${ }^{[60]}$. It has already been applied in the characterization of TMC-MPD polyamide top layers ${ }^{[61,62]}$. However, its use could also be of great interest to get more insight in the network formation of, for example, polyphosphazenes.

\subsection{General conclusions}

This thesis described the incorporation of new monomers in interfacial polymerization. Interfacial polymerization allows for the preparation of ultra-thin defect-free layers with potentially unlimited dimensions. The hyper-cross-linked nature of films prepared from monomers with a high functionality, significantly reduces the loss of membrane performance by, e.g., swelling or plasticization. Thus interfacial polymerization can be considered as a very powerful technique in the preparation of industrial relevant membranes.

The choice of monomers and reaction conditions plays a crucial role in the properties of the film formed. Here, we list some general conclusions on the monomer functionality, monomer reactivity, and reaction conditions.

\section{Monomer functionality}

The functionality, i.e. the number of reactive groups, of the monomers has a strong influence on the properties of the network formed. To allow for crosslinking, one of the monomers should have a functionality of at least 3, assuming that the second monomer has a functionality of 2 . However, it can be concluded that a higher functionality does not automatically result in better properties of the hyper-cross-linked network. For example, both the inorganic monomers POSS and HCCP have a high functionality $(f=>6)$, but only $3-4$ of these groups are found to participate in the interfacial polymerization. Therefore, we can speculate that the optimal functionality of a monomer is around 3-4, when the other monomer is bifunctional.

\section{Monomer reactivity}

In this thesis, we found that the reactivity of a monomer is strongly influenced by its chemical environment. For example, electron donating or electron withdrawing groups have a strong influence on the properties of the films formed. Monomers with a low reactivity require a longer reaction time to form a defect-free network compared to highly reactive monomers. The difference in reactivity between 
monomers can be used to tune the properties of the films formed. A good example are the HCCP-biphenol films reported on in this thesis, that are found to have their Young's modulus and surface morphology dependent on the pKa of the aromatic biphenol.

\section{Reaction conditions}

There are many reaction parameters that could be tuned to alter the properties of a film prepared by interfacial polymerization. For example, monomer concentration and reaction time have a strong influence on the film thickness and permeability. In this thesis, we found the choice of solvent-pair just as important. In a classical water-organic solvent system, the solubility of water in the organic phase plays an important role. Because of the low water solubility, $n$-hexane is often the preferred solvent. However, the solubility of the monomer can restrict the choices of solvents. Additionally, the solvent-pair can strongly influence the reaction kinetics. For example, the need for a phase transfer catalyst depends strongly on the chosen solvent-pair.

To conclude, interfacial polymerization provides a broad platform for the incorporation of new monomers into interfacial polymerization. Although this gives rise to a lot of opportunities, one must carefully tune the reaction conditions for each individual set of monomers, to in the end obtain the best possible membrane performance. 


\subsection{References}

[1] Lama, P.; Aijaz, A.; Sañudo, E. C.; Bharadwaj, P. K. Synthesis, Structure, and Magnetic Properties of Cobalt(II) Coordination Polymers from a New Tripodal Carboxylate Ligand: Weak Ferromagnetism and Metamagnetism. Crystal Growth 83 Design 2010, 10, 283-290.

[2] Peng, Y.; Li, G.; Hua, J.; Shi, Z.; Feng, S. Syntheses, topological structures and properties of six metal-organic frameworks constructed from a flexible tetracarboxylate ligand. CrystEngComm 2015, 17, 3162-3170.

[3] Gao, Y.-P.; Guo, L.; Dong, W.; Jia, M.; Zhang, J.-X.; Sun, Z.; Chang, F. Syntheses, structures and photoluminescent properties of $\mathrm{Zn}(\mathrm{II}) / \mathrm{Co}(\mathrm{II})$ coordination polymers based on flexible tetracarboxylate ligand of 5,5'-(butane-1,4-diyl)-bis(oxy)-di isophthalic acid. Journal of Solid State Chemistry 2016, 240, $82-90$.

[4] Dalwani, M.; Zheng, J.; Hempenius, M.; Raaijmakers, M. J. T.; Doherty, C. M.; Hill, A. J.; Wessling, M.; Benes, N. E. Ultra-thin hybrid polyhedral silsesquioxane-polyamide films with potentially unlimited 2D dimensions. J. Mater. Chem. 2012, 22, 14835-14838.

[5] Raaijmakers, M. J. T.; Hempenius, M. A.; Schön, P. M.; Vancso, G. J.; Nijmeijer, A.; Wessling, M.; Benes, N. E. Sieving of Hot Gases by Hyper-Cross-Linked Nanoscale-Hybrid Membranes. Journal of the American Chemical Society 2014, 136, 330-335.

[6] Raaijmakers, M. J. T.; Wessling, M.; Nijmeijer, A.; Benes, N. E. Hybrid Polyhedral Oligomeric Silsesquioxanes-Imides with Tailored Intercage Spacing for Sieving of Hot Gases. Chemistry of Materials 2014, 26, 3660-3664.

[7] Skaria, S.; Schricker, S. R. Synthesis and Characterization of Inorganic-Organic Hybrid Materials Derived from Polysilsesquioxanes (POSS). Journal of Macromolecular Science, Part A 2010, 47, 381-391.

[8] Kailani, M. H.; Sung, C. S. P. Chemical Imidization Study by Spectroscopic Techniques. 1. Model Amic Acids. Macromolecules 1998, 31, 5771-5778.

[9] J. Feher, F.; D. Wyndham, K.; Soulivong, D.; Nguyen, F. Syntheses of highly functionalized cube-octameric polyhedral oligosilsesquioxanes (R8Si8O12). J. Chem. Soc., Dalton Trans. 1999, 1491-1498.

[10] Neyertz, S.; Brown, D.; Pilz, M.; Rival, N.; Arstad, B.; Männle, F.; Simon, C. The Stability of Amino-Functionalized Polyhedral Oligomeric Silsesquioxanes in Water. The Journal of Physical Chemistry B 2015, 119, 6433-6447.

[11] Covington, A. K.; Robinson, R. A.; Bates, R. G. The Ionization Constant of Deuterium Oxide from 5 to $50^{\circ}$. The Journal of Physical Chemistry 1966, 70, 3820-3824.

[12] J. Feher, F.; D. Wyndham, K. Amine and ester-substituted silsesquioxanes: synthesis, characterization and use as a core for starburst dendrimers. Chem. Commun. 1998, 323324 .

[13] Akbari, A.; Arsalani, N.; Amini, M.; Jabbari, E. Cube-octameric silsesquioxane-mediated cargo copper Schiff base for efficient click reaction in aqueous media. Journal of Molecular Catalysis A: Chemical 2016, 414, $47-54$.

[14] Imoto, H.; Wada, S.; Naka, K. Efficient Isolation of Completely Decorated Polyhedral Oligomeric Silsesquioxanes by Utilizing Imine Bond Formation. Chemistry Letters 2016, $45,1256-1258$.

[15] Janeta, M.; John, L.; Ejfler, J.; Lis, T.; Szafert, S. Multifunctional imine-POSS as uncommon 3D nanobuilding blocks for supramolecular hybrid materials: synthesis, structural characterization, and properties. Dalton Trans. 2016, 45, 12312-12321.

[16] Zhang, Y.; Benes, N. E.; Lammertink, R. G. H. Visualization and characterization of interfacial polymerization layer formation. Lab Chip 2015, 15, 575-580.

[17] Majumdar, P.; Lee, E.; Gubbins, N.; Stafslien, S. J.; Daniels, J.; Thorson, C. J.; Chisholm, B. J. Synthesis and antimicrobial activity of quaternary ammoniumfunctionalized POSS (Q-POSS) and polysiloxane coatings containing Q-POSS. Polymer 2009, 50, $1124-1133$.

[18] Han, J.; Zheng, Y.; Zheng, S.; Li, S.; Hu, T.; Tang, A.; Gao, C. Water soluble octa- 
functionalized POSS: all-click chemistry synthesis and efficient host-guest encapsulation. Chem. Commun. 2014, 50, 8712-8714.

[19] Neumann, D.; Fisher, M.; Tran, L.; Matisons, J. G. Synthesis and Characterization of an Isocyanate Functionalized Polyhedral Oligosilsesquioxane and the Subsequent Formation of an Organic-Inorganic Hybrid Polyurethane. Journal of the American Chemical Society 2002, 124, 13998-13999.

[20] Mya, K. Y.; Wang, Y.; Shen, L.; Xu, J.; Wu, Y.; Lu, X.; He, C. Star-like polyurethane hybrids with functional cubic silsesquioxanes: Preparation, morphology, and thermomechanical properties. Journal of Polymer Science Part A: Polymer Chemistry 2009, 47, 4602-4616.

[21] Ze, L.; Yusuke, K. Formation of Incompletely Condensed Oligosilsesquioxanes by Hydrolysis of Completely Condensed POSS via Reshuffling. Chemistry Letters 2008, 37, 804-805.

[22] Hillson, S. D.; Smith, E.; Zeldin, M.; Parish, C. A. Cages, Baskets, Ladders, and Tubes: Conformational Studies of Polyhedral Oligomeric Silsesquioxanes. The Journal of Physical Chemistry A 2005, 109, 8371-8378.

[23] Shi, Y.; Gao, X.; Zhang, D.; Liu, Y.; Huang, G. Synthesis and thermal properties of modified room temperature vulcanized (RTV) silicone rubber using polyhedral oligomeric silsesquioxane (POSS) as a cross linking agent. RSC Adv. 2014, 4, 41453-41460.

[24] Allcock, H. R.; Fuller, T. J.; Mack, D. P.; Matsumura, K.; Smeltz, K. M. Synthesis of Poly[(amino acid alkyl ester)phosphazenes]. Macromolecules 1977, 10, 824-830.

[25] Allcock, H. R.; Fuller, T. J.; Matsumura, K. Hydrolysis pathways for aminophosphazenes. Inorganic Chemistry 1982, 21, 515-521.

[26] Allcock, H. R.; Morozowich, N. L. Bioerodible polyphosphazenes and their medical potential. Polym. Chem. 2012, 3, 578-590.

[27] Salih, A. A.; Yi, C.; Peng, H.; Yang, B.; Yin, L.; Wang, W. Interfacially polymerized polyetheramine thin film composite membranes with PDMS inter-layer for CO2 separation. Journal of Membrane Science 2014, 472, 110 - 118.

[28] Lee, K. P.; Bargeman, G.; de Rooij, R.; Kemperman, A. J.; Benes, N. E. Interfacial polymerization of cyanuric chloride and monomeric amines: $\mathrm{pH}$ resistant thin film composite polyamine nanofiltration membranes. Journal of Membrane Science 2017, 523, 487 - 496.

[29] Suematsu, K.; Nakamura, K.; Takeda, J. Polyimine, a C=N Double Bond Containing Polymers: Synthesis and Properties. Polymer Journal 1983, 15, 71-79.

[30] Yang, F.; Zhang, S.; Yang, D.; Jian, X. Preparation and characterization of polypiperazine amide/PPESK hollow fiber composite nanofiltration membrane. Journal of Membrane Science 2007, 301, $85-92$.

[31] Li, H.; Wang, W.; Zhang, Y. Preparation and characterization of high-selectivity hollow fiber composite nanofiltration membrane by two-way coating technique. Journal of Applied Polymer Science 2014, 131, n/a-n/a.

[32] Abd-El-Aziz, A. S.; Todd, E. K.; Afifi, T. H. Star-Shaped Polyaromatic Ethers Coordinated to Redox-Active Cyclopentadienyliron Moieties. Macromolecular Rapid Communications 2002, 23, 113-117.

[33] Abd-El-Aziz, A. S. Monomers, oligomers and polymers containing arenes with pendent transition metal moieties. Coordination Chemistry Reviews 2002, 233-234, 177 - 191.

[34] Abd-El-Aziz, A. S.; Abdelghani, A. A.; Wagner, B. D.; Pearson, J. K.; Awad, M. K. Design of blue fluorescence emitter star-shaped macromolecules based on pyrene and anthracene. Polymer 2016, 98, 210 - 228, Special Issue: Polymer Brushes.

[35] Manning, M. J.; Griffin, T. S. Kirk-Othmer Encyclopedia of Chemical Technology; John Wiley \& Sons, Inc., 2000; Chapter Boron-Nitrogen Compounds, Organic.

[36] Bonifazi, D.; Fasano, F.; Lorenzo-Garcia, M. M.; Marinelli, D.; Oubaha, H.; Tasseroul, J. Boron-nitrogen doped carbon scaffolding: organic chemistry, self-assembly and materials applications of borazine and its derivatives. Chem. Commun. 2015, 51, 15222-15236.

[37] Reich, T. E.; Jackson, K. T.; Li, S.; Jena, P.; El-Kaderi, H. M. Synthesis and characteriza- 
tion of highly porous borazine-linked polymers and their performance in hydrogen storage application. J. Mater. Chem. 2011, 21, 10629-10632.

[38] Jackson, K. T.; Rabbani, M. G.; Reich, T. E.; El-Kaderi, H. M. Synthesis of highly porous borazine-linked polymers and their application to $\mathrm{H} 2, \mathrm{CO} 2$, and $\mathrm{CH} 4$ storage. Polym. Chem. 2011, 2, 2775-2777.

[39] Reich, T. E.; Behera, S.; Jackson, K. T.; Jena, P.; El-Kaderi, H. M. Highly selective $\mathrm{CO} 2 / \mathrm{CH} 4$ gas uptake by a halogen-decorated borazine-linked polymer. J. Mater. Chem. 2012, 22, 13524-13528.

[40] Kavala, M.; Zálupský, P.; Szolcsányi, P. Syntheses and properties of cycloborazines and cyclocarborazines. Polyhedron 2012, 48, 9 - 20.

[41] Riensch, N. A.; Deniz, A.; Kuhl, S.; Muller, L.; Adams, A.; Pich, A.; Helten, H. Borazinebased inorganic-organic hybrid cyclomatrix microspheres by silicon/boron exchange precipitation polycondensation. Polym. Chem. 2017, 8, 5264-5268.

[42] Drury, J. S. Miscibility of Organic Solvent Pairs. Industrial \& Engineering Chemistry 1952, 44, 2744-2744.

[43] Jackson, W. M.; Drury, J. S. Miscibility of Organic Solvent Pairs. Industrial E Engineering Chemistry 1959, 51, 1491-1493.

[44] Ogata, N.; Sanui, K.; Onozaki, T.; Imanishi, S. Interfacial Polycondensation in Aqueous and Non-Aqueous Systems. Journal of Macromolecular Science: Part A - Chemistry 1981 15, 1059-1063.

[45] Eom, Y.; Kim, B. C. Solubility parameter-based analysis of polyacrylonitrile solutions in N,N-dimethyl formamide and dimethyl sulfoxide. Polymer 2014, 55, 2570 - 2577.

[46] Pulido, B.; Waldron, C.; Zolotukhin, M.; Nunes, S. Porous polymeric membranes with thermal and solvent resistance. Journal of Membrane Science 2017, 539, 187 - 196.

[47] Zhang, G.; Meng, H.; Ji, S. Hydrolysis differences of polyacrylonitrile support membrane and its influences on polyacrylonitrile-based membrane performance. Desalination 2009 , 242, $313-324$.

[48] Kao, S.-T.; Huang, S.-H.; Liaw, D.-J.; Chao, W.-C.; Hu, C.-C.; Li, C.-L.; Wang, D.-M.; Lee, K.-R.; Lai, J.-Y. Interfacially polymerized thin-film composite polyamide membrane: positron annihilation spectroscopic study, characterization and pervaporation performance. Polymer Journal 2010, 42, $242 \mathrm{EP}-$.

[49] Park, S.-J.; Choi, W.; Nam, S.-E.; Hong, S.; Lee, J. S.; Lee, J.-H. Fabrication of polyamide thin film composite reverse osmosis membranes via support-free interfacial polymerization. Journal of Membrane Science 2017, 526, 52 - 59.

[50] Choi, W.; Gu, J.-E.; Park, S.-H.; Kim, S.; Bang, J.; Baek, K.-Y.; Park, B.; Lee, J. S.; Chan, E. P.; Lee, J.-H. Tailor-Made Polyamide Membranes for Water Desalination. ACS Nano 2015, 9, 345-355.

[51] Ben-David, A.; Bason, S.; Jopp, J.; Oren, Y.; Freger, V. Partitioning of organic solutes between water and polyamide layer of RO and NF membranes: Correlation to rejection. Journal of Membrane Science 2006, 281, 480 - 490.

[52] Ogieglo, W.; Wormeester, H.; Wessling, M.; Benes, N. E. Spectroscopic Ellipsometry Analysis of a Thin Film Composite Membrane Consisting of Polysulfone on a Porous $\alpha$-Alumina Support. ACS Applied Materials \& Interfaces 2012, 4, 935-943.

[53] Raaijmakers, M. J. T.; Kappert, E. J.; Nijmeijer, A.; Benes, N. E. Thermal Imidization Kinetics of Ultrathin Films of Hybrid Poly(POSS-imide)s. Macromolecules 2015, 48, 30313039.

[54] Perry, L. A.; Coronell, O. Reliable, bench-top measurements of charge density in the active layers of thin-film composite and nanocomposite membranes using quartz crystal microbalance technology. Journal of Membrane Science 2013, 429, 23 - 33.

[55] Boussu, K.; der Bruggen, B. V.; Volodin, A.; Snauwaert, J.; Haesendonck, C. V.; Vandecasteele, C. Roughness and hydrophobicity studies of nanofiltration membranes using different modes of AFM. Journal of Colloid and Interface Science 2005, 286, 632 - 638 . 
[56] Johnson, D.; Malek, S. A.; Al-Rashdi, B.; Hilal, N. Atomic force microscopy of nanofiltration membranes: Effect of imaging mode and environment. Journal of Membrane Science 2012, $389,486-498$.

[57] Stawikowska, J.; Livingston, A. G. Assessment of atomic force microscopy for characterisation of nanofiltration membranes. Journal of Membrane Science 2013, 425-426, 58 70 .

[58] Lea, A. S.; Higgins, S. R.; Knauss, K. G.; Rosso, K. M. A high-pressure atomic force microscope for imaging in supercritical carbon dioxide. Review of Scientific Instruments 2011, 82, 043709.

[59] Broekmaat, J.; Brinkman, A.; Blank, D. H. A.; Rijnders, G. High temperature surface imaging using atomic force microscopy. Applied Physics Letters 2008, 92, 043102.

[60] Duer, M. J. Solid-State NMR Spectroscopy Principles and Applications; Blackwell Science Ltd, 2007.

[61] Kwak, S.-Y.; Ihm, D. W. Use of atomic force microscopy and solid-state NMR spectroscopy to characterize structure-property-performance correlation in high-flux reverse osmosis (RO) membranes. Journal of Membrane Science 1999, 158, 143 - 153.

[62] Lau, W. J.; Ismail, A. F.; Goh, P. S.; Hilal, N.; Ooi, B. S. Characterization Methods of Thin Film Composite Nanofiltration Membranes. Separation \& Purification Reviews 2015, 44, 135-156. 


\subsection{Supporting information}

Poly(PDMS-POSSamic acid) films supported on PAN were chemically treated to achieve the cyclization of the amic acid ring to the imide ring. Figure 8.13 shows ATR-FTIR graphs of these films treated with different dehydrating mixtures. It can be concluded that despite some minor differences in chemical composition of the films after treatment, none of the applied dehydrating mixtures resulted in fully imidized films.
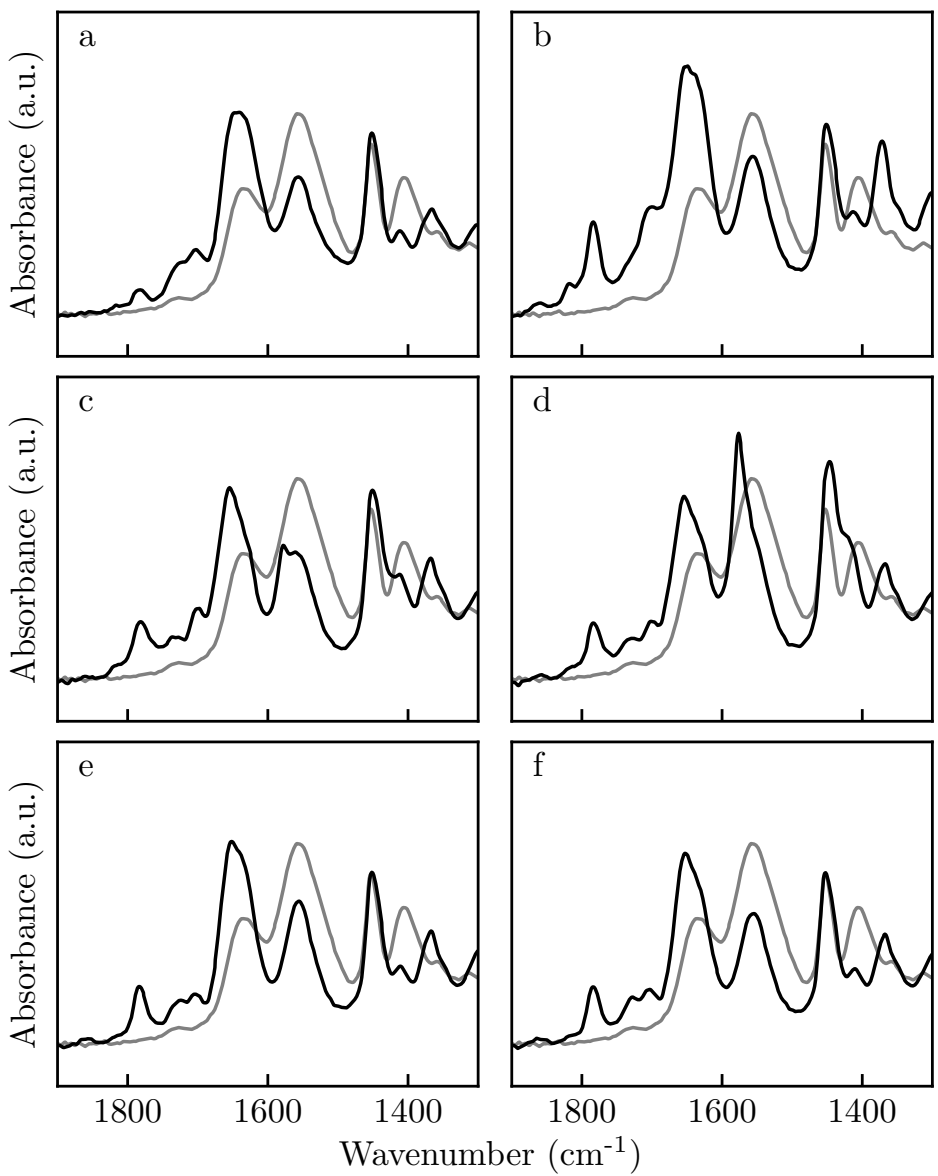

Figure 8.13: ATR-FTIR spectra of poly(PDMS-POSSamic acid) films before $(-)$ and after $(-)$ chemical imidization. Chemical imidization was performed for 2 days at room temperature in a mixture of (a) pyridine, (b), pyridine and acetic anhydride, (c) triethylamine and acetic anhydride, (d) triethylamine, pyridine, and acetic anhydride, (e) triethylamine, acetic anhydride, and toluene, and ( $\mathrm{f}$ ) triethylamine, acetic anhydride, pyridine, and toluene. 


\section{About the author}

Evelien Maaskant was born on the 5th of April 1991 in Arnhem, the Netherlands. In 2008, she obtained her VWO diploma at the Olympus College in Arnhem. In the same year she started her bachelor studies in Chemical Engineering at the University of Twente. During these years she was active as a board member of DHC Drienerlo, and she was active in several committees within C.T.S.G. Alembic, DHC Drienerlo, and ZPV Piranha. After her Bachelor's studies, she started her Master's studies in Chemical Engineering at the University of Twente, in the track Materials and Molecules. During her Master's studies she performed a professional internship at AkzoNobel Surface Chemistry in Chattanooga, United States. In 2013, she graduated cum laude from the University of Twente on the thesis entitled: 'Poly(ferrocenyl)silane as redox mediator in the enzymatic sensing of glucose' at the Materials Science and Technology of Polymers group.

Starting from February 2014, she has been working as a $\mathrm{PhD}$ candidate at the Films in Fluids group at the University of Twente, under the supervision of prof. dr. ir. Nieck E. Benes. Her research was presented at multiple international conferences and workshops, including the Gordon Research Conference on Membranes, Materials, and Processes in New London, United States in 2014 and the International Membrane Science and Technology Conference in Adelaide, Australia in 2016 . 



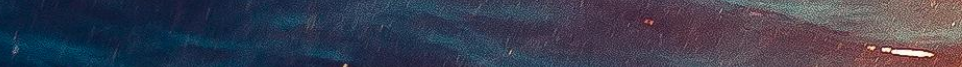

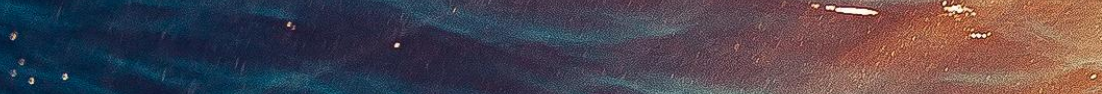

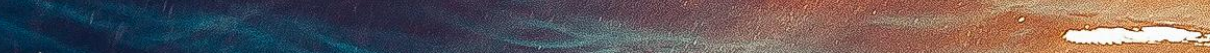

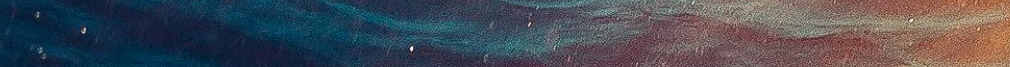

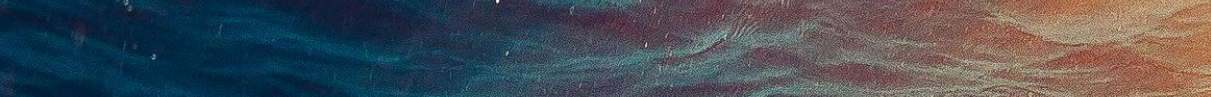

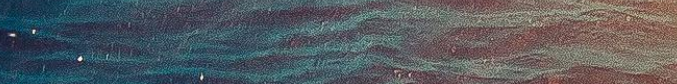

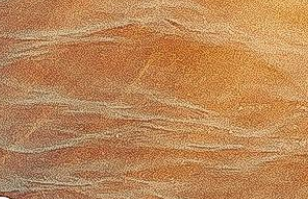

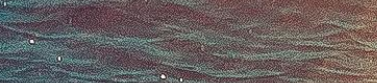

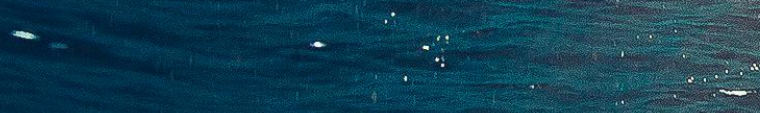

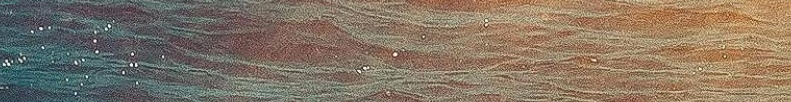

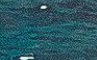

